


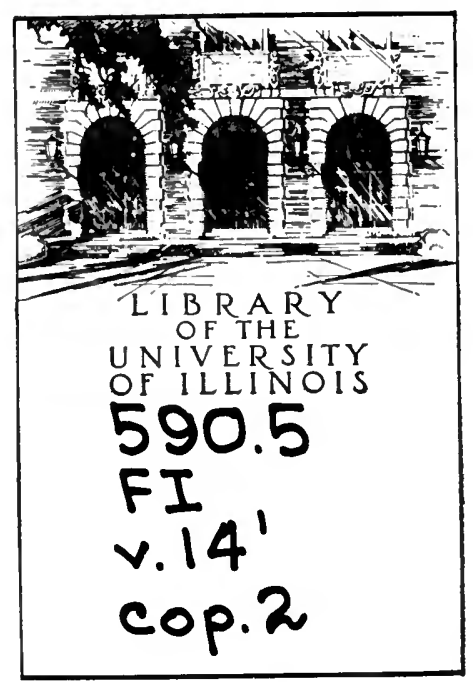






Field Museum of Natural History.

Publication 207.

Zoölogical Series.

Vol. XIV, No. I.

\section{A MONOGRAPHIC STUDY OF THE AMERICAN MARSUPIAL, CAENOLESTES.}

BY

Wilfred H. OsGood, Daplicate Collection
Curator of Mammalogy and

Assistant Curator of Mammalogy and Penifhology. Collectlon
with

A Description of the Brain of

Cenolestes.

- BY

C. Judson Herrick,

Professor of Neurology, University of Chicago.

Charles B. Cory,

Curator, Department of Zoölogy.

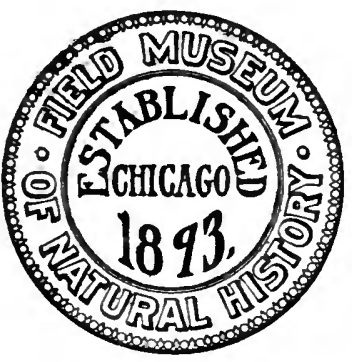

Chicago, U.S. A.

MAY, I92I.

THE LIBRARY OF THE

$F E B 1 \leq 1938$

UNIVERSITY OF ILINTOS 

ii.: : RRARY

OF THE

HNIVEASITY OF IILINOIS 

Field Museum of Natural History.

Publication 207.

Zoölogical Series.

Vol. XIV, No. I.

\section{A MONOGRAPHIC STUDY OF THE AMERICAN MARSUPIAL, CAENOLESTES.}

BY

WILFRED H. OSGOOD,

Assistant Curator of Mammalogy and Ornithology.

WITH

A Description of the Brain of

Cenolestes.

BY

C. Judson Herrick,

Professor of Neurology, University of Chicago.

Charles B. Corr,

Curator, Department of Zoölogy.

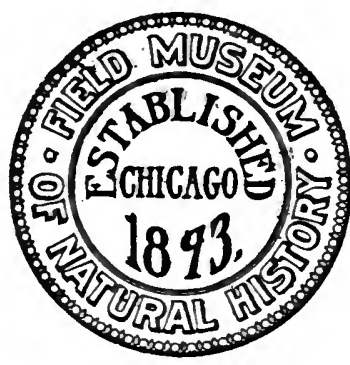

Chicago, U. S. A.

MAY, I92I.

THE LIBRARY OF THE

FEB $1 \leq 1930^{\circ}$ 


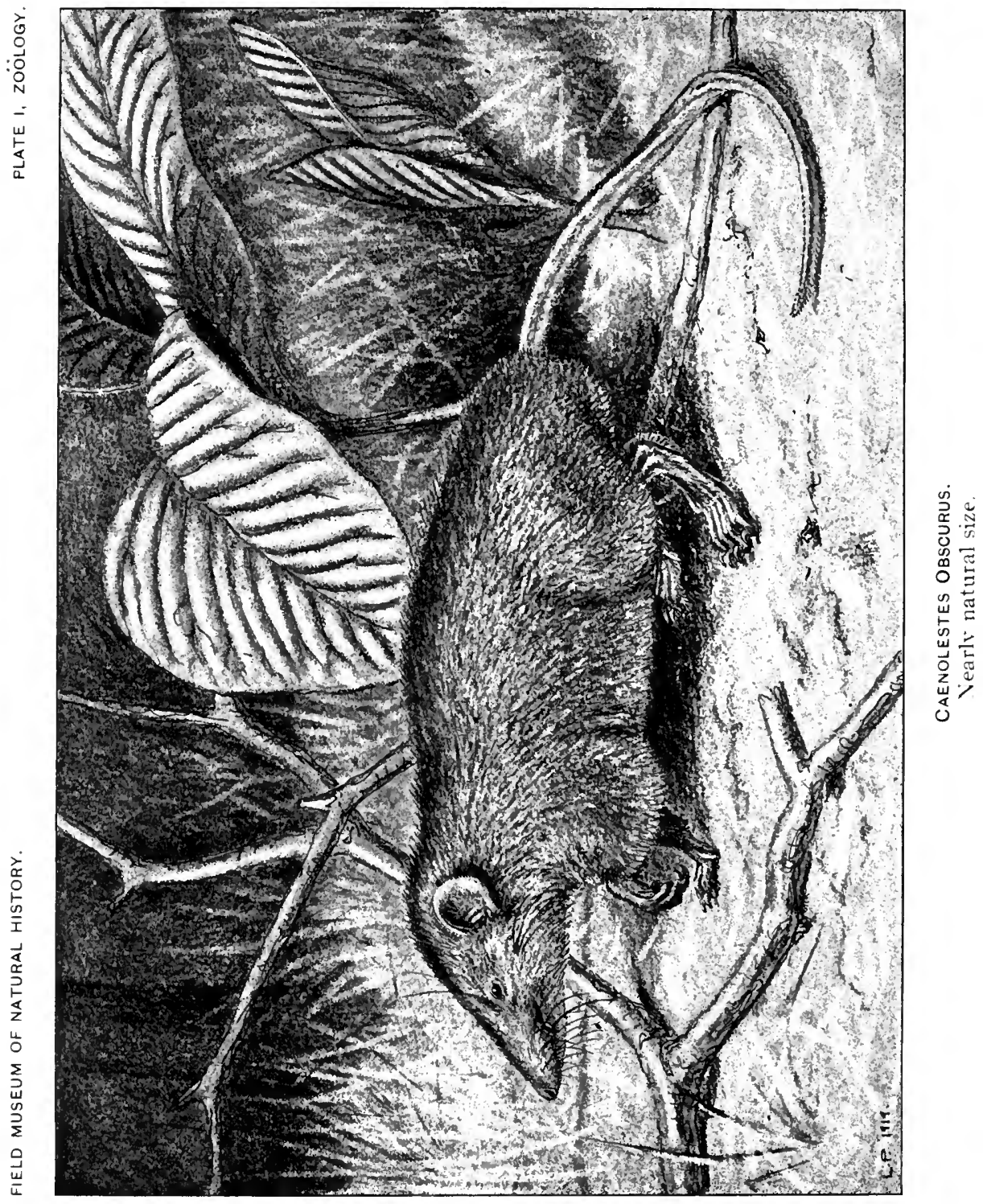




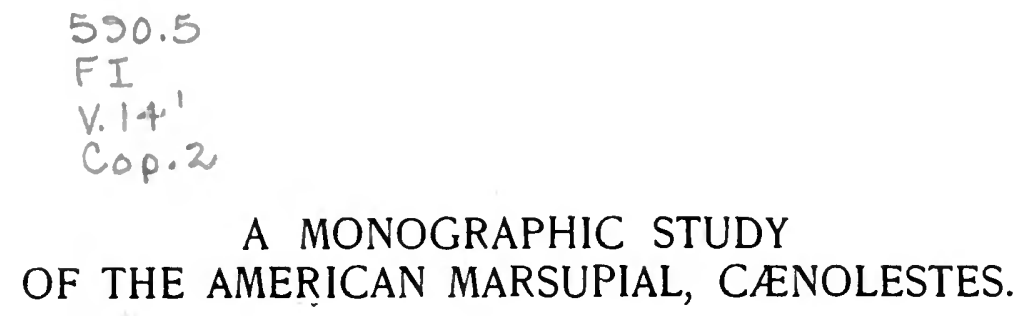

By Wilfred H. Osgood.

CONTENTS.

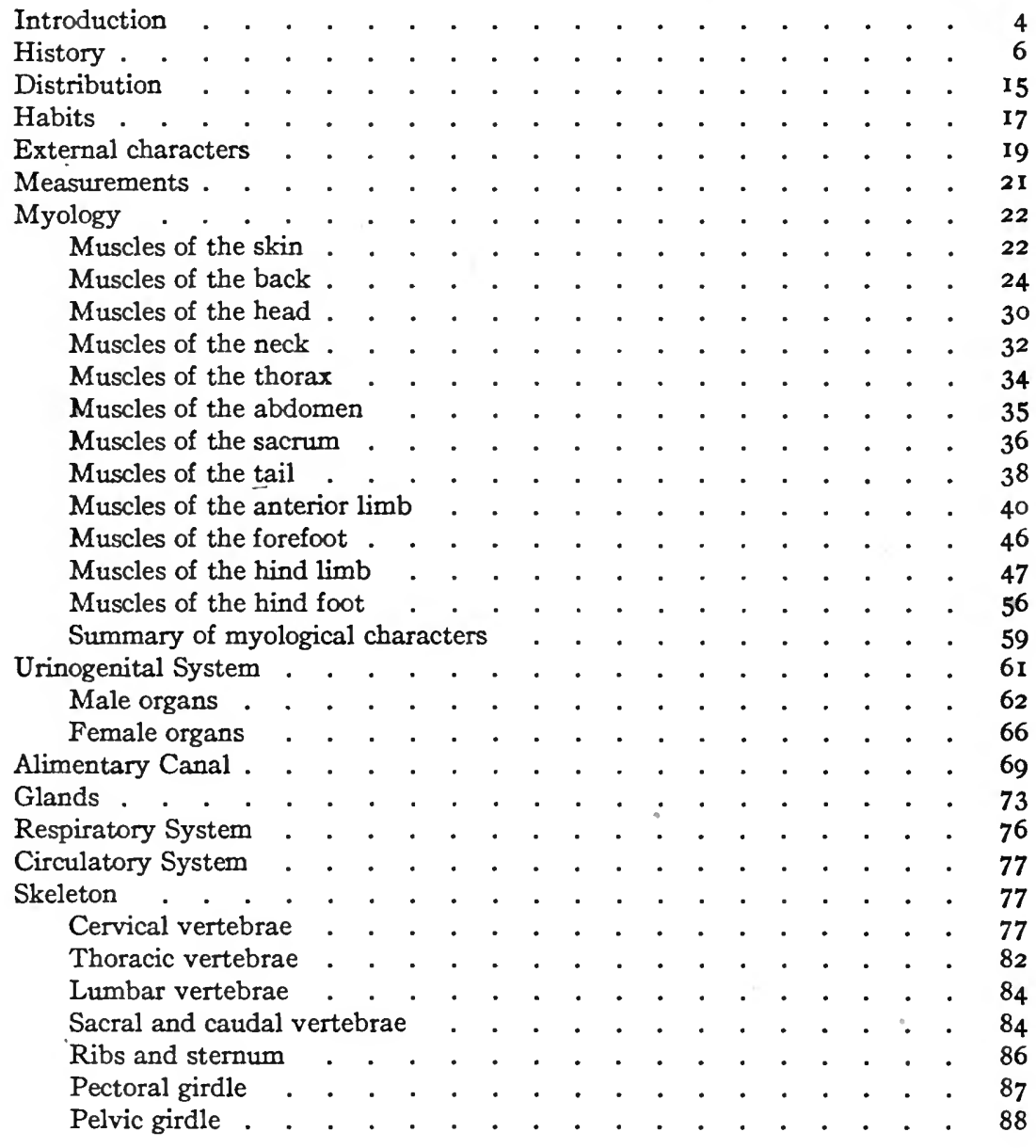


Skeleton-Continued.

Arm and forearm

Bones of the hand

Thigh and leg Skull

Bones of the foot

Summary of skeletal characters . . . . . . . . . . . . 97

$\cdot \cdot \cdot \cdot \cdot \cdot \cdot \cdot \cdot \cdot 99$

Dentition

Number and homologies of teeth

Upper incisors

Lower incisors

Canines

Upper premolars

Upper molars .

Lower premolars

Lower molars .

Origin of Diprotodonty

Relationships of Wynyardia

Relationships of Myrmecoboides

Phylogeny and taxonomy

Dispersal of marsupials

General summary .

Literature cited

The Brain of Canolestes obscurus

\section{INTRODUCTION.}

Owing to their many peculiarities of structure and their probable relationship to ancient and long extinct types, marsupials are among the most interesting of mammals. Their present distribution, largely in Australasia but also in South America, adds to the importance they possess for the morphologist and phylogenist. They have long been classified in two large groups or suborders, the Polyprotodontia and the Diprotodontia. These were first recognized by De Blainville in 1816 and later by Owen in 1866 . Broadly speaking, the polyprotodonts include the carnivorous or insectivorous forms with small and relatively numerous incisors, while the diprotodonts are the herbivorous forms with the incisors reduced in number and modified much as in rodents. Without exception, the diprotodonts are characterized also by a syndactylous foot, while the polyprotodonts, with the exception of one family (Peramelidae), are eleutherodactylous. This makes slightly different divisions (Diadactyla and Syndactyla) possible, but other considerations have favored the conclusion that the two major groups indicated by the dentition are the most natural ones.

Until recently, it was supposed that all modern diprotodonts and the 
majority of polyprotodonts were confined to Australasia, only one family of polyprotodonts being known elsewhere, the Didelphiidae or opossum family of South and Central America. Under these conditions, it was a matter of the greatest interest when a small marsupial, widely different from the opossums, was discovered in South America. This animal, now known by the generic name Canolestes, presented an apparent combination of diprotodont and polyprotodont characters, having a diprotodont dentition and an eleutherodactylous foot. Moreover, it was found to be closely allied to certain extinct forms known from fragmentary remains from the Tertiary of Patagonia, being clearly a surviving member of a highly differentiated group detailed knowledge of which promised to throw new light on problems connected with the origin and dispersal of marsupials. These facts were evident from examination of the few specimens, consisting merely of skulls and skins, which for many years were the only ones available. Such specimens had been obtained through aboriginal sources and the exact habitat of the animal was unknown.

In I9I I, while making general collections in the mountains of western Venezuela (Osgood, I9I2), I had the good fortune to discover Canolestes living in dense forests at an altitude of about 8000 feet. As a result of assiduous trapping, a total of eleven animals was captured and, despite poor equipment for the care of anatomical material, two entire specimens representing both sexes and two others with some parts mutilated were preserved in formaldehyde and bichloride of mercury. In addition, several dry skeletons and a small number of conventional skins and skulls were saved. This material has formed the basis of the following study. Its importance seemed to demand the fullest possible treatment and, although this has not been accomplished, it is hoped that sufficiently detailed information has been obtained to warrant general conclusions. Study of particular organs and systems by specialists would have been exceedingly desirable, but the nature of the material and the conditions under which it has been studied have not made this feasible except to a limited extent. ${ }^{1}$ The coopperation of Dr. C. Judson Herrick has been greatly appreciated and his description of the brain of Canolestes together with the figures drawn under his direction which are incorporated in the present publication will doubtless add greatly to its value.

Comparative material, especially of Australian forms, has been confined almost exclusively to skeletons and skulls. Fortunately a fairly representative collection of these is possessed by Field Museum and this has been supplemented by specimens borrowed from the U. S. made.

${ }^{1}$ It is especially to be regretted that no study of the organ of Jacobson has been 
National Museum, the American Museum of Natural History, and the Museum of Comparative Zoölogy. To the officials of these institutions, especially Dr. J. A. Allen and Dr. G. M. Allen, acknowledgment is gratefully made.

The accompanying illustrations are from drawings made by several different artists. The line drawings of muscles and soft parts (P1s. IV-X) are the work of Mr. Robert E. Snodgrass, now of the U. S. Bureau of Entomology; the wash drawings of skeletal parts (Pls. XI-XVIII) were done by Mr. Kenji Toda of the Department of Zoölogy, University of Chicago; the illustrations of the brain (Pls. XXI-XXII) are by Mr. A. B. Streedain formerly of the Department of Anatomy, University of Chicago; and the drawings of external parts (Pls. I-II) are by Mr. L. L. Pray of Field Museum.

\section{HISTORY.}

In a brief list of mammals from Ecuador published by R. F. Tomes in $\mathbf{I} 860$, the following note appeared without reference either to genus or species:

"A small animal about the size of the Water Shrew (Sorex fodiens), with external characters and incisor teeth so much like those of the Soricidae as to have led in the first instance to the belief that it was a placental Insectivore, perhaps in some degree resembling the Solenodon of Cuba. However, the existence of a small and rudimentary pouch sufficiently attests the implacental nature of the creature, which but for this must certainly, as far as external appearances go, be regarded as one of the Soricidae. A more ample account of it will be given on a future occasion."

This is the first published reference to the animal now known as Canolestes. Three years later (Tomes $\mathrm{r} 863$ ), the single immature specimen was described as to its dentition and external characters and given the name Hyracodon fuliginosus without any reference to its affinities within the order of marsupials. Subsequently it received little notice for many years. In I880, Alston referred to it in the following brief statement, published as a footnote (Alston r880, p. I95):

"A small Marsupial from Ecuador, named Hyracodon fuliginosus by Mr. Tomes (P. Z. S. $186_{3}$, p. 5I, pl. VIII), may represent a distinct family, but it is still only known from the very unsatisfactory original description. In any case it will require a new title, the name Hyracodon having been applied to a genus of fossil ungulates by Professor Leidy in 1856 , seven years before its use by Mr. Tomes." 
Again in the concluding paragraph of the very important Catalogue of Marsupialia and Monotremata in the British Museum (Thomas I888) it receives only this slight mention:

"And, finally, one animal, referred to this Order, has been so insufficiently described that no idea of its proper position can be gained, nor have any further specimens of it been collected. This is-

"Hyracodon fuliginosus, Tomes, P.Z.S. I863, p. 50, pl. viii (animal).

"Hab. Ecuador."

So meager were the data regarding it, that Lydekker (I894) completely ignored it in his very comprehensive Hand-book of Marsupials and Monotremes. Thus for more than thirty years after its discovery the subject of this monograph remained almost as unknown as if no specimen existed. In 1895 , however, a second specimen, consisting of a skin and skull, was received at the British Museum and in two brief but important papers (Thomas I895) was promptly described, tentatively classified, and figured. Its obvious affinity with extinct Patagonian forms was at once recognized and its importance in connection with theories of the dispersal of marsupials was noted. The preoccupied name Hyracodon was discarded and a new name, Cenolestes, was proposed as well as another specific name, obscurus, the second specimen having been obtained in the Bogota region and appearing to represent a different species of larger size. The following extracts from these papers of Thomas are of interest:

"In vindication of Mr. Tomes's paper I should like to say, firstly, that his description, hitherto supposed (from our ignorance of any such animal) to be imperfect or incorrect, proves to agree, so far as it goes, very closely with the present specimen; and, secondly, that remarks on the affinities of the animal must have been at that time more easily wanted than given, since even now, with infinitely greater material and the best of advice, I am unable to be at all positive about the exact position and relationships of the little marsupial described by $\mathrm{Mr}$. Tomes."

"The rediscovery of this long-lost genus, whose wide distinction from all other living marsupials its original describer does not appear to have fully appreciated, is one of the most interesting events in mammalogy that has happened for many years. A full description of the animal will be given elsewhere; but it may be here briefly stated (I) that Conolestes represents among the marsupials a family, and, perhaps, a suborder, entirely different from any now living; and (2) that it is closely related to, and evidently a surviving representative of, some of the fossil marsupials from the Santa Cruz beds of Patagonia."

"Apart from this, the survival to the present day of a member of so 
ancient a group, otherwise wholly extinct, is a fact of the utmost interest, and one whose discovery will be welcomed by every zoölogist."

"I have proposed for it the name Canolestes, as it is a modern member of an ancient group."

"The affix 'lestes' is connected in mammalogy with small and ancient fossil marsupials, e. g., Microlestes, Amphilestes, etc., so that the above name may be considered to represent an existing animal with ancient fossil relatives."

"Canolestes, with its uninteresting exterior, appeals mainly to the technical mammalogist. To him, however, with its intense palæontological and geographical interest, and the added puzzle its structure gives rise to in the general classification of the order, no animal will appear more important or more worthy of close and detailed study. That by the arrival of spirit specimens account of its anatomy may be rendered possible is very much to be hoped."

In these papers of Thomas, Canolestes was classified as a diprotodont and a member of the family Epanorthidae with the reservation that "It is, however possible that, in spite of the resemblance of the teeth of Canolestes to those of certain Australian Diprotodonts, the study of further material, including soft parts, skeleton, and milk-teeth, will bring out differences of such importance as to necessitate its subordinal separation from them." He says further, "It is clearly a diprotodont, as not only does it possess the characteristic development of the lower incisors, but even the molars resemble most closely in structure those of certain members of the family Phalangeridae, while being wholly unlike those of the typical Polyprotodonts. From all the existing Diprotodonts, however, apart from its habitat and numerous detailed differences, Canolestes is at once distinguished by not being syndactylous, a character which is always considered of family rank. It forms, therefore, among existing marsupials a peculiar family, and one which in America represents the Diprotodonts of Australia, just as Didelphyidae do the Polyprotodonts."

Although some further material was obtained in later years, it was similar to that used by Thomas and consisted only of a few native-collected skins and skulls. Additional study of these, therefore, added but little to what was already known and opinions varied as to the interpretation of the peculiar characters of the animal.

The next reference to Canolestes was a note by Ameghino (r897, p. 95) from which the following may be quoted:

"M. Thomas est venu à La Plata, rapportant avec lui un crâne de Canolestes que nous avons soigneusement comparé aux formes fossiles de Patagonie et nous avons pu reconnaitre qu'il presente plus de rap- 
ports avec les Garzonidæ qu'avec les Epanorthidae. Pourtant il est probable que le Coenolestes devra constituer le type d'une famille nouvelle."

Accepting the suggestion of Ameghino and others, Trouessart (I898) gave it the rank of a family, the Cænolestidae, including only the one genus, and assigned it to the suborder Diprotodontia. Ameghino (I900) later treated it as a family of diprotodonts, and still later (I903), in his well known rearrangement of marsupials and rodents, he included in the family the genus Canolestes and also the extinct genus $Z y$ golestes. The family was classified with four others, containing only extinct forms, in his suborder Paucituberculata, which in turn was referred to the order Plagiaulacoidea and regarded as directly ancestral to the Australian diprotodonts. The name Diprotodonta was reserved to designate a superorder conceived to embrace not only American and Australian diprotodonts but also the multituberculates and the rodents. Although Ameghino's ideas have not been generally accepted, especially those regarding the derivation of rodents, his strong conviction of the close alliance of American and Australian diprotodonts is noteworthy in the present connection. While differing from him in other respects, Weber (1904) agreed with Ameghino in placing Canolestes in neither the Diprotodontia nor the Polyprodontia but in a third suborder of marsupials for which Ameghino's name Paucituberculata was available. Meanwhile, Bensley (1903), in his very important paper on the evolution of Australian marsupials, included Ccenolestes in his "First Neogæic Radiation" and in casual references indicated his belief that its dentition is due to parallel or convergent development rather than to any direct relationship to Australian diprotodonts closer than that of common derivation from a didelphid ancestry.

On the other hand, Sinclair (I905, r906) and Scott (I9r3) revert to the opinion of Thomas and Ameghino that Conolestes and allied extinct forms are so closely related to Australian diprotodonts as to furnish strong evidence of a former land connection between South America and Australia. Sinclair includes all South American forms with diprotodont dentition in the family Cænolestidae which he divides into two subfamilies, of which the Cænolestinae embraces the genera Conolestes, Garzonia, and Halmariphus. Of this family he says (1905): "The Caenolestidae resemble the primitive phalangers in so many respects that it is impossible to escape the conclusion that the two families are related and not merely convergent groups." This statement is somewhat modified in a later paper (I906), as follows: 'While substantially the same conclusions are still held, it is proper to point out the evidence in favor of the view that the striking similarity in dental structure 


\section{io Field Museum of Natural History - Zoölogy, Vol. XIV.}

displayed by the two families may be explained by convergence. Until the upper dentition, skull and feet of the Cænolestidæ, and especially of the primitive members of the family, are fully known, this must remain an unsettled question. At present the arguments in favor of the alternatives expressed are about equally balanced."

The next author to give special attention to Canolestes was Miss Pauline Dederer (rgog), who made a study of the skull and pointed out certain resemblances to polyprotodonts, concluding that "While there is undeniably a series of forms connecting Canolestes with the Diprotodonts in tooth structure, yet Canolestes itself is so generalized in this respect that we may perhaps, in theabsence of carroborating characters, question its inclusion within this group. Possibly it may be found to be an offshoot from the Polyprotodonts, as it appears structurally to be more generalized than any Diprotodont, and therefore it might well occupy a separate suborder, as Thomas suggested-the Paucituberculata of Ameghino."

Gregory (rgro, p. 2rI) refers to Miss Dederer's work and concludes that "the detailed characters of the skull show no striking Diprotodont characters and the writer is inclined to regard Canolestes and its allies as an independent suborder, an offshoot of primitive Polyprotodonts, which has paralleled Diprotodonts in certain characters of the dentition." Accordingly he places Canolestes in the suborder Paucituberculata with the parenthetical suggestion that the group might be called the Cænolestoidea. Gregory also discusses the possible relationship of the cænolestids to Propolymastodon and allied forms regarded as multituberculates by Ameghino. He concludes his treatment of the marsupial group by stating that "The problem of the genetic relations of the Diprotodontia and the Polyprotodontia is complicated to a certain extent by the existence of the Cænolestoids; but the opinion may be expressed that probably the resemblance of certain Cænolestoids to the Multituberculates is an instance of convergence between related suborders, and that the same is true, but to a less extent, of the resemblances of other Cænolestoids to the Diprotodont phalangers." Subsequently (Osborn, I9Io, pp. 515-5I8) the classification proposed by Gregory was somewhat modified and the cænolestids were included in the suborder Diprotodontia as a superfamily, the Cænolestoidea.

Broom (IgI 2), in his special paper "On the Affinities of Cænolestes," reviewed the evidence adduced by Miss Dederer and pointed out certain resemblances to polyprotodonts not previously noted. He concluded that "as Canolestes differs from the typical Polyprotodonts only in tooth specialization, it should not be removed from the Polyprotodontia, but merely be made the type of a distinct family, or section at most." 
Gidley (I9I5), in a short footnote, expresses an opinion similar to that of Broom, saying: "The Cænolestidae have been placed in this great group [Diprotodontia] apparently on the diprotodont-like development of the lower jaw. However, this may be an entirely independently acquired character. This family more probably belongs with the Polyprotodonts."

With the exception of casual references in general works, nothing else of importance has appeared in reference to the systematic or phylogenetic position of Canolestes. The occurrence of the animal in several different localities has been recorded (Osgood, rgr2; Stone, r9r4) and the number of species has been increased at least nominally to three, one of which has been made the type of a second genus, Orolestes (Thomas, I9I 7), which, as described, seems only slightly different from the original form. ${ }^{1}$

Reviewing the foregoing it is seen that, within two decades and upon a knowledge of its cranial and external characters only, Canolestes has been placed in three different suborders and that various competent authors have disagreed as to its proper position. Thomas, Ameghino and Scott frankly classify it with Australian diprotodonts; Sinclair inclines to do the same; Bensley, Miss Dederer and Gregory believe its diprotodont characters are convergent and place it in a suborder of its own; while Broom and Gidley would rank it merely as an aberrant polyprotodont. Beginning with that of the period prior to the discovery of Canolestes, the following are the various classifications of marsupials concerned in its history, wholly extinct groups being indicated by a dagger:

\section{THOMAS I 888.}

Order Marsupialia

Suborder Diprotodontia

Family I. Macropodidae

2. Phalangeridae

3. Phascolomyidae

Suborder Polyprotodontia

Family r. Peramelidae

2. Dasyuridae

3. Didelphyidae

${ }^{1}$ At the time of writing, the privilege of examining specimens of Orolestes is denied me. 
i2 Field Museum of Natural History - Zoölogy, Vol. XIV. THOMAS I 895 .

Order Marsupialia

I. Suborder Diprotodontia

A. Non-syndactylous. American

Family I. Epanorthidae Conolestes

$$
\begin{aligned}
& \dagger \text { Epanorthus } \\
& \dagger \text { Decastis } \\
& \dagger \text { Paraepanorthus }
\end{aligned}
$$

B. Syndactylous. Australian

Family 2. Phalangeridae

3. Phascolomyidae

4. Macropodidae

II. Suborder Polyprotodontia

A. Syndactylous. Australian

Family 5. Peramelidae

B. Non-syndactylous. American and Australian

Family 6. Didelphyidae

7. Dasyuridae

8. Notoryctidae

TROUESSART 1898.

Order Marsupialia

I. Suborder Diprotodontia

Section I. Syndactylia

Family I. Phalangeridae

2. Phascolomyidae

3. TDiprotodontidae

4. Macropodidae

Section 2. Asyndactylia

Family 5. †Abderitidae

6. †Epanorthidae

7. †Garzonidae

8. Cænolestidae (Ccenolestes only)

II. Suborder Polyprotodontia.

Family 9. Peramelidae

Io. †Borhyaenidae

II. Dasyuridae 
May, ig2i. American Marsupial, Cenolestes - Osgood.

12. Notoryctidae

I3. † Microbiotheridae

I4. Didelphyidae

I5. †Amphitheridae

I6. †Triconodontidae

I 7. †Dromatheridae

AMEGHINO I903.

Subclass Marsupialia

Superorder Diprotodonta

Order Plagiaulacoidea

Suborder †Allotheria

Family †Plagiaulacidae

$\nmid$ Polydolopidae

$\nmid$ Neoplagiaulacidae

$\nmid$ Promysopidae

$\dagger$ Polymastodontidae

Suborder Paucituberculata

Family †Abderitidae

$\dagger$ Epanorthidae

Cænolestidae -Canolestes

$\dagger-Z$ ygolestes

†Garzonidae

$\dagger$ Microlestidae

Order HYPSIPR YMNOIDEA

Australian diprotodonts

Order Rodentia

Rodents. Equivalent to Glires

Superorder Polyprotodonta

Australian and American polyprotodonts

WEBER I9०4.

Subclass? MARSUPIALIA

Order Marsupialia

Suborder Polyprotodontia

Family Didelphyidae

Dasyuridae

Notoryctidae

Peramelidae 
i4 Field Museum of Natural History - Zoölogy, Vol. XiV.

Suborder Paucituberculata

Family Epanorthidae (Ccenolestes et al)

Suborder Diprotodontia

Family Phascolarctidae

Phalangeridae

SINCLAIR 1906.

Suborder Diprotodontia

Family Canolestidae

Subfamily Cænolestinae

Genus $†$ Halmarhiphus

†Garzonia

Cænolestes

Subfamily †Palaeothentinae

Genus †Palaeothentes

†Callomenus

$\dagger$ Decastis

Subfamily $†$ Abderitinae

Genus †Abderites

GREGORY I9IO.

Infraclass MetatHeria

Order †TRICONODONTA

Order †TRITUBERCULATA

Order Marsupialia

Suborder $\nmid$ Allotheria (Multituberculata)

Suborder Diprotodontia

Suborder Paucituberculata (Cænolestoidea)

Suborder Polyprotodontia

OSBORN I9IO.

Order Marsupialia

Suborder Polyprotodontia

Superfamily DidelPHOIDEA

Family I. Didelphiidae

2. Myrmecobiidae

3. Dasyuridae

4. Thylacinidae

Superfamily Perameloidea

Family I. Peramelidae 
May, i921. American Marsupial, Cenolestes - Osgood.

Superfamily NotoryctordeA

Family I. Notoryctidae

Suborder Diprotodontia

Superfamily CenolestordeA

Family x. Palæothentidae- $†$ Palcothentes

- $†$ Abderites

- Canolestes

2. Garzoniidae

Superfamily Phalangeroidea

Family I. Phalangeridae

2. †Thylacoleonidae

3. Macropodidae

4. Phascolomyidae

5. †Diprotodontidae

Suborder Allotheria

Family r. $\nmid$ Plagiaulacidae

Order Marsuptalia

SCOTT $1913^{1}$

Suborder Polyprotodonta

Didelphiidæ

Thylacynidæ

Suborder Diprotodonia

Cænolestidæ

†Garzoniidæ

Suborder Allotheria

$\dagger$ Plagiaulacidæ

$\nmid$ †olýdolopidæ

\section{DISTRIBUTION.}

The present known distribution of Canolestes (and Orolestes) is shown by the accompanying map. Only a few localities are represented, all Andean, and extending from the Venezuelan border on the north nearly to the Bolivian boundary on the south. In the extensive regions between these localities, no specimens have been obtained but it is not improbable that the animal has nearly or quite continuous range throughout the central Andes so far as local conditions meet its needs.

${ }^{1}$ American forms only. 
i6 Field Museum of Natural History - Zoölogy, Vol. XIV.

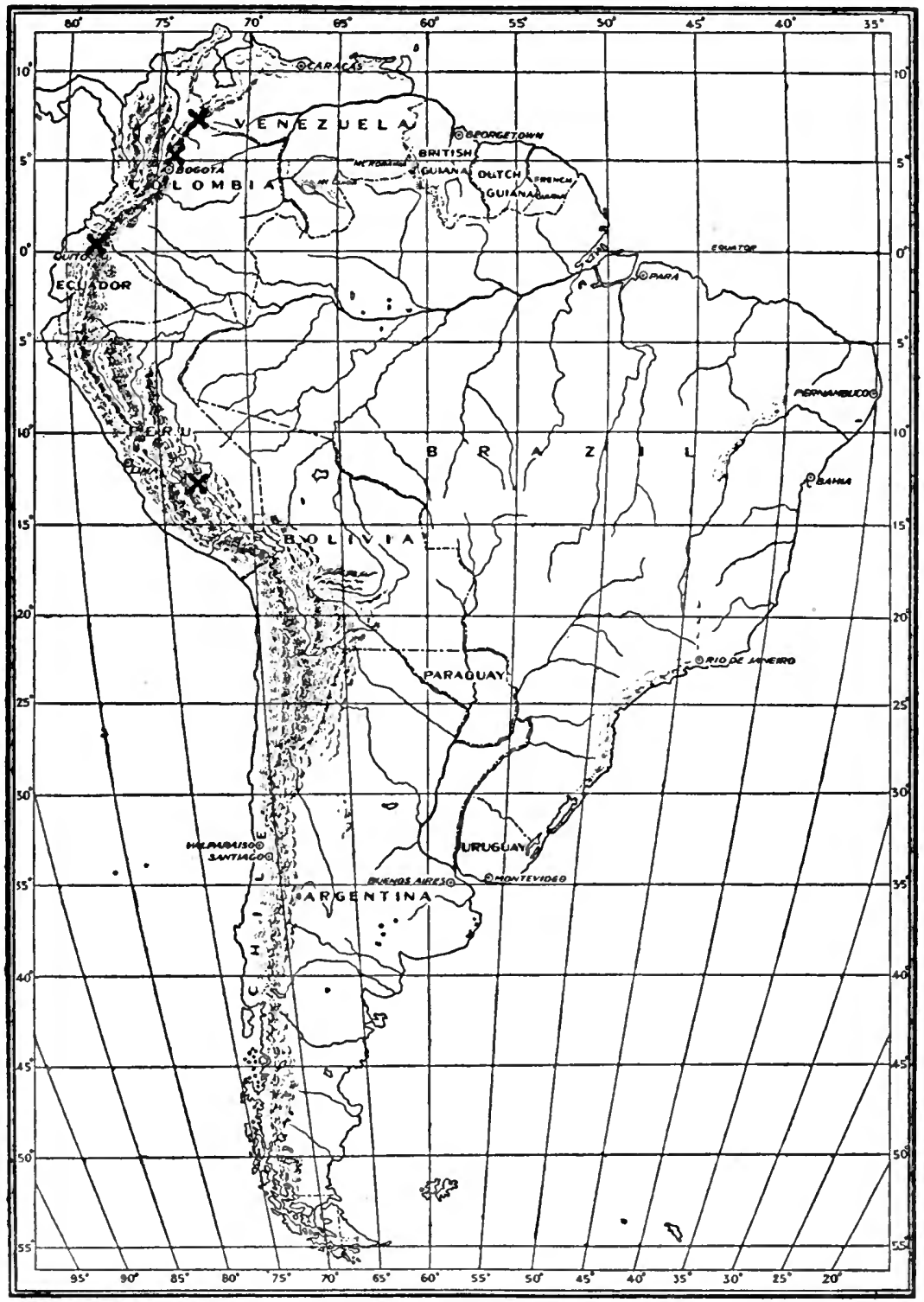

$\times$ Records of Canolestes and Orolestes

The original type of Hyracodon fuliginosus was received from the well-known collector Louis Fraser in a shipment from Ecuador of which Tomes (r86o, p. 2rI) says: "The greater portion of these are believed to have been collected at Pallatanga, on the western slope of the Cor- 
dillera; but the exact locality is not certain, from the specimens having been unfortunately mixed together." The elevation of Pallatanga is scarcely more than I500 meters and, since all exact records of Canolestes are from greater altitudes, it is probable that the first specimen did not come from there but from the paramos of Mt. Chimborazo or Mt. Pichincha where Fraser also worked. The type of Canolestes obscurus likewise came from an indefinite locality-the vicinity of Bogota, Colombia. In this case the probable actual locality is at the edge of the paramos north or east of the city of Bogota in the eastern Cordillera of the Andes. Exact records are only three in number: Paramo de Tama, Venezuelan-Colombian Boundary at 7000-9000 ft. (Osgood, 1912); Hacienda Garzon at ro500 ft., near the Paramo of Mount Pichincha, Ecuador (Stone, I9I4); and Torontoy, Peru, at I4000 ft. between Lats. $10^{\circ} 30^{\prime}$ and $13^{\circ} 30^{\prime} \mathrm{S}$. and Longs. $72^{\circ}$ and $73^{\circ} \mathrm{W}$. (Thomas, I9I 7 ). ${ }^{1}$

\section{HABITS.}

Canolestes is of terrestrial and crepuscular or nocturnal habits. It feeds upon insects. These statements compass in a large measure what is known of its habits. It lives at high altitudes in cool forests not far from timberline and may be found also in grassy openings in mountain valleys. On the Paramo de Tama, near the head of the Tachira River, I obtained it at an altitude of about 7500 feet on both the Venezuelan and Colombian sides of the international boundary line which is here formed by the Tachira River. Most of the specimens were secured in the heart of a dense forest on the Colombian side of the river not far from a hacienda belonging to Don Mario Gonzales of San Jose de Cucuta, Colombia. Wishing to collect and observe in such a place under wholly natural and undisturbed conditions, I had employed men for some days to cut a new trail directly into the deepest part of this forest for a distance of several miles. Camp was established at the terminus of this main trail and short radiating trails were cut thence to various points of the compass, the forest and undergrowth being so dense that but little freedom of movement would have been possible otherwise. In the dense growth along these trails, Canolestes were caught in small numbers, rarely more than one specimen to fifty "trap nights." The exact nature of the places in which individual specimens were taken varied widely, indicating that the animals move about freely. Some were caught in steel traps baited with small birds, others in rat traps baited with bacon rind,

${ }^{1}$ In a paper published since this was written, Thomas (I920, p. 246) gives three additional locality records: Machu Picchu, Peru, alt. I 2000-I $3000 \mathrm{ft}$.; Ocabamba Valley, Peru, alt. 9 Ioo ft.; Gualea, Ecuador, alt. $6000 \mathrm{ft}$. 
and still others in mouse traps with the conventional rolled oats as bait. In the case of the mouse traps, however, it was probable that the animals had not been attracted by the bait but had merely run across the lightly set traps. A preference for animal food was quite evident and it was only by continued effort with "meat baits" that a total of more than one or two specimens was obtained.

Beneath the heavy canopy of treetops and still further shaded by masses of low vegetation, the animals of the dark damp forests exercise their vision only to a limited degree and depend mainly upon the sense of smell. That this is the case with Canolestes is indicated by its small eyes and its highly developed olfactory organs. In fact, although somewhat ratlike in appearance and from its rather long hind legs doubtless active and roving, Canolestes is best described as to appearance by saying that it is a large forest shrew. Like a shrew, it is fond of fresh meat when such food offers itself, but its steady diet consists only of insects. The contents of three stomachs were submitted to the U. S. Biological Survey and as a result of examinations kindly made in their laboratories the following report was received:

"No. I. Contents: Parts of a weevil, three ants (Dorylidae), skin of caterpillar, lepidopterous pupa, adult lepidopteron, leg fragments of orthopteron, a Tipulid larva, centipede and spider. Dipterous and lepidopterous remains form the major portion.

"No. 2. Contents: Fragments of two beetles and a weevil, a caterpillar, an orthopteron, a hemipteron (?), spider and one seed of composite plant. Caterpillar - at least 60 per cent.

"No. 3. Contents: Unidentified insect fragments and parts of spider."

Other observations on the habits of Canolestes so far as published are meager. Mr. Geo. D. Child, through whom the type of $C$. obscurus was obtained, contributed the following note: "The little animal you speak of is called 'Raton Runcho,' which means 'Opossum-Rat.' It lives in the high brush-wood, and is supposed to feed on birds' eggs and small birds. It is very rare indeed, and is obtained with much difficulty." (Thomas, I895, p. 877.)

Mr. Samuel N. Rhoads, who collected two females on Mt. Pichincha, Ecuador, writes that "The two specimens were secured in swampy ground, the edge of a large pasture on the Hacienda Garzon, within a few feet of a swiftly flowing stream of considerable size. They wert caught in small cyclone mouse traps set in underground runway: among the thick grass, these runways being about on the level with the waterline of the swamp. They were caught on the same day, soon afte:

1 The book name selva was proposed by Lydekker in 1896 (Geog. Hist. Mamm.) but has seldom been used by others. 
placing the traps in that locality, but although I continued to trap there for a week longer, having as many as 40 or 50 traps in that place, I secured no more specimens there, nor in any other similar localities where trapping was done. The stream alluded to runs over a bed strewn with volcanic rocks and boulders and is in an open cultivated valley-head, draining the south slopes of Mount Pichincha, about 8 miles south of Quito and at an elevation of about 10,500 feet, the valley at this point being about half a mile wide and extending to even greater widths as far as one can see, in a southerly direction." (Stone, I 9 I4, p. I8.)

The type of Canolestes (or Orolestes) inca was collected by an experienced naturalist, Mr. Edmund Heller, whose notes, when published, will doubtless furnish substantial additions to what is now known of the animal. ${ }^{1}$

\section{EXTERNAL CHARACTERS.}

General form.-Although frequently referred to as "ratlike," the general form in Canolestes might with equal propriety be called soricine. Insectivorous forms such as Nesogale approach it closely and, as elsewhere shown (Pl. XIX), have practically identical major proportions. Among marsupials, the species most closely resembling it are perhaps to be found in the genus Phascologale. Many species of Marmosa approximate it in size of body, but distinctions in the feet, ears, and tail are so obvious that the parallel is at once seen to be only of the most general nature. The legs are of moderate length, the hind pair 20 to 25 per cent longer than the front.

Head.-The head is elongate conical and somewhat shrewlike in general appearance. The eyes are very small, the distance between the anterior and posterior canthi measuring only $2.2 \mathrm{~mm}$. in a female specimen in alcohol. The rounded ears project well above the pelage but are relatively small as compared to those of the didelphids. The thickness of the cartilaginous conch also is greater and it is set with fine short hairs within and without. The tragus is but little developed and the considerably larger antitragus is opposed mainly by the crus of the helix which forms a thin flap directed inward. Two parallel antihelical folds (metatragus) are prominent and separated from each other by a deep fossa (Pl. II, fig. I). A similar condition is found in Perameles (cf. Thomas, 1888, Pl. XXI, figs. 5, 7). The nostrils are lateral and bounded by a rhinarium which is extended dorsally to form a small vshaped plate. A shallow furrow traverses it anteriorly and dorsally.

${ }^{1}$ I am informed by Mr. Heller that these and other notes on Peruvian mammals have been prepared for publication by the National Geographic Society, Washington, D. C. 
The upper lips have a thin coriaceous edge that continues to the median sulcus which partially divides the rhinarium and forms an incipient cleft of the lips. The lower lips have a similar narrow edge which is only very slightly thickened in front. The lower lip is free in front from the base of the long incisors and has a high internal median ridge or frenulum which fits into the slight space between the incisors. Slightly in front of the angle of the mouth and just in advance of the molariform teeth is a pair of reciprocating labrets or outgrowths of the lips, one on the upper and the other on the lower lip (Pl. II, fig. 2). These appear to be an adaptation for the ejection of undesirable food particles during mastication. They are directed slightly outward and downward in such a way that with the lips wholly or partly closed in front they might in conjunction with the buccinator muscle serve to guide hard parts of insects or other matter to the exterior. A quite different function also is possible, that is, in closing the lips at this point and assisting in isolating the internal cheek pouch formed by the buccinator muscle. This pouch is fairly definite and includes a considerable space laterad of the molariform teeth.

Tail.- The tail is gently tapering and has no inordinate thickening at the base. The body fur extends upon it only a very slight distance. Thence to the tip it is thickly set with short stiff hairs which nearly or quite conceal the underlying scaly annulations. At the tip there is usually a slight hairy pencil. Nothing suggests prehensilism in the slightest degree. ${ }^{1}$ The contour of the tail is rather distinctly quadrilateral instead of cylindrical.

Feet.-The fore feet are pentadactyl, but the outer toes are decidedly reduced and furnished with small blunt nails instead of claws. The third or middle toe is slightly the longest and the second and fourth are subequal, all three bearing sharp curved claws. The reduction of the lateral toes and especially the absence of claws is in marked contrast to the condition general among Dasyuridae and Didelphiidae but is almost exactly paralleled in the Peramelidae in many of which the reduction of the first and fifth toes has proceeded much farther. In Canolestes, however, although the elongated middle toes seem to indicate a digitigrade adaptation, the plantar surface is carried well backward on the outer side and supported by an unusually large pisiform bone. There are five plantar pads well distinguished from each other and having smooth non-striated surfaces.

The hind foot is relatively long and narrow. Its general proportions

1 Thomas (1895), in describing $C$. obscurus, states that the tail has "its termina inch below wholly naked" and that "it is therefore presumably prehensile." Nc such condition has been observed in other specimens and it is probable the tail in the above-mentioned one was abnormal. 
might be said to lie somewhere between those of Phascologale and Antechinomys. The hallux is reduced and bears only a weak nail. It is set at a slight angle but it scarcely reaches the end of the second metatarsal and its functional importance is slight. The remaining four toes are subequal, the third and fourth possibly a trifle longer than the second and fifth. All are furnished with well-developed curved claws. The third and fourth digits are connected at the base by an integumentary web which is slightly more extensive than that between the other digits, but this is scarcely to be regarded as a tendency toward syndactylism. The soles are naked and provided with six plantar pads in much the same relative positions as in Phascologale. Three of them are digital, one hallucal, and two metatarsal. All are smooth without transverse striations. See Plate II, figures 3 and 4.

Pelage.-The pelage is soft and thick over the entire body. Owing to the peculiar distribution of hairs of different quality the coat is not smooth or velvety but has an appearance of superficial looseness and unevenness not uncommon in mammals of humid regions. The color is practically uniform throughout, the underparts being only slightly lighter than the upper owing to the absence of the fine exserted blackish hairs which are generally distributed on the upperparts. The claws and a few hairs at their bases are whitish but the hairiness of the upper sides of the feet shows no contrast with the body. The tail also is colored the same above and below and from base to tip except that in four out of eleven specimens the tip is white. There are no facial markings and in general it would be difficult to find a more uniformly colored animal. The color is dull Mars brown, clearer on the underparts and more mixed with darker and subject to light reflections on the upper parts.

Marsupium.-No trace of an external pouch can be detected in adult specimens of either sex and no immature examples have been examined. Tomes ( 1863 ), in describing the original type of Hyracodon fuliginosus, which was probably immature, states that it had a "small and rudimentary pouch." Hence it is probable that the pouch in Canolestes, as in Phascologale and some others, is present in the young but disappears in the adult.

\section{MEASUREMENTS.}

External measurements.-Fresh specimens measured in the field: Average of 5 males: Total length 240.6 (235-25I); head and body II 9.2 (I 13-135); tail vertebræ I21.4 (II8-1 26); hind foot with claw 23.5 $(23-24.5)$. Of 5 females: 223 (209-230); I07.6 (IO6-I I 3 ); I I 5.4 (IO3-I 2 I) 


\section{Field Museum of Natural History - Zoölogy, Vol. XiV.}

$22.5(22-23)$. The ear in a female in alcohol measures $12.5 \mathrm{~mm}$. from the intertragal notch to the apex. The tail at the base is $3.3 \mathrm{~mm}$. wide and $3 \mathrm{~mm}$. deep; at ro $\mathrm{mm}$. from the tip it is $\mathrm{Imm}$. $\mathrm{x} \mathrm{I} \mathrm{mm}$.

Measurements of skull.-Adult male and female, respectively: Greatest length $32.7,29.2$; basilar length $28.4,25$; zygomatic breadth I $5,13.8$; mastoid breadth Ir.4, 10.9; depth of braincase 8.2, 8.1 ; length of nasals I 5.I, I 4 ; greatest breadth of nasals $4.3,4.3$; least interorbital breadth $7.3,7.3$; length of palate from gnathion $18.3,16.2$; anterior palatal foramina $6.3 \times 2.5,5.4 \times 2.2$; palatal vacuities $6.7 \times 3.2,6 \times 3.2$; front of upper canine to back of $\mathrm{M}^{4} \mathrm{I} 2.9, \mathrm{II} .5$; combined length of four upper molars 5.7, 5.5; combined length of three lateral incisors 3.I, 2.8; length of bone of lower jaw from condyle $20.5,17.5$; angle to coronoid 8, 7.2; depth of jaw at second molar 2.2, I.7; combined length of four lower molars 6.6, 6.3; exposed length of median lower incisor 6,5 .

\section{MYOLOGY.}

\section{Plates III-VI.}

\section{Muscles of the Skin.}

Panniculus. - Immediately beneath the skin and separable from it only by careful dissecting is a thin, partly membranous and partly muscular layer which may be divided into several rather definite parts but which taken as a whole forms a sac enveloping the entire body and having relatively few and weak ental attachments. On the fore and hind legs it becomes exceedingly thin and cannot be traced beyond the middle of the epipodials. Over the posterior part of the body it is entirely membranous, thicker over the back and sides and very thin over the pectoral muscles. It is attached posteriorly on the biceps femoris lengthwise of its caudal fibers; dorsally it becomes slightly muscular and dips beneath the "cruro-coccygeus" to a definite insertion on the dorsoental surface of the tuberosity of the ischium. ${ }^{1}$ It is almost discontinuous over the pectoral and interscapular regions where it is lost in a thin scarcely perceptible aponeurosis. Over the head it reappears as a thin sheet chiefly membranous except along the under side of the ear and forward on the side of the face to the anterior base of the zygoma where a few muscle fibers run. The principal muscular division proceeding directly from this outer plane, superficial fascia, or panniculus is that which enters the axilla forming the so-called cutaneus maximus. Be-

'Possibly this dorsal part corresponds to the "ischiotergal" slip described by Macalister in Dasypus and by Wilson (1894, p. 6) in Notoryctes. 
ginning in the middorsal line near the origin of the latissimus dorsi (and immediately overlying and parallel to it), a thin sheet of converging fibers runs forward and downward to the axilla. Similar converging fibers from the mid-thoracic region and from the abdomen join those from above and unite to form a single muscle which enters the axillary region dorso-laterally just below the latissimus dorsi and ventrally parallels the outer edge of the pectoralis major. It makes a turn on itself and inserts as usual on the proximal two thirds of the inner edge of the deltoid ridge of the humerus. The abdominal part of this muscle is somewhat differentiated into a humero-abdominalis or xiphi-humeralis (pectoralis quartus). This begins to be fleshy on the middle of the abdomen and anteriorly divides to pass on either side of the pectoralis and parallel to it. On entering the axilla it becomes fused with the cutaneus maximus and has a common insertion with it. It has similar relations in most marsupials.

Cervico-auricularis. - This is a thin paired sheet arising from the occiput and the nuchal crest for a distance of about $10 \mathrm{~mm}$. or to the fatty deposit in the interscapular space. It is inserted on the cartilage of the back of the ear and into the ental surface of the superficial fascia below the ear for some $8 \mathrm{~mm}$. lengthwise of the side of the neck. Dorsally it leaves. the base of the ear for a short distance and attaches to the ectal surface of the muscle which elsewhere underlies it and which is here called the auriculo-occipitalis.

Auriculo-occipitalis.-Arises from the nuchal crest entad of the cervico-auricularis, the anterior limit of its origin being even with that of the cervico-auricularis and the posterior slightly cephalad of it. Its two halves separate on the occiput and diverge over the parieto-squamosal region to overly the caudal part of the temporal muscle. Directly above the ear, it passes into the ental surface of the superficial fascia or panniculus and thence around the anterior base of the ear the two are inseparable.

Dorso-cuticularis.-A long slender muscle arising on the side of the twelfth thoracic vertebra and running forward along the boundary between the latissimus dorsi and the trapezius to the side of the scapula where it widens slightly and inserts on the ental surface of the thin outer sheet of the panniculus. Its width at its insertion is $1.5 \mathrm{~mm}$. I have been unable to find any trace of this muscle in Didelphis nor any record of its occurrence in any other marsupial. Its form and relations are almost exactly as in the Insectivora where it is of frequent occurrence. Somewhat similar muscles are found also in certain edentates. (See Plate III.) 


\section{Muscles of the Back.}

Spino-trapezius.-Origin from the spines of the thoracic vertebrae from the fifth to the twelfth. Insertion on the middle of the vertebral third of the scapular spine. A thin rather elongate muscle passing forward superficial to the dorso-cephalic part of the latissimus dorsi. Dorsally it is separated from the acromio-trapezius by a small fascia overlying the rhomboideus. A separation has been noted also in Notoryctes (Wilson, I894, p. 6). It is the usual condition in the monotremes, insectivores and certain edentates. In Didelphis, the single muscle is weaker over the shoulder than elsewhere and in Sarcophilus (Macalister) also there is a tendency toward division. In Petrogale, Parsons (I896) found that it had a "continuous fleshy origin except opposite the first thoracic spine, where it is aponeurotic."

Acromio-trapezius.-Origin from the occipital crest slightly laterad of the median line and thence along the nuchal crest to the vicinity of the fifth thoracic spine. Insertion on the front of the scapular spine and metacromion and thence along a fascia crossing the acromiodeltoid to the clavicle. A broad thin sheet covering the dorso-caudal half of the side of the neck and part of the shoulder.

Latissimus dorsi.-Origin from the vicinity of the fifth thoracic spine along the vertebral column to the middle of the third lumbar vertebra and to the lumbar fascia. Insertion in common with that of the teres major entad of the biceps on the side of the bicipital groove. On its lower side near its insertion is the usual connection of the epitrochlearis. It is more definitely connected to the teres at its insertion than in Didelphis. It has no costal slips and in this agrees with Didelphis, Dasyurus, Notoryctes, Phascolarctos, etc.

Rhomboideus. - This is divisible into Rhomboideus major (vertebralis) and $R$. minor (capitis). R. major has its origin on the nuchal crest from the occiput slightly caudad of the anterior border of the trapezius to the fifth thoracic spine. Its insertion is on the inner side of the vertebral border of the scapula cephalad of the insertion of the serratus magnus. $R$. minor has its origin fleshy from the junction of the mastoid, squamosal and supraoccipital bones and thence along the occipital crest a distance of about four millimeters. It is a thin flat ribbon free from the vertebral division until a point halfway between the occiput and the scapula where it unites with its fellow. Its insertion is on the anterior distal base of the scapular spine dorsad of the insertion of the "atlantoscapularis." The rhomboideus in marsupials is usually undivided.

Levator scapulae.-Origin from the transverse processes of the last five cervical vertebrae just entad of the scalenus. Anteriorly a single slip 
passes ectad over the scalenus from an origin on the superior transverse process of the third cervical. This arrangement differs from that of Didelphis in which the scalenus is entirely laterad of the serratus. Insertion on the posterior vertebral border of the scapula craniad of the insertion of the serralus and continuous with it.

Serratus posterior superior.-Insertion by digitations from the fourth to the ninth ribs inclusive. Dorsally it is mostly aponeurotic but a broad fleshy prolongation extends anteriorly to the lower border of the splenius, thence becoming aponeurotic as it crosses that muscle and continues between the splenius and the rhomboideus to the most anterior point of its origin on the nuchal crest above the sixth cervical spine. Thence caudad its origin follows the mid-dorsal line and its wide aponeurosis covers the longissimus dorsi and continues into the lumbar fascia.

Serratus posterior inferior.-Origin on the middorsal line with the lumbar fascia. Insertion from the tenth to the thirteenth ribs. Practically as in Didelphis.

Splenius.-Origin from the nuchal crest from the vicinity of the front of the axial spine to the second thoracic vertebra. Insertion on the occipital crest from the mastoid process of the squamosal to a point about $2 \mathrm{~mm}$. from the median line. Its lower border is free as usual and near its caudal extremity it is somewhat attached to the aponeurosis of the serratus posterior superior.

Biventer cervicis.-Origin from the transverse processes of the fifth, sixth, and seventh thoracic vertebrae. Insertion fleshy or very slightly aponeurotic on the occiput between the median line and the complexus to which its lateral border is attached for some $4 \mathrm{~mm}$. Anteriorly it reaches nearly to the parietal bones. It is a larger and thicker muscle than in Didelphis and lies with its counterpart for a great part of its length in the space between the elevated axial spine and the second thoracic spine.

Complexus.-Origin from the articular processes of and the aponeurotic arches between the last six cervical and the first five thoracic vertebrae. A large slip somewhat connected also with the longissimus capitis runs forward to the transverse process of the atlas. Insertion by a broad tendon on the occipital crest laterad of the biventer to within about $3 \mathrm{~mm}$. of the mastoid bulla.

Longissimus capitis.-Origin from the articular processes of the last six cervical and the first four thoracic vertebrae in intimate relation with the slips of origin of the complexus. Insertion by broad tendon on the upper cranio-lateral border of the mastoid bulla and to a slight extent on the adjoining part of the squamosal. 


\section{Field Museum of Natural History - Zoölogy, Vol. XIV.}

The biventer, complexus, and longissimus capitis are well distinguished from each other and in their general relations are as in Didelphis. At least one distinct tendinous inscription crosses the anterior part of each some $4 \mathrm{~mm}$. from the insertion.

Rectus capitis posterior superficialis.-Origin from the crest of the axial spine. Insertion entad of the complexus on the occipital crest. It runs downward and forward with free upper and lower borders, leaving a triangle on either side of the median line in which the much smaller halves of the rectus minor and part of the rectus major are exposed.

This muscle, often found in carnivores, is not generally reported for marsupials, although Parsons (r896, p. 694) reports the rectus major as bilaminar in Petrogale. It is thin and flat and covers a great part of the rectus capitis posterior major. In Didelphis, it is only partially separable from the rectus major, in Marmosa it is somewhat freer, and in Canolestes it is quite independent.

Rectus capitis posterior major.-Origin from the craniad surface of the axial spine and intermuscular septa with the obliquus inferior. Insertion on the occiput from the base of the paroccipital process dorsad along the caudal border of the mastoid bulla to a point on the occipital crest midway to the median line. It meets its fellow of the opposite side in front of the axial spine and the two have tendinous connection there and to a slight extent also with the caudal border of the neural arch of the atlas. Its under surface has relation with the rectus capitis posterior minor and with the surface of the neural arch of the atlas. It is a rather thick muscle only slightly smaller than the obliquus inferior with which its lower border is in apposition.

Rectus capitis posterior minor.-Origin from the straight anterior border of the neural arch of the atlas. In a female specimen this measures $3 \mathrm{~mm}$. in length from side to side. Insertion on the occipital from a point near the median line nearly to the mastoid bulla. Its outer surface has relation with the biventer, complexus, and rectus posterior major. At the median line of the occiput it is separated from its counterpart by $\mathrm{r}-2 \mathrm{~mm}$. The two muscles approach each other and have tendinous union in their caudal halves.

Obliquus capitis superior.-Origin from the lateral surface of the transverse process of the atlas. Insertion tendinous on the occipital ridge immediately dorsad of the mastoid bulla. A short flat muscle crossing nearly at right angles to the large obliquus inferior and rectus capitis posterior major which has relation with its inner surface.

Obliquus capitis inferior.-Origin from practically the whole laterai surface of the axial spine. Insertion on the whole caudal surface of the transverse process of the atlas. It is a thick heavy muscle running 
downward and forward. In Didelphis, this muscle extends to the third, fourth and fifth cervical spines, but in Marmosa it is much as in Canolestes.

Rectus capitis anticus major.-Origin on the transverse processes of the last five cervical vertebrae. Insertion on the posterior third of the basisphenoid and the anterior two fifths of the basioccipital slightly laterad of the median line. Some of its superficial fibers extend caudad with the longus colli to the ventral side of the posterior thoracic vertebrae. Anteriorly it forms a good sized bundle and is not peculiar except for the extent of its attachment to the basisphenoid which is more than usual.

Rectus capitis anticus minor.-Origin on the middle third of the ventral surface of the neural arch of the atlas midway between the median tubercle and the transverse process. Insertion on the ventral surface of the basioccipital in its anterior lateral fourth. A thin flat muscle lying entad of the rectus anticus major and mediad of the rectus capitis lateralis but entirely free from both.

Rectus capitis lateralis.- Origin on the transverse process of the atlas. Insertion slightly tendinous on the outer edge of the basioccipital along the carotid canal and thence forward to the basisphenoid and by tendinous fascia to the presphenoid. Certain lateral fibers attach on the periotic. It is a well developed muscle and entirely distinct, extending farther cephalad than in Didelphis.

Longus colli.- The dorsal part of the longus colli is rather distinct, extending from the transverse process of the sixth cervical along the bases of the ribs and the sides of the vertebrae to the fourth dorsal vertebra. Between its two halves are fibers which extend into the cervical part but they are lateral in position and the median ventral surfaces of the dorsal vertebrae are mostly covered only with tendinous fascia. The cervical part consists of various converging slips from the transverse processes of the cervical vertebrae and caudally from the sides of the ventral surfaces of the vertebrae. Over the atlas it shows six rather distinct divisions, two medial ones inserting on the tubercle of the atlas and two on either side inserting on the body.

Spinalis dorsi_-The spinalis dorsi disengages from the medial side of the longissimus about opposite the eighth thoracic vertebra, the caudal part of the biventer cervicis forming a wedge between the two. Its inner fibers run to the spines of the anterior thoracic vertebrae but its lateral fibers form a practically distinct subvertical ribbon which runs forward and inserts on the side of the low spines and bodies of the fourth to the seventh cervicals and the first thoracic. It passes the high spine of the second thoracic without definite attachment, but between the 
first thoracic and the tip of the spine of the second it is traversed by a strong tendinous inscription which may be partially attached to either or both of the vertebrae. Anteriorly it passes between the lateral division of the semispinalis cervicis and the long interspinal which connects the spines of the fifth cervical and the second thoracic. In the opossum the spinalis inserts as high up as the third cervical and the outer surface of its anterior part is wholly in relation with the complexus.

Semispinalis cervicis. - In the region between the axial spine and the second thoracic spine are two paired muscles which run ventrad toward each other and meet at an angle over the sixth and seventh cervicals, the posterior one passing inside the spinalis between the two halves of the anterior one. The anterior of these muscles has been regarded as the semispinalis cervicis. It arises on the bodies of the first thoracic and the fifth, sixth and seventh cervical vertebrae and converges to insert on the tip and side of the axial spine in opposition to the obliquus capitis inferior. Its outer surface has relation with the complexus and its inner with the spinalis. It is not apparent in Didelphis, but is present in Marmosa. The posterior paired muscle, above-mentioned, which is in the nature of an interspinal, may be described here also. Its origin is on the side of the spine of the fifth cervical and its insertion on the front of the tip of the spine of the second thoracic vertebra. It stretches directly between these spines without connection with the intervening vertebrae. Between its two halves the ligamentum nuchae passes to the vertebral spines. Beneath its caudal part, but distinct from it, a paired intervertebral connects the spines of the first and second thoracic vertebrae. Its outer surface has relation with the biventer and the spinalis, its inner with the ligamentum nuchae. A corresponding muscle is found in the opossum running to the sides of the thickened third cervical spine, its two sides therefore being widely apart and, although its actual relations are much as in Conolestes, its appearance is quite different. In Marmosa the third, fourth and fifth cervical spines are not enlarged as in Didelphis. Consequently the arrangement of the neck muscles is more nearly as in Canolestes and many other marsupials.

Longissimus.-Anteriorly this is divisible into longissimus dorsi and longissimus cervicis. Superficially the two divisions appear as one muscle but the outer part which continues caudad may be partially separated from an inner mostly concealed part which only extends caudad to the fifth thoracic vertebra and which may be regarded as the longissimus cervicis. It arises by slips from the laminae of the cervicals and from the transverse processes of the thoracic vertebrae from the first to the fifth. It inserts on the transverse processes of the cervical vertebrae from the second to the fourth or fifth, being inseparable at this 
point from the longissimus dorsi. The longissimus dorsi separates from the spinalis dorsi about opposite the eighth thoracic vertebra and passes cranio-ventrad between the iliocostalis and the biventer and longissimus capitis from which it is entirely distinct. Its insertion is just caudad of that of the longissimus cervicis on the transverse process of the fifth and possibly also the fourth cervical vertebra. Its origin is from the lumbar tendinous sheet from which it becomes fleshy in the vicinity of the second lumbar vertebra. Passing forward it is conjoined with the spinalis and consists of slips from the transverse processes of the vertebrae.

Iliocostalis.-An anterior division or iliocostalis dorsi and a posterior or iliocostalis lumborum are fairly distinct. The iliocostalis dorsi arises by slips from the sides of the ribs from the first to the eighth. It passes cranio-ventrad on the side of the neck laterad of the longissimus and inserts on the superior transverse processes of the sixth and seventh cervical vertebrae. For a short distance just before its insertion it is merged with the longissimus.

The iliocostalis lumborum arises from the complicated lumbar tendons of the sacrospinalis and becomes fleshy opposite the fourth lumbar vertebra. It inserts by thin flat slips on the sides of the ribs from the sixth to the thirteenth. Between the ilium and the ribs it forms the anterior lateral boundary of the mass of muscle filling the space between the articular and transverse processes of the lumbar vertebrae. Over the ribs it is thin and the slips are fairly distinct from each other. Between the sixth and the ninth ribs it overlaps the iliocostalis dorsi which only reaches the eighth rib.

Sacrospinalis.-Origin from the crest and the ventro-medial surface of the cranial fourth of the ilium, meeting the origin of the iliacus, and from the tendinous lumbo-dorsal fascia. Insertion on the dorsal surfaces and caudal edges of the transverse processes of the lumbar vertebrae and the twelfth and thirteenth dorsals. A thick rounded bundle extending from the ilium to the ribs. Easily separable from the multifidae which lie mediad of it but covered by the tendinous fascia. It fills the space on the side of the vertebral column between the articular and the transverse processes of the lumbar vertebrae.

Quadratus lumborum.-Origin from the bodies of the 12 th and 13 th dorsal vertebrae and the lumbar vertebrae from the first to the fourth. Insertion on the tips and ventral surfaces of the transverse processes of all the lumbar vertebrae except the last. It lies somewhat flattened between the psoas parvus and the large rounded sacrospinalis and connects the series of transverse processes with each other by series of overlying tendons, the fibers from the under side of one running to the 


\section{Field Museum of Natural History - Zoölogy, Vol. XIV.}

upper side of the one succeeding. Anteriorly it is closely associated with the psoas parvus.

Psoas parvus.-Arises fleshy and also by tendinous heads from the first, second, third, fourth and fifth lumbar vertebrae. Thence it continues caudad as a broad flat tendon crossing the surface of the medial part of the psoas magnus and inserting dorso-craniad of the marsupial bone on the iliopectineal tubercle. In its cranial part it is closely connected with the quadratus lumborum which lies laterad of it. The caudal part of its fleshy origin on the fifth lumbar vertebra is overlapped by the psoas magnus which intervenes between it and the quadratus lumborum at this point.

Psoas magnus.-Origin from the sides of the bodies and the ventral bases of the transverse processes of the fourth, fifth, and sixth lumbar vertebrae and the cranial half of the first sacral. Anteriorly it reaches to the posterior epiphysis of the third lumbar. Insertion with the iliacus on the lesser trochanter and the adjacent inner surface of the femur nearly as far distad as the insertion of the pectineus.

\section{Muscles of the Head.}

Plates III-IV.

Masseter.-The superficial masseter has its origin on the lower side of the zygoma by a short stout tendon nearly opposite and slightly caudad to that of the inferior zygomaticus and in the vertical plane of the middle of the eye. It spreads over the lower part of the mandibular insertion of the deep masseter and covers the ventro-caudal part of the mandible with its insertion from the base of the coronoid process just caudad of the buccinator and along the lower side of the mandible to the angle and the pterygoideus. It does not reach the inner surface of the mandible and especially in its ventro-caudal portion is relatively weaker than in Didelphis. The deep masseter lies below it and is closely connected, but a division is evident. It has its origin on the inner and lower sides of the zygoma and the fascia over it and is intimately associated with the temporalis. It is broadly attached to the whole outer face of the coronoid fossa.

Temporalis.-This is in two layers. The superficial or outer temporal arises from the fascia along the middle of the parietal bone and across the caudal part of the underlying layer. Thence it spreads as a rather thin sheet over the deep temporal and narrows to pass into the orbital fossa and insert on the mandible at the anterior base of the ascending ramus. It is also attached superficially to the membrane between it and the eye. The deep temporal is more extensive; its origin runs from the 
glenoid fossa across the mastoid bulla along the supraoccipital crest halfway to the median line and thence directly forward along the rather indistinct parietal and supraorbital crests to the plane of the posterior canthus of the eye. Its insertions are extensive on the coronoid process, mostly on its ental surface and its anterior edge with a few of the fibers from the mastoid origin going to its ectal surface.

Buccinator.-Relatively extensive and forming a pouch behind the angle of the mouth. Its origin is along the alveolar border of the maxillary from the vicinity of the infraorbital foramen to the anterior base of the zygoma and likewise along the ramus of the mandible from the front and base of the coronoid process forward to the vicinity of the mental foramen. It is attached to or merged with the orbicularis oris around the lips.

Pterygoideus internus.-Origin from the whole of the external pterygoid fossa from the carotid foramen cephalad, passing the tips of the pterygoids but attached to their bases and thence along the ridge to the dorsal side of the lateral tuberosity of the palatal ridge. Insertion broad on the inner surface of the angle of the mandible and by certain medial fibers running to the fascia over the tympanic. Mediad of the internal pterygoid the small but distinct tensor veli palatini runs from the periotic and the edge of the basisphenoid to the hamular process of the pterygoid bone.

Pterygoideus externus.-Origin by two heads. The larger ventral one arises fleshy from the whole of the lateral base of the pterygoid bone laterad of the pterygoideus internus. The smaller dorsal head arises from the alisphenoid caudad and laterad of the sphenoidal fissure. The two heads spread over the convex surface of the alisphenoid between the sphenoidal fissure and the glenoid fossa and, after uniting as they pass the front of the tympanic, insert at the base of the mandibular condyle principally on the stylomandibular ligament.

The muscle is relatively large and broad, bulking fully two-fifths as much as the internal pterygoid. It is thus quite different from that of Didelphis in which it is single-headed and very weak. It is described (Macalister) in Phascolarctos as a "small rudiment crossing and inseparable from the internal" and in Sarcophilus as "exceedingly feeble"; in Myrmecobius also, it is weak and single (Leche); in Chcropus (Parsons, I903, p. 67), it is unusual and inserts on the inside of the mandibular ramus; in Petrogale (Parsons, 1896 ) and other kangaroos, it is small; for most other marsupials, data are lacking.

Mandibulo-auricularis. - The only prominent ear muscle seems to correspond to the one for which this name has been used by various authors. It is a small subcylindrical muscle arising in the fascia between 


\section{Field Museum of Natural History - Zoölogy, Vol. XiV.}

the superficial and deep masseters near the mandibular condyle and issuing between the masseters to an insertion on the anterior base of the ear.

Zygomaticus.-This is in three divisions all arising on the zygoma. Two of them originate from the lateral surface of the posterior half of the zygoma behind the eye. They are small well-formed fasciculi closely similar to each other and somewhat distinguished from the third division which lies below (entad) them. They run forward to the level of the angle of the mouth where they become tendinous and proceed thus for some distance to insertions in the tissue on the side of the upper jaw at the base of the whiskers.

The third division, to which some other name may be applicable, is similar in appearance but arises from the side of the lower anterior angle of the zygoma and its slender tendon is inserted into the skin of the inside of the upper lip in the vicinity of the base of the labret.

Retractor naris.-A slender muscle arising from the fascia between the eye and the zygoma. It crosses the outer surface of the anterior root of the zygoma and becomes a very slender threadlike tendon which runs forward to an insertion on the nasal cartilages.

Digastricus.-Arises on the paroccipital process between the condyle and the mastoid bulla and runs down around the ear and thence forward to spread over the interramal space and attach along the sides of the mandible from the base of the angular process to the symphysis. Anteriorly it is largely aponeurotic. A tendinous slip diverges at a point ventrad of the masseter and passes dorsad to the caudal median border of the mylohyoid. It is essentially as in Didelphis.

\section{Muscles of the Neck.}

Plates IV, VI.

Sterno-hyoideus. - This is the principal muscle exposed on removing the skin from the lower side of the neck. It arises on the ental surface of the second sternebra and runs directly forward opposite its mate and inserts on the posterior side of the hyoid bone caudad to the insertion of the genio-hyoid. Some of its superficial fibers inosculate with those of the genio-hyoid. Like the other muscles connected with the hyoid and the tongue, it is not peculiar.

Genio-hyoideus. - A flat paired muscle immediately cephalad of the sterno-hyoideus and entad of the mylo-hyoideus. It arises on the body of the hyoid bone and inserts on the mandibular symphysis.

Sterno-thyroideus. - A thin, paired muscle lying between the trachea and the sterno-hyoideus. Laterally it is thin and transparent and toward the median line it is somewhat thicker, especially in its caudal 
portion where its two sides become fused. It arises on the sides and ental surface of the second sternebra and inserts on the thyroid cartilage.

Mylo-hyoideus. - A very thin, paired, transverse muscle between the mandibles and immediately entad of the digastricus. It arises from the inside of the mandible near the alveolar border and has no bony insertion, merely meeting its fellow in a raphe in the median line and becoming aponeurotic anteriorly and posteriorly. Along the dorsal side of this raphe it is attached to the genio-hyoideus. Its posterior fleshy border runs from the angle of the mandible forward to the median line opposite the base of the angular process.

Hyoglossus. - Arises laterad and dorsad of the genio-hyoideus on the ventrocaudal border of the thyrohyals and basihyal cephalad of the insertion of the thyrohyoideus. It passes ventrad of the ceratohyals and free from them, diverges to enclose the genioglossus, and passes dorsad and cephalad into the body of the tongue.

Genioglossus.-Well-developed and having the usual relations, arising on the sides of the mandibles near the symphysis and forming a wedge between the two halves of the hyoglossus.

Styloglossus.-Runs laterad of the hyoglossus and merges with it about midway of the mandible. Its origin was not determined, having been destroyed inadvertently.

Thyrohyoideus. - Origin on the thyrohyal bone entad of the sternohyoid and the omohyoid and opposite the hyoglossus. Insertion on the posterior corner of the bony wing of the thyroid cartilage. A short stout triangular muscle, relatively well-developed.

Omo-hyoideus. - Origin on the lateral fourth of the posterior side of the hyoid bone. Insertion on the upper posterior angle of the scapula just craniad of the insertion of the levator scapulae. On the ental side near its origin it is joined to the sternohyoid by thin membrane.

Sterno-mastoideus. - Origin on the manubrium of the sternum slightly overlapped by the edge of the pectoralis. Insertion divided, one rather thin sheet inserting by broad aponeurosis on the occipital crest from a point midway between the median line and the auditory meatus to the middle of the anterior border of the mastoid bulla. The other division is a thickened bundle and inserts by a short tendon on the mastoid process slightly ectad and cephalad of that of the cleido-mastoid. The two divisions become fused about midway between origin and insertion.

Cleido-mastoideus. - Origin on the front of the distal end of the clavicle. Insertion fleshy or only slightly tendinous on the mastoid process. Its outer surface has relation with the splenius, the sterno-mastoideus and the cleido-occipitalis; its inner with the digastricus, atlantoacromialis and omo-hyoideus. 


\section{Field Museum of Natural History - Zoölogy, Vol. XIV.}

Cleido-occipitalis. - Origin on the clavicle just laterad of the sternomastoid. Insertion by aponeurosis on the side of the occiput just laterad of and in the same plane with the acromio-trapezius. On its outer surface its relations are with the cervico-auricularis; on its inner with the rhomboideus, the atlanto-acromialis, and the cleido-mastoideus.

Omo-cleido-transversarius. - This includes two distinct muscles as in Didelphis, a dorsal part or "atlanto-scapularis" and a ventral part or "atlanto-acromialis." The dorsal part has its origin on the side of the body of the atlas immediately laterad of the origin of the ventral part. The insertion is on the front of the scapular spine in its vertebral fourth just ventrad of the insertion of the rhomboideus minor. It is a weaker more slender muscle than the ventral part and does not widen so at its insertion. The ventral part has origin on the side of the hypapophysial tubercle of the atlas. Its insertion is broad from the caudal side of the metacromion process of the scapula and for a short distance ventrad along the deltoid fascia over the acromio-deltoid muscle where it sends a few fibers ventrad.

\section{Muscles of the Thorax.}

Pectoralis minor.-Origin from the sides of the fourth and fifth sternebrae. Insertion on the lesser tuberosity of the humerus and the deltoid ridge by a broad slightly tendinous aponeurosis much wider than in Didelphis. Its outer surface has relation with the pectoralis major, its inner with the rectus abdominis, scalenus, etc.

Pectoralis major.-Origin from the median line of the entire sternum. Insertion on the distal part of the inner edge of the deltoid ridge. Its outer edge is curled under and near the insertion it has a slight aponeurotic connection with the xiphihumeralis as in Didelphis.

Supracostalis.- Origin by broad aponeurosis from the second, third, fourth and fifth sternebrae. Insertion fleshy on the side of the first rib. This muscle, which Coues called "sterno-costalis" and others designate transversus costarum, has practically the same relations as in Didelphis. Its broad aponeurosis for its entire length covers the rectus abdominis.

Subclavius.-Arises from the first tib and inserts on the outer side of the distal end of the clavicle, not extending to the scapular spine as in Didelphis. In this it agrees with Phascologale, and some other Australian forms (Macropus sp., Phalanger sp.).

Serratus magnus. - Origin posteriorly by six very distinct digitations on the sides of the ribs from the third to the eighth inclusive. Anteriorly there are no distinct digitations and the origin is from the joints of costal cartilages with the first, second and third ribs. Insertion on the pos. 
terior border of the scapula where it is continuous with the levator scapulae.

Scalenus. - This has two fairly distinct divisions, at least posteriorly. The scalenus medius, or larger division, takes origin from the superior transverse processes of the third, fourth, and fifth cervical vertebrae over which it is somewhat narrow and thickened. Thence passing caudad it becomes thin and flattened and inserts by broad distinct slips on the middle of the third and fourth ribs, one slip on the third and two on the fourth, passing beneath and separating digitations of the serratus magnus in so doing. The scalenus anticus has its origin in coalescence with the medius, but about midway between the third cervical vertebra and the first rib it separates and inserts on the front of the first rib directly opposite the insertion of the supracostalis.

\section{Muscles of the Abdomen.}

Rectus abdominis.-Origin from the pubis and marsupial bone. Insertion on the sternal part of the first rib and on the adjoining side of the manubrium of the sternum. It is strong and well developed anteriorly, broader but thinner abdominally.

Obliquus externus abdominis.-Origin from the middle of the sides of the ribs from the fourth to the twelfth, interdigitating anteriorly with the serratus. Thence it follows the lumbar fascia to Poupart's ligament which is inserted at the inner anterior base of the marsupial bone. Ventrally it spreads over the abdomen covering the rectus and inserting by aponeurosis on the linea alba.

Obliquus internus abdominis.-Origin from Poupart's ligament and the ilium and thence dorsad to the lumbar fascia and craniad to the posterior borders of the roth to $\mathrm{I} 3$ th ribs. It is fleshy in its dorsal portion down to a line from the ventral third of the costal cartilage of the tenth rib diagonally across the side of the abdomen to the pubic region. Ventrad of this line the transversalis appears and no aponeurosis of the obliquus is demonstrable in the material available.

Transversus abdominis. - Origin from the inner sides of the IIth, I 2 th, and I 3 th ribs and from a coalescence with the diaphragm and thence along the lumbar fascia to the ilium. Ventrally it is inserted into the linea alba. Posteriorly it is broadly aponeurotic and anteriorly mostly fleshy.

Cremaster.-Arises in the male beneath the internal oblique near the crest of the ilium, and passes ventro-caudad across the iliacus and psoas major in the plane of the transversalis but separated from it by a slight space. It passes out of the body cavity through the ring in front of the 
marsupial bone and procoeds to the mid-ventral line and the testes. It is a well developed strand of muscle about one mm. in width but simply parallels or covers but does not enclose the spermatic cord until near the base of the testes where it nearly or quite surrounds the cord before spreading over the base of the testes and becoming aponeurotic.

\section{Muscles of the SaCrum.}

Plates III, V.

Gluteus maximus.-Origin from the crest and the anterior part of the acetabular border of the ilium and from the articular processes of the sacral and anterior caudal vertebrae as well as from the tendinous fascia covering the erector spinae as far caudad as the origin of the femorococcygeus. Insertion somewhat divided, an anterior part on the craniolateral and a posterior one on the caudo-lateral surface of the distal end of the great trochanter of the femur. It is a broad fan-shaped muscle, relatively thicker than in Didelphis, being fleshy from the erector spinae. Its cranial border is thickened and somewhat curled around the anterior fifth of the ilium and distad lies in the groove between the gluteus medius and the iliacus, continuing ectad of the proximal end of the vastus externus to the cranial border of the biceps femoris to which it has a short semitendinous attachment distad and ectad of its insertion on the great trochanter. Its caudal border parallels the femorococcygeus but except in the dorsal fascia is distinct from it. No separate tensor fascice femoris is evident and it is doubtless fused with the gluteus as in various other marsupials.

Gluteus medius.-Origin extensive from the dorsal fascia, the laminar tendons of the caudal muscles, the transverse processes of the sacral vertebrae, and the crest and ischial border of the ilium. Insertion on the caudo-lateral proximal part of the great trochanter of the femur ectad of that of the gluteus minimus which is distinct. It lies entad of the gluteus maximus and is almost equal to it in superficial extent. It is imperfectly divisible into two layers, the posterior one overlapping the anterior. A similar bilaminar arrangement is reported in Phascolarctos, Thylacinus, and Dasyurus, but not in Didelphis ${ }^{1}$ and Cuscus (see Leche, Bronn's Thierr., p. 853). It is likewise in Notoryctes (Thompson and Hillier, I905, p. 310). On its ental side it is somewhat connected with the pyriformis not only near the insertion but also elsewhere except along the anterior tendinous border of the pyriformis. Anteriorly it is curled under from the crest of the ilium to the femur but in the distal half of this extent $i$ is edge is free and merely overlies the gluteus minimus.

${ }^{1}$ Sidebotham (1885, p. 13) reports three layers in Chironectes. 
Gluteus minimus.-Origin from the dorsal surface of the ilium from a point on the acetabular border about midway between the crest and the acetabulum to a point opposite the middle of the acetabulum. Insertion broadly covering the antero-internal surface of the great trochanter of the femur. It is relatively large and completely distinct not only anteriorly from the gluteus maximus and gluteus minimus but posteriorly from the gemelli. In the didelphids and various other marsupials it is partially joined to the maximus.

Pyriformis. - Origin fleshy from the dorso-lateral surface and the caudal edge of the crest of the ilium and from the tips of the transverse processes of the two sacral and the first caudal vertebrae.

Insertion on the apex of the great trochanter of the femur just caudad of the insertion of the gluteus minimus and entad of the gluteus medius. A very large muscle lying entad of the gluteus medius and ecto-caudad of the gluteus minimus. Its anterior border which is full and rounded runs direct from the trochanter to the iliac crest and at least in its distal half is tendinous. Fleshy fibers pass dorsad from this broad tendinous edge to the sacral border. Its outer surface, at least caudally, is somewhat connected with the gluteus medius.

Quadratus femoris.-Origin on the inner side and slightly ventrad of the tuberosity of the ischium and on the inner edge of the ischium just craniad of the tuberosity. The fibers curve over the lesser sciatic notch to pass outward to their insertion on the middle of the ventral edge of the great trochanter of the femur and on the intertrochanteric ridge. It is relatively large and well developed and fairly distinguishable from the gemelli anteriorly.

Gemelli.-No distinction is evident between a gemellus superior and inferior. The origin is on the body of the ischium dorsad of the origin of the ischiococcygeus. The insertion is with the tendon of the obturator internus on the caudal edge of the great trochanter of the femur and in the digital fossa proximad of the insertion of the quadratus femoris. Its cranial border is distinct from the caudal border of the gluteus minimus.

Iliacus.-Origin from the ventro-lateral or iliac surface and the acetabular border of the cranial two-thirds of the ilium from the crest caudad. In its caudal portions its insertion is opposite that of the iliococcygeus on one side and the gluteus minimus on the other with a part of the psoas magnus lying loosely between. Its general relations are closely similar to those in Didelphis.

Obturator internus.--Origin from all of the caudal border of the ramus of the ischium which is ventrad of the quadratus femoris, from the inner side of the pubic symphysis, and from the caudal border of the obturator foramen. Insertion by a flat tendon in the digital fossa of the femur. 


\section{Field Museum of Natural History - Zoölogy, Vol. XIV.}

Obturator externus.-Origin from the side of the ascending ramus of the ischium from the lower edge of the tuberosity to the symphysis and thence on the side of the pubic ramus to a point nearly opposite the anterior base of the marsupial bone. Insertion by a thick tendon in the digital fossa and on the intertrochanteric ridge of the femur. It is a broad thickened muscle lying at its origin entad of the adductors. Dorsally it meets the edge of the quadratus femoris.

The obturator externus is said by Leche (p. 858) to be "nichts bemerkenswerthes" in the Marsupialia, but Macalister (I870, p. I67) states that it is "large and normal in Phascolomys and Sarcophilus, as well as in Macropus giganteus, the Wallaby, Phalanger, and Opossum." Thompson and Hillier (1905, p. 312) found it well developed in Notoryctes. The so-called differentiation of the obturator, which Leche names intermedius and reports only for Didelphis and Philander is doubtless not peculiar to these forms. It was not specially sought in Canolestes and may have been overlooked and included as an integral part of the externus. Whether it be called externus or intermedius, it is apparent that it is not peculiar in Canolestes.

\section{Muscles of THE TAIL.}

All the usual tail muscles of the pubic cavity are present and distinct but their muscular parts do not extend far beyond the base of the tail. On removal of the skin and the underlying fascia, the tail appears almost entirely encased in shining tendons from its base to its tip. On the dorsal aspect the continuations of the back muscles proceed somewhat farther caudad but these also soon become entirely tendinous. After all the tendons have been removed, however, a series of thin muscles connecting the vertebrae are exposed. These are short muscles, those next the median line extending from the chevron bone of one vertebra to that of the one succeeding; those laterad extend from the caudal transverse process of one vertebra to the cephalic articular process of the second succeeding vertebra, each muscle thus spanning a vertebra.

Dorsally the tendons from the dorsal extensors cover the angles of the tail, passing over the articular processes of the vertebrae, but in the median line the short intervertebral tail muscles are exposed.

Abductor caudae externus.-Origin on the medial side of the iliac crest and by tendinous connection with the lumbo-dorsal fascia. Insertion on the dorsal surfaces and tips of transverse processes of the caudal vertebrae. This is a spindle-shaped muscle filling the great part of the space between the transverse and the articular processes of the anterior caudal vertebrae and passing out on the side of the tail where it narrows and soon becomes wholly tendinous. 
Extensor caudae lateralis. - Origin by slips from the articular processes of the sacral and caudal vertebrae. Insertion on the sides and transverse processes of the caudal vertebrae. Lies between the abductor caudae externus and the multifidae which are continued to the base of the tail as an extensor caudae medialis.

Pubococcygeus.- Origin from the whole inner caudal border of the pubic ramus. It forms a thin sheet over the obturator foramen and continues fleshy to the front of the fifth caudal vertebra whence it finds attachment in the aponeurosis on the surface of the tail. In some cases it is slightly tendinous on its inner side and attached to the chevron bone of the fifth caudal. Laterally it has slight attachment to the colon.

Sacrococcygeus. - Origin from the ventral surfaces of the transverse processes of the sacral and the first four caudal vertebrae. Thence by numerous slender tendons it proceeds along the side of the tail to the distal caudal vertebrae. These tendons lie slightly laterad of those of the infracoccygeus and fill the space between the cephalic articular and transverse processes of the caudal vertebrae. Its muscular heads are thick and fleshy and lie between the caudal part of the infracoccygeus and the pubococcygeus and ventrad of the ischiococcygeus.

Ischiococcygeus. - Origin from the inner side of the ilium from a point opposite and slightly craniad of the caudal border of the gluteus minimus caudad about halfway to the tuberosity of the ischium. Insertion on the tips of the transverse processes of the first four caudal vertebrae.

Iliococcygeus.-Origin from the ischial border of the ilium from a point just caudad of the sacrum (posterior inferior spine of ilium) and thence caudad along the whole inner surface of the ilium (great sacrosciatic notch) nearly to the anterior border of the obturator foramen. A few fibers rise from the tendons of the psoas minor and at this point are closely connected with those of the pubococcygeus. Insertion by four distinct tendons which converge to the middle of the ventral surface of the tail. The outer tendon runs just laterad of the mid-ventral line of the tail to the chevron bone of the eighth caudal vertebra. The next one runs similarly to the seventh caudal. The inner pair of tendons run first mediad, then entad, and finally laterad of the outer pair. Of this inner pair the outer one inserts on the chevron bone of the ninth and the other on the tenth caudal. Near their attachments each of the tendons gives off a slight muscular fasciculus.

Infracoccygeus. - Origin from the medio-ventral surfaces of the bodies of the fifth and sixth lumbars and the two sacral vertebrae. Insertion by long slender tendons running on the ventral side of the tail next to the median line. The innermost tendon runs to the middle of 
the front of the first caudal. The next tendon laterad runs to the eleventh caudal, the next to the twelfth and so they continue to the twentieth caudal. The muscle is broadly spindle shaped and occupies the sacral basin, its two halves forming an elongate ellipse between the two halves of the psoas magnus anteriorly and of the iliococcygeus posteriorly. It consists of superposed laminae each becoming tendinous before issuing from the pubis.

\section{Muscles of the ANterior Limb.}

\section{Plate V.}

Spino-deltoideus.-Origin from the middle third of the scapular spine. Insertion on the distal end and outer edge of the deltoid ridge of the humerus. At its insertion it passes beneath and nearly at right angles to the acromio-deltoideus.

Acromio-deltoideus. - Origin on the acromion and the proximal half of the clavicle. Insertion on the inner end of the flattened surface of the deltoid ridge opposite the insertion of the pectoralis major. It covers the rather broad surface of the deltoid ridge and is a thicker muscle than in Didelphis and more distinct from the spino-deltoideus and the pectoralis. It is fan-shaped, the fibers from the clavicle and those from the acromion converging toward a median raphe and coming to a point ventrally.

Subscapularis.-Origin from practically the whole of the expanded ental surface of the scapula. Insertion by a short broad tendon on the lesser tuberosity of the humerus. It is slightly thicker dorsally than ventrally but in general is thin and flat.

Supraspinatus.-Origin from the surface of the supraspinous fossa. It passes entad of the clavicle between the coracoid and the acromion and inserts on the greater tuberosity of the humerus. It is about twice as large as the infraspinatus and relatively larger than in Didelphis, agreeing more nearly with Phalanger, Perameles, Phascologale, etc.

Infraspinatus.-Origin from the infraspinous fossa, including the ental surface of the metacromion and acromion, the axillary border of the scapula, and from a tendinous raphe between it and the proximal part of the teres. Insertion partly fleshy and partly tendinous on the greater tuberosity of the humerus. A weak aponeurosis from the infraspinous fossa near the base of the acromion may represent the teres minor, but it is very indefinite. A teres minor is reported for Chironectes (Sidebotham) but not for Didelphis.

Epitrochlearis.-Origin from the lower border of the latissimus slightly ( $2 \mathrm{~mm}$.) before it passes beneath the biceps. Insertion on the olecranon process of the ulna. 
Teres major.-Origin from the posterior ventral angle of the scapula in close relation with the subscapularis. Insertion on the bicipital groove slightly proximad of and in conjunction with that of the latissimus.

Coracobrachialis brevis.-Origin on the coracoid process entad of the biceps. Insertion on the humerus just proximad of the insertion of the teres. It is very slightly developed, almost rudimentary, and in its fleshy part consists of a very thin layer of fibers instead of a thick belly as in Didelphis. In one specimen it appeared to insert in the tissue of the medial head of the triceps rather than on the humerus.

Biceps brachii.-Origin by a single tendon from the coracoid process of the scapula and adjacent fascia. Soon after becoming fleshy it is readily divisible into two distinct muscles which run in close apposition to pass into the forearm between the pronator teres and the extensor carpi radialis brevis. The outer muscle inserts by a narrow flat tendon on the tubercle of the radius. The inner muscle is partially attached to the brachialis near its insertion and then its tendons divide and pass on either side of the tendon of the brachialis to insertions on the side of the ulna distad of the lesser sigmoid cavity. In some of the Macropodidae the biceps is completely divided but in some other diprotodonts and in polyprotodonts generally its relations are reported essentially as above.

Brachialis anticus.- Origin from the lesser tuberosity and the border of the head of the humerus passing around the middle of the front of the humerus and thence distad. At about the middle of the front of the humerus it becomes attached to the bone; between this and its origin it is free or nearly so. Thence it continues along the humerus to the elbow joint where it twists further and has final insertion just distad of the lesser sigmoid cavity on the inner surface of the ulna by a flattened tendon which passes between the divided tendons of the biceps.

Triceps brachii.-The long head has its origin as usual on the axillary border of the scapula just dorsad of the glenoid cavity. Its insertion by common tendon with the lateral head is on the outer angle of the olecranon process of the ulna.

The lateral head arises beneath the posterior border of the head of the humerus and thence is free from the humerus to its union with the long head. Its posterior aspect is hollowed to receive the long head for most of its length and the two are fairly distinct. The median head arises from the posterior aspect of the humerus for practically its entire length, reaching dorsally within $2 \mathrm{~mm}$. of the lesser tuberosity and thence to the olecranon fossa. Its insertion is on the inner angle of the olecranon process of the ulna quite distinct from that of the other two heads.

The triceps of Canolestes is characterized by the distinctness of the 


\section{Field Museum of Natural History - Zoölogy, Vol. XIV.}

median head which in Didelphis and many other marsupials is united with the lateral head near its origin.

Anconeus.-Origin from the inner condyle of the humerus. Insertion on the inner angle of the olecranon process entad of the epitrochlearis. A small muscle connected on its lower side by a tendinous raphe with the extensor carpi ulnaris and on its upper side slightly connected with the median head of the triceps.

Pronator teres.- - Has origin as a thick fleshy bundle from the posterior side of the inner condyle of the humerus and the epicondylar ridge. Insertion by broad aponeurosis on the middle third of the front of the radius.

Flexor carpi radialis.-Origin from the inner humeral condyle and the septa connecting with the pronator teres between which and the palmaris longus it lies. Its long slender tendon passes over the extremity of the radius and thence over the scaphoid to insertion at the bases of the second and third metacarpals. ${ }^{1}$

Palmaris longus.- Origin from the septa between it and the flexor carpi ulnaris, the flexor carpi radialis, and the digital flexors and by a few fibers from the inner condyle of the humerus. It covers the digital flexors almost completely and lies between the flexor carpi ulnaris and the flexor carpi radialis.

In the single specimen dissected it was divided into two parts. The superficial one (palmaris accessorius?) sends its tendon beside that of the flexor carpi ulnaris to a slight attachment on the inner side of the fascia on the pisiform bone and thence superficial to or partly attached to the flat transverse ligament of the wrist which extends across the wrist from the pisiform to the base of the first metacarpal. Above this transverse ligament it extends into the palmar fascia. The deeper division sends its tendon bound with its fellow to the transverse ligament where the two separate and the second dips beneath the ligament to reappear in the facia and send aponeurotic branches to the extremities of the second, third, and fourth digits. The fleshy parts of the two divisions are distinct for about one-half their length.

Flexor carpi ulnaris.-Origin from the inner condyle of the humerus, from the septa between it and the palmaris longus, the extensor digitorum communis, and the anconeus, and from the outer angle of the olecranon opposite the insertion of the epitrochlearis. Insertion on the end of the pisiform bone. A broad fan-shaped muscle with two sets of fibers converging toward its tendon which extends a short distance into its fleshy

1 This is also the case in Didelphis, although Coues states that the insertion is on the first metacarpal; Cunningham (I882, p. I7) found a similar disposition in Phalanger maculata. 
part. The fleshy divisions end abruptly and equally about one-third of the distance from the olecranon to the carpus. The posterior division, therefore is not longer than the anterior as it is in the opossum and the tendon is shorter.

Flexor digitorum sublimis. - Origin by three heads in the septa of the ulnar head of the profundus. These give rise to three distinct slips which send their tendons loosely bound together until they reach the palm where they pass beneath the annular ligament and insert ectad of the large profundus tendons at the bases of the first phalanx of the second, third, and fourth digits, respectively. Their tendons are slender and practically of the same size throughout. From their point of origin a short thick muscle with fibers running diagonally opposite those of the ulnar head of the profundus extends to an origin from the caudad surface of the inner humeral condyle and from the proximal edge of the glenoid cavity of the ulna. Whether it may be one head of the sublimis is doubtful. It is very distinct.

Flexor digitorum profundus.-Origin by four heads each of which sends a distinct tendon to the palm where all unite in a thick flat tendinous mass which occupies most of the palmar space. From this three strong tendons radiate to the middle digits. Two others going to the pollex and the fifth finger are much smaller and arise from the ectal surface of the common tendon. The heads are as follows:

I. Ulnar head. Origin on the flattened posterior surface of the proximal two-thirds of the ulna from the olecranon at least to a point opposite the neck of the radius. Its tendon is very large and strong, rounded in its proximal part, slightly tapering toward its middle, and flattening as it joins the outer side of the palmar tendinous mass.

This is the largest fasciculus of the forearm, lying beneath the flexor ulnaris and giving shape to the limb.

2. The second head lies superficially next to the flexor carpi radialis and connected with it in its proximal part by intermuscular septa. It is similarly connected with the fourth head for a distance of nearly half its fleshy extent. Its origin is from the inner condyle of the humerus entad of that of the palmaris longus. Its tendon joins the common tendon ectad of that of the third head, the two being approximately of equal size and lying midway between the tendons of the first and fourth heads which are much larger.

3. The third head is very distinct and wholly free but lies deeper than the second and is not exposed until that is reflected. It lies between the flexor ulnaris and the second head of the profundus together with the conjoined part of the flexor radialis. Its origin is from the inner side of the lip of the lesser sigmoid cavity of the ulna. Its small round tendon 


\section{Field Museum of Natural History - Zoölogy, Vol. XIV.}

runs direct to the common palmar tendon which it joins next to that of the ulnar head and entad of that of the second head.

4. The fourth head, which is almost as large as the first or ulnar head, has origin from a distinct slip from the front of the inner condyle of the humerus and from a broad fleshy expansion arising from the inner side of the proximal fourth of the radius. The two fleshy parts join to form a single tendon which runs along the radius to join the common tendon in the palm.

While obviously very different from that of Didelphis, in which there is no division above the palm, this muscle is so variable that detailed comparisons have not been attempted. In most marsupials it sends tendons only to the four ulnar digits.

Abductor pollicis longus (Extensor ossis metacarpi pollicis).-Lies in the deep groove in the proximal part of the ulna and takes origin from the adjacent sides of the ulna and the radius, the fibers converging from the two sides to the central tendon which extends some distance into the fleshy part. Its origin (male specimen) is thus some $5 \mathrm{~mm}$. in length. Its rather broad flat tendon passes beneath the ulnar and lateral digital extensors crossing the forearm and becoming superficial between the extensor digitorum communis and the extensor carpi brevis. It then curves around the radius and inserts on the lateral surface of the first metacarpal.

Pronator quadratus.-This muscle, which is present in didelphids and so far as known in all other marsupials except Notoryctes, is not found in Canolestes, or at most is represented by no more than an indefinite non-muscular fascia. It is reported as poorly developed in Thylacinus, Sarcophilus, Phalanger and Phascologale. It is lacking in monotremes, insectivores, bats, and certain edentates (Dasypodidae, Manidae).

Brachioradialis (Supinator longus).-Origin from the outer epicondylar ridge of the humerus proximad of the extensor carpi radialis longus. Its tendon passes under that of the abductor pollicis longus and over a groove in the extremity of the radius to insertion in the external lateral ligament which overlies the extremity of the radius.

Extensor carpi radialis longus.-Origin from the outer epicondylar ridge of the humerus distad of the brachioradialis. Insertion on the base of the second phalanx of the second digit.

Extensor carpi radialis brevis.-Origin from the outer epicondylar ridge and septa of the extensor digitorum communis, between which and the extensor carpi radialis longus it lies. Insertion on the outer lateral surface of the proximal third of the first phalanx of the third digit. It is somewhat larger than the longus and separate from it as in Thylacinus and Phalanger. 'In most other marsupials, the long and short radial 
extensors are reported to be fused at least proximally, but Parsons (I896, p. 697) expresses the belief that they are normally separate in the kangaroos.

Extensor digitorum communis.-Origin from the distal part of the outer epicondylar ridge, the outer condyle and from the septa of the muscles lying on either side, namely the extensor carpi radialis brevis and the extensor digitorum lateralis. The fleshy part divides into two slips, the more superficial of which sends tendons to the second and third digits and the deeper one to the fourth and fifth. The tendons are separate but closely parallel until they pass under the transverse ligament and separate to insertions on the terminal phalanges of the second to the fifth digits. The tendons become somewhat flattened or aponeurotic distally.

Extensor digitorum lateralis.-Origin on the front of the outer condyle of the humerus next to the extensor communis but quite distinct from it. Connected by septa with the extensor carpi ulnaris. The head of the radius lies immediately entad of the line of separation between the two muscles. In the distal two thirds of its fleshy extent it is divided into three distinct slips from which separate parallel tendons run one to the fourth and two to the fifth digit. On the fourth digit the insertion is at the base of the ungual phalanx. On the fifth the insertion in one case is at the base of the ungual phalanx and in the other in the fascia covering the second and third phalanges. A double tendon from this muscle to the fifth digit has been noted in Sarcophilus (Macalister, 1870 , p. 164), but not in other marsupials.

Extensor carpi ulnaris.- Origin from the front of the outer condyle of the humerus and the adjacent side of the ulna; also connected by septa with the extensor digitorum lateralis. Its tendon passes over a groove on the antero-internal surface of the extremity of the radius and inserts at the base of the fifth metacarpal. According to Macalister (1. c.) and Wilson ( 1894, p. 45 $\mathrm{r}$ ), this muscle has no ulnar origin in Sarcophilus, Didelphis, Trichosurus, and Dasyurus, but like Canolestes, has one in Macropus, Phascolomys, Phascolarctos, and Perameles.

Supinator (brevis). - Origin tendinous on the sesamoid laterad of the head of the radius. Insertion on the arched anterior surface of the proximal third of the radius. A broad flat muscle. It occupies the upper twothirds of the radius in Phascolomys, two-fifths in Phascolarctos, onethird in Macropus and Sarcophilus and only one-fourth in Didelphis and Dasyurus (Macalister 1. c.). The presence of a sesamoid in its tendon of origin appears to be unique among marsupials. It is reported in certain edentates and bats and an origin from the orbicular ligament of the radius was found in Dasyurus by MacCormick (fide Wilson, 1. c., p. 48). 
Extensor indicis.-Origin from the antero-external edge of the ulna opposite the greater sigmoid cavity. Its tendon divides into two about midway of its length. These pass under the digital extensors and across the carpus to insertions one at the base of the ungual phalanx of the first digit and one at the same point on the second digit.

\section{Muscles of the Forefoot.}

The delicate intrinsic muscles of the forefoot have been worked out as carefully as possible, but in all the specimens examined some of the metacarpal bones were found to be broken, making it very difficult to ascertain exact relations. In general the muscles of the hand differ from those of Didelphis more than they do from some of the Australian forms. The adductors are much less highly developed than in Didelphis and this in connection with the absence of a pronator quadratus indicates a relatively limited power of action of hand and fingers.

Lumbricals are present but not greatly developed.

Adductors.-Three adductors are readily distinguishable, the indicis, annularis, and minimus. They arise in the palmar fascia at the base of the metacarpals and radiate to their insertions as practically separate muscles without any development of a central raphe. The indicis arises over the bases of the second and third metacarpals and inserts on the ulnar side of the distal extremity of the second metacarpal. It is separable with some difficulty from the ulnar head of the flexor brevis indicis. The annularis and minimus arise over the bases of the third and fourth metacarpals and insert on the radial sides of the distal ends of the fourth and fifth metacarpals respectively. They are separated from the flexors by a large palmar nerve. An adductor pollicis could not be distinguished. In general the adductors seem to be very similar to those of Thylacinus as figured by Cunningham.

Flexors.- Short flexors are well developed on all the fingers. The flexor brevis pollicis could not be divided into two parts. It arises on the ulnar side of the base of the first metacarpal and inserts medially with a sesamoid at the first joint of the pollex. It is a relatively thick muscle and possibly may include a fused adductor. A rather definite aponeurotic strand running from the carpus to the ulnar side of the first joint of the pollex may represent a second head of this flexor. The remaining flexors are divided except proximally and lie in the usual position on the metacarpals with their tendons of insertion embracing the metacarpo-phalangeal joints of each of the digits.

Abductors and interossei.-Two marginal muscles regarded respectively as abductor pollicis and abductor digiti minimi are present. 
There is also an abductor of the index digit which is separately described owing to its more palmar position than the other interossei.

The abductor pollicis is a short thick muscle with origin from the trapezium, the transverse ligament and the base of the first metacarpal. Its insertion is on the radial side of the distal extremity of the first metacarpal.

The abductor digiti minimi also is a relatively large muscle. It originates on the pisiform bone opposite the insertion of the flexor carpi ulnaris and inserts by a flattened tendon running under the annular ligament to the outer side of the metacarpo-phalangeal joint of the fifth finger.

The abductor digiti indicis arises on the trapezium and the base of the first metacarpal and inserts near the distal end and on the radial side of the second phalanx in close apposition with the short flexor. It is in nearly the same plane as the flexors and is visible alongside the abductor pollicis before removal of the large tendons. It is also visible from the dorsal aspect of the hand.

Excluding the above described abductor indicis, there are three dorsal interosseus muscles. These lie over the spaces between the four outer metacarpals, are almost wholly dorsal in position, and resemble those described and figured for Phalanger (Cuscus) by Cunningham (loc. cit., p. 23, pl. II, fig. 2). The one between the index and the medius has origin principally on the ulnar base and side of the second metacarpal and insertion with the tendon of the short flexor on the radial side of the third metacarpal. That between the medius and the annularis arises from the bases and the sides of the third and fourth metacarpals and inserts on the tendon of the short flexor on the ulnar side of the third metacarpal. That between the annularis and minimus arises from the bases and sides of the fourth and fifth metacarpals and inserts on the tendon of the short flexor of the ulnar side of the fourth metacarpal, also sending a short tendinous slip to the radial side of the fifth metacarpal.

\section{Muscles of the Hind Limb.}

\section{Plates V-VI.}

Adductor longus.-Origin from the side of the ramus of the ischium from the symphysis pubis to the insertion of the semimembranosus. Its origin is ectad of the adductor magnus and entad of the gracilis. Its caudal border parallels the semimembranosus. Insertion on the inner condyle of the femur and the inner side of the head of the tibia.

Adductor magnus.-Origin from the side of the pubic symphysis and thence dorso-craniad along the edge of the pubis to the middle of the 
base of the marsupial bone and dorsad along the ramus of the ischium to the semimembranosus. Insertion on most of the length of the caudal surface of the femur from the insertion of the adductor brevis near the lesser trochanter to the insertion of the longus at the base of the inner condyle. This muscle lies between the brevis and the longus and its exposed surface lies next to the pectineus. At its origin it lies entad of the longus which parallels it distad.

Adductor brevis.-Origin from the side of the dorsal half of the ascending ramus of the ischium to the side and front of the tuberosity of the ischium and for a slight distance craniad. Insertion on the distal caudal edge of the great trochanter of the femur caudo-entad of the insertion of the gluteus maximus and thence transversely of the femur to a point slightly distad of the lesser trochanter. The outer surface of this short broad muscle is wholly covered by the gracilis, the semimembranosus, and the other adductors.

Caudofemoralis. - Origin by a broad tendinous aponeurosis from the fascia covering the multifidae and somewhat attached to the articular processes of the third caudal vertebra. The insertion is double, one slender slip inserting by a short tendon on the inner edge of the inner condyle of the femur between the adductor longus and the gastrocnemius. The other division of the muscle passes on the opposite side of the adductor longus and inserts by several fasciculi on the caudal surface of the distal fourth of the shaft of the femur. Near its insertion it is slightly connected with the adductor. This muscle, which is not present in the didelphids, is well developed, but shows some variation even in the small number of specimens dissected. At its origin it lies immediately entad of the femorococcygeus and slightly distad is separated from it by the great sciatic nerve. It passes transversely to the bases of the adductors, but is free from the femur to its insertion. Its ental surface near its origin has relation with the caudal muscles, the quadratus femoris, and the obturator internus as it passes distad just craniad of the biceps femoris. Its presence is reported in Notoryctes, Phalanger, Thylacinus, Myrmecobius, and Dasyurus.

Pectineus.-Origin from the side of the pubis at the anterior base of the marsupial bone. Insertion on the inner surface of the femur slightly proximad of the middle. A short thick muscle lying ectad of the insertion of the psoas major.

Femoro-coccygeus.-Origin aponeurotic from tendinous fascia between the cephalic and caudal articular processes of the third caudal vertebra. Insertion by several fasciculi on the distal third of the caudolateral surface of the femur. It is separate from the gluteus maximus except near the insertion where the fascia join. It has a slight twist 
in passing between the biceps and the gluteus and lies "edgewise" for a short distance, its distal part being covered by the biceps. It is separate from the gluteus in Sarcophilus (Macalister, I870, p. 166) and Notoryctes (Thompson and Hillier, 1905, p. 310 ), but in other marsupials is in the same plane and more or less fused with it.

Vastus internus.-Origin from the proximal three-fourths of the anterior and dorsal surface of the femur, extending from the anterior edge of the great trochanter to the lesser trochanter and thence distad. Insertion with the vastus externus on the inner side of the patella and thence by aponeurosis to the head of the tibia. A very large muscle greatly exceeding the vastus externus.

Subcrureus.- Origin on the dorsal surface of the femur just distad of the vastus internus. Insertion in the tendinous fascia surrounding the patella. A short flat muscle.

Vastus externus.-Origin from the anterior border of the great trochanter of the femur. Insertion conjoined with the rectus femoris on the patella. About equal in size and form to the rectus, with which it forms the anterior border of the thigh. Decidedly smaller than the vastus internus to which it is closely appressed but from which it is distinct except for a short distance near its origin.

Biceps femoris. - Origin by a short tendon from the lateral surface of the tuberosity of the ischium craniad of the inner division of the semitendinosus and entad of the outer division or crurococcygeus. Insertion by broad aponeurosis from the patella across the proximal third of the leg to the outer edge of the tibia. This aponeurosis covers a large part of the outer side of the leg. A large triangular muscle of great width but moderate thickness. Its anterior border meets the vastus externus and covers the insertion of the femorococcygeus.

Rectus femoris.-Origin from the dorso-lateral ridge of the ilium immediately craniad of the acetabulum. Insertion with the vasti on the patella. It passes between the gluteus minimus and the ileopsoas and forms the inner anterior boundary of the thigh.

Semitendinous.-Origin by two heads, an outer one ("crurococcygeus") from the fascia over the fourth caudal vertebra and an inner one from the tuberosity of the ischium just caudad of the biceps. Midway between the tuberosity and the flexed femur these two slips unite and then divide into three parts, two passing inside the gastrocnemius and one outside. The inner slips insert by aponeurosis, one with a twist on the front of the tibia one-third of the distance from the tibial head and the other (entad) on the same surface of the tibia halfway between its fellow and the head of the tibia. The outer slip inserts on the outer surface of the tibia and in the fascia of the biceps femoris. The relations 
of this muscle are essentially as in Didelphis and different from those of most other marsupials, in which the so-called crurococcygeus is not so well developed, although tendinous intersections have been found in Thylacinus, Dasyurus, and Trichosurus (fide Thompson and Hillier, I905, p. 3I6) and in Charopus (Parsons, I903, p. 73).

Gracilis.-Origin from the pubic symphysis and the ascending ramus of the ischium nearly half way to the tuberosity. Anteriorly a few fibers reach to the base of the marsupial bone. Insertion aponeurotic on the inner surface of the distal half of the proximal third of the tibia.

Semimembranosus.-Origin fleshy from the outer side of the ascending ramus of the ischium, occupying the middle two-thirds of the space between the symphysis and the tuberosity. Insertion by a broad tendon on the inner side of the head of the tibia entad of the internal lateral ligament of the knee joint which is strongly developed. A large thick muscle elliptical in cross section. No presemimembranosus was distinguished, but it may be represented in the somewhat anomalous muscle here called caudofemoralis although that has no ischial origin.

Sartorius.-Origin on the dorsal border of Poupart's ligament. Insertion in the fascia extending from the knee joint and the patella to the proximal third of the front edge of the tibia. It is a thin band consisting of one layer of muscle fibers only and can scarcely be functional. This muscular part is clearly differentiated from the fascia on either side of it which cover a great part of the inside of the leg immediately beneath (entad) the mass of fat. Between the sartorius and the next layer of muscle is the crural nerve and its branches, of which the saphenus innervates the sartorius and runs down the side of the leg (P1. VI, fig. 2). It is practically imbedded in the sartorius at this point and is visible through the thin muscle layer. The insertion of the muscle is ectad of the gracilis.

This much-reduced, almost rudimentary muscle, is easily overlooked and it was at first thought that a sartorius was entirely absent or fused with the gluteus maximus. It was possible also that it might be a second gracilis. It has been demonstrated in two specimens, however, and its relations with the saphenus nerve seem to justify the conclusion that it is in reality the sartorius. Its origin from Poupart's ligament is paralleled in certain edentates, as sloths and armadillos. A partial origin from Poupart's ligament has been noted in Sarcophilus by Macalister (1870, p. I 70). In the Insectivora, although usually absent, the sartorius is found in Gymnura partly attached to the gracilis.

Gastrocnemius. - The medial head arises by a short thick tendon from the inner transverse surface of the inner condyle of the femur and the intercondyloid notch just distad of the caudofemoralis and the adductor 
longus. It lies against the lateral head with various nerves intervening and is joined with it in the distal fourth of its fleshy extent. It thus agrees with most marsupials and differs from Didelphis in which it is wholly free from the lateral head. The lateral head has two divisions, one of which probably represents the soleus. These are:

I. The principal part arises from the extremity of the fibular sesamoid opposite the end of the collateral tibial ligament and joins the second part about midway of its fleshy extent. Except for a small triangular area along its outer proximal edge where the second part is visible beneath the fascia, it overlies the second part.

2. The second part arises from the caudal surface of the fabella and from the tendinous edge of the plantaris for about two-fifths of the fleshy extent of the plantaris. It joins the outer part about midway of its fleshy extent. This second and more deep-seated part of the muscle may be the soleus which is not otherwise evident. The conjoined parts form a rounded tendon which runs to an insertion on the calcaneum. As a whole the gastrocnemius forms a deep belly on the leg curving rather abruptly inward to its tendon and occupying in its fleshy part only forty per cent of the length of the leg, the remainder being tendinous. Its outer or anterior edge is continuous with the fascia lata which extends to the patellar region and down the leg entad of and intimately associated with the fascia of the biceps femoris. In one specimen a slight cleft in this outer edge was observed separating a thin slip which may represent a third or patellar division of the gastrocnemius.

Plantaris.-Origin from the side of the fabella, mediad of the second division of the lateral head of the gastrocnemius and more or less united with it. It continues joined with the gastrocnemius for about two-fifths of its fleshy extent and then becomes free as a slender bundle which proceeds distad covered by the gastrocnemius. Its slender tendon, which at first is entad of that of the gastrocnemius, curves around it and passes over the calcaneum ectad of the gastrocnemius tendon and widens to merge into the plantar fascia where its prolongations could not be traced.

Flexor digitorum fibularis. - This has two divisions scarcely separable in their fleshy part. The smaller one, which is on the tibial side, sends a small tendon beneath the larger one but separate from it until just before it passes the os calcis when the two merge. The fleshy part of the muscle is relatively large, lying next below the gastrocnemius and taking origin from the greater part of the inner and posterior aspects of the fibula from the inner side of the outer tuberosity distad not only in the grooved inner expanded part but also on the proximal part of the rounded posterior aspect. Proximally it is connected by septa with the tibialis anticus and distally some of its fibers arise from the interosseous mem- 


\section{Field Museum of Natural History - Zoölogy, Vol. XiV.}

brane. Its large tendon passes inside the calcaneum where it becomes broad and heavy and soon divides into four strong tendons bearing the lumbricals and running to the ends of the outer toes. Just before the common tendon divides it receives on its ental surface the two flattened tendons of the flexor digitorum tibialis between which passes the flexor accessorius.

Flexor accessorius.-Arises on the tuberosity of the distal outer extremity of the os calcis, spreads over the ventral surface of the distal part of the calcaneum, passes beneath the plantar ligament and then becoming tendinous, continues diagonally entad of the common tendon of the large flexor fibularis. Thence it perforates the tendon of the flexor tibialis, or at least is somewhat attached to it, and proceeds to insertion on the distal phalanx of the hallux. Just before passing through the annular ligament at the first joint of the hallux its tendon unites with that of the flexor tibialis.

This muscle is present in Didelphis and has been described by Coues (1872, p. 134) under the name flexor brevis pollicis obliquus. In Didelphis, however, it passes ectad of the common tendon of the flexor fibularis and its tendon joins the tendon of the flexor tibialis before it reaches the hallux. An accessorius is recorded also for Chironectes (Sidebotham, I 885 , p. I6).

The accessorius is stated by Leche (Bronn's Thierr., p. 904) to be generally lacking in marsupials and perhaps the above described muscle should be regarded as a part of the flexor digitorum communis brevis which is otherwise rather weak and slightly represented (see postea, p. 57). Whatever its name, it is evident that it is more independent in Conolestes than in other marsupials or most other mammals, especially in the distinctness of its tendon for a considerable distance on the hallux. A somewhat similar accessorius found in an insectivore, Gymnura, is regarded as abnormal by Parsons ( 1898, p. 324). It is of regular occurrence in edentates.

Flexor digitorum tibialis.-Origin from the greater part of the proximal half of the interosseous membrane, from the popliteus, and by a few fibers from the inner side of the inner tuberosity of the fibula. Its tendon, closely associated with that of the tibialis posticus, passes the inner malleolus and soon divides into two, one of which runs directly to the ental surface of the large tendon of the flexor fibularis and the other joins the small tendon of the accessorius and after a lateral connection with the main tendon of the fibular flexor it continues to an insertion on the terminal phalanx" of the first digit.

Peroneus brevis.-Origin tendinous from the inner tuberosity of the fibula and proximally by septa with the muscles lying on either side and 
beneath it. Its large tendon passes beneath the annular ligament outside the external malleolus and after passing over the front of the calcaneum turns downward and inserts on the outer side of the tuberosity of the base of the fifth metacarpal. Just above its insertion it is distinctly increased in size and is perforated by the tendon of the peroneus tertius. The same arrangement has been noted in Trichosurus (Thompson and Hillier, 1905, p. 322).

Tibialis anticus.-Origin from the deeply excavated outer surface of the proximal part of the tibia. Its muscular part lies mostly in this broad groove but is directly attached to the bone only in its proximal third. Its principal tendon passes along the fibular edge of the tibia and after passing over the astragalus turns down entad of the tendon of the extensor hallucis longus and widening slightly inserts on the under side of the entocuneiform bone. A second and smaller tendon runs from an indistinct division of the fleshy part of the muscle and, paralleling the larger tendon, inserts in front of it on the side of the base of the first metatarsal.

In Myrmecobius (Leche, Bronn's Thierr., VI, p. 893) it is joined by the tendon of the extensor hallucis longus, but in this case that muscle and its tendon are independently developed. An accessory tendon to the first metatarsal similar to that in Conolestes was found in Notoryctes by Thompson and Hillier.

Peroneus tertius.- Origin from the external condyle of the femur and the under surface of the collateral ligament jointly with the peroneus longus, from the outer surface of the inner condyle of the fibula and also by a distinct slip or second head from the surface of the fibula just distad of the outer tuberosity. It lies entad of the peroneus longus and although not so completely bicipital there is a distinct correspondence between the divisions of each. It has only slight connection with surrounding muscles, being distinct throughout its fleshy extent. Its tendon passes through the malleolar ligament, perforates the tendon of the peroneus brevis and continues directly to its insertion in the fascia on the outer side of the base of the first phalanx of the fifth digit.

This muscle is regarded by Leche as a division of the extensor brevis digitorum. Its relations in Didelphis are similar to those in Canolestes and also in Thylacinus, Myrmecobius, Cuscus, and in Phascolarctos, but in these latter it has no femoral origin (Leche).

Peroneus longus.-Arises by two heads which are separate proximally but which join midway of their fleshy extent to form a single tendon. The inner head lying next to the peroneus brevis takes origin from the inner tuberosity of the fibula and from the outer edge of a collateral ligament running from the external condyle of the femur to the inner tuber- 


\section{Field Museum of Natural History - Zoölogy, Vol. XiV.}

osity of the fibula. A few fibers also arise from the outer base of the peroneus brevis. The outer head arises from the outer tuberosity of the fibula and the inner surface of the fibular sesamoid. Its tendon lies deep to that of the peroneus brevis and passes with it through the annular ligament over the external malleolus. Distad it passes over the peroneal tubercle of the calcaneum and down the side of the cuboid deeply imbedded in tissue. Turning to the under side of the tarsus, it passes over the cuboid and after being somewhat enlarged and attached near the base of the fifth metacarpal, it passes the bases of the third and fourth metacarpals and goes to insertion on the inner base of the hallux. Its course and insertion are thus much the same as in Phascolarctos, Phalanger and Didelphis.

Tibialis posticus.-A distinct muscle with its fleshy part lying between the flexor digitorum fibularis and the flexor digitorum tibialis. Its origin is from the inner side of the outer tuberosity of the fibula, from the expanded inner surface of the fibula and from septa of the fibular flexor. Its tendon runs beneath that of the flexor digitorum tibialis and crosses it midway to the ankle finally inserting on the palmar surface of the scaphoid.

Extensor brevis digitorum.-This is in three distinct divisions two of which are of fibular origin while the third is on the dorsum of the foot. The first is a thin flat muscle arising from a small space on the outer expanded surface of the fibula slightly mediad and distad of the outer condyle. Its tendon runs through the outer malleolar ligament and inserts in the fascia on the outer side of the base of the first phalanx of the third digit. The second division is slightly larger in its muscular part which arises subjacent to the first and between it and the extensor hallucis longus. Its origin occupies the distal two-thirds of the proximal half of the outer expanded surface of the fibula. The proximal part of the fibula between the tuberosities is without muscular attachments and directly in relation with the inner surface of the peroneus tertius which overlies the above-described divisions of the short extensor. The tendon of the second division passes the outer malleolus with that of the first and proceeds over the dorsum of the pes to insertion in the fascia on the outer side of the base of the first phalanx of the fourth digit. These two divisions obviously belong to the peroneal group of muscles and are quite as distinct as the others. They are united in Didelphis and Dasyurus and send tendons to the second, third and fourth toes; in Thylacinus and Myrmecobius, they are in three divisions (Leche).

A very slender tendon imbedded in fascia crosses the third metatarsal and connects the tendon of the second division with that of the third or pedal division. The third division or extensor hallucis brevis 
consists of a short flat muscle much involved in fascia and arising chiefly from the dorsal surface of the fibular side of the distal annular ligament and the fascia over the os calcis. Its fleshy fibers scarcely reach beyond the base of the metatarsals and its tendon runs to the fascia on the fibular side of the base of the second metatarsal. Fascial connection with the hallux may include a minute tendon but this was not distinguished. A similar extensor hallucis brevis is found in Didelphis, but it is lacking in Dasyurus, Thylacinus and Myrmecobius. Its presence in Canolestes appears to be an exclusive resemblance to Didelphis. It is common, however, in other mammals, as for example, the Dasypodide among edentates.

Extensor longus digitorum. -The digital extensors lie next to the tibialis anticus and take origin from the outer tuberosity of the tibia, the inner tuberosity of the fibula, and septa joining them to the peroneus brevis. Their origin is more largely from the fibula than the tibia. They are united for no more than the proximal third of their fleshy extent and in the remainder of their length are distinct both as to the distal fleshy parts and the tendons. Passing over the ankle they are bound down in common with the tibialis anticus and the extensor hallucis by a broad annular ligament (ligamentum cruciatum) and also by a short stout annular ligament (ligamentum fundiforme) which serves for the passage only of their four ligaments. The most deep-seated of these extensors is that lying next to the tibialis anticus and its tendon goes to the terminal phalanx of the second digit, the next to the third digit and the others to the fourth and fifth, the tendons passing on the inner side of the second phalangeal joint in each case and thence to the dorsal surfaces of the third phalanges.

Extensor hallucis longus.- Origin from the inner edge of the fibula just distad of the inner tuberosity and thence about one fourth of the way to the junction of the fibula and the tibia. A few fibers also spring from the popliteal fascia. Its thin flat muscular part passes beneath the common digital extensor and the peroneus muscles in a diagonal direction from the head of the fibula to the base of the tibial flexure and thence its tendon passes down the tibia beneath the large annular ligament and inserts on the base of the first phalanx of the hallux.

Popliteus.-Origin from the greater part of the inner surface of the proximal half of the tibia. Proximally it reaches nearly to the inner condyle of the tibia while distally it extends almost to the union of tibia and fibula. Its fibers run diagonally across the interosseous space but do not reach the fibula except proximally. Distally the fibers reach not more than half way across the interosseous membrane to which they are attached as a thin nearly transparent sheet. Proximally the muscle has 
tendinous attachment to the posterior side of the inner tuberosity of the fibula and the tendon continues broad through the muscle, which is pinnatifid. An indistinct layer lies superficial to this part of the muscle and is also pinnatifid, but in reverse direction, the tendon attaching to the shaft of the tibia and the fibers radiating toward the fibula. This may represent the so-called pronator tibiae, indications of which are found also in Myrmecobius and Didelphis (Leche, p. 899), forms in which there is some possibility of rotatory movements between tibia and fibula, whereas in Canolestes such movements are quite precluded by the closely appressed distal halves of the bones. The retention of these muscles in Canolestes, therefore, is possible evidence that the arrangement of the bones is a recent specialization. This is partly negatived, however, by the entire absence of the pronator quadratus in the foreleg. There is no trace of a distal pronator tibiae such as is described by Macalister (1870, p. I73) for Phascolomys, Sarcophilus, Phalangista, and Perameles.

\section{Muscles of the Hind Foot.}

The number and relations of the muscles of the hind foot, the socalled intrinsic muscles, are broadly similar to those of various other pentadactylous marsupials. The size and independence of the hallucal adductor and the divided abductor indicis are noteworthy, as well as the sesamoid origin of certain of the short flexors. Although the other adductors and abductors are present it seems doubtful whether many of them can be more than very slightly functional on account of the closely appressed metatarsals. These are almost in contact proximally for nearly half their length in such a way as to permit of only very slight lateral motion.

Lumbricales. - These are fairly well developed, but of uneven size, arising from the sides of the tendons of the flexor digitorum fibularis and inserting with them at the ends of the toes. Each tendon has two of these small muscles. Those on the tendons of the second, third and fourth digits are progressively shorter and rise from the sides of the tendons a considerable distance distad of their separation from the common tendon. Those of the tendon of the fifth digit are very unequal, the outer being short and rising far distad while the inner is long and rises as high as the point of separation of the tendon from the common tendon.

A single lumbrical rises on the medial side of the flexor digitorum tibialis. Another thin muscle rises on the ventral surface of the common tendon of the fibular flexor just above its digital divisions and sends weak aponeurotic connection to the fourth digit and possibly also to 
others but this could not be determined. It represents, at least in part, the flexor digitorum communis brevis, which is similarly but more highly developed in Didelphis.

Adductors.-All the adductors except the medius are present. Those of the outer digits arise in the membranous fascia just proximad of the metatarsals. The indicis goes to the medial or fibular side of the first joint of the index digit, the annularis goes to the tibial side of the same joint of the fourth digit, and the minimi digiti to the tibial side of the fifth digit. In one specimen the indicis and annularis were joined proximally for at least half their length, the minimi digiti being distinct from the base of the metatarsus. They are rather flat, wide, and quite delicate, but have small central tendons.

The adductor hallucis lies along the lateral surface of the first metatarsal between the abductor hallucis and the short flexors and is the largest of the intrinsic hallucal muscles. It is not connected with the other adductors but has independent origin from the scaphoid by a selatively stout tendon which passes along the grooved surface of the ectocuneiform becoming fleshy at the base of the metatarsal. It inserts with the abductor on the tibial side of the distal extremity of the first metatarsal. The adductor hallucis is thus quite different from that of Didelphis and somewhat similar to that of Phascologale as described by Cunningham ( 1882, p. 55), but is even more independent, its origin being completely separate from that of the other adductors.

Abductors. - These consist of an abductor hallucis, abductor minimi digiti in two divisions, abductor ossis metatarsi minimi digiti, and four interosseus muscles.

The abductor hallucis is rather poorly developed and muscular only in its short fan-shaped proximal part. It arises in the fascia surrounding the small sesamoid laterad of the base of the first metatarsal and sends a thin tendon to insert on the radial side of the distal extremity of the same phalanx.

The abductor ossis metatarsi minimi digiti is well developed arising on the os calcis and running laterad of the plantar tendon to insert on the tuberosity of the fifth metatarsal.

The abductor minimi digiti is in two divisions. The first arises as a thin fan-shaped fleshy muscle from the os calcis ectad of the foregoing and soon becoming a slender tendon continues by a marginal course to its insertion on the radial side of the distal extremity of the fifth metacarpal. The second division, which is muscular throughout, arises from the sesamoid at the inner (medial) base of the fifth metacarpal and inserts on the outer (radial) sesamoid at the distal extremity of the fifth metacarpal, passing between the divided short flexors. The external 


\section{Field Museum of Natural History - Zoölogy, Vol. XiV.}

plantar nerve passes entad of it near its origin and its general relations are much as described by Cunningham for Dasyurus, Phascologale and Thylacinus but it is a relatively larger muscle than in these, rather thin and flat, and it seems not impossible that it may be an opponens minimi digiti. The usual four dorsal interossei are present but have a tendency to fusion with the short flexors. With the exception of the first, they are entirely palmar in position and cannot be seen from the dorsal aspect of the foot owing to the nearly united basal metatarsal bones.

The abductor indicis is in two divisions. The larger has tendinous origin as high up as the scaphoid near the origin of the abductor hallucis and continues tendinous to the medial base of the first metacarpal where it has slight attachment and becomes a well-formed fleshy belly running diagonally to insertion on the side of the first joint of the index digit. The second and smaller division of this abductor arises on the medial side of the base of the hallux and runs close to the flexor indicis slightly dorso-mediad of the first division and joins the tendon of the first division on its medial side slightly before its insertion. This twoheaded arrangement of the abductor indicis is reported for Thylacinus, a tetradactylous animal, and a somewhat similar condition is found in Phalanger which is syndactylous. In Didelphis and Dasyurus the $a b-$ ductor indicis is single-headed.

The third metacarpal has the usual two abductors inserting on each side of the first joint on the sesamoids. They are dorsad of the flexors at their extremities but mostly laterad in the middle where they are visible without disturbance of the flexors. The outer one is rather closely associated in its proximal half with the flexor brevis of the fourth metacarpal. The fourth interosseous is less dorsal in position than the others and runs nearly laterad of the flexor from origin in the palmar cartilage to insertion on the outer side of the end of the fourth metacarpal. The interossei insert very close to the extensor tendons but do not appear to be definitely connected with them. Near the insertions of the second, third and fourth interossei there is a tendinous connection with the joint opposite the one on which they are directly inserted and thus the ends of the metacarpals are bound together and necessarily have but little freedom of movement.

Short flexors. - There are five pairs of short flexors, one for each metatarsal. They are only slightly connected at their origin in the palmar fascia just above the bases of the metatarsals and thence to their insertions on the distal sesamoids the divisions are clearly marked. Those of the hallux are weaker than the others and the lateral division is partly aponeurotic and smaller than the median division. Those of the second and third digits enclose a small flattened sesamoid in the fascia 
where they arise. This sesamoid may not be homologous with that of Notoryctes, but it is otherwise unique among marsupials and, as noted by Thompson and Hillier, ${ }^{1}$ is suggestive of certain edentates. The flexors of the fifth digit are separated at their insertion by the tendon of the shorter division of the abductor minimi digiti. It is somewhat doubtful as to whether the outer or radial division is properly to be regarded as a flexor, especially since it inserts by a slender tendon whereas its fellow has a broad fleshy insertion extending to both sesamoids. Possibly this supposed outer division of the fifth flexor should be regarded as a third division of the abductor minimi digiti.

\section{Summary of Myological Characters.}

The trunk muscles of Canolestes are, as was to be expected, of the prevailing marsupial type. It is in the muscles of the limbs and head that the most significant deviations are found and although these seem quite numerous when comparison is made only with American forms, there is such variation among Australian forms that similarity is found with first one and then another. It is quite evident that some Australian forms, especially in the Dasyuridae, approach Didelphis more closely than does Canolestes. It is also clear that many of the points in which Canolestes differs from Didelphis are to be found in Australian forms. Although some of these resemblances are plainly cases of convergence, others do not seem so. Therefore, aside from the question as to the nearest relationships of Cenolestes, it is evident that it contributes in a positive way to the broad general conclusion, already well grounded, that American and Australian marsupials are of common derivation. That is, many of the points in which Didelphis fails to show resemblance to Australian forms are supplied by Canolestes.

From the standpoint of myology there seem to be few if any distinctions that can be definitely drawn between Polyprotodontia and Diprotodontia. Nevertheless, in viewing the possibility that Cenolestes is to some extent transitional between the two large groups, the musculature can scarcely be adduced as contrary evidence, since it shares many features with the diprotodonts that are not possessed by all polyprotodonts. That it shares more than any polyprotodont cannot be said,

${ }^{1}$ Regarding the sesamoid in Notoryctes, these authors say: "In connection with the plantar sesamoid bone, which as far as we know has not been recorded in any other marsupial, it is interesting to find that in some edentates there is a very similar arrangement. Windle and Parsons state that in the Dasypodidae the tibial and fibular flexors unite in the lower part of the leg, and are inserted into a very large sesamoid bone in the sole of the foot, which is held in place by a fibrous band from the calcaneum, the equivalent of the accessorius. From the front of the sesamoid bone five tendons pass to the terminal phalanges of the five digits." Jour. Anat. \& Phys., XXXIX, p. 326, 1905. 
although better comparisons than are here possible might prove this to be the case. It is worthy of particular note that it has a considerable number of points in common with the extraordinary form Notoryctes and that, as in Notoryctes, some of its most exclusive features as a marsupial are suggestive of edentates and insectivores. Among such are the divided trapezius, the dorso-cuticularis, the absence of a pronator quadratus, the sesamoid origins of the supinator and the short flexors of the hind foot, and the peculiar sartorius. It is also to be noted that some of the resemblances between Canolestes and Didelphis not shared by most other marsupials are however to be found in other mammals, especially edentates, and therefore cannot be taken as certain indications of close relationship between Canolestes and Didelphis. The well-developed pedal extensor hallucis brevis and the flexor accessorius pedis are perhaps examples of this kind.

The muscles of the legs and feet in Canolestes are adapted to a terrestrial, almost cursorial, life. The leg muscles have short thick fleshy parts and very long tendinous extensions, relatively longer even than in such terrestrial forms as Phascologale, and in this respect are perhaps most similar to those of the saltatorial but otherwise generalized Australian polyprotodont Antechinomys, the myology of which has not been thoroughly described. The proportion of tendinous to fleshy parts is about as 60 to 40 and the outline of the leg thus resembles that of a digitigrade animal. It is markedly different from that of Didelphis in which fleshy extensions reach nearly or quite to the carpus and tarsus. Specialization for terrestrial life has proceeded far beyond that in Peramys whose habits are presumably not greatly different from those of Canolestes but whose musculature is only slightly different from that of Didelphis. "The absence of the pronator quadratus is not accompanied by such reduction of other muscles as might be expected in view of the facts that otherwise a large number of muscular elements are present in the limbs and that their distinctness from each other is marked. There is some reduction of the intrinsic muscles of the feet, especially in the adductorial sets, and the grasping power is distinctly limited.

All the important muscles have been worked out with considerable care, but the nature of the material, the small size of the animal, and the lack of comparative material, have made it impossible to be certain of relations in all cases. Such comparative notes as are ventured are based on examination of the scattered literature and the comprehensive work of Leche in Bronn's Thierreich. Comparison of actual specimens has only been possible with Didelphis, Marmosa, and to some extent with

${ }^{1}$ No careful study of Peramys has been possible, but cursory examination of its feet and legs indicates close similarity to Didelphis. 
Peramys and Macropus. That this is not an ideal method of comparative work can be apparent to no one more fully than the author; but, it is the best that circumstances permit and if small errors have crept in it is hoped that they will not seriously affect general conclusions. The nomenclature adopted has been that of Bronn's Thierreich with occasional changes where it seemed feasible to conform to the BNA terms.

Features in the myology of Canolestes which seem especially noteworthy are as follows:

Trapezius divided into spinotrapezius and acromiotrapezius.

Rhomboideus divided.

Dorso-cuticularis present.

Distinct rectus capitis posterior superficialis.

Pterygoideus externus relatively large and bicipital.

Subclavius not extending to scapular spine.

Median head of triceps brachii distinct.

Origin of supinator brevis including a sesamoid.

Pronator quadratus absent.

Distinct caudo-femoralis present.

Femoro-coccygeus practically distinct from gluteus maximus.

Gluteus medius partially divided into two layers.

Sartorius on inner side of thigh, much reduced, and originating from Poupart's ligament.

Extensor carpi ulnaris with ulnar as well as humeral origin.

Radial extensors of carpus separate from each other.

Median and lateral heads of gastrocnemius partly united.

Fibular divisions of extensor brevis digitorum distinct from each other.

Pedal extensor hallucis brevis well-developed.

Flexor accessorius present.

Pronator tibiae partly separate from popliteus.

Short flexors of second and third toes arising from a sesamoid.

\section{URINOGENITAL SYSTEM.}

The interesting urinogenital system has been studied only by gross dissection and the use of the binocular microscope. With the scanty material available and the means at hand, no other course seemed possible. It is to be regretted that serial sections could not be obtained of the embryo. One of the imperfect females examined was pregnant, having three embryos, two in the right uterus, and one in the left. The uteri were greatly expanded and the foetuses lay surrounded by their 
thin membranes and the thickened walls of the uteri. The largest was approximately $4 \mathrm{~mm}$. in length and well advanced in development. By a most unfortunate accident, these embryos, after being removed and set aside for special study, were totally destroyed.

Mere gross dissection, however, is sufficient to show that the reproductive system of Canolestes is markedly different from that of the primitive polyprotodonts.

\section{Male Generative Organs.}

\section{Plates VIII-X.}

The prostate gland is exceedingly large, relatively larger than in any other marsupial known to me and therefore probably larger than in any other mammal. It is a prominent ovate body occupying practically the entire space in the posterior part of the body cavity and extending from the kidneys to the pubis. In a normal adult with a body length of II $3 \mathrm{~mm}$., it measures $16 \mathrm{~mm}$. in length and I I mm. in greatest diameter. The bladder, which is small and inconspicuous in comparison, is situated on the dorsal surface of the prostate somewhat caudad of its anterior expansion and thus scarcely visible from the ventral aspect. The gland is not tapering and radiciform as usual but is only slightly smaller posteriorly than anteriorly and the narrow urethral canal makes exit from its walls abruptly on its dorso-caudad surface. The prostate is enclosed in a thin membranous or slightly muscular covering of transverse fibers. The thickened portion consists of numerous slender cylinders of glandular tissue radiating from the urethral canal to the periphery. The urethra in its course through the prostate is quite small and is longitudinally plicated on its inner surface (Pl. X, Fig. 5).

The ureters and vasa deferentia enter a groove between the base of the bladder and the prostate, the former going to their orifices on the dorsal side of the bladder near its neck and the latter turning sharply caudad into a groove in the prostate to a common opening into the urethra a short distance beyond its enclosure by the prostate (P1. X, Fig. I). The vasa deferentia have the usual course, leaving the base of the testes and diverging to enter the body cavity and pass dorsally on each side of the colon to their terminations. Before entering the raphe in the prostate they are somewhat enlarged and slightly convoluted. There are no obvious seminal vesicles.

From its exit from the prostate the urethra continues as a slender tube for about $5 \mathrm{~mm}$. to its bulbous portion where it enlarges and receives the ducts of the Cowper's glands. This bulbous urethra is short and wide and has a slight forward projection or cul de sac on its ventral 
side. There are three pairs of Cowper's glands. The anterior pair are elongate pear shape and open into the anterior part of the bulbous urethra ventro-laterally. These have been designated in the figures as Cowper's gland No. r. The two other pairs are situated dorso-laterally just anterior to the base of the stalk of the corpus spongiosum and have a common opening (Pl. IX, Fig. I). In fact the smaller one (No. 2) appears to be scarcely more than a division of the larger (No. 3) since they unite at an appreciable distance from the urethra. This gland No. 3 is very large, several times larger than the others, even larger than the paired testicles, and more than half the size of the enormous prostate. It measures $12 \mathrm{~mm}$. $\times 8 \mathrm{~mm}$. Although not examined histologically, its superficial appearance indicates a structure somewhat different from that of gland No. 1 . Gland No. 2 appears to have the same structure as No. 3 , of which, as noted above, it is scarcely more than a division. In Marmosa and Didelphis there are only two pairs of Cowper's glands, but in Peramys I find three as in Canolestes, the posterior pairs being on a common stalk but showing no such discrepancy in size as in Conolestes. The substance of gland No. I, except near the base, appears as nearly solid, slightly granular tissue of a whitish color, whereas No. 2 and No. 3 are highly fenestrated and spongy and even in gross examination are seen to consist of numerous thin-walled tubules which converge toward the duct and divide into branches toward the periphery of the gland. In the glands of Marmosa and Didelphis, the same difference of structure obtains. In a pouch specimen of Macropus there are three glands, as in Canolestes, and the posterior ones have a common stalk, but their structure seems identical with that of the anterior pair. Histological study of fresh material is necessary before the significance of the differences in these glands can be understood. ${ }^{1}$ That some of them may function as seminal vesicles is perhaps not impossible.

The corpus cavernosum has its origin in a bulb invested with muscles and situated slightly caudad of the first pair of Cowper's glands. The stalk of this bulb, which is slightly bilobate, expands into a layer around the ventral wall of the urethra and continues to the base of the glans penis. The muscle covering the bulb of the corpus cavernosum turns on itself and attaches on the stalk of the bulb instead of continuing to form a levator penis as in the opossum. However, there are three pairs of small thin muscles lying flat on the base of the corpus cavernosum and the adjoining part of the bulbous urethra, some one of which may be the homologue of the levator penis, although this seems

${ }^{1}$ Such work may have been done already, but the scope of the present study has not extended to the literature in which it might be recorded. 
doubtful (P1. IX, Fig. 2). In the opossum the levator penis arises as a direct continuation of the muscles covering the postero-ventral part of the lateral bulb of the corpus cavernosum and proceeding inward turns abruptly caudad and continues to the base of the glans penis. There is no muscle occupying this position in Canolestes and none that could function as a levator penis. There is another paired muscle in the opossum, of which the function is not apparent, which corresponds closely in position to one of the small paired muscles in Ccenolestes, the most anterior and superficial one. These small muscles have been designated in the figure as Nos. I, 2 and 3. No. I arises along the median line on the anterior part of the bulbous urethra and continues as a slender, free, and slightly thickened fascia to the anterior surface of the muscle on the bulb of the corpus cavernosum. No. 2 lies partly beneath No. I and overlaps No. 3 , which covers the anterior side of the stalk of the corpus cavernosum. There is no trace of any such muscles in Macropus. From the ventral side of the corpus cavernosum near the extremity of the stalk a large flattened tendon extends to an attachment on the postero-internal surface of the ischium opposite the origin of the gracilis muscle (P1. IX, fig. $2, i . t$.). No such tendon is found in Didelphis, but a similar attachment is normal in Macropus. A plexus of nerves, blood vessels, and connective tissue emerges between the pubococcygeus muscle and the ischium and reaches the corpus cavernosum and adjacent glandular surfaces, assisting in attaching the very large postpubic mass to the body.

Behind the bulb of the corpus cavernosum but more dorsal in position is the bulb of the corpus spongiosum, its stalk meeting the bulbous urethra slightly below (ventrad) the common opening of the posterior Cowper's glands. It is also enclosed in a thick layer of muscles but these do not extend beyond its stalk which expands within the dorsal wall of the urethra in a very thin layer. This continues to the base of the glans penis where it rapidly thickens and extends to the end of the glans. The corpus cavernosum continues, forming the central part of the glans, practically to the pointed tip.

The glans penis is so deeply cleft as to appear like two separate organs. Each half is of acicular shape, narrowing at the tip to a sharp point. The extreme tip is separated by a circular fold from the main body of the glans as a sort of secondary glans. In front of the base of the glans the urethra forks to empty into a deep groove which runs down the dorsal surface of each division of the glans, terminating at the circular fold which marks off the tip of the organ. This groove is expanded in its ventral part and occupies the center of the glans. In cross section in a preserved specimen it appears as a transverse opening connected with 
the dorsal surface of the glans by a vertical slit. In life it would doubtless function almost as efficiently as a closed tube. The surface of the glans is slightly rugose in its proximal two-thirds and distally it is covered with small circular papillae. The total length of the cleft part of the glans is approximately $\mathbf{2} 2 \mathrm{~mm}$. The penis when retracted lies in a pouch formed by the expanded distal part of the urethra and opening into the cloaca (See Pl. IX, Fig. 3).

The retractor muscles of the penis are attached one on each side near the anterior end of the penis pouch. They originate from the narrow tendons of the infracoccygeus on the ventral surface of the fifth lumbar vertebra and run for a short distance caudad above the colon and then turn slightly ventrad, inclosing the colon and continuing caudad along its latero-ventrad surface, and pass dorsad of the Cowper's glands to their insertion on the sides of the penis pouch.

The cloaca, the penis pouch, and at least certain of the Cowper's glands are enveloped in a thin layer of muscle, the sphincter cloacae and its accessory folds. About the cloaca it is thicker and the fibers have a circular course, but more anteriorly it becomes thinner and follows the interstices between the organs where it is lost in the connective tissue. Anteriorly it is attached by the flat tendons to the ventral surface of the pubic symphysis. These, in crossing the ventral surface of the urethra, have partial attachment near the base of the corpus cavernosum.

The testes are of relatively large size, broadly elliptical in shape and slightly flattened on one side where the two are closely appressed in the scrotum. A single one in a preserved specimen measures $6.5 \times 4.5 \mathrm{~mm}$. The testis is clasped by the epididymis in the usual manner and loosely attached. The globus major is somewhat thickened and has considerable convexity. It is slightly larger than the globus minor which lies folded upon itself and in its course toward the exit of the vas deferens has several convolutions which lie against the testis in the inferior curvature of the epididymis. Part of this is evidently the vas deferens itself and its position here is evidently somewhat peculiar since the arrangement in Didelphis and Macropus is not quite the same.

The most noteworthy features of the male generative organs of Canolestes are the extraordinary size of the prostate and Cowper's glands, the very deeply cleft glans penis, and the absence or great reduction of the levator penis muscle. It is difficult to see indications of relationship in any of these. The bifid glans penis occurs in both polyprotodonts and diprotodonts. It is most pronounced in polyprotodonts and, according to Owen (Anat. Vert., III, p. 648), is associated with the presence of a levator penis muscle. But in Conolestes there is the unusual condition of a deeply bifid glans penis and a rudimentary 
levator muscle. The divided glans and the well-developed levator muscle are doubtless both to be regarded as generalized conditions and it may be concluded that if Canolestes has retained one it is at least in a secondary stage as regards the other. It is by no means certain that any of the small paired muscles on the cephalo-ventral surface of the bulbous urethra are homologous with the levator penis, but if not, then that muscle, which is so well developed in Didelphis and some other polyprotodonts, is entirely absent in Canolestes as it is in the Macropodidae.

\section{Female Organs.}

\section{Plate VIII.}

The female specimen dissected was a virgin. The ovaries were found lying entirely exposed on the latero-ventral surface of the colon slightly clasped by the fimbriated funnel of the oviduct. They are smooth and disklike, about $2 \mathrm{~mm}$. in diameter. The Fallopian tubes are rather short and heavy as compared to those of the opossum. The uterine bodies also are relatively short and less flattened than in Didelphis. They appear simply as gradual expansions of the Fallopian tubes with only a slight line of division. They are shorter than the outstretched vaginal canals and measure approximately $6 \mathrm{~mm}$. in length from the end of the oviduct to the base of the median vaginae. The general relations of the peritoneal folds forming the uterine fossa and the broad ligament are as in other marsupials.

The round ligament is well developed. In gross dissection its relations to the ovary and the uterus could not be determined positively. Apparently it does not extend directly to the uterus but is lost in the thickened part of the broad ligament to which the ovary is attached and from which a well-defined branch runs to the anterior part of the uterus. Possibly this branch is a continuation of the round ligament, but this could not be determined. This round ligament is attached by a membranous fold which extends in directly transverse relation to the broad ligament and thence to the dorso-parietal wall of the body cavity. Its antero-ventral border is rounded and about equal in diameter to the oviduct. Seen from the ventral side it passes at right angles beneath (dorsad) the folds of the oviduct and the broad ligament and makes a sharp turn craniad to join the thickened mass upon which the ovary rests. It is so distinct and well-developed that it does not seem likely that it can be anything other than the homologue of the round ligament of higher mammals. Its occurrence is one of the most noteworthy features of the female urinogenital system of Canolestes. I am unable to detect any trace of a similar ligament in Marmosa. A round ligament, 
apparently of similar character, is recorded by Hill (Proc. Linn. Soc. N. S. W., XXIV, p. 46, I899) for Perameles and Macropus.

The bladder in its posterior half and the adjoining part of the urogenital sinus have their ventral surfaces connected with the abdominal wall at the linea alba by a vertical membrane, the "Ligamentum vesicae medium" of Brass and Hill. The bladder is also attached at the base laterally by a fold on each side running forward into the broad ligament. The ureters pass dorsad of the uteri and dorso-laterad of the uterine neck, enveloped in the broad ligament, and enter the base of the bladder dorso-laterally, passing between the vaginal cul de sac and the lateral vaginal canals and parallel to them.

The uterine necks are very closely attached to each other along the median line but may be separated without destruction of their walls to the beginning of the median vaginae. The os tincae, however, are completely coalesced and in the virgin female examined they are of extraordinary size, extending the full length of the vaginal cul de sac and having thick, slightly rugose walls. They are attached dorsally and ventrally by strong septa, forming two distinct lateral vaginal chambers. In an older female they were found to be relatively much smaller.

The thin-walled vaginal cul de sacs extend nearly to the base of the bladder on its dorsal surface and are attached to it and to the urogenital sinus by connective tissue, but without direct communication in the virgin female specimen examined. In a pregnant and probably multiparous female a possible connection was observed between the median vaginae and the urogenital sinus. An irregular opening was found but some destruction of tissue had occurred before the specimen was examined, so the point needs verification. If this should prove to be of regular occurrence it would be an important indication of relationship to the diprotodonts, for it is essentially characteristic of most of them.

The lateral vaginal canals leave the median vaginae in a dorsal direction and turn sharply caudad and then craniad in several convolutions, nearly to their origin, where they again turn and run directly caudad to their endings on the lateral walls of the urogenital sinus posterior to the ureters. The length of one of the canals fully extended is ro $\mathrm{mm}$. or two-thirds longer than the uteri. In this respect, therefore, Canolestes shows some approach to the condition in Macropus, where the vaginal canals are always longer than the uteri. The urogenital sinus from the base of the ureters to the cloaca is $9 \mathrm{~mm}$. long in a young female.

The rectum and the urogenital sinus open into the common cloaca at about the same level, $3 \mathrm{~mm}$. from the lips of the external orifice. The clitoris is situated in a pocket of membrane on the dorsal wall of the 
sinus and is a highly developed organ, deeply bifid, and attached only at its base. It consists of two long, smooth, and sharply pointed rods the apices of which reach nearly or quite to the cloacal opening of the urogenital sinus. Each of these divisions is sharply and deeply grooved on the dorsal surface of its basal half. The entire organ is $3.5 \mathrm{~mm}$. in length and of this each fork is $3 \mathrm{~mm}$. The form of the clitoris, therefore, is not very unlike that of the divided glans penis of the male. In an old female, the clitoris appears to be a single organ, hanging free, and having several longitudinal plications and a transverse cleft behind its rather blunt apex.

The cloaca is inclosed in an extensive muscle, the sphincter cloacae. It surrounds the cloacal orifice and spreads over the large rectal glands, terminating anteriorly in a transverse plexus of nerves and muscle fibers which is attached to the ventral surface of the urogenital sinus and which sends fibers and fascia into the pelvic cavity. The relations of the rectal glands have been described elsewhere (p. 76 ).

From the comparative standpoint, the female reproductive organs of Canolestes are more significant than those of the male. They are distinctly of a diprotodont rather than a polyprotodont type. This is evidenced at once by the deep median vaginae and the long lateral vaginal canals. Many polyprotodonts give birth to their young by way of the lateral vaginae. In fact this seems th 3 only method possible in such forms as Didelphis which have extremely small median vaginae. Certain others do not conform to this rule, as Perameles, which Hill (r 899) has shown to have a parturition somewhat less perfected but similar to that of the Macropodidae, in which the foetus has direct passage from the median vaginae to the urogenital sinus and thence to the exterior. In certain other respects the reproductive system of Perameles is regarded by Hill as primitive. Data are not available as to the phenomena of parturition in all diprotodonts, but the direct median passage has been observed, according to Fletcher (fide Hill, I 899, p. 74), in no less than twelve species of Macropodidae. Hill found it also in Tarsipes, and, although it is evident that much study of well prepared serial sections is necessary for a thorough understanding of the subject, the inference is very strong that those forms having large median vaginae and relatively long convoluted lateral canals give birth to the young by median rather than lateral passage, some by an opening from the median vaginae to the urogenital sinus which becomes permanent after the first parturition, and others by a rupture at this point and subsequent closing for each parturition, the connection being made through a "pseudo-vaginal canal" in the connective tissue. This method of parturition is at least functionally an approach to the method in the higher mammals having 
a single vagina, but is regarded as a special development not necessarily leading to nor derived directly from the single eutherian vagina. That it should have been independently developed in different phyla seems highly improbable. Hill's statement (p. 74) in regard to this is as follows: "That this median passage has not been twice independently acquired within the Marsupial Class I am convinced, and its existence in Perameles in a condition so obviously unspecialized and in association with such a persistently embryonic condition of the genital organs, tends to suggest that its acquisition is of ancient date." Elsewhere he says: "Finally, as regards parturition, it seems to me that the foregoing discussion sufficiently upholds the conclusion that Perameles, in respect to the phenomena connected with that process, in no way stands alone amongst Marsupials as an aberrant and specialized type, but quite on the contrary, exhibits more primitive features in the mode of birth of the young than are shown by any other Marsupial hitherto described as possessing a direct median passage. That the direct passage in Perameles is in a much more primitive condition than that of Macropods, will, I think, be admitted without question. Indeed, the condition of the passage in Perameles can only, in my opinion, be regarded as the precursor of the Macropine one and as showing us in use today the earliest stage in the evolution of that direct median passage which reaches its highest development in the specialized Macropodidae."

So far as gross examination indicates, Canolestes is more advanced than Perameles and, although final proof must await microscopic study of serial sections, all the present evidence points to the conclusion that the direct median passage is nearly or quite as well-developed in Canolestes as it is in various Australian diprotodonts. In a virgin female, the median cul de sac extends almost to contact with the urogenital sinus and in an old female, openings were found in the vaginae and the adjacent surface of the sinus, but the connection between them was imperfect and possibly due to adventitious circumstances in the history of this particular specimen.

\section{ALIMENTARY CANAL.}

Mouth.-The hard palate has numerous transverse ridges. Including the one at the posterior edge of the palate, there are nine of these ridges that extend completely across the palate and five which do not but merely reach to varying points on either side of the median line (P1. XVIII, Fig. 3). The ridge between the last molars has 8 to ro forwardly directed protuberances giving it a somewhat serrate appearance. The ridge between or just behind the canines projects forward in 


\section{Field Museum of Natural History - Zoölogy, Vol. XIV.}

a sharp angle. Of the incomplete ridges, the hindmost is scaroely more than a rounded papule, the next one is posteriorly angled, two others are straight and another has its ends directed backward. This is the condition found in a male specimen. A female shows a similar but not identical arrangement, two of the short ridges being absent and one of the long ones, that between the third molars, being interrupted in the middle.

The soft palate and the naso-pharyngeal cavity are relatively long. The naso-pharyngeal isthmus is guarded on the dorsal side by several slender filaments directed anteriorly.

Tongue.-The tongue ( $\mathrm{Pl} . \mathrm{X}$, Figs. 3 and 4 ) is rather slender and somewhat pointed at the tip. In a male specimen, it measures $22.5 \mathrm{~mm}$. from the tip to the epiglottis and $4.5 \mathrm{~mm}$. in greatest width. The under surface is sharply keeled and from the median ridge a longitudinal flap extends from the basal part of the tongue to the tip. A slight median raphe is indicated on its upper surface from near the middle almost or quite to the tip.

The upper surface is densely covered with coronate papillæ. No microscopic preparations were made, but under a strong binocular lens these coronate papillæ appear simpler than those of Didelphis, not being strongly hooked and including relatively few secondary hairlike papillæ. No differentiation of the anterior from the posterior coronate papillæ was detected (see Poulton, I883, p. 6r8).

Fungiform papillæ are scattered somewhat irregularly among the coronate papillæ and are rather small and disklike. There is nothing comparable to the highly developed fringe of fungiform papillæ on the end of the tongue which is found in Didelphis and Marmosa. ${ }^{1}$

The circumvallate papillæ are as usual three in number. They are about equidistant from each other and the angle formed by the posterior one is somewhat obtuse. Each has a peculiar retrorse process developed on its dorso-caudal surface, giving it a form resembling a helmet. Similar backwardly directed circumvallate papillæ were found by Poulton (1. c., p. 6ro) in Dasyurus and said by him to be unique in his observations of the tongues of various marsupials.

Filiform papillæ are present in small numbers in the usual position. No lateral organ could be discerned.

On the whole, the tongue of Canolestes seems much more similar to

1 This characteristic of these American forms appears not to have been noted previously, since the specimen (Metachirus) used by Poulton (1.c.) lacked the extreme tip. The tongues of Didelphis and Marmosa are broad at the tip and thickly studded with somewhat elongate and pedunculate fungiform papillæ, giving the end of the tongue a fringed or dentate appearance not reported for any other marsupials. 
that of Australian than American forms. It agrees quite closely with Poulton's description of the tongue of Dasyurus and that in turn is said to be of the same type as Halmaturus.

Oesophagus. - The oesophagus from the larynx to the stomach is 30 $\mathrm{mm}$. long. It has membranous attachment to the vertebrae and lies just dorsad of the aorta until it passes through the diaphragm and almost immediately joins the stomach in the middle of the lesser curvature. Its lining has four to six longitudinal plications which continue into the lumen of the stomach and hang free there. This condition of the lining of the oesophagus evidently has general similarity to that reported for most other marsupials except Didelphis. The transverse folds of the lower oesophagus, which are characteristic of Didelphis, are not represented in Cenolestes, but they are absent also in Marmosa and Peramys. ${ }^{1}$ The lower oesophagus of Marmosa is smooth, however, and markedly different from that of Canolestes.

Stomach.-The stomach (P1. VII, Figs. 4 and 5) of a male spocimen in somewhat distended condition measured $24 \mathrm{~mm}$. in longitudinal diameter and $16.5 \mathrm{~mm}$. in transverse diameter. It is regular in form, roughly elliptical, with the cardiac expansion only slightly exceeding the pyloric. In gross examination, the interior shows three marked divisions which may be called oesophageal, cardiac and pyloric, without regard to their histological structure. The first or oesophageal division is the smallest and consists of thin plications or lamellae surrounding the orifice of the oesophagus and extending along the lesser curvature to a point nearly midway between the oesophagus and the pylorus. The cardiac division consists of a strongly differentiated glandular area, forming a compound gastric gland comparable, at least in certain respects, to the gastric glands of Phascolarctos, Phascolomys, and Manis. It is developed principally on the sides of the stomach, being separate on the two sides toward the pylorus but uniting around the cardiac side of the oesophagus. In an undistended stomach, it is plainly evident from the exterior through the rather thin outer muscular walls. From within it appears as a thick, elevated, and well circumscribed area of glandular tissue inclosing 40-60 slitlike openings (P1. VII, Fig. 5). Especially toward the cardiac end of the stomach, these openings have a distinctly linear arrangement and seem to be the result of an amalgamation of the usual rugae of the stomach. In an undistended specimen there is one prominent fold or ruga which extends three-fourths of the way to the pylorus and runs about midway between the compound gland and the greater curvature. The pyloric division of the stomach

1 This is a rather important distinction between Didelphis and Marmosa which, so far as I am aware, has not been noted previously. 


\section{Field Museum of Natural History - Zoölogy, Vol. XiV.}

is relatively smooth and undifferentiated and is continuous with the area along the greater curvature to the fundus.

The differentiation of areas of the stomach in Canolestes is of course a specialization and as such is referred to in discussion elsewhere, but in view of the wide range of the character of the stomach in marsupials, it is difficult to draw any direct inference of relationship. In fact, the stomach of Canolestes is unique and serves to strengthen the general conclusion that the animal stands by itself quite as independently as any of the highly specialized Australian forms.

Intestines. - The intestines lie in the abdominal cavity with the main mass of the small intestines, or Meckel's tract, in ventral position. The duodenal loop is well differentiated. On leaving the stomach (from which it is separated by the pyloric sphincter, showing externally as a distinct band $2 \mathrm{~mm}$. in width), it passes slightly dorsad, then caudad and turning sharply on itself runs cephalad a short distance ventrad of and almost in contact with the colon, and thence it passes ventrad to the center of the mass of Meckel's tract. Throughout this course it appears to have slightly thicker walls than the distal part of the small intestine and in an alcoholic specimen is lighter colored. The diameter of the collapsed duodenum just beyond the stomach is nearly $9 \mathrm{~mm}$. The duodenum is weakly attached to the dorsal mesentery near the end of its loop and very close to the colon. The folds of the intestines are simple and on a continuous mesentery but cannot be straightened in a preserved specimen without cutting. They seem to be in the condition figured as stage II by Beddard (1908, p. 592, Fig. I 2I).

The large intestine is relatively very short and straight and has no indication of loops. It is scarcely more than $30 \mathrm{~mm}$. in length as compared to $340 \mathrm{~mm}$. for the small intestine from the pylorus to the caecum. The hindgut is imperfectly divisible into colic and rectal parts. The colon has the usual longitudinal folds on its inner surface but at its termination, that is at the beginning of the rectal part for a distance of about $4 \mathrm{~mm}$., both the large primary folds and the interspaces are crossed by numerous delicate transverse ridges which in relaxed condition appear as undulating transverse lamellae. Externally the rectum is covered with longitudinal muscle fibers, somewhat more numerous dorsally than ventrally.

The caecum is very small, scarcely more than a vermiform appendix (P1. VII, Fig. 3). In one specimen it is only $4.5 \mathrm{~mm}$. in length; in another it is 5.5. It opens into the intestine by a simple aperture and its inner surface does not differ from that of the ileum. Immediately distad of its opening the colon begins with a muscular, plicate inner surface in contrast to the villous surface of the ileum. 
The short colon combined with the small caecum in Canolestes is contrary to the usual condition in marsupials and is most nearly met in certain of the dasyures. Although the short colon is perhaps primitive, the small caecum is obviously a secondary condition.

\section{GLANDS.}

Liver.-The liver is relatively large in size. It has three primary divisions, the left lateral, the right central and the right lateral, the last being subdivided into right lateral proper, caudate and spighelian (P1. VII, Fig. 2). The largest lobe is the left lateral, although the right central or cystic lobe almost equals it and the combined bulk of the three subdivisions of the right lateral is nearly or quite as great as either of the other primary divisions. In a male specimen hardened by preservative, the right central lobe is $\mathrm{I} 8 \mathrm{~mm}$. wide; the left lateral has practically the same width but is slightly more bulky.

The large left lateral is entire without trace of a division, although a slight projection of its dorsal part is somewhat separated to curve around the oesophagus. In Didelphis and Marmosa there is at least one cleft in its lateral boundary partially dividing it into left lateral and left central.

The right central is entire except for one fissure extending about halfway to its base and inclosing the gall bladder in a wholly concealed position similar to that in some other marsupials but unlike that of Didelphis in which it is exposed and in contact with the diaphragm.

The right lateral proper lies next to the right central and is regular in shape although its dorsal border has a slight cleft. It is about half as large as the right central and its dorso-caudal border is in contact with the kidney. Although for the most part separate from it by a deep fissure, it is united at its base to the caudate.

The caudate is in ventral position and incloses a considerable part of the right kidney. It has an anterior projection and two posterior ones through the inner of which the vena cava passes.

The spighelian lobe arises from the base of the caudate and divides into two lobes almost at right angles to each other, one appressed to the left lateral and the other hanging free caudad of it and ventrad of the caudate lobe. Its peduncle attaches it to the caudate but the portal vein and the ductus choledochus pass between the free surfaces of the caudate and the spighelian. The pancreatic duct and the ductus choledochus unite just before entering the duodenum.

The liver of Canolestes differs from that of Didelphis and at least some other polyprotodonts in its large bipartite spighelian lobe, in its 


\section{Fieid Museum of Natural History - Zoölogy, Vol. XiV.}

small concealed gall bladder, and in its complete fusion of left lateral and left central lobes. In Didelphis, the spighelian lobe is quite small and undivided. In Antechinomys (Beddard, r908, p. 563) the spighelian is entirely absent and left lateral and left central are completely divided. A spighelian lobe is present in most of the Macropodidae and in one (Dendrolagus), at least, it is bilobate (Beddard, r895, p. r34).

Spleen.-The spleen is suspended from the omentum and the dorsal mesentery and lies closely appressed to the dorso-caudad surface of the stomach. It is an elongate organ with a single triangular lobe directed dorsad from the right hand third of the dorsal border. The spleen thus has a general shape resembling a figure four or a bisected head of a bluntpointed arrow (Pl. VII, Fig. $\mathrm{r}$ ).

Pancreas.-The pancreas is an extensive, much divided gland lying ventrad of the spleen and suspended between it and the intestines over the surface of which some of its smaller digitations run. In common with the spleen it has some attachment to the omentum and dorsally it is connected with the main dorsal mesentery. One long branch of it lies between the principal longitudinal folds of the duodenum. The main pancreatic duct, joined with the common bile duct, enters the duodenum some ro $\mathrm{mm}$. below the pylorus (P1. VII, Fig. 2). The two ducts meet nearly at right angles a very short distance from or practically at the surface of the duodenum. Thence through the membranes of the duodenum there is an appreciable common duct carrying both biliary and pancreatic products to the common opening on the inner surface of the duodenum. At a point nearly opposite the union of the main ducts, the pancreatic duct receives an important branch or accessory duct derived from that lobe of the pancreas which lies along the duodenal fold.

Salivary glands.-The parotid gland (P1. IV, Fig. 2) is extensive and invests the base of the external ear except in its dorsal third. It covers a part of the trapezius muscle, the sternomastoid and all the superficial muscles of the side of the neck. Three lobules are distinguishable, one anterior and two posterior, the dorsal of these latter being the larger. In a male specimen, the length of the gland is $16 \mathrm{~mm}$. and its greatest dorso-ventral depth ro mm. Its duct leads forward crossing the masseter superficially and then, sinking slightly, opens into the mouth near the first upper molar tooth.

The submaxillary gland also is large and is intimately associated with the parotid. It lies in ventro-lateral position relative to the parotid and has a detached lobe lying between its principal longitudinal lobe and the parotid. Its duct was not traced with certainty.

A large sublingual gland lies along the inside of the mandibular 
ramus. Posteriorly it lies between the mylohyoid and the styloglossus muscles and anteriorly it is between the mandible and the genioglossus. It extends from the vicinity of the base of the angular process to the symphysis. Its ducts were not sought but it is evidently independent of the other large salivary glands.

Thyroid.--In a male specimen, the thyroid was found in two elongate pisiform divisions (Pl. VI, Fig. I) lying on the lateral surface of the trachea. The larger anterior one extended from the vicinity of the thyroid cartilage caudad about $4 \mathrm{~mm}$. The smaller lay just caudad in the same longitudinal plane and was about one-third the size of its fellow. In a female specimen, only one thyroid was detected.

Thymus.-All the specimens examined were fully adult and show only traces of the thoracic thymus. No indication could be found of the presence of the superficial cervical thymus regarded as characteristic of the Diprotodontia by Symington (I 898 ) and Johnstone (I9OI). Four distinct fatty lobes lying ventrad of the carotids and cephalo-ventrad of the base of the heart were noted in one specimen as probably representing the thymus.

Mammae.-There are four mammae, regularly arranged, two on each side of the abdomen inside the thighs. This is the number present in the majority of diprotodonts and less than the number usually found in the polyprotodonts. In comparison with the Didelphiidae, however, the number is perhaps less important than the regularity of arrangement, for members of that family are distinguished from all other marsupials by having the mammae present only in odd numbers and more or less asymmetrically arranged. The number in diprotodonts never exceeds four; in polyprotodonts it is usually more than six, although Thylacinus, Myrmecobius and a few species of Phascologale have only four, while the greatly specialized Notoryctes has but two. The following are the number found in the principal marsupial genera:

\section{POLYPROTODONTIA:}

Peragale

Perameles

Chæropus

Thylacinus .

Sarcophilus

Dasyurus

Phascologale

Sminthopsis

Myrmecobius

Notoryctes .

Didelphis

Metachirus

Lutreolina

Philander

Marmosa

Peramys

\section{DIPROTODONTIA:}

8
$6-8$
8
4
4
$6-8$
$4-10$
$8-10$
4
2
$5-13$
$7-9$
9
7
$9-15$
$9-27$

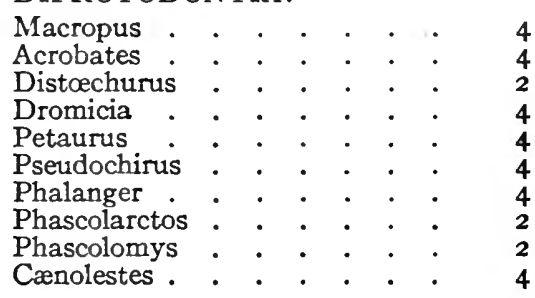


Miscellaneous glands.-The smaller sebaceous and lymphatic glands were not systematically sought but a few have been noted in the course of dissecting other parts.

Three rather conspicuous axillary glands are found imbedded in a fatty mass lying laterad of the cutaneus maximus and partially enclosing the elbow. The largest of these is long ovate pyriform and lies dorsolaterad of the cutaneous muscle, projecting also over the latissimus. It is about $4 \mathrm{~mm}$. long and $2 \mathrm{~mm}$. wide. Two others, slightly smaller, lie together ventro-laterad of the cutaneus maximus.

Two large superficial inguinal lymphatic glands in the male are situated in the deposit of fat ectad of the cremaster muscle. In one specimen, the larger of these glands measured $7 \mathrm{~mm}$. in length and the other $5 \mathrm{~mm}$.

A rather prominent precardial lymphatic gland is situated in the acute angle between the base of the oesophagus and the fundus of the stomach (Pl. VII, Fig. 4). In one male, this gland measured $4 \mathrm{~mm}$. in length, being approximately equal to the diameter of the oesophagus.

An ovoid lymphatic gland about $3 \mathrm{~mm}$. in greatest diameter is situated in the angle between the sternomastoid, omohyoid, and digastric muscles (Pl. IV, Fig. I). It lies close to the trachea and is separated from it only by the carotid blood vessels.

In the male, a large paired lymphatic gland (P1. VIII, Fig. 2) lies laterad of the large Cowper's gland (No. 3). It is about $6 \mathrm{~mm}$. long by $3.5 \mathrm{~mm}$. in width. Its wider end rests in the angle at the base of the penis pouch between the base of the penis and the bulb of the corpus spongiosum. Its smaller end lies in connective tissue and fat on the side of the large Cowper's gland. It is not directly connected with the rectum and has no duct that is apparent.

In the female, there is a large ovate pyriform rectal gland lying on each side of the cloaca with its small end directed dorsally and a duct leading from near its large end to the ventro-lateral wall of the cloaca slightly caudad of the opening of the rectum. The gland is $4 \mathrm{~mm}$. long and has a tough thickened wall somewhat differentiated from the glandular mass within.

\section{RESPIRATORY SYSTEM.}

Plate X, Fig. 2.

Lungs.-The left lung is entire. In two specimens, the right lung has two lobes besides the azygos and the anterior of these is slightly notched at a point corresponding to that where a conplete division is found in the d:delphids. In a third specimen, the right lung was found to be trilobate although the anterior division was relatively small. The 
evidence is therefore inconclusive as to whether the normal arrangement in Canolestes is bilobate or trilobate. In most marsupials, except the wombat and some of the Macropodidae, it is said to be trilobate. In several specimens which I have examined of Didelphis, Marmosa, and Peramys it is trilobate. In Canolestes, there is at least a tendency for it to be bilobate.

Trachea.-The tracheal rings are about nineteen in number and are not united dorsally but separated by a broad interspace.

Larynx.-The epiglottis is large and elevated, and has a slight anterior emargination which is most evident in the cartilage after removal of the soft external membranes. It is attached to the thyroid cartilage ventrally. The thyroid is continuous medio-ventrally with the cricoid and its bony wings partially inclose the cricoid laterally. Its anterior or superior horn has ligamentous attachment to the thyrohyal; its posterior or inferior horn attaches similarly to the outer extremity of the cricoid which is here very slightly ossified. The arytenoids are large, subtriangular and partially united dorsally. The cartilage of Santorini is developed into a prominent curved protuberance which is continuous with the high muscular crest of the arytenoid which, meeting its fellow of the opposite side, nearly closes the cavity of the larynx with the exception of a very small passage on the ventral side.

\section{CIRCULATORY SYSTEM.}

Owing to the condition of the material, no attempt was made to study the circulatory system in detail. The heart is as usual in marsupials. In comparison with that of Didelphis it shows no very important characters. In ventral view the auricles meet over the base of the pulmonary artery, entirely concealing it, whereas in Didelphis it is broadly exposed. The bases of the right subclavian and right carotid are very closely approximated and both join the left carotid scarcely higher than its junction with the aorta. In Didelphis there is an appreciable space between the origins of the right subclavian and right carotid.

\section{SKELETON.}

Plates XI-XVI.

\section{Cervical Vertebrae.}

Plate XI.

The seven cervical vertebrae are freely movable and distinct. As in the majority of marsupials, the only one having a prominent spinous process is the axis. The neural arches have relatively thin, flattened 


\section{Field Museum of Natural History - Zoólogy, Vol. XiV.}

laminae which are weak as compared to the bodies. They are well separated from each other and have no tendency to imbrication. All except the first and seventh have vertebrarterial foramina. Only the first and second have hypapophyses.

The atlas is practically entire, having a body which evidently ossifies in normal manner and having no large foramina for the passage of nerves and blood vessels. A very minute perforation (P1. XI, fig. I, $n$.f.) at the posterior dorsal base of the transverse process is of doubtful significance, but its position does not seem to indicate homology with either of the usual foramina of the atlas. A perforation with exactly similar relations is found in the extinct Borhyaena (Sinclair, I9o6, p. 350, Pl. LIII). The cephalic border of the neural arch of the atlas is nearly straight for about the width of the neural canal and thence on either side it is angled latero-caudad to meet the base of the cephalic articular process. A groove between this angle of the border of the arch and the articular process serves for the passage of the first cranial nerve and supplies the office of the foramen found in most other marsupials. That this foramen is formed by the closing of the points bounding the mouth of this notch is shown by immature examples of Didelphis in which the union is slightly cartilaginous. In the adult of Didelphis, the foramen is well isolated as it is in Philander, Dasyurus, Myrmecobius, Thylacinus, Sarcophilus, Phascologale, Trichosurus, Petaurus, Petrogale, Macropus, Phascolomys, and Phascolarctos. The only living marsupial genera agreeing with Canolestes in this open "intervertebral notch" are Marmosa, Peramys, and Perameles. The atlas of Perameles is otherwise similar to that of Canolestes, but that in Marmosa and Peramys resembles it still more closely, differing chiefly in the pedunculation of the transverse process and its slight obliquity and in the tendency to the formation of a vertebrarterial canal with a partly cartilaginous border.

The transverse process of the atlas has decided obliquity to the spinal axis and is relatively short and broad with no constriction at its base and with only a shallow groove between it and the posterior zygapophysis in the position corresponding to the usual course of the vertebrarterial canal. The only genera examined in which the arterial canal has complete bony boundaries are Philander, Dasyurus, Sarcophilus, Myrmecobius, and Petaurus. In all others except Canolestes, however, the transverse process is pedunculate and in some, as Phascologale and Peramys (Marmosa and Didelphis to a lesser extent), there is a slight bony elevation on the pedicel of the arch cephalad or laterad of the postzygapophysis from which a cartilage extends to the posterior angle of the transverse process and forms the arterial canal. So far as material at hand shows, the gradual formation of the vertebrarterial canal of the 
atlas is illustrated in various stages from the wide open channel to the heavy bony ring in a series of forms the sequence of which would be about as follows: Canolestes, Perameles, Didelphis, Phascologale, Peramys, Dasyurus, Philander, Petaurus, Myrmecobius. In this series, Didelphis is about midway between the extremes and various other forms, including the macropods and phalangers, would occupy a similar position.

The atlas in Canolestes has no trace of a spinous process. The body of the atlas is directed downward and slightly forward, being almost vertical and nearly at right angles to the laminae of the arch. Its lower part is thus a thin triangular plate with a hypapophysis or median ridge on its posterior aspect and forming a pointed tubercle at its apex. The odontoid process, therefore, does not have its usual flattened seat but rests on the sharp edge of this nearly vertical body of the atlas. This part of the atlas differs from that of practically all other marsupials, although it is closely approached in Phascologale, Marmosa, and Peramys. The neural canal of the atlas is slightly wider than deep and measures $4 \mathrm{~mm}$. $3.4 \mathrm{~mm}$.

The imperforate condition of the atlas in Canolestes, both anteriorly and posteriorly, is doubtless primitive. It is found in the monotremes and among living marsupials examined only in Marmosa, Peramys, and Perameles. ${ }^{1}$ It is characteristic also of the extinct Borhyaena but, so far as known, of none of the other forms of the Santa Cruz beds. The atlas, however, is unknown in all the fossil forms placed by Sinclair (Igo6) in the family Canolestidae. In other mammals, including all the higher groups, no instances have been found in which both the atlanteal and vertebrarterial foramina are absent.

The axis has a high laminate spinous process similar in general to that of the majority of marsupials. The anterior wing of this process is not equal to the posterior and reaches only to the posterior part of the dorsal surface of the atlas. The posterior wing overhangs the third cervical. The front border of the neural arch seen from the side is a continuous curve, and the prominent dentation found in Didelphis, Peramys, Marmosa, Philander, Trichosurus, Petaurus, and some others is absent. At the base of this curve is the prezygapophysis which is an oval facet only very slightly elevated from the pedicel of the arch. The odontoid process is completely ankylosed in the adult and forms a simple projecting knob of the usual character. The body of the vertebra is a fairly thick shield-shaped piece with two relatively large foramina in the floor of the neural canal. The hypapophysis is peculiar. It is

${ }^{1}$ In Notoryctes the atlas is imperforate, but this is obviously due to extreme specialization and has no significance in this connection. (See Stirling, 1891.) 
divided into two parts one of which probably appertains to the odontoid and the other is the usual hypapophysis of the axis. The anterior of these is a sharp hooked process rising from the base of the odontoid and projecting backward along the median line. The posterior process is a ridge rising beneath this hook and gradually becoming more elevated to terminate in a tubercle which has slight projection caudad beyond the centrum and thus to some extent effects imbrication with the front edge of the body of the third vertebra. In Marmosa there is a prominent axial hypapophysis and in the skeleton of a half-grown Didelphis with the odontoid still distinct there is a small median knob but in adults I find nothing in any marsupial comparable to the hooked process described above. It very strongly suggests the large recurved hypapophyses of Ornithorhynchus. The posterior border of the neural arch in lateral view presents an even curve from the spine to a prominent angle above the postzygapophysis. The neural canal has the outline of a horseshoe and its width and depth are nearly equal.

The transverse process of the axis has a superior and an inferior division, each a small backwardly directed projection from the caudal aspect of the pedicel of the arch, ventrad of the postzygapophysis and caudad of the prezygapophysis. The extremities of these processes are articulated to the slightly produced basal angles of a small, distinct, subtriangular pleurapophysis or cervical rib which serves to complete the boundary of the arterial canal and which is obviously the homologue of the fully ankylosed processes serving the same purpose in the succeeding vertebrae. In a fully adult animal this cervical rib has only cartilaginous union with the vertebra and in the undesiccated specimen it is freely movable (Pl. XI, fig. 7). It is essentially similar to the persistently distinct cervical ribs in Ornithorhynchus and in reptiles. It has not been reported among marsupials or higher groups except in Perameles and Phascologale. In Perameles lagotis, it is noted by Owen (Trans. Zool. Soc. Lond., II, p. 394, I84 I) in a single instance. The only skeleton of Perameles ( $P$. nasuta) I have been able to examine, has the axial pleurapophysis fully ankylosed. Whether it is normally so in this genus, therefore, is uncertain; but its persistence as a distinct part in Canolestes is none the less significant. Beddard (I902, p. II9) mentions a separate axial rib for Phascologale.

The third, fourth and fifth cervicals are not peculiar and resemble each other in general characters. In the third the neural canal is relatively deeper, its vertical and transverse diameters being nearly equal, whereas in the fourth and fifth the width considerably exceeds the depth. In the third the spinous process is very slight; in the fourth and fifth it is a low but distinct mammillate process. In all three the inferior 
branch of the transverse process is only slightly developed. The superior branch of the transverse process is directed obliquely backward and upward and at its base is pierced by the arterial canal. In the fifth it is slightly thicker than in the third and fourth, has less backward deflection and is definitely faceted at the tip.

The sixth cervical is similar in general features to that in the majority of marsupials. The arterial canal perforates the base of the transverse process as usual but it is to be noted that the dorsal wall of the canal is very much thicker than the ventral. The inferior branch of the transverse process is expanded into a dolabriform plate practically parallel with the spinal axis. This has only very slight forward projection but is extended caudad nearly or quite to the plane of the centrum of the first thoracic vertebra.

The seventh cervical has a slightly higher spinous process than the three preceding vertebrae, but the distinction is not marked. It has the superior branch (diapophysis) of the transverse process with its tubercle directed almost at right angles to the spinal axis in the horizontal plane of the body of the vertebra. The inferior branch (parapophysis) and consequently the arterial canal are obsolescent, that is, they are variable, being present in some specimens and reduced or absent in others. In one specimen, the arterial canal on the left side of the vertebra is enclosed by the merest bony thread representing the parapophysis and having no tubercle. On the right side of the same vertebra, the condition is similar but the canal is exceedingly small, scarcely one-tenth as large as that on the left side. In several other specimens, the seventh cervical is quite imperforate, the vertebral side of the base of the transverse process being merely grooved (Pl. XI, figs. 4-6). In a single specimen of Phascologale, the lower boundary of the arterial canal is incomplete, indicating a condition very similar to that in Canolestes; in a single specimen of Sarcophilus, one side is perforate and the other imperforate. The seventh cervical is imperforate in Trichosurus, Dasyurus, Perameles, Sarcophilus, Didelphis, Marmosa, and Peramys. The arterial canal has complete bony boundaries in Thylacinus, Petaurus, Philander, Phascolomys, Phascolarctos, and the Macropodidae. It is complete also in the extinct genera Borhyaena and Cladosictis. Thus in the majority of diprotodonts the seventh cervical is perforated and in the majority of polyprotodonts it is imperforate, although the perforate condition is more primitive. In this as in other respects, therefore, Canolestes combines the characters of the two groups.

None of the cervicals have foramina piercing the lateral $\pi^{-11}$ ls of the neural arches like those in some other marsupials (Thylacinus, Dasyurus, Didelphis, etc.). 


\section{Field Museum of Natural History - Zoölogy, Vol. XiV.}

Considered as a series, the cervical vertebrae of Canolestes seem more similar to those of Perameles than of any other marsupial. The imperforate atlas, the persistent cervical rib attached to the axis, the evenly curved front edge of the neural canal of the axis, and the imperforate seventh vertebra all are found in Perameles. The inferior lamellae of the transverse processes of the third, fourth, and fifth cervicals are much larger in Perameles than in Canolestes and this constitutes the principal distinction between them. In comparison with those of other American forms, the cervicals of Canolestes show a general resemblance to those of Marmosa and Peramys and, among Australian small polyprotodonts, to those of Phascologale, but the characters of the atlas and axis are distinctive. With the highly modified cervicals of Didelphis, comparison is scarcely necessary.

\section{ThORACIC VerTebrae.}

There are thirteen thoracic vertebrae as in all other marsupials with the exception of Phascolarctos (I I), certain species of Phascolomys (I 5), and Notoryctes ( $\left.{ }_{5}\right){ }^{1}$ The spine of the first thoracic is scarcely higher than that of the last cervical (Pl. XII, fig. 4). The second spine is slender and much the highest of the series, measuring about $3.5 \mathrm{~mm}$. The third to the eighth also are slender and progressively shorter and more recumbent. The ninth is still shorter, and although directed backward, it is longer basally and less acicular in form. The first thoracic differs from the last cervical mainly in the elevation of the transverse process and in its differentiation for articulation with the rib. In most marsupials there is an abrupt transition from the last cervical to the first thoracic, especially in the length of the spinous process, but in Canolestes this break is between the first and second thoracics. The only form examined which agrees with it in this respect is Perameles nasuta. In Phascolarctos, the spine of the first thoracic only slightly exceeds that of the last cervical but it is nevertheless the longest of the thoracic spines and there is nowhere any marked break in the series. Owen (I 84I) in his paper on the osteology of marsupials does not mention a relatively short spine for the first thoracic of Perameles and it is therefore possible that it is not found in all species of the genus.

The tenth is the anticlinal vertebra and its spinous process is a low upright plate with a straight crest occupying practically the entire length

${ }^{1}$ In a single specimen of Didelphis paraguayensis from Ceara, Brazil, there are fourteen ribs instead of the thirteen normal in Didelphis. Moreover, there are twenty vertebrae in the thoracico-lumbar series, the extra vertebra apparently being the fourteenth, corresponding to the extra rib. This is probably an abnormality, but the examination of other specimens of this species is desirable, especially since, as noted elsewhere (p. 86), it has other skeletal peculiarities. A pouch specimen of $D$. p. andinus has the normal thirteen ribs. 
of the dorsal surface of the arch. The eleventh, twelfth and thirteenth spines are similar, but although only slightly elevated, they are definitely directed forward instead of backward. The thirteenth is slightly lower than the eleventh and twelfth and closely resembles the spines of the succeeding lumbars.

The position of the so-called center of motion sharply distinguishes Canolestes from all living American polyprotodonts and aligns it with the majority of Australian forms, as well as with most higher mammals. In Didelphis, Marmosa, Philander, and Peramys there is practically no anticline since the spines of all the thoracic vertebrae and of all the lumbars, except the last or at most the last two, are inclined backward. The only other marsupials having this characteristic are the koala, the wombats, and certain of the phalangers. In all the Australian polyprotodonts and at least in the macropods of the diprotodonts the center of motion is in the posterior thoracic vertebrae and in most of these forms the anticline is very marked. ${ }^{1}$ This is also the case in Canolestes and in the Patagonian fossil form Cladosictis. Whether the condition in the didelphids is palaeotelic or not is problematical. Essentially the same condition is found in the monotremes and edentates, and it is usual among reptiles, whereas among higher mammals it is rare and generally correlated, perhaps secondarily, with high specialization, as in seals and anthropoids. In practically all insectivores, rodents, bats, carnivores, ungulates, and in Primates, except the higher apes and man, there is a marked convergence of vertebral spines to a center of motion. In agreeing with the majority of mammals in this respect, therefore, Canolestes at least shows a lack of affinity with the didelphids.

The first nine thoracic vertebrae are essentially similar in form. The arches and pedicels, although progressively increasing in length, are relatively narrow and each vertebra is separated from the succeeding one dorso-medially by a considerable space between the projecting zygapophyses. Each has a transverse process bearing a facet for the tubercle of a rib. The tenth begins to assume the character of the lumbars. It has only a trace of a facet for the tubercle of a rib, its spinous process is low and ridgelike instead of spinous, its laminae and pedicel are broad and its body is less compressed. The eleventh has these characters further developed. There is no trace of a lateral rib attachment and posteriorly there is a tiny pointed accessory process below the postzygapophysis. In the twelfth and thirteenth this accessory process is slightly larger and in these the prezygapophyses begin to turn upward, but there is only a slight rudimentary mammillary process.

${ }^{1}$ In the single skeleton of Sarcophilus examined there is a double anticline, one at the eleventh thoracic and another at the third lumbar. 


\section{Field Museum of Natural History - Zoölogy, Vol. XIV.}

In the character of the first thoracic and essentially in other respects, the thoracic series of vertebrae, like the cervical, resembles that of Perameles more closely than that of any other marsupial. It differs chiefly in the last three thoracics which in Perameles have relatively high spines and prominent mammillary processes.

\section{LUMbar Vertebrae.}

Plate XIII, Figs. $1-2$.

The six lumbars have no important peculiarities. The first three increase slightly in size caudad but aside from the appearance of small inferior anterior transverse processes they scarcely differ from the last thoracic. There are still small accessory processes (anapophyses), the spinous processes are low and ridgelike and the mammillary processes (metapophyses) scarcely protrude beyond the articular surfaces of the zygapophyses. The fourth lumbar retains the ridgelike spinous process, but the transverse process, directed downward and forward, is considerably increased in size. The fifth and sixth lumbars are somewhat differentiated from the others. The transverse processes are longer, the spinous processes, which are directed forward, are higher and more hooklike, and the postzygapophyses are nearer together and turned slightly upward. There are no accessory processes but the mammillary processes are more prominent than in preceding vertebrae and the laminae of the arch are compressed posteriorly for a narrowing neural canal. The ventral surfaces of the bodies of the lumbars are slightly differentiated posteriorly into two slight ridges or tubercles for the psoas muscles. A single median ridge or a long hypapophysis is found in various forms, in Phascologale, Antechinomys, Perameles and to some degree in Marmosa. Double ridges on the posterior half of the body of the vertebra similar to those in Canolestes have been observed in Didelphis, Dasyurus, and Petaurus.

The lumbar series as a whole may perhaps be said to be characterized by the low and inconspicuous condition of the vertebral processes which in most other forms are more highly developed. In this respect there is some resemblance to immature specimens of Didelphis, but even in these the anterior and posterior zygapophyses are connected by a sharp ridge and the accessory processes are broad, heavy, and blunt instead of small and pointed.

\section{Sacral and Caudal Vertebrae.}

Plate XIV.

Two vertebrae have been regarded as sacral, although the second touches the ileum only at the anterior extremity of its transverse process. 
The first has a much broader and heavier transverse process, the whole lateral surface of which is firmly attached to the ileum. The condition is much like that in Phascologale, Sminthopsis, Philander, and Myrmecobius. A slightly greater proportion of the second sacral touches the ileum in Marmosa, Peramys, Dasyurus and Perameles; a still greater in Didelphis, Phascolarctos and Phascolomys; and in Trichosurus, Petaurus, Petrogale and Macropus the second vertebra is almost or quite as fully attached as the first; while in a single specimen of Thylacinus, the second sacral, although heavily ankylosed to the first, does not reach the ileum at all. The two sacrals are ankylosed to each other laterally, but a large perforation persists between their transverse processes. Their general character corresponds closely with that of the last lumbar, the chief differences being in their widened and more horizontal transverse processes and in the greatly compressed zygapophyses, both anterior and posterior in the case of the second, and mainly the postzygapophysis in the case of the first. The first has a well-developed and forwardly directed spinous process similar to that of the last lumbar. The second has a smaller, more pointed spinous process directed slightly backward.

The first caudal and sometimes the second is ankylosed to its predecessor by a narrow bony strip stretching between the extremities of the transverse processes. The first and second are essentially similar to the sacrals except that they have no traces of spinous processes and that the zygapophyses are expanded slightly in the first and greatly in the second, with short rounded metapophyses. The third and fourth caudals are similar to the second but their transverse processes are inclined forward and the first chevron bone is found over their intervertebral space. The fifth caudal is the first to lack the neural canal and postzygapophyses, but the transverse process is still undivided, although somewhat reduced in lateral extent and lengthened antero-posteriorly. In some specimens this transverse process is distinctly emarginate laterally. The sixth caudal is elongate and subcylindrical with rather prominent metapophyses and short crescentic anterior and posterior transverse processes. The succeeding vertebrae are almost exactly similar up to the sixteenth which has only the merest traces of processes. The remainder taper gradually to a very slender tip, the total number of caudals being twenty-seven. The ninth and tenth are the longest of the caudals each measuring about $7.7 \mathrm{~mm}$. Nineteen chevron bones are present from the third to the twenty-second caudals. These have one to four longitudinal ridges on their under surfaces which give them a fluted appearance. They are nearly as wide as the bodies of the vertebrae.

The characters of the caudals are of course of little or no significance in the indication of relationships, but it is of some interest to note that 
the absence of spinous processes on the proximal caudals is a more frequent condition among Australian than American forms. With the exception of Perameles, which has six caudal spines, and Phascolarctos and Phascolomys, with practically complete sets, all the Australian forms examined either have no caudal spines or have them few and extremely rudimentary. In no form are they so completely absent as in Canolestes. On the other hand, there are no less than four in Marmosa, three in Peramys, and three to six in Didelphis. ${ }^{1}$ Slight caudal spines are reported in Notoryctes (Stirling I89r).

The angle at which the sacrals are set between the ilia is less in Canolestes than in most of the polyprotodonts examined and, as in Trichosurus and Macropus, the spinal axis is nearly parallel with the longitudinal axis of the superior outline of the pelvis. Thus, if the caudals are extended in the axis of the sacrals the transverse processes of the fourth and fifth caudals lie below the ischial tuberosity instead of well above it as in Didelphis, Dasyurus, Perameles, Myrmecobius, etc.

\section{Ribs ANd Sternum.}

Plate XII.

There are thirteen pairs of ribs as usual, seven pairs articulating directly with the sternum and six pairs not reaching it. Nine pairs are doubly articulated with the vertebrae by tubercles and capitulae. The succeeding four pairs lack tubercles and arise from the bodies of the vertebrae. The first rib is much heavier than the others and its costal element is longer than the vertebral which is true of no other marsupials examined except Trichosurus and Petaurus. Its costal element is fully ossified, basally flattened and slightly bicipital near its union with the lateral extension of the manubrium. The vertebral element is similarly expanded at the head and narrowed toward its union with its fellow. A strong first thoracic rib, it may be noted, is an edentate character. The remaining ribs from the second to the thirteenth are very slender and subcylindrical, especially the vertebral series. The sternal series are slightly flattened, the seventh being rather noticeably wider than the others. The sternal ribs from the first to the seventh show a greater degree of ossification than usual in marsupials. The seventh pair of costals articulate directly with the caudal end of the last segment of the mesosternum and therefore lie ventrad of the xiphisternum and nearly or quite touch each other at this point (P1. XII, fig. 2). In Didelphis and most other polyprotodonts these ribs only reach the sides of the meso-

${ }^{1}$ Although six caudal spines are distinguishable in Didelphis virginiana, a specimen of $D$. paraguayensis from Ceara, Brazil, has only traces of three and the spine of the second sacral also is undeveloped. 
sternum and are separated at their extremities by the xiphisternum, whereas in Perameles and most diprotodonts the condition is as in Canolestes.

The manubrium of the sternum is like that of most of the smaller claviculate marsupials. It consists of an anterior prong which is somewhat deflected ventrad and slightly faceted dorso-cephalad for the clavicular union. A small triangular lateral process projects from each side of the base of this prong and the body of the bone extends thence caudad as a subcylindrical rod with a slight keel on its ventral surface. In a male specimen the manubrium is $7 \mathrm{~mm}$. in length.

The four segments of the mesosternum are of nearly uniform width throughout without pronounced median constriction or lateral expansion even in the fourth which is scarcely wider posteriorly than anteriorly. The first is somewhat more rounded than the others which are slightly flattened but with their ventral surfaces rather more convex than otherwise.

The xiphisternum is a long slender bony rod with slightly greater width than thickness, but, in general, rounded in form especially proximally where it is somewhat expanded. Distally it has a more abrupt and more flattened slight expansion where it joins the xiphoid cartilage, which is relatively large and scutate. The xiphisternum is separated from the last segment of the mesosternum dorsally by a broad epiphysial cartilage and ventrally by the extremities of the seventh pair of ribs. Hence, although the plane of the dorsal surface of the xiphisternum is continuous with that of the mesosternum, its ventral plane is distinctly higher. This epiphysial cartilage and this relation of the proximal end of the xiphisternum, although apparently trivial, are nevertheless characteristic of the diprotodonts as opposed to the polyprotodonts. In all polyprotodonts examined, except Perameles, both surfaces of the xiphisternum are practically continuous with the corresponding surfaces of the mesosternum and the sixth or seventh ribs do not meet ventrad of the base of the xiphisternum. In all diprotodonts, including Canolestes, the reverse is the case. Perameles, as judged by one specimen, seems to occupy an intermediate position in this respect, for although ribs meet on the end of the mesosternum, the epiphysial cartilage is so reduced as to be scarcely noticeable in a dried specimen.

\section{Pectoral Girdle.}

The clavicle (P1. XII, fig. 5) is well developed and stretches from the sternum to the acromion in the manner usual among marsupials. Its lateral or acromial end is compressed and curved upward. In the adult, the union with the acromion is almost direct, the intervening cartilage being scarcely evident. It is attached also to the coracoid process by a 
broad flat coraco-clavicular ligament. The medial or sternal end of the clavicle is somewhat expanded and deeply notched for the short stout omosternal cartilage ${ }^{1}$ by which it is attached to the front of the manubrium.

The scapula (P1. XIII, fig. 3 ) is less angular than in the majority of marsupials, having a slightly elongate, gently curving outline without sharp prominences. The suprascapular notch, so-called, is not a notch but a long sweeping curve which does not reach its highest point until about two-thirds of the distance from the coracoid process to the vertebral border of the scapula. The axillary border has a slight convexity, instead of being practically straight, and it meets the vertebral border in a modified curve which in some specimens may be a trifle angular. The slightly thickened vertebral border is covered by a small, elongated, cartilaginous, or sometimes partly osseous, suprascapular epiphysis. ${ }^{2}$

The spine is relatively low and continuously deflected so that it is nowhere perpendicular to the fossae on either side of it. Thus the antero-ventral triangular half of the infraspinous fossa is overhung by the flat deflected surface of the spine, which continues to the welldeveloped acromion, turning sharply, forward beyond the triangular metacromion. The coracoid process is a prominent prong with a slight notch in its glenoid surface. The superior fossae are nearly equal in extent, the supraspinous usually having slightly the greater surface. The inferior surface or subscapular fossa presents a deep longitudinal channel opposite the base of the spine and on either side of this the surface is somewhat bulging.

Taken as a whole the scapula of Canolestes is more similar to that of Sminthopsis than to that of any other form which is available for comparison. It agrees with this in its general outline and in its much deflected spine, whereas practically all other forms have a more angular shape, a less deflected and usually higher spine, and a shorter more abrupt suprascapular notch.

\section{Pelvic Girdie. \\ Plate XIII, Fig. 4.}

The pelvis is completely ossified and shows no traces of division in adult specimens. It is relatively long and deep but light in structure. Although it is not especially peculiar in other respects, it is strikingly distinguished from that of all other marsupials by its extremely short

${ }^{1}$ In a skeleton of Philander, this cartilage is partially ossified.

${ }^{2} \mathrm{~A}$ distinct bony suprascapular epiphysis is especially evident in Perameles and Thylacinus. 
pubic symphysis. This scarcely equals the diameter of the acetabulum. The general proportions of the pubes and ischia are thus essentially similar to those in various edentates and insectivores. The rami of the pubis and ischium together with the body of the ischium form a nearly equilateral triangle having its angles respectively at the ischial tuberosity, the pubic symphysis, and the cephalic border of the acetabulum. The pubic ramus is very slender and is slightly ridged on its lateral surface. The ischial ramus is slightly wider and more compressed and the body of the ischium is a trifle more so, but all these bones are relatively slender and the obturator foramen which they enclose is large and subtriangular. The ischial rami are not greatly divergent but more nearly approach the perpendicular than those of any other marsupial and in this respect show resemblance to certain insectivores. The ischial tuberosity is fairly well developed and in some specimens forms a decided protuberance.

The ilium is slender and of the ordinary prismatic shape, being somewhat flattened and everted at the tip. Its ischial border forms a high ridge contimuous with the inner edge of the ischium and to some extent overhanging the anterior part of the obturator foramen in shelflike manner. A slight iliopectineal tubercle is present. The acetabular border of the ilium forms a fairly well marked ridge, especially anteriorly where it separates the gluteal and iliac surfaces of the ilium. The acetabulum and cotyloid notch are of the usual character.

The marsupial bones are well developed, their unusually long straight bases being attached to almost the entire anterior edge of the long ascending pubic ramus, that is, from the symphysis to a point directly below the acetabulum and caudad of the iliopectineal tubercle. The base of the marsupial bone is thus almost as long as the anterior projecting spine and proportionally longer than in any other marsupial. In a male specimen, the marsupial bone measures $5.6 \mathrm{~mm}$. in length as against a base of $4.8 \mathrm{~mm}$., the ratio of base to length being 85.7 . This ratio is approached only in a few forms in which the marsupial bones are notably rudimentary. The following ratios indicate how widely Canolestes differs from the majority of marsupials in this respect: Canolestes 85.7; Didelphis, 40; Dasyurus, 34; Myrmecobius, I5; Sminthopsis, 52; Perameles, I4.2; Trichosurus, 4I; Phascolarctos, 37.3; Petrogale, 9.

\section{ARM AND Forearm.}

Plate XV.

In proportion to the size of the animal, the humerus is large and heavy, being much the largest single bone in the body. It differs conspicuously from that of most marsupials in its great degree of curvature 
and in its prominent flat-faced deltoid ridge. This occupies about threeeighths of the inner proximal part of thefront of the humerus, and instead of forming a single trenchant ridge it presents an elevated flat rhomboidal surface extending downward from the greater tuberosity and ending bluntly and abruptly. Its surface is slightly roughened and lies at a considerable angle to the long axis of the humerus. From its distal extremity the front of the shaft abruptly recedes and forms a long sweeping curve to the condyles. The deltoid ridge or tuberosity has a flattened surface in some other forms, as Perameles, Dasyurus, and Peramys, but in these it is triangular, coming to a point distally. In the fossil form Garzonia patagonica, of which a humerus is figured by Sinclair (1906, Pl. XLIII, fig. II), the deltoid surface is very broad, and although it is less blunt distally, it seems to approach the condition in Conolestes more nearly than does that of any recent form.

The head of the humerus is rather large and has considerable backward extension beyond the axis of the shaft. The external or so-called greater tuberosity is much smaller and less marked than the internal. It is greatly compressed and its outer surface is continuous with the deltoid ridge. Its upper surface is continuous medially with the surface of the head of the humerus. The internal tuberosity is prominent and distinctly separated from the head by a deep groove as well as from the external tuberosity by the bicipital groove. A well-marked ridge extends distad from it parallel with the internal border of the deltoid ridge and terminating in a roughened area for the insertion of the latissimus muscle.

The middle of the shaft of the humerus for about one-third the length of the bone is relatively smooth, slightly compressed, subcylindrical, with only traces distally of the upper continuation of the external epicondylar or supinator ridge. The caudal outline from the head of the humerus to the supinator ridge is a deep sigmoid curve. The distal end of the humerus is broadly and rather abruptly expanded. The internal condyle is prominent and the sulcus between it and the ulnar trochlea is developed as an articular surface for the inner upper lip of the sigmoid cavity of the very obliquely situated ulna. The trochlea is somewhat smaller than the capitellum with which it is continuous. Thus there are three articular surfaces at the distal end of the humerus, a very unusual condition. The third or internal articular surface is fully developed only on the caudal aspect of the bone and does not continue to the front as the trochlea and capitellum do. Although partly confluent, these three articular surfaces are sufficiently distinct from each other, but of course the third or inner one could be regarded as an extension of the trochlea which might be developed without difficulty. 
Nevertheless, I have been unable to find a case of a similar extension in any other marsupial or in other mammals. Its effect is a much wider articulation with the ulna than usual and, as described below, there is a corresponding increase of the articular surfaces of the ulna. Functionally it may have some correlation with the distinctness of the median head of the triceps muscle, and although it might not be remarkable in an animal of fossorial habits, it seems quite incompatible with the distal elements of the arm and leg which are adapted to cursorial life.

A small oval epicondylar foramen is present and the ridge bounding it has a smooth rounded surface directed with a spiral curvature toward the distal end of the deltoid crest but widely separated from it by the smooth shaft. The outer epicondylar ridge is similarly twisted and gradually merges with the surface of the shaft without any abrupt angle or hooked process. Its edge distally is broadly curled so that it presents a relatively broad flattened lateral aspect instead of the sharp edge of most other marsupials. The external epicondyle is little more than the extremity of this ridge. It has a decidedly concave surface for the seat of the sesamoid of the tendon of the supinator brevis muscle. This sesamoid, as mentioned elsewhere, is not present in other marsupials. It is sufficiently distinct to be obvious to the preparator and is usually found in situ in first class ligamentary skeletons.

The ulna is broad, heavy and compressed proximally but rapidly tapers to its distal third which is subcylindrical and scarcely half the diameter of the radius. The outer side of its proximal half is deeply channelled. Its inner side is smooth and convex except an excavated area on the side of the olecranon. The upper lip of the greater sigmoid cavity is unusually broad, especially its inner division which extends well beyond the inner base of the olecranon from which it stands out prominently. Its inner division has the usual position opposite the lesser sigmoid cavity. This broad upper lip articulates with the whole of the posterior articular surface of the humerus and in doing so brings the ulna into a very oblique or nearly transverse position with its broad grooved outer side directed nearly forward. Except at its distal end the ulna is caudad of the radius. The olecranon is relatively thick and heavy with a rhomboidal roughened extremity for various muscle attachments.

The radius has a rounded ovoid head supported on a distinct neck below which is a prominent tubercle having a rounded roughened face quite two-thirds as large as that of the head. The proximal third of the radius is rather abruptly flexed forward leaving a considerable space between it and the ulna. For the remainder of its length it is in close 
contact with the ulna, so close that more than a slight degree of rotation is not probable.

While the heavy humerus and the broad elbow joint of Canolestes seem adapted for digging or scratching habits, the character of the forearm distinctly tends toward the cursorial type of structure. Aside from a few detailed peculiarities, it may be said that the humerus has considerable general resemblance to that of Peramys and Marmosa while the radius and ulna are clearly nearer those of Antechinomys and Sminthopsis or even Perameles.

\section{BONES OF THE HAND.}

Plate XVI, Fig. I.

The carpal bones are eight in number, four in the distal row and four in the proximal row, including the pisiform. In the distal row the trapezium forms the seat of the first metacarpal and is in contact also with the inner proximal extremity of the second metacarpal. Its inner surface articulates with the trapezoid and its inner palmar surface with the distal projection of the scaphoid. It is a short longitudinally compressed bone with broad grooves on its distal and proximal surfaces respectively. No sesamoids could be detected in relation with it. The trapezoid and magnum are about equal in size. The former is rounded distally for articulation with the concavity of the proximal end of the second metacarpal. It articulates also with the trapezium, magnum, and scaphoid. The magnum is subtriangular in its anterior or dorsal aspect and articulates with the third metacarpal, the trapezoid, scaphoid and unciform. The unciform is large and roughly pentagonal in outline. It supports the fourth and fifth metacarpals. Its contact with the fifth however is limited to its radial side. The unciform articulates with five bones, viz., the two metacarpals, the magnum, lunar, and cuneiform. Its dorsal surface has two deep pits. The cuneiform receives the head of the ulna in its deeply concave proximal surface. Distally it articulates with the unciform and medially with the lunar. The lunar is quite distinct and presents a triangular dorsal surface about half as extensive as that of the magnum. With the scaphoid it supports the broad head of the radius. The scaphoid is nearly as large as the unciform. It lies between the head of the radius and the trapezoid and sends a curving process beneath the palmar surface of the trapezium. Its medial or ulnar surface is in contact with the lunar. No sesamoids were found associated with it. The pisiform is exceedingly well developed and broadly expanded distally. It is nearly as long as the fifth metacarpal and relatively longer than in any other marsupial which has been 
examined. It articulates principally with the outer lateral surface of the cuneiform but also has slight contact with the ulna.

The metacarpals are slender and rounded with somewhat expanded heads and bases, the former slightly the larger. The medius is the largest. The indicis and annularis are slightly shorter and of about equal length. The pollicis is about three-fifths as long as the indicis and the minimus is scarcely more than half as long as the annularis. The first three are of approximately equal diameter, the annularis is very slightly more slender, and the minimus is slightly broader. The outer pairs are evenly and slightly divergent from the middle. The phalanges are regular in number and form. The basal ones of the second, third and fourth fingers are nearly equal in length; that of the fifth finger is slightly shorter, and that of the pollex is shortest. The claw of the middle finger slightly exceeds the others. The claw of the pollex reaches to the middle of the first phalanx of the index finger and the claw of the fifth finger extends to the first phalangeal joint of the fourth finger. The ungual phalanges of the first and fifth fingers are pointed but less curved and clawlike than those of the middle fingers. The usual paired sesamoids are present on the palmar sides of the metacarpo-phalangeal joints.

\section{Thigh and Leg.}

\section{Plate XII, Figs. I, 3.}

The femur is slightly shorter and decidedly more slender than the humerus. The shaft is cylindrical and nearly straight but the extremities are considerably expanded. The head is supported on a slight neck and is definitely directed forward as well as inward. Its smooth articular surface is partially incomplete behind. The outer or greater trochanter rises to the level of the top of the head and is inclined slightly inward so that its apex is practically in the long axis of the shaft. Laterally it is much compressed and it is only superficially separated from a broad ridge extending distad a short distance to a small rounded protuberance having a roughened surface and clearly representing a third trochanter. This has approximately the same relations as the third trochanter in Phascolomys, the only other marsupial except the extinct Wynyardia in which there is any obvious development of the kind. The great trochanter is bounded on the inner side by a deep slitlike digital fossa which has as its other boundary a high thickened intertrochanteric ridge almost as prominent as the great trochanter. This ridge runs from the apex of the great trochanter distad with slight inclination toward the lesser trochanter and then turning sharply and losing most of its eleva- 
tion joins the lesser trochanter. A considerable depression lies between its lower half and the base of the head of the femur. In many marsupials, this ridge is only represented by a tubercle between the great trochanter and the head. It is fairly well developed in Didelphis and in Perameles. The lesser trochanter forms a prominent triangular projection on the inner side of the femur separated from the head by a short rounded notch.

The distal end of the femur is of the usual character. The condyles are produced backward to a marked degree and the intercondylar notch is narrow and deep. The anterior rotular groove is broad and shallow being scarcely more marked than in forms with a ligamentary patella. The patella itself is rather short and broad and well ossified. This is an important peculiarity of Canolestes, for among living marsupials the only others having an osseous patella are Tarsipes, Perameles and Notoryctes. It is recorded also as present in the extinct genera Prothy. lacynus and Amphiproviverra (Sinclair).

The tibia is very long and much curved, resembling that of the macropods and certain small saltatorial polyprotodonts, as Sminthopsis and Antechinomys. Its proximal half is bowed inward and forward in a long curve and is widely separate from the fibula but sweeps downward into the same longitudinal axis for its distal half. The proximal half is of the usual trihedral form, its wide inner surface being longitudinally channelled and its antero-internal surfaces convex. The distal half is nearly cylindrical. The internal malleolus is highly developed, only being equalled among forms examined in the macropods. Its perpendicular articular surface exceeds the horizontal surface of the end of the tibia.

The fibula is very slender, especially in its distal three-fourths. Proximally it is compressed and somewhat expanded antero-posteriorly, its inner surface being somewhat grooved. It is surmounted by a rather large ovoid fabella. The tibia and fibula are closely appressed but not fused in the distal half of their length. The hind leg of Canolestes is thus of a cursorial or saltatorial type and closely resembles that of Antechinomys, although even in this notably saltatorial form the internal malleolus is relatively small. A leg of similar character with tibia and fibula practically joined distally is found in Sminthopsis, Perameles, and in the Macropodidae. In almost all other marsupials the tibia and fibula are widely separate throughout.

The relative length of the lower leg in Canolestes is very great. In proportion to the length of the femur, the length of the tibia in Canolestes is only exceeded, among forms examined, by that of the Giant Kangaroo. The proportions in various genera are indicated by the following table, 
the ratio given being that of the femur to the tibia. From this table it is seen that this ratio is less in Canolestes than in any other forms examined except the Giant Kangaroo and that it is approximated only by saltatorial forms.

\begin{tabular}{|c|c|c|c|c|c|c|}
\hline & & & & $\begin{array}{l}\text { Length of } \\
\text { Femur }\end{array}$ & $\begin{array}{l}\text { Length of } \\
\text { Tibia }\end{array}$ & $\begin{array}{l}\text { Rat io of Femur } \\
\text { to Tibia }\end{array}$ \\
\hline Macropus giganteus & - & - & - & . 265 & 465 & 57 \\
\hline Cænolestes obscurus . & - & . & . & $14 \cdot 3$ & 22.5 & 63.5 \\
\hline Sminthopsis crassicaudat & & . & . & 13.6 & I9.8 & 68 \\
\hline Antechinomys laniger & - & - & - & 19 & 27 & 70 \\
\hline Petrogale xanthopus & . & . & - & 153 & 195 & 78 \\
\hline Phascologale cristicauda & . & - & . & 23.3 & 28 & 82 \\
\hline Marmosa mexicana & - & - & - & 23 & 26.8 & 85.8 \\
\hline Dasyurus viverrinus . & - & . & - & 65 & 73 & 89 \\
\hline Myrmecobius fasciatus & - & - & - & $45 \cdot 5$ & $5 I$ & 89 \\
\hline Perameles nasuta . & . & . & - & $64 \cdot 5$ & 69 & 93.4 \\
\hline Peramys domesticus & - & - & - & $2 I$ & 22 & 95.4 \\
\hline Philander philander . & - & . & - & $35 \cdot 4$ & 37 & 95.6 \\
\hline Didelphis virginianus . & . & . & . & 76.8 & 78 & 98.4 \\
\hline Sarcophilus harrisi & . & . & . & 91.5 & 91.5 & IOO \\
\hline Trichosurus vulpecula & . & . & - & $94 \cdot 5$ & $92 \cdot 5$ & 102.1 \\
\hline Thylacinus cynocephalus & & . & . & 195 & 190 & 102.6 \\
\hline Phascolomys ursinus & . & - & . & 175 & I33 & I3I \\
\hline Phascolarctos cinereus & . & . & . & I55 & I I 5 & I34 \\
\hline
\end{tabular}

Bones OF THE Foot.

Plate XVI, Figs. 2-5.

The foot is long and narrow, the tarsus being relatively short and the metatarsus very long. It has general resemblance to the foot in Dasyurus, Sminthopsis, Antechinomys and similar forms, but its structure shows decided approach to that of Perameles and the macropods. Although the hallux is present and relatively well developed (longer than in Dasyurus, for example) the relations of the ankle joint are more adapted to cursorial life than in some of the forms in which the hallux has nearly or quite disappeared. This is shown especially by the astragalus which is somewhat intermediate between that of the pedimanous marsupials and that of the highly saltatorial forms. Although it retains general similarity to the astragalus of Didelphis, Sarcophilus, Myrmecobius, Phascologale and various other polyprotodonts, it shows a distinct approach to the condition in the Macropodidae in which there is one large trochlea and facets on either side, nearly at right angles, for the outer malleolar parts of the tibia and the fibula. The body of the astragalus stands at right angles to the neck and head and scarcely exceeds them in size. The neck is not constricted to differentiate it 


\section{Field Museum of Natural History - Zoölogy, Vol. XIV.}

from the head. The inner malleolar facet is extensive and sharply deflected from the medial tibial facet from which it is separated by a high trenchant ridge which extends over the neck to the head at the navicular facet. In all other forms examined, this ridge is discontinuous or confined to the trochlea. The formation of a depression in this ridge between the trochlea and the head would seem to be the first step in the separation of the head from the trochlea. Hence, in this respect the astragalus of Canolestes may be primitive. The tibial facet is very slightly concave and merges imperceptibly with the fibular facet which is narrow and considerably deflected. The sharp division of the two principal tibial facets virtually permits the tibia and astragalus to be locked together almost as effectively as in the macropods. Lateral movement of the tibia is practically precluded and the general freedom of the ankle joint found in most polyprotodonts is quite impossible. Even such forms as Sminthopsis and Antechinomys have much looser ankle joints than Canolestes.

The inferior surface of the astragalus in Canolestes is largely occupied by the sustentacular facet which is unusually broad and convex. It is nearly at right angles but confluent with the large navicular facet which covers the head of the bone and runs up the inner side for a considerable distance. The ectal facet is crescentic in outline and is separated from the sustentacular by a deep groove. The inner anterior margin of the navicular facet has slight contact with the cuboid bone but there is no distinct development of a cuboid facet. A small sesamoid is situated between the astragalus and the posterior distal extremities of the tibia and fibula.

The os calcis has the tuber laterally compressed and very slightly flexed downward and inward. The anterior sustentacular part of the bone is relatively large and broad. In addition to the usual ectal, sustentacular, and cuboid facets it has a prominent triangular projection on its antero-external surface for the attachment of the tarsometatarsal and perhaps other ligaments.

The navicular is somewhat anvil-shaped with a smaller dorsal head articulating with the astragalus and slightly constricted from the larger plantar part which spreads inward to the middle of the sole, its plantar surface being broad and flat instead of narrow and ridgelike. Distally it articulates with the ectocuneiform, entocuneiform and mesocuneiform. The cuboid articulates distally with the two outer metatarsals and with the proximo-external surface of the mesocuneiform. Its plantar surface has the usual groove for the tendon of the peroneus longus muscle. The ectocuneiform, entocuneiform and mesocuneiform are rhomboidal bones, the first supporting the hallux, and the others the second and third 
metatarsals respectively. The ectocuneiform is about twice as large as the mesocuneiform and nearly four times the size of the entocuneiform.

The hallux is supported on the distal end of the ectocuneiform more especially toward its plantar side and has considerable freedom of movement, although it is but slightly divergent. It is much more slender than the other digits and its terminal phalanx reaches only to the distal extremity of the second metatarsals. The proximal bases of the metatarsals form a very uneven row. The fifth reaches farthest proximad, the second and third are considerably short of it, and the first and fourth are still more so. The irregularity in this respect is greater than in any other forms examined. The second and fifth extend distad about the same distance and are slightly exceeded by the third and fourth which also end evenly. The fourth however is somewhat longer than the third by actual measurement since the uneven bases give it greater extension proximad. In a male specimen it is $9 \mathrm{~mm}$. long. The first and also the second phalanges are approximately equal in length from the second to the fifth digits. The paired sesamoids on the metatarsophalangeal joints are as usual. There is no prehallux.

\section{Summary of Skeletal Characters.}

The skeleton of Canolestes has the broad general features found in most other marsupials. With the exception of modifications correlated with cursorial limbs, most of its peculiarities are of a primitive or generalized nature rather than of high specialization. The movable cervical rib and the very short pubic symphysis are examples. The general form of the pelvis is remarkably similar to that of some insectivores. In fact the whole skeleton in its general aspects is so closely paralleled by that of one species of insectivore (Nesogale dobsoni), which chances to be available, that the two have been illustrated together (P1. XIX).

Skeletons of the following marsupials have been available for comparison: Antechinomys laniger, Sminthopsis crassicaudata, Phascologale (Chcetocercus) cristicauda, Dasyurus viverrinus, Thylacinus cynocephalus, Sarcophilus harrisi, Didelphis virginianus, Marmosa marica, Peramys domesticus, Philander laniger, Myrmecobius fasciatus, Perameles nasuta, Petaurus australis, Trichosurus vulpecula, Phascolarctos cinereus, Macropus giganteus, and Phascolomys mitchelli. A larger representation would have been desirable and it is possible that some conclusions will need modification when wider comparison is made. Numerous minor peculiarities of general characters of the skeleton have been discussed in preceding pages. 


\section{Field Museum of Natural History - Zoölogy, Vol. XIV.}

The features which seem most noteworthy, although of widely varying significance, are the following:

I. Atlas with open grooves or notches instead of closed foramina for passage of cranial nerves and vertebral arteries; agreeing only with Perameles, Marmosa, and Peramys.

2. Axis with movable cervical rib; agreeing only with certain species (or individuals?) of Perameles and Phascologale.

3. Seventh cervical tending to become imperforate; intermediate between diprotodonts and polyprotodonts.

4. Spine of first thoracic vertebra scarcely exceeding that of last cervical but greatly exceeded by that of second thoracic; agreeing only with Perameles.

5. Vertebral spines converging to a center of motion; disagreeing with Didelphiidae.

6. Costal element of first rib longer than vertebral; agreeing only with Trichosurus and Petaurus.

7. Ventral surface of xiphisternum not continuous with that of mesosternum; agreeing only with diprotodonts.

8. Pubic symphysis exceedingly short; unique among marsupials.

9. Ischial rami not flaring.

I0. Marsupial bone with very long base; unequalled among marsupials.

II. A large heavy humerus combined with a relatively slender forearm; unique among marsupials.

I2. Trochlea of humerus extended inward to form a partially separate articular surface; unique among marsupials.

I3. A sesamoid in the supinator tendon at the external epicondyle of the humerus; unique among marsupials.

I4. Radius flexed forward in its proximal third, in contact with ulna distally; agreeing with saltatorial or semi-saltatorial forms.

I5. Pisiform large, relatively larger than in other marsupials examined.

16. Patella ossified; agreeing with Perameles, Notoryctes and Tarsipes; also with extinct forms Amphiproviverra and Prothylacynus.

I7. Femur with a rudimentary third trochanter; agreeing only with Phascolomys and Wynyardia.

I 8. Tibia and fibula relatively long and in close contact distally; agreeing only with saltatorial forms.

I9. Internal malleolus of tibia large; agreeing with Macropodidae. 
20. Astragalus with a large inner malleolar facet nearly perpendicular to the medial tibial facet; agreeing with saltatorial forms.

2I. Prehallux not present; agreeing with Macropus, Trichosurus, and Phascolomys; disagreeing with Didelphis.

\section{SKULL.}

Plates XVII, XX.

General form.-The skull of Canolestes is characterized superficially by the great elongation of the facial region, by the deep and extremely thin-walled braincase, the swollen interorbital and lacrymal regions, the general absence of crests or ridges, the slender zygomata, and by the modifications of the maxillary by which the anterior teeth are at a different level from the posterior.

The general resemblance to the skull of Perameles was immediately noticed by Thomas, who says (I895, p. 872): "Skull in its general proportions something like that of a Perameles, although thinner and more delicately built, with a similarly elongated muzzle, smooth and rounded brain-case, and obsolete supraorbital and cranial crest and ridges; the zygomata are, however, so much more boldly expanded as somewhat to spoil the resemblance, which in any case does not apply to details." A still stronger statement of this resemblance to the skull of Perameles might be made and, as appears later, it does apply at least to a certain number of details. The zygomata are more spreading than in some of the peramelids but their sweep is practically identical with that of others (e. g. Isoodon). Certainly the general form of the skull is nearer that seen in the peramelids than that of any other living marsupial. The resemblances of general shape to the smaller dasyurids noted by Miss Dederer (I 909 ) seem mostly to be associated merely with small size and are found also in Acrobates and Dromicia.

The ratio of zygomatic breadth to total length of skull in various marsupials is as follows: Perameles nasuta 39.7 , Perameles bougainvillei 43.2, Canolestes 47.7, Isoodon barrowensis 51, Phalander 54, Phascolarctos 54.3, Myrmecobius 56.4, Peramys 56.9, Didelphis 57, Chironecles 57.I, Phascologale (Chetocercus) cristicauda 63.7, Petaurus australis 66.4, Dactylopsila 67.5, Dasyurus viverrinus 69.7, Trichosurus vulpecula 71.7, Sarcophilus 8r.2. In this series, Canolestes falls with the peramelids. The didelphids occupy a position midway between these dolichocephalic forms and the broader types presented among the phalangers and dasyurids.

Braincase.-The braincase is relatively large and its walls are 
exceedingly thin and papery. Viewed in longitudinal section (P1. XVII) its depth is seen to be proportionately greater than in other marsupials. The ratio of the depth to the length measured inside the braincase in several forms is found to be as follows: Canolestes 53.9 ; Perameles nasuta 48.8; Petaurus australis 47; Myrmecobius 44.4; Trichosurus 42.2; Phascologale flavipes 4ז.7; Marmosa cinerea 4ז.6; Didelphis virginiana 39.7; Peramys domesticus 38.6 .

The dorsal outline of the braincase is broadly arched, agreeing in this respect with Perameles and with most diprotodonts and contrasting with the didelphids and dasyurids in which the dorsal outline is more nearly straight. The olfactory fossa is large and full, especially in its lateral parts, but it is relatively short antero-posteriorly as compared to didelphids and dasyurids. In these polyprotodonts its median section is subtriangular, often with an acute angle in front, whereas in Canolestes and Perameles, and the several diprotodonts examined, it is broadly rounded anteriorly. It is separated from the cerebral fossa by a light ridge, the position of which is plainly indicated externally by the furrow running upward and slightly backward from the ethmoid foramen.

The cerebral fossa is very full, especially in its lower anterior part where it is extended forward on either side of the median part of the cribriform plate. The floor of the braincase is thus wider and flatter anteriorly than in other marsupials and it meets the cribriform plate more abruptly. This is in the region occupied by the tuberculum olfactorium which, as elsewhere noted, is unusually large (see p. I59). In front of the occipito-sphenoid suture is a shallow pituitary fossa. The sphenoidal fissure and the foramen rotundum open posteriorly on the floor of the braincase and have no lateral exposure like that in other marsupials. Externally the sphenoidal fissure and the foramen rotundum have what is practically a common opening, the bony septum between them being quite internal and not visible in lateral view. In this, the condition seems nearer that of the diprotodonts than of the polyprotodonts in which the foramen rotundum opens decidedly posterior to the sphenoidal fissure with the septum between them broadly exposed in lateral view.

The cerebellar fossa is smooth and without obvious division into lateral and median parts. It is separated from the cerebral fossa by an exceedingly slight tentorial ridge. The outline of the cribriform plate as seen in section is more similar to that of Perameles than to that of any other form examined. It is more nearly vertical than in polyprotodonts generally and more abruptly divided between its upright and its posterior basal extension in the presphenoid region. This posterior extension is broader and higher than in any other marsupial examined. 
The foramina leaving the braincase include the sphenoidal fissure and foramen rotundum, which already have been mentioned, the foramen ovale, transverse canal, entocarotid foramen, and ethmoid foramen, in all of which the relations are generally similar to those in other marsupials although there is much variation, especially in diprotodonts.

Ethmoid and turbinals. - The cribriform plate of the ethmoid, as previously stated, is more nearly upright than in the didelphids and resembles that of Perameles. Its exact relations with the orbitosphenoid and presphenoid are not distinguishable in the adult, but the bony floor of the olfactory fossa is high and has a more rounded surface than in other marsupials. It extends exactly parallel to the palate and hence nearly at right angles to the anterior wall of the braincase. The principal ethmo-turbinals visible in a simple section (PI. XVII, et.) are four in number. The lowermost is relatively larger than in any other form examined and is most nearly approached in Perameles nasuta. The uppermost and longest of the ethmo-turbinals is relatively short, extending forward only to the plane of the front of the last premolar. This seems to be a resemblance to diprotodonts since it agrees with the condition in Trichosurus and Petaurus. In the didelphids and in Phascologale this upper ethmo-turbinal is very long, reaching as far forward as the canines and almost completely inclosing the fenestrated part of the maxillo-turbinals. In Perameles and Myrmecobius an intermediate condition appears.

The naso-turbinal offers no especial peculiarities. The maxilloturbinal springs from the nasal wall at a somewhat higher level than in polyprotodonts and the nasal floor is narrower. ${ }^{1}$ In these respects, there is some variation among polyprotodonts but in general the resemblance seems to be to diprotodonts. The maxillo-turbinal, as in diprotodonts, is not largely enclosed by the anterior extension of the ethmo-turbinal. The mesethmoid is a thin vertical plate of the usual character.

Nasals.-These are long and slender, coming nearly to a point anteriorly and being abruptly expanded posteriorly. Their anterior extremities exceed the dorsal edges of the premaxillae and overhang the anterior nares, reaching nearly as far forward as the lower anterior extension of the premaxillae. In this they differ markedly from the Dasyuridae, Thylacynidae, and Myrmecobiidae but are approached by most diprotodonts, by the didelphids and especially by the peramelids. The posterior expansions of the nasals include a slender curved prong on each side projecting across the extraordinary vacuity which lies

1 This is contrary to the observation of Broom (I91I, p. 318), whose material may have been imperfect. 


\section{2 \\ Field Museum of Natural History - Zoölogy, Vol. XiV.}

between the nasals, frontals and maxillary. They do not exclude the maxillaries from contact with the frontals, however, and despite their great length their posterior endings are in advance of the orbits.

Premaxillae.-The premaxillae are longer than high and reach quite to the bases of the canines. The maxillary suture approaches the perpendicular as in Perameles and most diprotodonts. A narrow posterior ascending branch extends backward between the nasals and the maxillary to the plane of the front of the middle premolar. The palatine processes of the premaxillae do not extend the full length of the anterior palatine vacuities as in most other marsupials, but meet similar processes of the maxillary which extend forward. The bony division of the anterior vacuities thus consists of premaxillary elements only in its anterior three-fifths. The only other marsupials in which I have found this arrangement are the peramelids; in all others the premaxillary processes extend nearly or quite to the posterior boundary of the vacuities. In every respect, therefore, the premaxillae are more similar to those of the peramelids than of any other marsupial.

Maxillae.-The slender processes of the maxillaries projecting forward in the anterior palatine vacuities are only paralleled among the peramelids. The posterior fenestration of the palatal aspect of the maxillae also resembles closely that of Perameles. In their upward extension, the maxillae are not greatly narrowed between the antorbital vacuities and the lacrymals, but meet the frontals broadly at a point about even with the front of the orbits and somewhat caudad of the posterior nasal endings. In these respects they are conspicuously different from those of the didelphids.

In uniting with the jugals, the maxillaries send out a slender prong which takes a larger part in the formation of the anterior root of the zygoma than is usual in marsupials and contrasts especially with the condition in most polyprotodonts in which the jugal is expanded on the face below the lacrymals. In general, however, the relation of the anterior root of the zygoma to the maxillary is as in polyprotodonts, that is, the principal part of the maxilla, including all the molars except the last two, is anterior to the zygoma. This is in decided contrast to the diprotodonts in which that part of the maxillary bearing the molars is largely posterior to the anterior root of the zygoma. In some forms, especially among the Phalangeridae, the root of the zygoma rises from a point as far forward as the last premolar and consequently the entire molar series is posterior to it. In polyprotodonts, on the contrary, it is rare for more than the last reduced molar to lie posterior to the zygoma. This constitutes one of the most striking resemblances to polyprotodonts shown by the skull of Canolestes. 
Frontals.-The frontals are nearly as wide anteriorly as posteriorly. They are smoothly rounded at the orbital border and have neither ridges nor post-orbital processes, thus differing from most polyprotodonts. There is no post-orbital process in Phascologale and some allied forms but in these the frontals are more flattened and the orbital border is more angular. Within the orbit, the frontals of Canolestes are less deflected toward the midventral line than in other marsupials and thus provide for the unusual space required by the large olfactory lobes of the brain. A distinct venous foramen perforates the orbital border in its upper anterior part.

Lacrymals. - The lacrymal is of moderate size and not largely extended beyond the orbit. It is slightly gibbous but not ridged between its facial and orbital parts. It is well separated from the nasals by the frontal process of the maxillary. The lacrymal canal has a single opening, thus differing from the didelphids and many other marsupials. It opens on the orbital border, not within the orbit, but not so definitely outside it as in other forms. ${ }^{1}$

Parietals.-The parietals are broad and smooth with no suggestion of a sagittal ridge. The suture between the two parietals and that between them and the supraoccipital is practically obliterated in adults although easily visible in most other marsupials except the peramelids. Apparently the parietals reach laterally to the vicinity of the lambdoid ridge as in other forms and are not shortened as in the figure published by Miss Dederer (1909). A minute postparietal foramen is usually present.

Zygomata.-The anterior root of the zygoma, as previously stated, rises at the level of the third molar in marked contrast to the position general among diprotodonts. The jugal is sharply narrowed anteriorly and comes to a point just below the lacrymal canal. The arch has a general sweep somewhat as in Phascologale and the bone is similarly flattened but the anterior base is narrower and there is no trace of a postorbital process, this last character being a resemblance to Perameles. The jugal reaches the glenoid fossa as usual and its ending is truncate to form a slight anterior boundary for the fossa, thus agreeing more nearly with polyprotodonts than diprotodonts. The posterior root of the zygoma is not inflated as in most diprotodonts, but it is more slender than in dasyurids and didelphids and more nearly resembles the condition in the peramelids.

Squamosal.-The cranial part of the squamosal is not peculiar, being

${ }^{1}$ In Gregory's exhaustive comparative study of the lacrymal (Bull. Am. Mus. Nat. Hist., XLII, p. 235, I920), made since the above was written, it is concluded that "The evidence of the lacrymal region is in harmony with the view that the cænolestoids are allied with the Peramelidae." 


\section{io4 Field Museum of Natural History - Zoölogy, Vol. XIV.}

smaller than in Perameles and Sarcophilus, smaller also than in some diprotodonts, but relatively quite as large as in others. Its proportions are nearly as in the didelphids and smaller dasyurids. The glenoid fossa is considerably above the basicranial axis and is distinctly longer than wide. Except on its extreme outer edge where the end of the jugal bounds it, it is open in front. Posteriorly it is bounded on the outer side by a papillate bony elevation which is unconnected with the tympanic and has only very slight transverse extent. The general features of the glenoid fossa are thus somewhat intermediate between those in polyprotodonts and in diprotodonts. The transverse extent and the broad platelike posterior boundary usually found in polyprotodonts are changed in the direction of the narrower more open condition of the diprotodonts which allows of greater antero-posterior motion of the jaws in conformity with the requirements of their dentition. The arrangement of the foramina at the base of the squamosal is slightly different from that of the Didelphiidae and similar to that in the smaller Dasyuridae and the Peramelidae. As in these, the postzygomatic foramen is lacking and the postglenoid and subsquamosal are closely associated. The subsquamosal foramen opens laterally just behind the postglenoid process and the postglenoid foramen antero-ventrally between the postglenoid process and the superior end of the tympanic. A thin bony plate bounds the subsquamosal foramen ventrally and extends from the postglenoid process to a short flat mastoid process of the squamosal.

Occipitals.-Contrary to the usual condition in marsupials, supraoccipital, exoccipitals and basioccipital are completely ankylosed in adult skulls making it impossible to determine their exact boundaries. In other forms, especially among polyprotodonts, the sutures separating these bones are usually obvious. The supraoccipital shows no clear indication of a forward extension to the dorsal surface of the skull and the median occipital region is smooth without any sharp angle between the dorsal and occipital surfaces. Laterally a slight ridge rises on each side suggesting a lambdoid crest at the union of the supraoccipital and the parietals.

The exoccipitals are small and extend but little beyond the condyles. Probably they do not meet above the foramen magnum. Small paroccipital processes lie prostrate between the mastoid and the periotic and do not form projecting points. Their condition is nearly the same as in Perameles and Myrmecobius but different from other forms examined. The exoccipitals are perforated by two small condylar foramina near the apparent line of union with the basioccipital.

The basioccipital is deeply cleft by the inferior lip of the foramen 
magnum. Its ventral surface is smooth or even slightly concave medially without suggestion of a central ridge. This constitutes another slight and perhaps unimportant, but still practically exclusive, resemblance to the peramelids.

Sphenoid bones.-The basisphenoid is decidedly concave on its exposed surface but has no sharp lateral ridges. It is perforated as usual by the transverse canal and the entocarotid foramen. The suture between it and the basioccipital is closed in adults although usually indicated by a faint transverse ridge. On its superior or cranial surface it is excavated posteriorly for the reception of the hypophysis but there is no distinct sella turcica nor clinoid process.

The presphenoid is only slightly exposed ventrally, being largely inclosed by the thin irregular extensions of the palatine, vomer, and pterygoids. The suture between it and the basisphenoid, usually so distinctly open, is but faintly indicated. Within, the vertical part of the presphenoid is slightly thickened basally but soon becomes exceedingly thin. The orbitosphenoid occupies a small area between the lacrymal and the sphenoidal fissure, its exact boundaries being uncertain. The alisphenoids show no peculiarities beyond those connected with the unusual fullness of the braincase in the region covered by them. As stated elsewhere, the sphenoidal fissure and foramen rotundum are practically confluent just before reaching the exterior but those of the two sides of the skull are more distinctly separated from each other than in any other form examined. The alisphenoid bulla forms a simple subhemispherical capsule similar to that of the didelphids and dasyurids.

Palatine.-Owing to the very large posterior vacuities the palatine bones are relatively small. In the median line they send a pair of slender processes forward to the plane of the middle of the second molar where they meet similar processes from the maxillaries. Posteriorly they are bounded by a slight transverse ridge which is perforated on each side by a small postero-lateral foramen. In close proximity to this foramen is the slightly larger spheno-palatine foramen piercing the upright plate. This plate forms the side walls of the posterior part of the nasal passage, but anterior to the spheno-palatine foramen the walls become discontinuous since the turbinals are fenestrated and exposed much farther caudad than usual and the narrow vomer does not reach the side walls. Posteriorly the palatines form part of the sloping ridge which supports the pterygoids. The pterygoid processes are essentially similar to those of polyprotodonts although they take the form of slender rounded prongs rather than flattened subtriangular plates.

Vomer.-The vomer is narrow in front and expanded posteriorly 


\section{io6 Field Museum of Natural History - Zoölogy, Vol. XIV.}

enclosing somewhat more of the ventral surface of the presphenoid than usual. It is not emarginate posteriorly and extends slightly beyond the posterior nares. Its ventral surface has a low median ridge but this has no contact with the palatines nor with the maxillaries except anteriorly.

Tympanic.-The tympanic is a simple ring open behind and attached to the alisphenoid bulla by cartilage. It is wider and heavier than in the didelphids but is essentially the same as in Australian polyprotodonts.

Periotic.-The petrous part of the periotic is exposed ventrally as a subtriangular bone between the basioccipital, the tympanic and the alisphenoid bulla. It is thus almost wholly exposed as in polyprotodonts and not partly or almost completely covered by the alisphenoid bulla and the tympanic as in diprotodonts. It is less inflated than in the dasyurids but projects below the surface of the basioccipital slightly more than in the didelphids. Internally it shows the usual openings, including a large floccular fossa. The foramina surrounding it are much as in the other marsupials except for the so-called carotid canal which forms a long open slit between the petrous periotic and the basioccipital which are actually in contact scarcely more than enough to separate this opening from the jugular foramen behind and the entocarotid foramen in front. Such an opening has not been found in any other marsupial examined, although in polyprotodonts it may be represented by the small foramen which Gregory (rgro, p. 223) has called the posterior carotid foramen.

The mastoid is relatively larger than in any other form examined and is especially characterized by its great lateral extent. Its occipital surface is not more than one-third its lateral and between them there is only a gentle curve or an exceedingly feeble ridge. The lateral surface is slightly convex and meets the squamosal evenly. The short flattened paroccipital process and the mastoid process of the squamosal clasp it on either side making the entire mastoid region relatively smooth and continuous with the general outlines of the skull. This lack of prominences is in marked contrast to the condition in the didelphids and is nearer to that of Antechinomys and other primitive dasyurids. A very large mastoid foramen is situated at the upper end of the occipital part of the mastoid separating it from the supraoccipital for a considerable distance. A mastoid foramen occurs in the didelphids but in adults it is very small or practically closed, whereas in Canolestes it is as large in the adult as in the very small pouch young of Didelphis.

Hyoid.-The hyoid apparatus is of the usual marsupial type. The basihyal is flat and subcircular with its posterior edge free but its anterior and lateral boundaries united with the ceratohyals and thyrohyals. The ceratohyals are slightly arched forward and only ossified 
basally, becoming cartilaginous and slender in their distal two-thirds. The thyrohyals are flattened bars standing nearly at right angles to the general axis and ossified to their tips which are united by a short cartilage to the osseous wing of the thyroid cartilage.

Vacuities.-The palate is highly fenestrate, its bony floor being relatively less extensive than in any other living marsupials with the possible exceptions of some of the peramelids. There are two pairs of vacuities of constant occurrence and fairly regular form. The anterior pair extend from the front of the second lateral incisor to the front of the middle premolar and occupy nearly all the space between the toothrows. They are divided by the median processes of the maxillaries and premaxillaries which are flattened ventrally to an extent about equalling one-third the width across the paired vacuities. These vacuities are thus about equal to the combined length of the two separate pairs found in peramelids and they are much longer than the single pair of most other polyprotodonts although they are rather closely approached by Sminthopsis. The posterior vacuities begin at the front of the last premolar and reach nearly to the transverse ridge bounding the palate. Their endings are almost exactly at the level of the back of the last molars. They are divided by a narrow median extension of the maxillaries and a similar one from the palatine, the two meeting midway of the length of the vacuities and forming a slight expansion at their union. Laterally the boundaries of the vacuities are slightly irregular but anteriorly they are always evenly rounded and the general shape and extent in different specimens is very constant.

The palatal vacuities are regarded as secondary developments and, since they vary so widely throughout the marsupial group, it is not probable that their character in Canolestes has any special significance. The palate in extinct cænolestids is only imperfectly known.

A prominent vacuity on each side of the face directly above the infraorbital foramen is one of the most unusual features of the skull of Canolestes. It is bounded by the nasal, frontal and maxillary bones and opens into the large sinus between the naso-turbinal and the maxillary. Its relations to the overlying dermal tissues are simple and no glandular or other specialized development is apparent. As noted by Thomas (1895), a vacuity in this part of the skull is found in other mammals only among ungulates.

Auditory ossicles. - The malleus has the general features usual in marsupials. The neck is relatively short, the lamina very thin, and the processus muscularis is but feebly indicated. The manubrium is about two-thirds as long as the processus gracilis and forms a thin flattened blade with a pointed apex and a slightly falcate outline when seen from 
the flat side. The processus brevis at the base of the manubrium is relatively insignificant. The processus gracilis has two thin longitudinal ridges bounding a long $\mathrm{v}$-shaped groove which seats the tympanic ring. The extremity of the process is somewhat expanded and obtuse. The union with the tympanic is close and considerable care is required in forcing the parts away from each other. The malleus differs from that of Perameles ( $P$. bougainvillei) principally in its shorter neck; from that of Didelphis it is distinguished by its generally frailer construction and its closer union with the tympanic.

The incus is practically identical with that of Perameles, differing mainly in the processus brevis which is somewhat compressed and truncate instead of long and conical. The processus longus is very slender distad of the sharp right angle at which it is bent. The Sylvian apophysis is elliptical. The incus in adults is rather firmly attached to the malleus and does not separate except after slight pressure.

The stapes is strictly columelliform without trace of an opening and there is not even an appreciable difference in its diameter from the head to the base. The head is very small and the base relatively large and elliptical. In adults, the stapes is well ossified.

The auditory ossicles of Canolestes are clearly of a type closely approaching that of Perameles, which was regarded by Doran (1879) as the lowest among marsupials. They also show resemblance to some of the dasyures, which, as described by Doran, have the stapes columelliform. Whether this simple stapes is in truth a primitive character or not, it serves at least to distinguish Canolestes sharply from the didelphids, in which the stapes is always bicrurate. So far as the auditory ossicles are concerned, therefore, Canolestes resembles Australian rather than American forms and especially approaches the peramelids and dasyurids.

Mandible.-The mandible is slender and relatively straight anteriorly, its greatest curvature being just below the base of the coronoid process. The symphysis is long but weak. The rami have exceptionally little divergence. The coronoid is large, broad, and nearly upright. Its anterior border is gently curved but approaches the vertical more closely than in any polyprotodonts. The broad masseteric fossa is rather shallow and is indistinctly divided into an anterior and a posterior portion by a weak elevation between the tips of the coronoid and the condyle. Near the lower edge of the masseteric fossa is a tiny foramen, indistinct in some specimens, but obvious in others. A similar foramen is found in many Australian diprotodonts but does not occur in polyprotodonts. Its presence in Abderites and Garzonia has been noted by Ameghino and Sinclair. Mental foramina of the usual character are present, a larger 
one below the posterior root of the middle premolar and a smaller below the anterior root of the first molar.

On the lingual side of the mandible the dental foramen is situated as usual at the base of the angular process. In some specimens a shallow groove runs along the inner side of the proximal half of the jaw but in no case does its position or character seem to warrant any assumption that it is a true Meckelian groove.

The angular process is moderately inflected and subtriangular in shape with a fairly wide base and a rounded but not decidedly obtuse tip. The inflection is slightly less than in the majority of polyprotodonts and the process is not produced into a slender prong like that in the smaller dasyurids. The condyle is relatively high in position, slightly more than halfway from the angle to the tip of the coronoid and extending well beyond a line drawn between them. In this respect, therefore, it is more like Phascologale and other dasyurids than like the didelphids in which the condyle is seated on a relatively short base.

The length of the bony lower jaw is proportionately less than in most polyprotodonts and this is especially true if it is considered in relation to the upper jaw. In two specimens of nearly equal size, the length of the bony part of the jaw in Canolestes is 77 per cent of the total length (including terminal incisors) and that in Phascologale is 95 per cent.

Owing to the wide variation in the lower jaws of marsupials, it is difficult to draw any conclusions from the findings in regard to Canolestes. Miss Dederer (1909) has regarded the jaw of Canolestes as indicative of polyprotodont affinity, believing it to be very similar especially to Antechinomys and Sminthopsis. It differs from these in many respects, as in the broader more upright coronoid, the less inflected and less attenuated angle, the less divergent rami, and in the presence of a foramen in the masseteric fossa, this last being a diprotodont character.

Among the didelphids, the mandible shows considerable variation and comparison is difficult. It might be said that as respects the angle, Canolestes is somewhat intermediate between Didelphis and Philander and as respects other characters it shows no especial indications of relationship to the didelphids more than to other marsupials.

\section{Summary of Cranial Characters.}

The great range of variation among both polyprotodonts and diprotodonts leaves relatively few characters that are diagnostic of the two groups. Without a complete representation of all known forms it can only be said that certain characters are regarded as polyprotodont or diprotodont because they are mutually exclusive in the majority of forms examined. On this basis, it is clear that the skull of Canolestes 
shows more polyprotodont than diprotodont characters. These are as follows:

I. Anterior root of zygoma only slightly in advance of end of toothrow.

2. Posterior root of zygoma not inflated.

3. Tympanic narrow and annular.

4. Petrous part of periotic largely exposed ventrally.

5. Alisphenoid bulla not fused with paroccipital process.

6. Foramina of squamosal arranged in general as in Dasyuridae.

Practically all of these characters relate to the otic bones or to the backward extension of the palate with relation to the zygomata. In the extinct Palcothentes, a close relative of Canolestes, the zygomata and palate are practically as in diprotodonts, so the polyprotodont characters of the skull in cænolestids are reduced to those of the tympanic region. The additional characters supposed to indicate polyprotodont affinity and cited by Miss Dederer (rgog) and Broom (rgrr) are found in the smaller diprotodonts, as Dromicia and Tarsipes. Hence their importance is doubtful.

A few characters are at least in agreement with those of some diprotodonts, and with no polyprotodonts so far as known. These are the following:

r. Upper anterior ethmo-turbinal short and enclosing but little of the maxillo-turbinal.

2. Maxillo-turbinal arising relatively high up on the nasal wall.

3. Glenoid fossa relatively long and with a small postglenoid process which is not extended transversely.

4. A small foramen in masseteric fossa of mandible.

Distinctions in cranial characters between Canolestes and the didelphids are numerous; in fact the only characters in common are of quite a general nature. ${ }^{1}$ On the other hand, resemblances to Australian forms, especially peramelids, are abundant. In the following respects there is agreement with some or all Peramelidae or Dasyuridae and disagreement with all Didelphyidae:

I. Rostrum slender and elongate.

2. Palatine processes of premaxillae not extending full length of incisive foramina.

3. Basioccipital concave medially.

4. Maxillo-premaxillary suture nearly upright anteriorly.

5. Cribriform plate approaching the vertical.

6. Fronto-maxillary suture broad.

${ }^{1}$ The mastoid foramen may be an exclusive resemblance, but in the absence of immature specimens I am unable to learn whether or not it occurs in dasyurids. 
7. Sagittal and lambdoid crests absent.

8. Postorbital processes absent.

9. Paroccipital and mastoid processes small and prostrate.

ro. Lacrymal canal with a single opening.

I I. Postzygomatic foramen lacking.

I2. Stapes columelliform.

The first five of these characters are exclusive resemblances to the peramelids while the others are common to the peramelids and certain of the dasyurids. The total number of resemblances to the peramelids therefore, is very large. Moreover, important distinctions between Canolestes and Perameles are comparatively few, being confined mainly to the region between the sphenoidal fissures and to the proportions of the processes of the mandible.

In a number of respects the skull of Canolestes differs from all other living marsupials. The most important of these are as follows:

I. A preorbital vacuity between the nasals, maxillary, and frontal.

2. A large mastoid foramen persisting in adults.

3. A long narrow carotid canal between the petrous periotic and the basioccipital.

4. Floor of braincase very wide between sphenoidal fissures.

5. Mastoid large and broadly exposed laterally (approached by peramelids).

6. Olfactory fossa relatively large and wide.

\section{DENTITION.}

\section{Plate XVIII.}

The dentition and the cranium of Canolestes have been known since the original discovery of the animal and have been variously described, figured, and subjected to comment by different authors, notably Thomas, Bensley, Sinciair, Dederer, and Gregory. The diprotodont modification of its lower incisors combined with a polyprotodont upper incisor formula and quadrate bunolophodont molars at once furnished conditions not found elsewhere among living marsupials and not typically representing either the diprotodont or the polyprotodont group. The teeth have been well described in considerable detail by Thomas (I 895), but his specimen was somewhat affected by wear, which obscured a few important points. For this reason and for the sake of completeness and convenience of discussion full description of the teeth is given in the following pages. Unfortunately it is still impossible to give any information as to the succession of the teeth, since all the specimens at hand are fully adult. 


\section{i 2 Field Museum of Natural History - Zoölogy, Vol. XIV.}

\section{Number and Homologies of Teeth.}

The teeth are 46 to 48 in number. In the upper jaw there are one pair of terminal incisors and three pairs of lateral ones, a pair of sharp, well-differentiated canines, three pairs of more or less triconodont premolars, and four pairs of molars, the first and second of which are quadrate and the third and fourth subtriangular. In the lower jaw there is a pair of long terminal chisel-like incisors resembling those of the most pronounced diprotodont dentitions. Behind these in lateral position are four and sometimes five pairs of small unicuspids, practically undifferentiated from each other, which are interpreted as two (or three) incisors, one canine, and one premolar. Next are two pairs of doublerooted premolars and four pairs of molars. The dentition, therefore, is a rather highly modified one but retains approximate numerical agreement (at least in certain specimens) with the polyprotodont dentition usually regarded as generalized. With the exception of the didelphids, which have five upper incisors, and Myrmecobius, which has supernumerary molars, no living polyprotodont has more teeth than Canolestes. The formula may be written:

$$
\text { I. } \frac{4}{3-4} ; \text { C. } \frac{I}{\mathrm{I}} ; \mathrm{Pm} \cdot \frac{3}{3} ; \mathrm{M} \cdot \frac{4}{4} ; \mathrm{x} 2=46-48 \text {. }
$$

This is essentially the classification made by Thomas (1895) who divided the four unicuspids behind the median incisor into two incisors, one canine, and one premolar. "Any other determination," he says, "would involve the presence of four incisors or four premolars, each equally unlikely." It now appears that, although the normal number of lower incisors is three as decided by Thomas, the presence of four would by no means have been unlikely. The number of lower unicuspids or intermediate teeth is normally four, but a variation in which there are five is not infrequent. In one specimen (Field Museum No. I8603), there are five on the right side of the jaw and four on the left. Bensley (1903, Pl. 5, fig. 38) has figured a specimen belonging to the British Museum in which there are five on each side of the jaw. Others, so far as examined, have four unicuspids on each side, but since the total number of specimens is very small the percentage of variation is high. It is possible, therefore, that these aberrant specimens represent a condition once normal and in which the lower antemolar formula was equal to that of the didelphids and in excess of other living marsupials. This is further suggested by the occurrence of the same lower antemolar formula in the extinct genus Halmarhiphus, regarded by Sinclair as the direct ancestor of Canolestes. A closely allied form, Garzonia, has as 
many as six unicuspids in the lower jaw, giving it a total antemolar formula of nine, exceeding that of any living mammal. While this formula, as observed in only one specimen, may be abnormal, as suggested by Sinclair, it is evident that the formula of Canolestes, large though it be, has already undergone a reduction. A further and gradual reduction may be traced in Australian diprotodonts to those in which only the median or terminal pair of incisors and one pair of differentiated premolars remain, two pairs of antemolar teeth in all, as in Phascolarctos and Phascolomys.

Representatives in this series with the number of antemolar teeth in each would be as follows: Garzonia, 9; Halmarhiphus, 8; Canolestes, 7-8; Phalanger, 6-7; Acrobates, 5; Dromicia, 4-5; Distaechurus, 4; Trichosurus, 3-4; Macropus, 3; Phascolarctos, 2. When the form and character of the teeth as well as their number is considered, the probability that the series is an expression of homologies seems very great. Among the living forms of the Phalangeridae the reduction is going on at present, as indicated by the great instability of the number of the "small intermediate teeth" in various species. This was shown especially in the genus Phalanger by Jentink (I885) who examined a considerable series and found great variation. The subject has been further elaborated by Bateson (1894). In the extinct forms Palcothentes, Acdestis, and Callomenus, a reduction also has occurred, these having only five or six antemolar teeth. Hence, Canolestes is more primitive than these. In fact, so far as mere number of teeth is concerned, Canolestes and the allied extinct forms like Halmarhiphus and Garzonia are almost as primitive as the didelphids. Assuming their common ancestry, it is necessary to believe that the diprotodont modification preceded any numerical reduction. Moreover, it is not impossible that all living and extinct polyprotodonts are more reduced than these primitive diprotodonts. The case of Garzonia with its nine lower antemolar teeth is of interest in this connection. At least five of these must be regarded as incisors unless reduplication with no reference to homologies be assumed. This is a larger number of lower incisors than is possessed by any known polyprotodont. Further, if the specialized median incisor is not the first but the second as shown by embryology in the macropods (Woodward I 893), we must assume the ancestral formula to be six. Such an assumption is further justified by Woodward's (1. c.) discovery of vestiges of six upper incisors in the macropods and by the occurrence as an abnormality of six upper incisors in Didelphis (Bateson 1894, p. 247; Allen r9or, p. I 58). If there were six in the upper jaw there may well have been six in the lower, although of course it is not yet known that the cænolestids

${ }^{1}$ In abnormal cases only. 


\section{in 4 Field Museum of Natural History - Zoólogy, Vol. XIV.}

agree with the macropods in the ontogeny of the upper jaw. The dental formula of the primitive diprotodont would then have been as follows:

$$
\text { I. } \frac{6}{6} ; \mathrm{C} \cdot \frac{\mathrm{I}}{\mathrm{I}} ; \mathrm{Pm} \cdot \frac{3}{3} ; \mathrm{M} \cdot \frac{4}{4} \mathrm{X}_{2}=56 \text {. }
$$

The earliest known mammals, whether they were pro-marsupials or not, furnish no indication that such a large mammalian incisor formula ever existed and it must be admitted that the evidence in favor of it is little more than suggestive. Still, if early mammals only were considered, it would be almost as difficult to believe in an incisor formula of $\frac{5}{5}$ as one of $\frac{6}{6}$, for the usual number of lower incisors in the Triconodonta and Trituberculata was four. Both Thomas (I888) and Winge (I895) bave presented evidence that the primitive formula was at least $\frac{5}{5}$ and the case for it must be regarded as considerably stronger than that for one of $\frac{8}{6}$ so to that extent the testimony of the little known "promarsupials" is weakened. In fact, in this as in some other respects, it is evident that the long known Mesozoic mammals are extremely liable to misinterpretation. Evidence is accumulating to show that even these early triconodonts were not altogether generalized and many connectant forms are needed before the main mammalian stem will be definitely revealed. The highly specialized nature of the dentition in some of the theriodont reptiles, including both secodont and crushing types and even showing a mammalian succession, suggest that some basic lines of the general evolution of mammalian teeth may have been laid down in these early reptiles and, although lost in the triconodonts, persisted in still later forms the immediate ancestors of which are unknown. Although most of these theriodonts had only four upper incisors on a side, there were some (e. g. Pristerognathus) which had as many as six. Hence a mammal with six is theoretically open to no serious objection. In any case it is clear that as early as Miocene times cænolestids were at least as primitive as polyprotodonts in the number of the teeth in the lower jaw. The number in the upper jaw is one less than in the didelphids and certain of the peramelids, which have five upper incisors, most other polyprotodonts having four.

The lateral lower incisors of Canolestes are small and while not wholly functionless are apparently approaching that condition, so variations in their number are more to be expected than would be the case with fully functional teeth. It is possible that the occasional appearance of an extra unicuspid has no reference to ancestral conditions and therefore that all the specimens of the extinct forms Halmarhiphus and Garzonia are abnormal. Evidently this would be the conclusion of Bateson (I 894) who places no confidence in "reversion" or ancestral influences as the 
explanation of such variations. However, he regards "the variability of a form as much a part of its specific character as any other feature of its organization." Without dissenting from this, it may be added that specific and especially generic characters (regardless of how they were initiated or established) are themselves the result or sequence of ancestral conditions. Whether or not characters are "presence or absence" characters, that is, "meristic" rather than "substantive," matters little. In specialized dentitions the loss of a series of several teeth can plainly be traced from species or genera in which the whole series is constantly present to those in which all of it is constantly absent. In such a series, the intermediate forms, or those in which the process of reduction is going on, are notoriously variable. How else, it may be asked, could a reduction take place, especially if discontinuous variation be assumed? No better example of a variable intermediate type could be had than Phalanger, which is treated by Bateson at considerable length. In the artificial series from the extinct cænolestid Garzonia to the modern Phascolarctos the lower antemolar teeth are reduced from nine to two and the "small intermediate" teeth from seven to none. Phalanger lies between the two extremes. Among 76 specimens of one species ( $P$. orientalis) examined (Bateson, p. 253), 57 had three intermediate teeth on each side of the mandible. The remaining I 9 varied from those having only one on each side to one specimen having five on one side and four on the other. Of these, $\mathrm{r} 3$ had at least three intermediate teeth on one side of the jaw. This variability is what might be expected as the result of interbreeding after the occurrence of a discontinuous variation in certain individuals. Or, as seems more probable to a taxonomist and comparative anatomist, it may be the result of the interbreeding of individuals which have in varying degrees gradually developed tendencies toward the loss of certain teeth. Such tendencies are illustrated by the familiar example of the tardily developed and frequently absent third molar or wisdom tooth of Homo. The vestigial incisors (many of which are partly calcified) which have been found in all marsupials investigated by embryologists would doubtless be admitted by everyone as indications of ancestral conditions. These vestigial incisors are shown by Woodward and Wilson and Hill to be, at least in some cases, not members of a pre-existing series (lacteals or prelacteals) but persistent rudiments of suppressed members of the existing series. Hence it seems not improbable that there may be cases in which these vestiges arise in place and become functional as "supernumerary" incisors. An embryological study of an extremely variable form like Phalanger should yield interesting results bearing on this point. 


\section{it6 Field Museum of Natural History - Zoölogy, Vol. XIV.}

Therefore, while it is undeniable that some cases of supernumerary teeth are teratological with a basis that may be largely physiological and mechanical, it cannot be admitted that there are no cases of which phylogenetic influence is the chief determining factor. The objectionable term reversion need not be applied to them but it might be justified to refer to them as examples of persistence of ancestral characters. Aside from what has been said above, it is evident to anyone familiar with the dentition of many species of mammals, that cases are innumerable in which a nonfunctional or slightly functional tooth is present in one species and normally absent but occasionally present in a closely related species. Among bats and rodents instances are particularly abundant. The homology of such a tooth is invariably too clear to be questioned for a moment.

That the fifth lower unicuspid sometimes found in Canolestes is evidence of an ancestor in which this tooth was normally developed may not now be proved conclusively but the evidence from paleontology, from embryology, and from phylogenetic series is sufficient to render it exceedingly probable. That the primitive diprotodont incisor formula was at least $\frac{5}{5}$ is also strongly indicated. Hence the main points in the present connection seem fairly certain, that is, that primitive diprotodonts had numerous teeth and that the diprotodont modification may have arisen prior to any reduction from the primitive number.

\section{UPPER INCISORS.}

Description.-The median incisors are set near the end of the premaxillae in nearly terminal position, only a slight shelf of bone extending in front of them. Their alveoli are more elevated than those of the succeeding teeth and they are separated from the next incisors by a slight space. They are inclined forward slightly away from the perpendicular and their points exceed the lateral incisors. They are separated at the base sufficiently to permit the insertion of a needle or bristle but their points are closely in contact. Their cutting edges are beveled and receive the extreme tips of the lower incisors. They are closely similar in shape to corresponding teeth in the Australian diprotodonts, especially some of the smaller macropods. They have relatively broad faces which suggest the undifferentiated median incisors of Perameles quite as much as they do those of the didelphids. The median upper incisors of typical polyprotodonts (dasyures and didelphids) are usually slender and peglike and in most cases the tips are not in contact although occasional specimens may be found having some resemblance to those of Canolestes.

The three succeeding incisors (second, third, and fourth) are wholly lateral in position and the series on one side is almost exactly parallel 
with that on the other, a condition approached in no polyprotodonts except Myrmecobius and Perameles. The second and third are in contact with each other, the second being somewhat larger than the third. They are laterally compressed into relatively broad blades, their cutting edges are truncate and their bases narrow. The blades, which are distinctly hatchet-shaped, are somewhat produced anteriorly. These teeth, although small, are completely functional since they engage the sharp, beveled, outer edges of the median lower incisors with which they have a very effective shearing action. Similar action is seen between the incisors of some of the macropods, and especially of certain of the Phalangeridae, as for example, Dactylopsila, in which it is very pronounced. Somewhat similar relations occur in Perameles.

The fourth upper incisor is abruptly smaller than the preceding ones and is usually separated from them by a slight space. In superficial view it appears to be pointed but closer examination shows that this is due to a partial forward rotation which has elevated the posterior angle of its cutting edge. This cutting edge is thus inclined forward so that it is parallel to the unbeveled edge of the lower incisor and in this relation it is possible for it to be slightly functional.

Discussion.-All the upper incisors are definitely adapted for relation with the long procumbent lower incisors. The result is the modification of the lateral upper incisors from simple seizing or grasping teeth to cutting or shearing blades. Such a modification, as shown by Bensley, is easily derived from the conical tooth by lateral compression accompanied by the movement of its anterior edge to a horizontal position and its posterior edge to a vertical one continuous with the root. The original apex of the tooth thus becomes the posterior angle. In less marked degree this change has been noted and figured in Myrmecobius and Perameles by Bensley (I903, p. I05) who speaks of it as a "curious appearance, due to a subcaniniform modification of their tips," and makes a rather obscure comparison with a condition in the degenerate teeth of the Madagascan viverrine Eupleres.

In viewing these teeth comparatively in Myrmecobius, Perameles, and Canolestes, one is at once impressed with the practical identity in form and function in all three forms and it is evident that the modification of the lateral upper incisors is correlated with the elongation and specialization of the median lower incisors. In other words, this form of lateral upper incisor is an indication of beginning diprotodonty and is only found in the Australian diprotodonts and forms conceivably ancestral to them. This subject is discussed elsewhere. It may only be said further that the reciprocal relations of the median lower incisors and the lateral upper ones are exceedingly well-developed in Canolestes. 


\section{ir 8 Field Museum of Natural History - Zoölogy, Vol. XIV.}

In fact they appear so efficient for cutting that their relation to the animal's insectivorous habits is not obvious. Functionally, they are quite as well adapted for cutting vegetation as those of strictly herbivorous forms and the possibility that they may have passed through a herbivorous or partly herbivorous stage is to be considered.

\section{LOWER INCISORS.}

The median pair of lower incisors are long, slender, and only slightly curved, merely continuing the inferior outline of the mandibular ramus. They are strongly beveled on the upper side anteriorly and their outer edges are sharp and almost bladelike. They are separated from each other by a considerable space and in this and in the other foregoing respects they are closely similar to the lower incisors in the macropods. Their inner edges are not highly developed for cutting and seem to show a slight tendency to imitate even this character of the macropods. The lower incisors of most phalangers are close-set and decidedly upcurved. Among those examined, the only form showing general resemblance to Canolestes is Petauroides.

Of the small unicuspidate, single-rooted, "intermediate" teeth situated between the terminal incisors and the two-rooted premolars, there are two, and in some cases three, which are to be regarded as incisors. They are indistinguishable by size or shape from the supposed canines and anterior premolars except that the foremost one shows an extreme of pronation which is slightly less pronounced in the succeeding ones. Their crowns are turned forward and lie overlapping each other, the first being in contact with the base of the median incisor and the second with the upper exposed surface of the root of the first. Thus the original apex of each tooth is directed forward and the posterior side of the tooth including a part of the exposed root has come into horizontal position. This arrangement appears to be unique among living marsupials although slight approaches to it are seen in some of the Phalangeridae. It is duplicated in every feature, however, in the extinct Patagonian cænolestids.

\section{Canines.}

The upper canines in Canolestes obscurus and apparently in most specimens of $C$. fuliginosus are simple slender prongs slightly more curved but otherwise similar to the canines of other omnivorous or carnivorous marsupials. In the male they are much more prolonged than in the female, the exposed part measuring $2.5 \mathrm{~mm}$. in a male and only I. $3 \mathrm{~mm}$. in a female. In a specimen of $C$. fuliginosus figured by Bensley ( $1903, \mathrm{pl} . \mathrm{V}$, fig. $3^{8}$ ) the canine is shown to have a deep lateral 
groove extending from the middle of its outer surface to the broad single root. In the closely allied genus Orolestes recently described by Thomas, the canine is said to be double-rooted, and shaped like a premolar. Hence we have in the cænolestids now living a graded series showing a change in the character of the canines from a two-rooted premolariform condition to a single-rooted caniniform condition. That this is the direction of the change and not vice versa seems fairly clear. In the first place, the two-rooted condition is the more primitive. Moreover, although it might be reacquired through "retrogression," as held by Bensley, it is very unlikely that the reversal would be represented by these particular stages. Thus, while the grooved root is the obvious intermediate state in change from a double to a single root, it is scarcely what would be expected if the direction of change were reversed. The logical intermediate stage, if we were dealing with a retrogression from a single to a double-rooted condition, would be a lengthening of the crown with possible appearance of antero-posterior cusps before tendencies to division of the root began. Hence it seems that the change in this case is toward rather than away from a long single-rooted piercing type of canine. It is plainly a very recent specialization and is quite in accord with the animal's present insectivorous and predaceous habits. Of still further interest in this connection is the fact that this change has progressed farthest in the northernmost form, that is, the one presumably most distant from the parent stock.

The lower canines have no intrinsically distinctive characters but are quite like the incisors preceding them upon which they lie in semiprostrate position.

\section{UpPer Premolars.}

The anterior premolar is small, greatly compressed laterally, and its crown in side view is nearly triangular, its anterior outline being practically straight and its posterior slightly concave. In wholly unworn condition, traces of a posterior cusp are evident but none of an anterior one. It is situated about midway between the canine and the middle premolar and is separated from each of these by a space equal to approximately one and one-half times its own length.

The middle premolar is somewhat larger than the anterior, but is similarly compressed. Its posterior outline is concave and sweeps backward to a definite posterior cusp. It is separated from the posterior premolar by a slight space about half as long as that between it and the anterior premolar.

The posterior premolar, which is probably a replacing tooth, is separated by a slight space from the middle premolar. It is situated 
somewhat obliquely with its small anterior cusp slightly internal to its high triangular posterior blade. Posteriorly it stands closely against the first molar and, although its principal cusp is higher than any of the molars, it is functionally a member of the molar series and fairly well separated from the anterior teeth as in diprotodonts generally. It is slightly thickened posteriorly but has no internal cusps although the cingulum is well-developed. Of its two roots, the anterior one beneath the small antero-internal cusp is the longer and heavier.

\section{UPPER MOLARS.}

Description.-The first and second molars are essentially alike in structure and size, the first being only very slightly longer relative to its width. They are quadrate and have four principal cusps, two inner and two outer, i. e., paracone, metacone, protocone, and hypocone. ${ }^{1}$ At the inner base of the metacone is a small but high and very distinct intermediate conule which in worn teeth is sometimes obliterated. In lateral view, the paracone and metacone appear as nearly equilateral triangles rising from the cingulum. The angle between these two cusps is more acute in the first molar than in the second and both cusps of the first are slightly higher than those of the second. The protocone is well developed and more thickened but is somewhat lower than the outer cusps. At its antero-internal base it is distinctly bulging. A distinct internal cingulum bounds its base and extends to the anterior base of the hypocone. The hypocone is about half as high as the protocone and its apex scarcely reaches the height of the intermediate conule, so it is much the smallest of the four principal cusps. Protocone and paracone are connected anteriorly by a commissure which forms the front boundary of the deep central depression of the tooth. A low commissure connects the protocone and the hypocone and near the middle of this is a slight ridge somewhat imperfectly connecting the posterior base of the protocone with the intermediate conule. Between the hypocone and the intermediate conule there is an open channel to the back of the tooth.

The third upper molar is subtriangular and the hypocone is practically undeveloped, although a very slight shelf exists between and slightly posterior to the intermediate conule and the protocone. The first, second, and third molars have three strong roots each and these are situated respectively beneath the protocone, paracone, and metacone. The external cingulum in all these teeth is well-marked, but shows no differentiation into styles. The fourth molar is very small, scarcely

${ }^{1}$ These terms and others are used without reference to homologies to designate the cusps to which they have been commonly applied in connection with the CopeOsborn tritubercular theory. 
one-sixth as large as the third, and it is turned slightly inward from the toothrow. It is roughly triangular and carries three small cusps apparently representing paracone, protocone, and metacone. They are scarcely higher than the commissures which connect them and inclose a central depression. There is still retained an external cingulum, a minute anterior shelf, and two roots, one of which is larger and obviously formed by coalescence. This tooth is plainly undergoing reduction and is in about the same stage as the fourth molar of Dromicia. In Acrobates and Distaechurus it has quite disappeared.

Discussion.-The upper molars of Canolestes show an obvious resemblance to those of the diprotodont family Phalangeridae. Two principal types of molars are found in this family: (I) the bunoid and (2) the selenoid, respectively characterizing the two subfamilies Phalangerinae and Phascolarctinae. In general, the bunoid group are without styles or intermediate conules while the selenoid group usually have at least traces of both styles and conules, but in these respects there are exceptions in both groups. ${ }^{1}$ Several theories have been advanced as to the origin and mutual relationships of the two groups. Winge considered them derivative the one from the other and regarded Phascolarctos ancestral to the bunoid Phalangerinae with Pseudochirus as a connecting form. On the other hand, students of placental molars have usually inclined to the belief that, among ungulates especially, bunoid types were ancestral to selenoid. Bensley, however, comes to the conclusion that "the molars of the Phascolarctinae and Phalangerinae have been derived by a divergent evolution from a common insectivorous secodont type," that is, independently from a tritubercular or post-tritubercular type similar to that seen in the Peramelidae. This divergent evolution took place, according to Bensley, as follows:

I. The selenoid type evolved by the simple addition of a hypocone and the reduction of the styles, no change in the shape of the principal cusps being required since they are already selenoid in the tritubercular molar. This method was recognized also by Winge. For the production of the molar of Pseudochirus the addition of the intermediate conules was further required and that these were secondary elements which arose de novo seems to have been taken for granted, although, as shown later, there is some evidence that they are not.

2. The bunoid type evolved also by reduction of styles but accompanied by a lowering of the principal cusps and a gradual change in their form from crescentic to subconical. These and other changes involved

${ }^{1}$ In the Phalangerinae, traces of a metaconule occur in Petaurus and a large persistent style is present in Dactylopsila. On the other hand, the Phascolarctinae include some species of Pseudochirus in which styles are lost and Phascolarctos in which conules are scarcely evident. 


\section{I22 Field Museum of Natural History - Zoölogy, Vol. XIV.}

with them are foreshadowed in the molar of Philander. As in the selenoid group the quadrate form was produced by the addition of a hypocone.

It is in their relation to these theories of the origin of bunodont and selenodont molars and also to some of the still more debatable theories of the general evolution of mammalian teeth that the molars of Canolestes must be viewed. The essential difference between the bunoid and selenoid groups of Phalangeridae is in the shape of the outer labial cusps of the upper molars, these being in the one convex in their external aspect and in the other concave. Judged by this character alone, the molar of Canolestes at once classifies itself with those of the bunoid Phalangerinae. Among these, however, it stands out as a relatively primitive type. This is evidenced by (a) the high lanceolate labial cusps, (b) the difference in height between the labial and lingual cusps, (c) the practical absence of a hypocone in the third molar (d) the presence of a distinct metaconule in the first, second and third molars. ${ }^{1}$ When, in addition to these characters of the molars themselves, the primitive nature of the antemolar formula is considered, it is clear that there are strong reasons for considering the molar of Canolestes as possibly prototypal to those of the Phalangerinae. It is of course conceivable that it is now becoming specialized in an insectivorous direction secondary to a previous bunodont stage. This possibility is suggested by the cursorial adaptations in the skeleton of Canolestes, but, as shown by the Peramelidae, these may accompany relatively slight modifications of molar structure.

Assuming that the molar of Canolestes represents a late stage in the development of bunodonty, it becomes difficult to harmonize it with current theories. Such a molar would scarcely be produced by the lowering and thickening of cusps which appear in Philander. These changes are only relatively slight deviations from the conditions prevailing among all Didelphiidae. They are seen to some extent also in Didelphis where, as in Philander, they are probably related to habits which are more frugivorous and omnivorous than those of Peramys and Marmosa. It is conceivable that they might have led either to the bunoid or the selenoid section of the Phalangeridae or to some of the conditions seen in the Peramelidae. But they cannot be accepted as any indication of the genesis of the quadrate buno-lophodont molar of Canolestes.

How, then, was this molar derived? Considerable evidence points to a possible evolution by persistence of stylar elements rather than by their reduction and total elimination. The theories of Bensley and others, with the exception of Winge (I882), invariably give a minor role

${ }^{1}$ The interpretation of the metaconule as primitive is discussed on a later page. 
to the styles, although they are so highly developed in the tritubercular molar. They are supposed to grow up from the cingulum and then to shrink back into it to complete extinction. In some cases this may occur, especially in placentals, but in the marsupials there is much to show that the styles have played an important part and that they may be the principal elements preserved in the outer cusps of the molars of Canolestes and the bunoid Phalangerinae. In some cases they may have wholly supplanted the paracone and metacone and in others they may have fused wholly or partly with them, the resulting cusp usually preserving more of the character of the style than of the so-called primary cusps. This hypothesis favors Winge's theory that the styles are the original elements of the molar crown persistent from the triconodont stage, but it is only facts bearing on the evolution of the bunoid molar from the tritubercular that are of present importance. Some of these are the following:

I. The stylar elements of the molar crown are deep-seated structures, being recognizable in many early mammals and in developmental stages of recent ones.

2. They occupy the outer or labial side of the teeth which is phylogenetically older than the inner or lingual.

3. They are well developed in polyprotodont marsupials and show a high degree of consistency in general relations (Bensley, 1906).

4. Morphologically they are bunoid, at least conical or compressed conical in section.

5. The cusps of the trigon in the tritubercular molar are selenoid, essentially alike and essentially different from the styles.

6. Hence the crown of this molar consists of two elements one of which is fundamentally bunoid and probably primitive while the other is selenoid and secondary.

7. The styles are situated directly over the buccal roots and in line with the primitive longitudinal axes of the premolars in the identical position of the outer cusps of the quadrate bunoid molar.

8. On the contrary, the paracone and metacone are midway between the lingual and buccal roots and in order to become the outer cusps in the bunoid molar would require not only a change in form but a migration from their position.

9. Aside from the confusing factors introduced by minor adaptations, therefore, the general relations in the tritubercular molar are favorable for positive participation of stylar elements in the formation of the bunoid molar.

With these broader facts in view, evidence may be sought as to detailed methods of change other than that of downward reduction 


\section{i24 Field Museum of Natural History - Zoölogy, Vol. XiV.}

and elimination of styles. The high bladelike cusps in the molar of Canolestes suggest an evolution along lines similar to those which have produced the carnivorous dentitions. In the Dasyuridae, the carnivorous evolution obviously has proceeded by lateral compression and fusion of styles and cusps. In this process it is difficult in all cases to demonstrate to what extent one element dominates the other, but the styles are quite as consistent as the so-called cusps of the trigon. In Sarcophilus, the style dominates the paracone in the first and second molars and the two are evenly divided in the third. Metacone and style, on the other hand, are evenly divided in the first molar, while the metacone dominates in the third. The character of the outer aspect of the teeth in all cases seems determined by that of the styles. In Thylacinus, stylar elements persist in reduced condition anteriorly and posteriorly but in the intervening region have completely fused with the metacone, doubtless somewhat after the manner indicated in Sarcophilus. Even after these extensive changes, the resulting cusp, which is derived principally from the metacone, is situated in the same relation to the roots as the metacone of the tritubercular molar of the didelphids and dasyurids. In the carnivorous evolution, therefore, although the tendency to consolidation of cusps is very great, the styles have been reduced only when their corresponding cusps were reduced and in cases of fusion they have given their character to a large part of the combined product.

In the formation of the molar of Canolestes with its decidedly convex labial surfaces it seems probable that fusion of styles has played quite as large a part as in carnivorous forms. In the bunoid Phalangerinae it is possible that fusion and reduction may have been combined in some cases. As compared with the upper molars of other living marsupials, those of Canolestes are unique in the possession of a marked undifferentiated external cingulum. It forms a continuous faintly crenulate ledge along the bases of all the molars. A similar structure is found in various degrees of perfection in the extinct cænolestids but nothing exactly comparable occurs in modern forms. It is not necessarily evidence of reduction of styles and may easily have been developed independently. In fact an exactly analogous structure is found at the inner base of the protocone of the first upper molar and cingula of the same character appear on the lower molars to which no suspicion of reduced styles attaches. The irregular swelling at the bases of the upper molars in primitive Phalangeridae, as Dromicia and Petaurus, is regarded by Bensley as a vestigial external cingulum which "appears to be equivalent to that bearing the external styles in polyprotodont forms." In a certain sense this is apparent enough, but I believe that at most only the minor stylar elements are represented and that the principal 
ones (styles $b$ and $c$ ) are no more reduced than they are in the anterior molars of Sarcophilus in which there is a similar slight basal ridge combined with large obvious styles.

Evidence of combined fusion and reduction is seen in the first upper molar of Dactylopsila. In this the quadrate form is complete so far as the principal cusps are concerned, but there remains on the antero-external border of the tooth a single well-marked style, which is well distinguished from the paracone. Apparently the other styles have fused, but this one has changed only little and that by reduction. It is to be noted also that this style retains a primitive relation to the root. Most interesting is the fact that the antero-external surface of the paracone, that is, the part opposite the style, is concave or semi-selenoid while its posteroexternal surface is convex like that of the succeeding molars. In other words, it seems that where fusion takes place, the outer surface of the style is added to the cusp making it convex and where fusion does not take place, the outer surface remains concave as at first.

To produce a bunoid molar from a tritubercular one by this method requires less change than by reduction of styles. In the primitive Dasyurinae and in Marmosa and Peramys the styles are very welldeveloped and their convex external surfaces and sublanceolate form closely parallel the conditions in Cenolestes and some of the primitive Phalangerinae. Moreover, the paracone in these forms is obviously derived from the styles, in most cases being subordinate to them and in none reaching a stage of development which overshadows them. In the first upper molar of Phascologale cristicauda the paracone is not yet differentiated and in the corresponding tooth in Dasyurus viverrinus nearly the same condition obtains. This tooth, on account of its anterior position, is probably more primitive than those posterior to it. In these forms, its antero-external cusp has all the characteristics of a style $($ style $b$ ). A very slightly bifid tip indicates the beginning of the separation of the paracone and its complete differentiation is seen progressively emphasized in the succeeding third and fourth molars. This first upper molar in the dasyurids is at least superficially similar to the deciduous molar of the didelphids in which, as suggested by Bensley, the anteroexternal cusp appears to be the result of fusion of style and paracone and may be retrogressive. However this may be, the tendency to persistence of the styles is evident and the conclusion seems justified that the same elements are still represented in the quadrate bunoid molars of diprotodonts. If this be true it is possible that the small metaconule in the molar of Canolestes is not a new element but a persistent unfused vestige of the metacone of the ancestral tritubercular tooth. This at first seems improbable on account of the large size and 


\section{i26 Field Museum or Natural History - Zoólogy, Vol. XIV.}

functional importance of the metacone in polyprotodonts. Gregory (rgr6, p. 248) has suggested even that the metacone in these forms represents the apex of the original two-rooted tooth. It is to be noted, however, that with the reduction of the metacone spur and the growth of the hypocone the relative importance of the metacone decreases and in some cases (e. g. Dactylopsila) the postero-external cusp, presumably the metacone element, is exceeded by the hypocone which was nonexistent when the metacone dominated the tritubercular crown. In Phascologale, Antechinomys and other generalized dasyurids, the stylar element (style $c$ ) is very well-developed and only slightly exceeded by the metacone. According to Sinclair, style $c$ is well-developed also in Microbiotherium tehuelchum of the Patagonian Miocene. To totally eliminate this style and change the selenoid form of the metacone to bunodont, meanwhile transposing the relations of the two to the root, would be a much more extensive process than fusion of style and metacone or even more than increased growth of the style and elimination of the metacone. Moreover, it would be contrary to general evidence on cusp migration, most of which is negative (Gidley, I906; Tims, I903).

\section{LOWER PREMOLARS.}

Description.-The single-rooted, unicuspid, anterior lower premolar lies in series with the canine and the lateral incisors and is essentially like them in size, form, and implantation. It is separated from the middle premolar by a slight space. In the abnormal specimen having five unicuspids, this space is unaffected, indicating that the extra tooth is an anterior rather than a posterior one.

The middle premolar is two-rooted and tricuspid but it is in a rather advanced stage of reduction toward the unicuspid condition. The principal or middle cusp has taken an anterior position directly above the anterior root leaving a long sweeping curve between it and the posterior cusp. The anterior cusp is practically eliminated, although its position is still indicated by the angle between the root and the front of the main cone. A further reduction involving the loss of the small posterior cusp and root would produce a tooth like the unicuspid anterior premolar.

The posterior lower premolar, like the corresponding upper tooth, is functionally associated with the molars rather than with the anterior premolars. A slight space separates it in front from the middle premolar but posteriorly it is closely engaged with the front of the first molar. It rises considerably above the anterior teeth and even exceeds slightly the level of the molars. It has one large upright cusp rising above its anterior root and a short depressed heel which is over- 
lapped by the anterior shelf of the first molar. Thus, although higher, it is slightly shorter than the middle premolar. On its antero-external surface is a faint indication of a cingulum.

Discussion.-The lower premolars, like the upper ones, show tendencies toward the condition prevalent in diprotodonts. This is evidenced principally by the reduction of the anterior teeth and the separation of the posterior one from them to a position at the head of the row of grinding teeth. The only approach to this among polyprotodonts is seen in the Peramelidae.

\section{Lower MOLARS.}

Description.-The first lower molar has a relatively small trigonid and an enlarged talonid. The protoconid, which is only very slightly larger and higher than the other cusps of the trigonid, is connected by crests with the paraconid and metaconid. The talonid is broad and extended and the lateral angle between the protoconid and the entoconid is relatively shallow. No hypoconulid is distinguishable. A distinct external cingulum is present and continues forward to form a slight anterior shelf. The second lower molar is similar in general to the first, but is larger and its trigon is relatively wider, although still somewhat narrower than the talonid. There is a slight indication of a hypoconulid and the paraconid is flattened or even emarginate anteriorly where it meets the entoconid of the preceding tooth. The third molar is smaller than the second and approximately equal to the first. The talonid exceeds the trigon in width only very slightly and the general outline of the tooth from above is rectangular. The flattening of the paraconid is more pronounced and almost divides it into two distinct tubercles.

The fourth molar is compressed and greatly reduced in size, being narrower and only slightly longer than the trigon of the preceding tooth. The metaconid persists nearly as large and well-differentiated as in the other molars but the other cusps are rudimentary. The entoconid is slightly elevated and distinguishable; the hypoconid is represented merely by the postero-internal angle of the short blunt talonid; the protoconid has disappeared; and the imperfectly divided paraconid is vestigial. Despite its small size, this tooth is two-rooted, agreeing in this respect with the extinct form Halmariphus, but disagreeing with Garzonia.

Discussion.-The lower molars, as compared with those of primitive polyprotodonts, show three conspicuous tendencies.

(I) The reduction of the protoconid and the general reduction in size and height of the outer cusps as compared to theinner ones. (2) The elevation of crests connecting all the cusps. (3) The production of a 
subrectangular tooth by the extension of the talonid and the anteroposterior compression of the paraconid. These characteristics are seen to a somewhat lesser extent in the Peramelidae and in general they lead to conditions found among diprotodonts. The talonid still remains slightly wider than the trigon, the individual cusps are still distinctly elevated above the crests, and the molars as a whole are relatively long and narrow. These appear to be primitive features and it is evident that the lower molars are less advanced than the upper. Among the extinct cænolestids, as noted by Sinclair, some are even slightly more primitive in these respects than Canolestes while others show increased development of transverse crests making the evidence quite clear for the derivation of buno-lophodont types from tuberculo-sectorial.

\section{THE ORIGIN OF DIPROTODONTY.}

The diprotodont modification of the antemolar teeth has arisen in so many diverse groups of mammals that it may well have had different causes and courses of development in different cases. In some, however, at least the general factors involved must have been the same. It occurs in multituberculates, modern marsupials, insectivores, primitive edentates, rodents, ungulates, bats and the lemuroids. In its most specialized condition it consists in the complete suppression of all the antemolar teeth except one pair of incisors in each jaw, these being functionally modified and situated terminally. Among living marsupials, the progressive steps of this modification are illustrated by a series which is so nearly complete that, except for the incipient stages, it could scarcely be more convincing if it were in reality a linear phylogenetic series, which of course it is not. Of living forms in which diprotodonty is unmistakably developed, Canolestes undoubtedly has the most generalized dentition. From Canolestes to the more primitive phalangers, as Dromicia and Distechurus, the step is very slight; thence to the herbivorous phalangers of the genus Trichosurus and on through Hypsiprymnodon and Bettongia we come to the more typical macropods; and in Phascolomys, although in other respects it is not a true terminal member of this series, we see diprotodonty highly developed. This has been traced in great detail and described by Bensley (1903) in the important paper to which reference is so frequently necessary. Beginning with Canolestes, the gradation from one form to another is almost as complete as could be desired.

The idea that Canolestes is not a true diprotodont, but has only paralleled the diprotodonts in dentition, need not here be considered at length, since it is only dentition that is important in this connection 
and so far as that alone is concerned there could be no possible objection to considering Canolestes directly prototypal to the Australian diprotodonts. It may be said, however, that the ancestor of diprotodonts by merely a priori reasoning would at some point have the general characters of Canolestes, that is, it would have a diprotodont dentition while retaining a number of polyprotodont characters. This will be discussed elsewhere, but in the series of diprotodont dentitions we can at least place that of Canolestes as the first and most generalized among living forms.

The uncertainty lies in the steps preceding the development of the cænolestid type of dentition, for the gradations between generalized polyprotodont dentitions and the cænolestid stage of diprotodonty are not recognizable with certainty among known living or extinct forms. Hence the most constructive stages in the development of diprotodonty in this case must be supplied theoretically. Bensley, whose opinion is most important, states that "the diprotodont modification, although characteristic of the herbivorous section of the Marsupials, is the result of an insectivorous adaptation which must have been developed in the minute ancestors of the Phalangeridae during the incipient stages of the omnivorous evolution, but after the separation of the peramelid stem." $\mathrm{He}$ therefore finds the beginnings of diprotodont tendencies in small polyprotodonts such as Phascologale and Peramys which have undifferentiated lower incisors but show a slight differentiation of the median upper ones. Since primitive diprotodonts like Dromicia have upper incisors of this same character he concludes that such incisors are part of the course toward diprotodonty. With enlargement of the median lower incisors in a form like Phascologale ${ }^{1}$ he would expect a shortening of the lower jaw and consequent disturbance and reduction of the "intermediate" antemolar teeth. These conditions he finds exemplified in Dromicia and Cenolestes. This explanation by Bensley may be the true one, for it is difficult to gainsay; but if applied to Canolestes it practically assumes a direct didelphid ancestor and therefore needs careful examination. Before granting that diprotodonty arose exclusively in this manner, it may be inquired whether there is any other way in which it might have originated among marsupials. The didelphids and cænolestids were already well distinguished in the Patagonian Miocene. Hence the origin of the diprotodonty of Canolestes is still farther back, perhaps in the Mesozoic, and it is certain that the ancestral form was not the present day didelphid but an ancient generalized type, all the characters of which are not preserved in any recent forms.

${ }^{1} \mathrm{~A}$ much greater development of the anterior incisors is found in Oxygomphius frequens, a European Miocene form usually referred to the Didelphiidae. 


\section{i30 Field Museum of Natural History - Zoölogy, Vol. XIV.}

Besides the didelphids and dasyurids there are at least two other groups which may have retained some of the characters of the generalized marsupial and which may throw some light on the origin of diprotodonty. These are the Myrmecobiidae and the Peramelidae, the former group with only one living species and the latter with a considerable number. Myrmecobius, as is well known, has a very remarkable dentition combining an excessive number of molars and a relative degeneration of all its teeth. This apparently incompatible condition has been explained in at least three ways. Owen, Thomas, Leche and others believed it to be a primitive survival from ancestral forms having numerous post-canine teeth such as Dryolestes of the North American upper Jurassic. Winge has advanced the hypothesis that it is due to the retention of teeth originally belonging to the deciduous series. In this he is followed by Gidley (I9I 5), who points out that "it requires but the addition of two more permanently retained deciduous molars to equal the greatest number of post-canine teeth found in this species, namely, nine." A third explanation is offered by Bensley who believes that the extra molars of Myrmecobius are due to a "simple reduplication of teeth from the posterior position of the dental lamina" induced by "the favorable conditions of increased space in the molar region." This conclusion is obviously influenced by the reduced incisor formula of Myrmecobius which he believes is derived through the dasyurids from the didelphids which have a more primitive number of incisors. But he fails to take into account the fact that similar reductions of incisors have taken place in the early history of marsupials in Tertiary or even Mesozoic times.

To the writer, these different explanations seem equally theoretical and the original one of Owen, if stated in general terms, is not less probable than the others; that is, the resemblances between Myrmecobius and Mesozoic forms seem quite as great as those between it and the modern forms and, since other considerations point to great antiquity for several different types of marsupials, there would seem to be no great improbability in the belief that the extra molars are a survival rather than a modern development.

At the present time Myrmecobius is obviously in process of losing rather than gaining teeth. This has been noted by Gidley who says: "The variability in the molar series in Myrmecobius seems due to the presence or absence of the last molar, probably a disappearing tooth. In the upper jaw the last molar seems to be normally wanting, while the second is apparently in the process of disappearing, being sometimes present and sometimes wanting." It seems highly improbable that the causes which originally brought about an increase in the tooth formula are the same as those now producing a decrease. A more reasonable 
assumption would be that the increase took place before degeneration of individual teeth began and for a different reason. The process of reduction now beginning in Myrmecobius may perhaps be compared to the more advanced condition in Tarsipes which retains but three or at most four post-canine teeth and is evidently well on the way to an edentulous state.

Gidley makes the unequivocal statement that "There is in our present knowledge nothing to support Owen's hypothesis regarding the derivation of Myrmecobius." But in succeeding pages of the same paper he argues for an ancient origin of the Myrmecobiidae, which he supposes to have been well differentiated from the didelphids and dasyurids as early as the Paleocene. Evidently he believes in a Mesozoic ancestor for Myrmecobius and to that extent at least agrees with Owen. Whatever the case may have been with respect to the history of the extra molar teeth of Myrmecobius, the view that all the living families of marsupials were well differentiated early in the Tertiary seems to be well founded. Therefore, without reference to possibly archaic characters other than teeth, it is still possible to believe in an early predidelphid origin for Myrmecobius. As a possible forerunner of diprotodonts, the Myrmecobius line is thus entitled to some consideration. It has the same antemolar formula as Canolestes, its upper canines are somewhat reduced, and its median lower incisors are greatly specialized and relatively larger than in any other polyprotodont. These incisors are completely terminal in position and, although slightly recurved at the tips, are essentially proclivous with their roots nearly in the principal longitudinal axis of the mandible and set at a decidedly different angle from the lateral incisors. Thus the median lower incisors of Myrmecobius are essentially like those of diprotodonts. If these teeth are as much reduced as the rest of the dentition, they must have been derived from a type which might easily have led to the diprotodonts. The median upper incisors of Myrmecobius are reduced in size and slightly smaller than the lateral ones. They are set very far apart and are slightly procumbent, obviously in a secondary condition which differs from that of polyprotodonts and diprotodonts alike. Hence no conclusion is to be drawn from them although it is to be noted that the median upper incisors are widely separated at the base in diprotodonts more generally than in polyprotodonts. The first pair of upper lateral incisors are modified to meet the median lower ones as in diprotodonts and all the lateral incisors are laterally compressed. The differentiation of the median upper incisors is scarcely to be regarded as a diprotodont character for it is not pronounced except in a few extreme cases, as Phascolarctos and Phascolomys, and in many it is distinctly less than in 
some polyprotodonts. In Trichosurus, for example, and in Canolestes, the median upper incisors are less differentiated than in some species of Phascologale.

For the development of diprotodonty from such a form as Marmosa the following are among the changes which would be necessary: Reduction in number of incisors; enlargement of median lower incisors; reduction in size of canines and anterior premolars; decrease in the depth of the mandible; increase in craniofacial length; formation of short diastemmata between at least some of the teeth; assumption of proclivous and fully terminal position by median lower incisors; assumption of wholly lateral position by posterior incisors; lateral compression of incisors and development of long and forwardly directed cutting edges, especially in those of the upper jaw. All of these modifications are found to a considerable degree in Myrmecobius and in these respects this form resembles the diprotodonts more closely than do any of the didelphids or dasyurids. Whether these characteristics were more or less pronounced before the present degeneration of teeth began cannot be said, but at least it must be conceded that Myrmecobius has some claims to a position in or near the line of the diprotodonts whether it be regarded as an ancient type derived from Jurassic forms or a more recent one proceeding from the dasyurids.

Leaving Myrmecobius for further discussion later, it may now be inquired whether the peramelids could have furnished the beginnings of diprotodonty. Although Bensley finds in the Peramelidae many indications of an ancestral relation to the modern diprotodonts and an advance over the primitive dasyurids and didelphids, he is not inclined to regard the diprotodont dentition as directly derived from them. In this he was influenced largely by the undifferentiated condition of the median upper incisors in the peramelids; by the retrogressive(?) character of the upper canines and premolars, the existence of primitive and advanced stages of the hypocone in both groups, and the hypsodonty of the peramelids. The development of the hypocone and the hypsodont modifications in the peramelids are progressions beyond the most primitive stages of the known diprotodonts. But they need not be considered wholly homoplastic and their inception may have preceded the divergence of the peramelid stem. In any case they do not preclude a belief in a common ancestry for the peramelids and the diprotodonts and one which was not very remote. Such an ancestry at most need only be removed to a stage in which the hypocone and the hypsodonty were approximately at the most primitive stage common to both peramelids and diprotodonts. This would carry us back to a brachyodont condition but not to a total absence of the hypocone. So of the two characters 
involved, only one-hypsodonty—needs to be accounted for. This may well be regarded as a recent specialization for it is of a very peculiar nature, a sort of half-hypsodonty confined to one side of the teeth and not fairly comparable with the full hypsodonty of the most advanced diprotodonts.

The undifferentiated median upper incisors of peramelids and the supposed retrogressive canines and premolars, in the light of a study of Canolestes, do not seem at all unfavorable to a hypothesis that a diprotodont dentition might have proceeded from the peramelid stem. The incisors, while not differentiated for seizing as in the dasyures and didelphids, are unquestionably in a secondary condition of which no further development is seen elsewhere, unless it be among diprotodonts. These incisors have become broad and somewhat bladelike with their cutting edges in the same horizontal plane as those of the adjacent lateral incisors. In fact they are practically indistinguishable in shape from the pair of lateral incisors situated next to them. Hence it seems that the same factors which have led to modification of the lateral teeth, may have affected the median ones. The principal of these factors is the functional interaction with the lower incisors. In Perameles the three pairs of lower incisors are collectively so modified in form and especially in position that their functional relation to the upper incisors is much like that of the elongated single pair of lower incisors in diprotodonts, certainly much more so than in any other polyprotodont. They are set so closely together that their cutting edges are practically continuous. In addition they are exceedingly proclivous with their roots almost as near the long axis of the mandible as in diprotodonts. Thus the functional effect of the three incisors in Perameles is practically the same as that of the one in diprotodonts and it is probable that specialization in the lower jaw has conditioned that in the upper rather than vice versa.

Another interesting character correlated with the proclivity of the lower incisors in Perameles is found in their exposed roots, those of the first and third especially being without bony covering in front. The second incisor is more fully rooted, but the other two, although welldeveloped, are very weakly attached to the jaw. Perhaps enlargement of any one of the three might lead to the loss or reduction of the others which would result in a diprotodont dentition. This is uncertain, but it is probably fair to assume that the proclivity and the exposed roots of these teeth are indications at least of some instability, possibly following the li)ss of the fourth pair or foreshadowing a changed relation of those remaining. The reduction that has already taken place in Perameles corresponds to the reduction in the diprotodonts, that is, the first pair of lower incisors has been lost and thus one of the stages preliminary to 


\section{I34 Field Museum of Natural History - Zoölogy, Vol. XiV.}

diprotodonty has been passed. Embryological evidence so far adduced points to the conclusion that this is the case. Woodward's (1893) studies of developing teeth in the Macropodidae led him to believe that the large functional lower incisor is a persistent member of a series in which it formerly stood in second place. Wilson and Hill ( 1897 ), from extensive work on the development of Perameles, find that the first lower incisor has been lost and that the one now found in terminal position is homologous with the large lower incisor of the macropods. These authors say (p. 509): "It is interesting to compare the condition in Perameles with that described by Mr. Woodward for Petrogale. In that form he found two small calcified vestigial incisors. The anterior of these was entirely in front of the large permanent lower incisor, which latter he therefore regarded as really $i_{2}$. . . . And may it not be that Woodward's second vestigial incisor (his $i_{3}$ ) to which he was unable to recognize any ancestor, is really the homologue of our di $i_{1}$ whose legitimate successor is Woodward's $i_{2}$, the almost certain homologue of our ' $i_{1}$ ' of the adult Perameles?"

The dasyurids have the same number of lower incisors as Perameles, but whether they also have lost the first pair has not as yet been demonstrated. Embryological evidence in their case seems lacking. It was formerly supposed (Cf. Thomas, I887) that the dasyures had lost the fourth incisor and therefore that the maximum of three incisors in higher mammals represented the first, second, and third of the primitive series. The evidence for this supposition adduced by Thomas now seems inadequate, but in connection with theories of the origin of diprotodonty it would be important to know whether the dasyurids have lost the same incisor as the peramelids.

The canines and premolars, which Bensley interprets as retrogressive, constitute a similarity between Perameles and Canolestes and would seem to favor a common ancestry rather than otherwise. Whether they are in reality retrogressive is another question. Retrogression in this sense is a sort of reversed homoplasy which can be recognized only if the immediate ancestry of the form in question is known. That is, in the case of Perameles, a didelphid ancestry is essential to a belief in the retrogressive nature of its canines. On the other hand, if Perameles had no distinct didelphid ancestry but descended from a more primitive form also ancestral to the didelphids, it may have retained a primitive premolariform canine. Highly specialized canines appeared very early, in fact they were well differentiated among some early reptiles, and various Mesozoic mammals had simple single-rooted canines, but others, like the Jurassic Triconodon, possessed double-rooted or grooved canines similar to those now found in Perameles, Canolestes, and Myrmecobius- 
all of which it should be noted are forms having certain primitive characters not retained by the didelphids. Double-rooted canines are not unknown in other groups than marsupials but are very rare except in insectivores, another primitive group. Among these, premolariform canines show no evidences of retrogression. Double-rooted canines are said to occur also in the Miocene pig, Hyotherium (Beddard). In Antechinomys laniger, one of the most primitive polyprotodonts, the canine is single-rooted but has its crown distinctly premolariform. To interpret this as primitive seems quite as reasonable as to call it retrogressive (see p. I I9). Canines with lateral or antero-posterior cusps are found also in certain bats (e.g. Cynopterus, Harpionycteris). In the Miocene cænolestids the canine is mostly unknown, but in Paraepanorthus, as figured by Ameghino (1903, fig. 62), the canines are small and single-rooted, not unlike those of many phalangers. These teeth may have been derived from double-rooted ones but indicate no tendency toward them. Such a form as Paraëpanorthus, however, is evidently farther advanced in some respects than Canolestes, for its incisers are more reduced in number.

On the whole, it appears that double-rooted, groove-rooted, or premolariform canines are found almost exclusively among forms exhibiting various primitive characters. The Peramelidae are primitive in certain other respects and, although it is not unlikely that their canines may have passed through various changes prior to recent times, it seems quite as possible that they may have retained an early condition like that shown in the Jurassic Triconodon. The same may be true of Myrmecobius and of Canolestes.

The objections to a diprotodont evolution from the peramelids therefore, are not insuperable. In fact it is clear that many of the changes necessary to a transition from a didelphid to a phalanger or cænolestid are already present in Perameles and it does not seem demonstrable that these changes took place subsequent to the separation of the peramelid and diprotodont stems. In other words, the early peramelids may have become considerably differentiated from the generalized didelphoid marsupial and later divided into one line leading to the modern peramelids and another to the diprotodonts. At least, the conclusion is unavoidable that among living forms those most suggestive of what the ancestor of Canolestes and other diprotodonts was like, are the Peramelidae. Moreover, if the early Tertiary form Myrmecoboides is in reality a "properamelid," as suggested on another page (p.'142), belief in the origin of diprotodonty from this group is greatly strengthened. The following resemblances between Conolestes and Perameles are to be noted: Six or more exclusive cranial characters (see p. I ro), tooth 


\section{I36 Field Museum of Natural History - Zoölogy, Vol. XIV.}

formula, molariform teeth with hypocone, lower incisors proclivous, lateral upper incisors compressed, reduced canines and premolars, specialized posterior premolar, movable cervical rib, osseous patella, large median vagina, cursorial structure of legs, first and fifth toes of forefeet reduced, caecum small, tail not prehensile. Many of these characters, while not diagnostic of the diprotodonts as a group are present in the majority of that group and absent in the majority of polyprotodonts.

It may be concluded, therefore, that diprotodonty in the cænolestids may have originated in one of three ways:

(I) from didelphid pre Miocene types through undiscovered intermediate forms existing prior to the differentiation of the peramelids.

(2) from an ancient line now represented by Myrmecobius.

(3) from primitive peramelids after their separation from the dasyurid-didelphid stem.

The first of these is the theory of Bensley and in general of those who have followed him. The second is perhaps less entitled to consideration, but is still not wholly baseless. The third is to the writer more probable than either of the others.

\section{RELATIONSHIPS OF WYNYARDIA.}

The extinct marsupials known from the Australian region are nearly all of Pleistocene age and unequivocably diprotodont or polyprotodont. The most conspicuous exception to this is Wynyardia bassiana Spencer (I900) from beds at Table Cape, Tasmania, which are regarded as late Eocene or early Oligocene. This form, the remains of which include parts of limb bones and an imperfect skull without teeth, exhibits such a curious mixture of characters that it has so far been omitted from formal classifications. Spencer summarizes his study of it as follows: "A consideration of all the features would appear to lead to the conclusion that the fossil is the representative of a now extinct series of forms which were more nearly allied to ancestral Polyprotodonts than are any of the existing Diprotodont forms. It may, in fact, be regarded as intermediate between the former and the latter, and as indicative of a stage in the development of Australian marsupials when the ancestors of the recent diprotodontia were beginning to diverge from the original Polyprotodontid stock from which they have been developed within the limits of the Australian region."

Bensley ( 1904, p. 200) is somewhat more definite, saying: "While it would be difficult to add to the excellent comparisons presented by Spencer, it is probable that the reference to the animal as an inter- 
mediate form must be excluded, if for no other reason, on account of its large size. ... All the forms which approach the hypothetical intermediate type are of small size. Not only this, but the diprotodont modification itself may, as already explained, be shown to represent an insectivorous adaptation which could only have taken place in comparatively small animals. The relations of $W$ ynyardia are more probably with one of the advanced genera, such as Pseudochirus, Phascolarctos, or Phalanger."

Osborn (1907) says: "Among fossil forms the gap between the two suborders is largely bridged over by the extraordinary genus Wynyardia of Baldwin Spencer, which presents a perfect mélange of characters seen elsewhere only in the Opossums and Dasyures (Polyprotodonts), and in the Phalangers and Kangaroos (Diprotodonts)." Gregory (rgro, p. 214) speaks of Wynyardia as "another form that helps to bridge over the structural gap between the Polyprotodontia and the Diprotodontia." Later (Osborn, I9I0) it fails to receive formal classification.

Spencer, in summarizing the important characters of Wynyardia finds five which he interprets as indicating polyprotodont affinities. These, as numbered and stated by him are as follows:

"(I) Proportionate length to breadth of the skull, 100:67. This approximates most nearly to Dasyurus, and shows a decidedly greater width than in the Phalangeridae.

“(2) Lambdoidal crest well developed, as in Dasyurus.

“(3) Sagittal crest strongly developed, resembling that of Dasyuridae and species of Didelphys.

"(5) The wide sweep and upward curvature of the zygomatic arches, as in Dasyuridae.

"(7) The transverse elongation of the glenoid cavity, the downward produced plate of bone which forms the boundary is not connected with any structure forming part of the auditory passage. In this respect it agrees with Dasyuridae and Perameles, and differs markedly from the Phalangeridae, amongst which it forms the anterior part of a bony auditory canal."

At least the first three of these characters cannot be regarded as exclusively polyprotodont. Taking them up numerically, it is found as to (I) that, although Dasyurus and Sarcophilus have very wide skulls, polyprotodonts in general have relatively narrow ones. The ratio runs from only 39.7 in Perameles to 81.2 in Sarcophilus (see p. 99). On the other hand the average relative width is greater in diprotodonts than in polyprotodonts, the only very narrow type seen among diprotodonts being in the primitive Canolestes.

As to (2), it is to be noted that a high lambdoid crest is no more than a generic character among polyprotodonts. Within the limits of the 


\section{i38 Field Museum of Natural History - Zoölogy, Vol. XiV.}

Dasyuridae and the Didelphiidae it is extremely variable. Various diprotodonts, including most of the macropods and some phalangers have considerable indications of a lambdoid crest and in Phascolarctos it is highly developed. Thylacoleo also is described as having a high crest.

As to (3), much the same is true of the sagittal as of the lambdoid crest. In the Didelphiidae we find a high sagittal crest in Didelphis and none in the closely related Peramys and Philander. A sagittal crest of some prominence is seen in the skull of Trichosurus. Its presence is less frequent than its absence in both polyprotodonts and diprotodonts and cannot be regarded as of great significance.

Spencer's characters (I), (2), and (3), therefore, cannot be taken as evidence of the polyprotodont affinity of Wynyardia.

Characters (5) and (7) seem somewhat correlated and it is evident that in the region of the glenoid fossa and the posterior base of the zygoma we have a more pronounced resemblance to the condition in polyprotodonts than in any living diprotodont with the exception of Canolestes. In the relatively high position of the glenoid fossa, however, there is approach to the phalangers. It seems, therefore, that only one of the supposed resemblances to polyprotodonts is important and this is approximated in the primitive diprotodont Canolestes.

The resemblances to diprotodonts are almost as variable and as difficult to regard as diagnostic, but there are more of them and on the whole they seem more convincing of relationship. This is especially true if comparisons are made only with typical polyprotodonts (as didelphids and dasyurids) and with typical diprotodonts (phalangers), leaving aberrant forms, as Perameles on the one hand and Canolestes on the other, out of consideration. Thus the large squamosal is found in Phascolarctos much as in Wynyardia completely excluding the alisphenoid from contact with the parietals; and in general the squamosal tends to forward extension among diprotodonts but, while this offers considerable contrast to the condition in the Dasyuridae and Didelphidae, it is fully equalled or even outdone in the Peramelidae. One of the characters suggesting diprotodont relationship of Wynyardia is the large premaxilla but here again the peramelids must be ruled out. The relatively large cranium, the high position of the glenoid fossa, the elevated mandibular condyle, the position and shape of the anterior root of the zygoma, the massive ischium, and the proportionately long hind limbs all seem to point to diprotodont affinity in Wynyardia. Hence, while it may be agreed with Spencer and others that it combines many features of the two groups, it seems best for practical purposes to classify it with the diprotodonts and in recognition of its various unique features to regard it as the type of a distinct family, the WYNYARDIIDAE. 
A comparison of Canolestes with Spencer's figures and description of Wynyardia, although rather unsatisfactory as a basis for positive conclusions, reveals a number of points in common. These may be enumerated as follows: (1) Cranial part of skull large as compared to facial. (2) Relations of glenoid fossa to auditory meatus similar. (3) Squamosal not inflated and posterior base of zygoma somewhat Dasyurine. (4) Glenoid fossa relatively high. (5) Nasals extended anteriorly and expanded posteriorly. (6) Premaxillae large and separated from the maxillae by a suture which is only slightly oblique. (7) Mandibular condyle relatively high. (8) Femoral trochanters similar and a third tuberosity present as in Phascolomys.

Comparison of Wynyardia with extinct American forms allied to Canolestes, as Palcothentes and Abderites, also shows several interesting points. Thus Palceothentes has lambdoid and sagittal crests combined with zygomata of a type similar to those of Wynyardia and the frontals are widest in their cranial part. In Abderites, as previously noted by Spencer, the seat of the large lower sectorial tooth forms a deep transverse furrow in the mandible which seems closely comparable to the condition in Wynyardia.

Present material is not adequate for the positive conclusion that Wynyardia is intimately allied to the American forms but the above similarities are most suggestive and must be regarded at least in some degree as strengthening belief in extensive community of relationship between Australian and American marsupials, both polyprotodont and diprotodont.

\section{RELATIONSHIPS OF MYRMECOBOIDES.}

The genus Myrmecoboides was established by Gidley in I9r 5 for an incomplete lower jaw from the Paleocene (Fort Union) of Montana. It was tentatively classified as belonging to the family Myrmecobiidae and characterized as follows: "Canine semipremolariform, being irregularly triangular in cross section and but slightly curved; canine and the three simple premolars evenly spaced with short intervening diastemae. There is also a short diastema between the canine and $i_{3}$ (the position of the other incisors is not known). Fourth tooth behind the canine (probably $d p_{4}$ retained) completely molariform; true molars tritubercular, with well-developed basin heel, but with inner cusps of trigonid (paraconid and metaconid) as high or higher than main outer cusp (protoconid)."

The principal characters regarded by Gidley as suggesting possible affinity with Myrmecobius are (I) the diastemata between the premolars, 
(2) the indicated straightness of the jaw anterior to the canine, (3) the premolariform canine, (4) the compressed premolars, (5) the absence of cingula, (6) the relatively high inner cusps (metaconid and entoconid). He also points out that the extinct form differs from Myrmecobius in at least three important particulars (I) the possession of the normal number of post-canine teeth, (2) the approximation of the paraconid to the metaconid, (3) the more elevated and better defined trigonid.

Comparison of Gidley's figures and description with several species of Peramelidae shows at once that practically all the above enumerated points of resemblance are to be found in that family and none of the important points of difference. This is indicated by the following parallel:

\section{Myrmecoboides and Perameles}

Canine equal to or lower than premolars.

Protoconid and hypoconid well developed.

Paraconid and metaconid approximated.

Trigonid elevated and distinct.

Post-canine teeth seven.

\section{Myrmecobius}

Canine higher than premolars.

Protoconid and hypoconid small or rudimentary.

Paraconid and metaconid not approximated.

Trigonid not differentiated.

Post-canine teeth more than seven.

The important points of difference between Myrmecoboides and Perameles are (a) the unicuspid anterior premolar in the extinct form, (b) the large last molar with its well-developed hypoconulid, (c) the exceptionally large paraconid of the first molar, and (d) the somewhat more brachyodont condition of the molar series. The unicuspid premolar is a specialization such as might be expected in an ancestral diprotodont but the other characters are primitive and doubtless hark back to a tritubercular stage. The resemblances to Perameles are pronounced, however, and cannot be overlooked, although the classification of such an ancient form on fragmentary material has much possibility of error. In view of the many similarities to Perameles shown by Canolestes, the occurrence in the early American Tertiary of a form with distinct leanings to Perameles becomes especially significant. The hypothesis can scarcely be avoided that, provided Myrmecoboides is a marsupial, it may well be ancestral to the cænolestids. A point of especial interest and significance is the unicuspid premolar which is paralleled among marsupials only in cænolestids and diprotodonts.

\section{PHYLOGENY AND TAXONOMY.}

The great range of variation in structure and adaptive characters shown by existing marsupials makes it possible without reference to extinct forms to construct linear series in which the sequence from 
generalized to specialized types is remarkably free from interruptions. If their present distribution also be disregarded, that is, if both American and Australian forms be included, the problem is simplified. As worked out in great detail by Bensley (1903), the American Didelphiidae stand in a prototypal morphogenetic relation to the remaining groups of marsupials. This conclusion is based upon their possession of a combination of various generalized features which are distributed over at least three different Australian groups. They have the primitive tritubercular molar as in the Dasyuridae, the upper incisor formula and upper molar stylar characters as in the Peramelidae, and the pedimanous foot-structure (including incipient syndactyly in one form) as in the Phalangeridae.

As the probable ancestor of the modern Didelphiidae, Bensley finds the Oligocene Peratherium fulfilling practically all theoretical requirements including a distribution in both Europe and North America which might permit its dispersal either to South America or Australia or to both. This dispersal he supposes to have taken place in at least three radiations, the first being represented by the Australian fauna, the second by the Miocene fauna of South America and the third by the present day Didelphiidae of South America, this last being in its incipiency. The evolutionary series so thoroughly expounded by Bensley is an exceedingly plausible one in spite of its having been based largely upon existing forms. The various modern polyprotodonts are obviously reducible to a common type and, although the diprotodonts offer more difficulty, they may at least be traced from one to another. Between the two groups is a rather definite hiatus but there is little room for doubt that diprotodonts proceeded from polyprotodont ancestors. Indications of some of the steps leading from one group to the other are seen principally in the Peramelidae, the Wynyardiidae, the Myrmecoboididae and the Palæothentidae. No one of these aberrant groups is free from objection as an ideal transitional type, yet taken together they serve to bridge quite thoroughly the gap between the generalized polyprotodonts and the more primitive diprotodonts. Bensley dealt chiefly with modern Australian forms, giving relatively little attention to Wynyardia or Canolestes, and Myrmecoboides was unknown to him. But the Peramelidae he regarded as proceeding from a hypothetical stem-group called Properamelidae, one branch of which led to modern peramelids and another to the diprotodonts. This group presumably had begun to acquire subquadrate upper molars with incipient hypocones as in modern peramelids but had not developed a terrestrial foot structure. The Properamelidae themselves were supposed to have evolved from the generalized polyprotodont having the characters of the Didelphiidae 
and giving rise through another line to the Dasyuridae and modern polyprotodonts. Interesting in this connection is the fact noted by Bensley (I903, p. III) that the modern peramelids agree with the Oligocene Peratherium more closely in the character of the important styles of the molars than they do with the Australian dasyurids.

The fossil record is very incomplete but its testimony accords in a surprising degree with the hypothetical requirements of Bensley's scheme. Myrmecoboides might without serious objection be looked upon as in the direct line between the "Properamelids" and the diprotodonts, since it has begun to reduce its premolars, the first being small, unicuspid, and single-rooted as in many diprotodonts. Furthermore, Canolestes shows numerous resemblances to Perameles, so many that a common ancestry subsequent to the generalized polyprotodont stage is by no means impossible. The material representing Myrmecoboides is too imperfect to warrant more than a provisional conclusion that it may be an early stage in the line of the cænolestids. Nevertheless the evidences of affinity between Myrmecoboides, Perameles, and Canolestes cannot be overlooked. Moreover, if Myrmecoboides is in truth a representative of the early differentiation of a diprotodont stem then it is the first form of the kind to be discovered outside the southern continents and goes far toward explaining the present day occurrence of diprotodont types in both Australia and South America.

Further points of interest in connection with the resemblances of Canolestes to the peramelids are found in the slight indications of common relationship to Notoryctes. This peculiar form is so highly specialized that its affinities are very problematical, but Bensley is inclined to regard it as an offshoot of the "properamelids." Certain features of the myology (see p. 6o) and osteology of Canolestes and Notoryctes are similar and favor belief in a common (properamelid) derivation rather than otherwise. The actual course of evolution must be inferred to a considerable extent even under the best of circumstances. The view that Canolestes is a primitive diprotodont is not proved but is strongly supported by its resemblance to the peramelids which of all polyprotodonts are the ones most suggestive of the incipient stages leading from one large group to the other. It is probably not too much to say that if the cænolestids had been discovered in Australia instead of South America they would have been accepted without question as ancestral diprotodonts. This geographical difficulty is at least partly overcome by the presence of Myrmecoboides, also with peramelid affinities, in North America. Hence it is a hypothesis of considerable probability that the cænolestids, like the Australian diprotodonts, developed 
from "properamelid" ancestors and that the characters or tendencies fundamentally distinguishing them from polyprotodonts were a heritage which they had in common with the Australian diprotodonts.

Increased knowledge frequently, perhaps usually, leads to increased difficulty in defining taxonomic concepts. This is especially true if it be attempted to express both morphogenetic, and phylogenetic relationships in one and the same scheme of nomenclature. The division of modern marsupials into polyprotodonts and diprotodonts was made originally upon a morphological basis and until the discovery of extinct forms, which not only were connectant themselves but drew attention to connectant characters in certain modern forms, the two groups were clearly defined. In the case of the peramelids, a position with the polyprotodonts was generally conceded, notwithstanding their syndactyly which was otherwise characteristic of diprotodonts; Wynyardia was left without definite allocation; and Ccenolestes, as detailed in preceding pages (pp. 6-15), was regarded by some authors as a diprotodont and by others as a polyprotodont.

The foregoing study of Canolestes, while adding much to knowledge of fact, does not make classification easier. It is believed that the cænolestids and the peramelids, possibly with Notoryctes also, proceeded from the same stem as the phalangeroid diprotodonts. Hence these might be brigaded as one group. To characterize such a group on the basis of the morphological characters exhibited by modern forms, especially with relation to degree of specialization, however, seems practically impossible. After trying various alternatives and considering the present state of knowledge, no more satisfactory primary division of marsupials offers itself than the old one into Polyprotodontia and Diprotodontia. In such a classification, as already shown, Canolestes and Wynyardia may be placed with the diprotodonts. The line must be drawn somewhere and the least objectionable place for it seems to be between the cænolestids and the modern peramelids. The position of Myrmecoboides must remain doubtful until better material is forthcoming, but its close alliance with Perameles is scarcely to be doubted unless it should prove to have placental affinities. The recognition of a superfamily Cænolestoidea, as in the classification of Osborn and Gregory, serves to divide American and Australian diprotodonts and has its advantages as a matter of convenience. The modern genus $C$ cnolestes, however, need not take separate family rank but may be included in the Palceothentidae with the very closely allied extinct forms from the Santa Cruz beds of Patagonia. To rank it as a subfamily, Cænolestinae, would be convenient. 


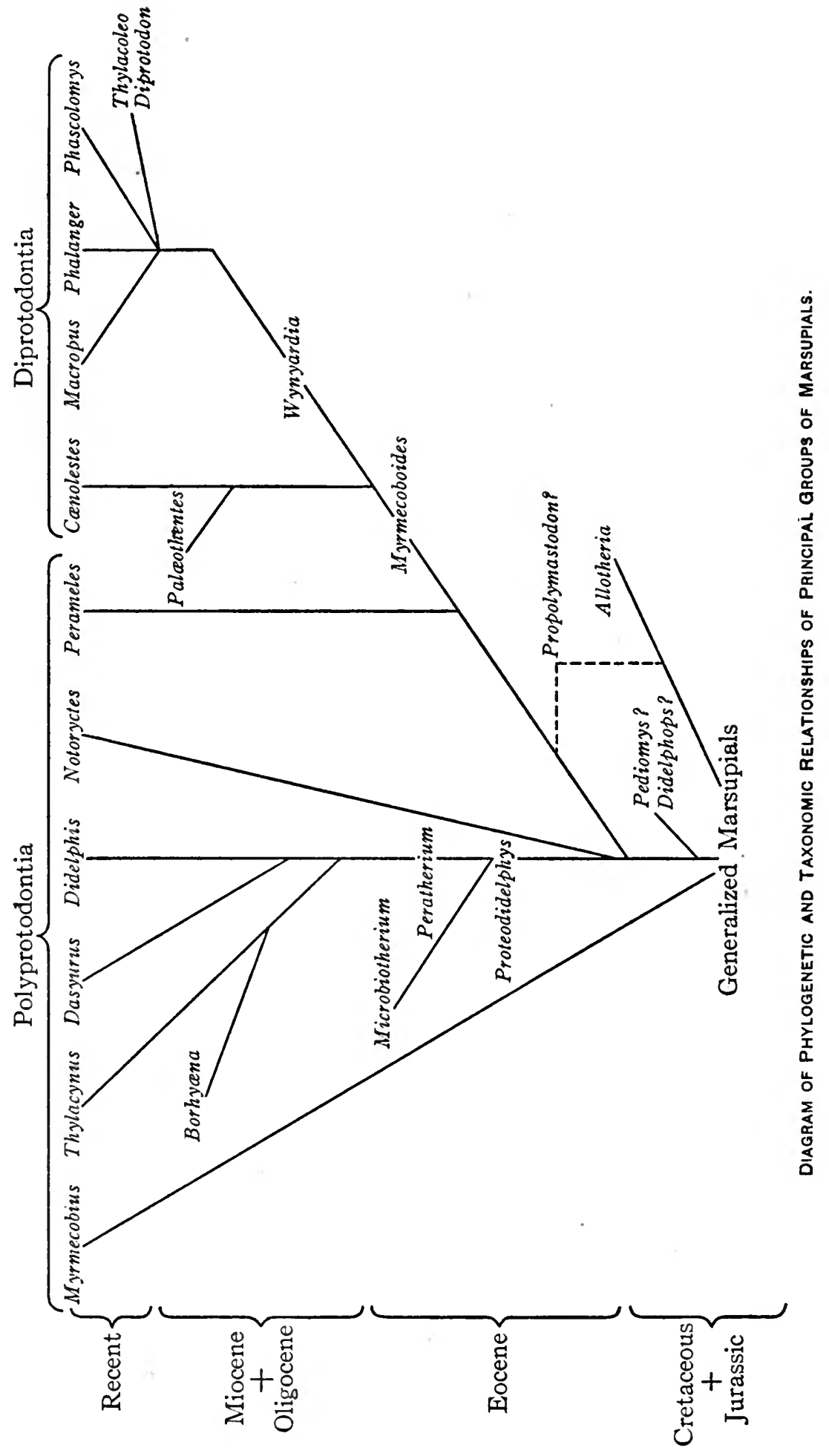


The accompanying diagram (p. I44), like others of its kind, has many shortcomings and some inconsistencies. It is offered only provisionally as an aid in indicating the relative position of Canolestes. Various problems in the phylogeny of marsupials must somehow be met in such a diagram even though they seem properly beyond the scope of the present study. So far as any conclusions are indicated, they are to be regarded mainly as suggestive rather than decisive, as indeed they would be in any case. Myrmecobius is separated from the main polyprotodont stem and from the dasyurids in order to indicate its possible direct descent from mesozoic types, but a position nearer the dasyurids is almost equally probable. ${ }^{1}$ The problem of the relationship of Propolymastodon has not been studied and its uncertain position is merely suggested (see Gregory, I9ro, p. 212). The same is true of Pediomys and Didelphops, while the multituberculates (Allotheria), which Broom contends are monotremes rather than marsupials, are indicated as probably proceeding from the unknown forms indefinitely termed "generalized marsupials" and in reality meaning very little.

\section{DISPERSAL OF MARSUPIALS.}

Broadly speaking there are only two theories of the dispersal of marsupials, one that the group originated in Holarctica and spread southward, the other that it had its beginnings in Antarctica, the hypothetical southern continent which formerly may have connected part of present-day South America and Australia. Advancing knowledge has from time to time favored one or the other hypothesis but opinions are still divided. A review of the subject with many references is given by Osborn (1910, pp. 64-80).

Before the discovery of the extensive extinct fauna of Patagonia, the distribution of marsupials offered no serious objection to a theory of northern origin for the group. Practically the only fossils known were didelphids from the Upper Miocene and Oligocene of Europe and North America, and the conclusion was fairly obvious that these might represent the ancestral stock from which both Australia and South America received their marsupial populations. The best known advocate of this theory was Wallace. A reference to his work on the Geographical Distribution of Animals ( 1876 ), however, shows at once that the information

${ }^{1}$ Although this disposition of Myrmecobius is somewhat heretical, I am led to it through the cumulative effect of encountering in this study and in the published work of others the continual necessity of special theory or explanation to account for first one and then another peculiarity of this animal. Much of this would be obviated by carrying its origin farther back. The possibilities for longer lines of descent than usually assumed is evidenced by Canolestes itself in its persistence from Miocene times to the present in practically unchanged condition. 


\section{i46 Field Museum of Natural History - Zoölogy, Vol. XiV.}

on which his conclusions were based was vastly inferior to that now available.

Although it may be admitted that some of the Mesozoic mammals were generalized marsupials, it is hardly possible to consider them in efforts to follow the course of differentiation and dispersal of the modern groups. For present purposes the multituberculates also may be disregarded. From the early Tertiary we now know relatively primitive types of marsupials from North America, Europe and South America. Correlation of these different forms has been a matter of much difficulty but according to the most recent authorities, there is little difference in age between the northern and the southern types. Thus in North America and Europe we have the didelphoid forms collectively placed in the genus Peratherium and regarded as of upper Eocene and Oligocene age. We also have in North America Myrmecoboides, which, although a less primitive form, is found in the Basal Eocene (Fort Union). Of still earlier age, but more doubtful relationship, are Pediomys and Didelphops from the North American Upper Cretaceous. From South America the most primitive type known is Proteodidelphys from the Notostylops beds the age of which has been variously placed from Lower Cretaceous to Upper Eocene. From Australia the earliest known form is Wynyardia which is of at least Oligocene age and, although not primitive, has a combination of diprotodont and polyprotodont characters which at this early period is significant.

Subsequent to these primitive types there are three large marsupial faunas the members of which show various similarities to each other and any or all of which may have been developed from the early generalized forms. These faunas are represented by (I) the Miocene fossils from South America including the cænolestids, the borhyænids and the so-called Microbiotheridae which have didelphid characteristics; (2) the present day Australian fauna with its diversity of specialization; and (3) the present day American fauna all referred to the single family Didelphiidae. The first and second of these faunas, broadly speaking, are mutually representative, that is, the South American cænolestids are at least to some degree counterparts of certain Australian diprotodonts; the borhyaenids stand in the same or even closer relation to the Australian thylacine; and probably it is not too much to say that the Microbiotheridae, in spite of didelphid similarities, are not far removed, structurally, from the generalized Australian polyprotodonts.

This correspondence between the South American Miocene forms and the Australian recent forms has not unnaturally led to the conclusion that a direct interchange between the faunas actually took place 
perhaps in Cretaceous times by means of an Antarctic land bridge. Further evidence of the former existence of such a bridge is afforded by plants, mollusks, crustaceans, insects, amphibians, reptiles, and other forms of life of which closely allied species are now found inhabiting both Australia and southern South America. Enumeration of these forms has been made at great length by various authors and need not be repeated. It is sufficient to admit that the evidence is very extensive and if the southern continent be supposed to have been one of no great permanence, but, as Hedley (I895) has indicated, may have been attenuated, irregular and unstable at many points, belief in its existence is greatly strengthened and the objections based upon geological and isostatic data do not weigh so heavily against it. To cite only a few of the believers in Antarctica, it may be said that among its most recent adherents have been Sinclair (I906), Ortmann (I905), Scott (I9I3), and Osborn (Igro). One of its earliest and most distinguished advocates was Huxley. In general it seems to have been conceded that with so much and so varied evidence there could be little doubt that some sort of connection must have existed. The northern origin of many and very important groups, however, could scarcely be denied and the general theory of mammalian dispersal was thus a bipolar theory. Nevertheless the Argentine paleontologist Ameghino went so far as to regard South America as the original home and center of dispersal of practically all the larger groups of mammals.

In contradistinction to these views and in reversal of his own previous acquiescence to belief in Antarctica, Matthew (I9I5) has presented a powerful argument for the dispersal of mammalian life exclusively from Holarctic centers. ${ }^{1}$ His conclusions are based upon a broad and comprehensive survey of geological and biological data and the similarities between certain southern faunas are regarded as exceptions to the general rule to be explained either by the imperfection of the paleontological record, by natural raft transportation, or by convergent evolution. The case of Canolestes is mentioned by Matthew and treated as one of convergence, the views of Broom and Dederer as to its polyprotodont affinities being accepted. A similar view of Canolestes and its allies has been taken by Gregory. The present study does not favor a great degree of convergence, but it tends to substantiate the opinion that an Antarctic land connection is not required to explain the presence of Canolestes in South America.

The many resemblances which Canolestes shows to the Australian

${ }^{1}$ The north polar theory had been presented also by Haacke in 1887 and by Haseman in 1912. 
peramelids would be difficult to interpret from the distributional standpoint were it not for the occurrence in the Eocene of North America of Myrmecoboides, the imperfect remains of which are so suggestive of peramelid relationship. This form seems to show that differentiation along diprotodont lines was well advanced in North America during the basal Eocene at an earlier period than the appearance of any of the South American cænolestids, all of which are of Miocene age. Since all modern peramelids are Australian while Canolestes and Myrmecoboides are American, the simplest explanation of their distribution is found in a common northern origin subsequent to the generalized polyprotodont stage; in other words, it may be assumed that the main lines of divergence between polyprotodonts and diprotodonts were laid down in the northern hemisphere. In this case the supposed convergence or parallelism exhibited by Conolestes may be merely of a superficial nature, all its fundamental characters having been derived directly from its northern ancestor.

The absence of fossil marsupials from Asia leaves us without direct evidence of the history of the group in that region, but a wide distribution of the early Tertiary fauna throughout the Holarctic region is generally admitted. Hence it may be assumed that if a division of the marsupial stem had taken place in the early Tertiary of North America the same division or one arising in a similar manner may have extended to Eurasia and thence to Australia. The lack of ancient fossil types from Australia is almost as complete as that from Asia. Still it is important to note that Wynyardia, from the Upper Eocene or at latest Oligocene, is the oldest known Australian form and has many diprotodont characters. Moreover, the diprotodonts exhibit various primitive features, in some respects (e. g. auditory ossicles) being more primitive than the didelphids. They reached a very high degree of specialization in the Pleistocene of Australia when such forms as Diprotodon and Thylacoleo were abundant. At the present time the group is decidedly the dominant one in Australia.

The time of the introduction of marsupials into Australia has been variously estimated from the Jurassic to the Eocene, recent authors being inclined to the later period. Bensley concludes that it is "unlikely that the marsupial radiation could have begun until well on into the middle of the Tertiary period." Elsewhere (I903, p. 86) he speaks of the possibility "that the ancestors of the Australian fauna passed the incipient phases of their evolution in another country, such as Asia or even South America." The same idea is expressed by Matthew (I9I5, p. 267 ) as follows: 
"There is nothing unlikely in the view that they (Diprotodonta) originated primarily in the North like their polyprotodont and allotherian relatives and were driven southward with the former group and somewhat more thoroughly extinguished in the north, while in Australia they blossomed out into a great adaptive expansion paralleling the absent ungulate mammals."

Therefore, the conclusion that the South American and Australian marsupials had a common Holarctic origin is in accord with the contentions of Matthew as to the origin of mammalian life in general. In fact the case of Canolestes might be regarded as exemplifying the manner in which he has assumed that forms with irregular distribution are to be explained. Thus it is not only a case in which some convergent development may have occurred, but also one in which a slight addition to the fossil record (i. e. Myrmecoboides) is of great importance.

The evidence in this case may be divided as follows:

I. The many primitive features of Canolestes indicating the possible development of diprotodont characters very early in the history of the order Marsupialia.

2. The existence of very primitive characters among Australian diprotodonts (see Gregory, 1910, p. 227).

3. The large number of minor resemblances between Canolestes and the peramelids.

4. The probable affinity of Myrmecoboides to the modern peramelids.

5. The correspondence of Myrmecoboides with the hypothetical ancestor of diprotodonts, that is, the "properamelid" of Bensley.

6. The diprotodont characters shown by the earliest known Australian fossil, Wynyardia.

7. The lack of any special affinity between the cænolestids and the didelphids.

8. The probability of a more ancient origin for various marsupial groups than has been supposed (see Gidley, I9I5, p. 400).

9. The fact that the Miocene cænolestids were specialized to a high degree and coeval with polyprotodont types which differed from them in essentially the same characters as those which separate modern diprotodonts and polyprotodonts.

I0. The presumption of a northern origin of all mammalian groups as indicated by Matthew. 


\section{GENERAL SUMMARY.}

The most significant results of the foregoing study may be summarized as follows:

I. Canolestes is a surviving member of an ancient group and retains many primitive characters.

Among these may be mentioned: (a) small size and insec.tivorous habits; (b) in the brain - the very large olfactory bulbs and tubercles and the small simple cerebellum; (c) in the myology - the agreement in certain respects with edentates and insectivores, as in the divided trapezius, the dorso-cuticularis, the reduced sartorius, the sesamoid origin of the supinator and the absence of the pronator quadratus; (d) in the reproductive system - the possession of a median vagina of similar primitive type to that of Perameles; (e) in the alimentary canal-the short colon; (f) in the skeleton- - the movable cervical rib and the short pubic symphysis; $(\mathrm{g})$ in the skull-the smooth braincase, large olfactory fossa, proximally expanded nasals, broad frontals, small paroccipital processes, annular tympanic, large persistent mastoid foramen, and columelliform stapes; $(h)$ in the dentition-the large upper incisor formula only exceeded by certain peramelids and didelphids, the large number of lower antemolar teeth, the premolariform canines.

\section{It has numerous resemblances to modern peramelids.}

These are not of equal importance, but collectively seem significant of affinity. Among them are the following: (a) in external characters-first and fifth toes of forefeet reduced and having nails instead of claws, ear with double antihelical folds, limbs cursorial, tail not prehensile; (b) in the brain-general primitive structure; (c) in the myology ${ }^{1}$ - general cursorial adaptations; (d) in the skeleton-movable cervical rib, imperforate atlas, short spine of first thoracic vertebra, ossified patella; (e) in the skull-elongate rostrum, short palatine processes of premaxillae, concave basioccipital, nearly perpendicular maxillopremaxillary suture, long fronto-maxillary union, absence of postorbital processes, lateral exposure of mastoid, small paroccipital and mastoid processes, lacrymal canal with single opening, postzygomatic foramen lacking, stapes columelliform; (f) in the dentition-large incisor formula, quadrate molars with hypocone, proclivous lower incisors, compressed lateral upper incisors, made.

${ }^{1}$ Adequate comparison of the myology of Canolestes and Perameles has not been 
premolariform canines, specialized posterior premolar; $(\mathrm{g})$ in the urinogenital system-presence of round ligament, median vaginae indicating parturition by direct median passage; $(h)$ in the alimentary canal-small caecum.

3. It has few non-marsupial characters and no great degree of specialization.

The important characters not shared with at least some other marsupials are: (a) the preorbital vacuity found elsewhere only among ungulates; (b) the large persistent mastoid foramen; (c) the large carotid canal; (d) the very short pubic symphysis; (e) the extended articular surface of the trochlea of the humerus; (f) the sesamoid in the supinator tendon.

The cardiac gland of the stomach has a counterpart in Phascolarctos and Phascolomys; otherwise it is unique among marsupials.

4. It has no especial affinity to the American Didelphiidae.

Except for a few relatively unimportant myological characters concerning which data are not available for many Australian forms, Canolestes shows practically no exclusive resemblances to the didelphids. On the other hand it differs from them in numerous characters including nearly all the above-mentioned resemblances to the Peramelidae.

5. The ancestor of the canolestids was probably a northern form which had already separated from the generalized polyprotodont stock.

This conclusion is based chiefly upon the probable affinity of Canolestes to modern peramelids and of both to the Eocene Myrmecoboides which partially fulfils the hypothetical requirements of the ancestral diprotodont. Many considerations favor this assumption.

6. The North American ancestor of the canolestids possibly extended throughout Holarctica and therefore may also have given rise to the Australian diprotodonts.

This assumes that the main lines of divergence between diprotodonts and polyprotodonts were established in the north prior to the Australian and South American radiations. Hence an Antarctic land connection is not necessary to explain the resemblances between American and Australian marsupials.

7. The phylogenetic and morphological relations of Canolestes are best expressed by classifying it in the suborder Diprotodontia, family Palcothentidae, subfamily Canolestinae. 


\section{I52 Field Musedm of Natural History - Zoólogy, Vol. XIV.}

This does not emphasize its supposed phylogenetic relationship to the peramelids, but recognizes its advance beyond them to greater morphological similarity to the specialized diprotodonts. On the basis of present findings, the only logical alternative would be to remove peramelids from the Polyprotodontia and unite them with the cænolestids in a group co-ordinate with ( $\mathrm{I}$ ) the Australian Diprotodontia and (2) the remaining Polyprotodontia. This, however, could not be done consistently without further division, especially of polyprotodonts, which does not seem advisable in the present state of knowledge.

\section{LITERATURE CITED.}

Allen, J. A.

1901. A Preliminary Study of the North American Opossums of the Genus Didelphis. Bull. Am. Mus. Nat. Hist., XIV, pp. I49-1 88, June 15, I901.

Alston, E. R.

I880. Biologia Centrali-Americana, Mammalia. I879-I882.

1880. On Antechinomys and its Allies. Proc. Zool. Soc. Lond., pp. 454-46I, 1880.

Ameghino, Florentino.

1897. Mammifères crètacés de l'Argentine. Deuxième contribution à la connaissance de la faune mammalogique des couches à Pyrotherium. Bol. Inst. Geog. Argent., XVIII, pp. I-I I 7, 1897.

1899. On the Primitive Type of Plexodont Molars of Mammals. Proc. Zool. Soc. Lond., pp. 555-57 I, 1899.

1903. Los Diprotodontes del Orden de los Plagiaulacoideos. Anales del Museo Nac. Buenos Aires, ser. 3, vol. II, pp. 81-I92, July, I903.

BARDELEBEN, KARL voN.

I894. On the Bones and Muscles of the Mammalian Hand and Foot. Proc. Zool. Soc. Lond., pp. 354-376, 1894 .

Bateson, Willias.

1 894. Materials for the Study of Variation. Pp. I-598.

BEDDARD, F. E.

1902. Mammalia. Camb. Nat. Hist. Pp. I-590. London, I902.

1895. The Visceral Anatomy and Brain of Dendrolagus bennetti. Proc. Zool. Soc. Lond., pp. 13 I-I37, figs. I-6, I 895 .

1908. On the Anatomy of Antechinomys and Some Other Marsupials with Special Reference to the Intestinal Tract, etc. Proc. Zool. Soc. Lond., p. 56I, I908.

Bensley, B. Arthur.

1903. On the Evolution of the Australian Marsupialia; with Remarks on the Relationships of the Marsupials in General. Trans. Linn. Soc. London (2), IX, pp. 83-217, 3 pls., 6 figs., I903.

1906. The Homologies of the Stylar Cusps of the Upper Molars of the Didelphyidae. University of Toronto Biological Series, No. 5, pp. I49-I59, I906.

Broou, R.

1911. On the Affinities of Canolestes. Proc. Linn. Soc. N. S. W., XXXVI, p. 3I5, I9II. 
Coues, ElliotT.

1872. The Osteology and Myology of Didelphys virginiana. Mem. Bost. Soc. Nat. Hist., II, pp. 4I-I 54, figs. I-35, 1872 .

CunninghaM, D. J.

1882. Report on Some Points in the Anatomy of the Thylacine (Thylacinus cynocephalus), Cuscus (Phalangista maculata), and Phascogale (Phascogale calura), collected during the Voyage of H. M. S. Challenger in the years $1873-$ 1876; with an account of the Comparative Anatomy of the Intrinsic Muscles and Nerves of the Mammalian Pes. Voy. H. M. S. Challenger, Zool., V, pt. XVI, pp. I-I 92, pls. I-XIII, I882.

Dederer, Pauline $\mathrm{H}$.

1909. Comparison of Conolestes with Polyprotodonta and Diprotodonta. Amer. Nat., XLIII, pp. 6I4-6I8, figs. I-2, Oct., 1909.

Doran, A. H. G.

1879. Morphology of the Mammalian Ossicula auditus. Trans. Linn. Soc. Lond., (2), I, Zool., pp. 37I-497, pls. 58-64, I879.

Gidley, James Williams.

1906. Evidence Bearing on Tooth-Cusp Development. Proc. Wash. Acad. Sci., VIII, pp. 9I-I 1o, July Io, 1906.

1909. Notes on the Fossil Mammalian Genus Ptilodus with Descriptions of New Species. Proc. U. S. Nat. Mus., XXXVI, pp. 61 I-626, I pl., 9 figs., I 909. 1915. An Extinct Marsupial from the Fort Union with Notes on the Myrmecobidae and other Families of this Group. Proc. U. S. Nat. Mus., XLVIII, pp. 395-402, pl. 23, Jan. 28, 1915.

Gregory, William K.

1910. The Orders of Mammals. Bull. Amer. Mus. Nat. Hist., XXVII, pp. I524, Feb., 1910.

1916. Studies on the Evolution of Primates. Bull. Am. Mus. Nat. Hist., XXXV, pp. 239-355, June 16, 1916.

I920. Studies in Comparative Myology and Osteology; No. IV. A Review of the Evolution of the Lacrymal Bone of Vertebrates with Special Reference to that of Mammals. Bull. Am. Mus. Nat. Hist., XLII, pp. 95-263, Dec. 4, 1920.

HAACKE, W.

1887. Der Nordpol als Schŏpfungscentrum der Landfauna. Biol. Centralblatt, VI, pp. $363-370,1887$.

Haseman, J. D.

1912. Some Factors of Geographical Distribution in South America. Ann. N. Y. Acad. Sci., XXII, pp. 9-112, May 31, 1912.

HEDLEy, C.

1895. Considerations on the Surviving Refugees in Austral Lands of Ancient Antarctic Life. Jour. \& Proc. Roy. Soc. N. S. W., XXIX, pp. 278-286, I895.

HILL, JAMES P.

1899. Contributions to the Morphology and Development of the Female Urogenital Organs in the Marsupialia. I. On the Female Urogenital Organs of Perameles, with an Account of the Phenomena of Parturition. Proc. Linn. Soc. N. S. W., XXIV, pp. 42-82, 12 pl., 3 figs., i 899.

1900. Contributions to the Morphology and Development of the Female Urogenital Organs in the Marsupialia. II. On the Female Urogenital Organs of Myrmecobius fasciatus. Proc. Linn. Soc. N. S. W., XXV, pp. 519-532, pls. XVII-XIX, I900. 


\section{r54 Field Musedm of Natural History - Zoölogy, Vol. XiV.}

HUXLEY, T. H.

1880. On the Application of the Laws of Evolution to the Arrangement of the Vertebrata, and More Particularly of the Mammalia. Proc. Zool. Soc. Lond., pp. 649-661, 1880.

JENTINK, F. A.

1885. A Monograph of the Genus Cuscus. Notes Leyden Mus., VII, pp. 87-1 I9.

JOHNSTONE, JAMES.

1898. The Thymus in the Marsupials. Jour. Linn. Soc. Lond., XXVI, pp. 537-557, 3 pl., 2 figs., 1898.

1899. On the Gastric Glands of the Marsupialia. Jour. Linn. Soc. Lond., Zool., XXVII, pp. I-I 4, I pl., I fig., I 899.

1901. The Neck Glands of the Marsupialia. Trans. Liverpool Biol. Soc., XV, pp. 354-362, 3 figs., 1901.

LECHE, W.

1874-1900. Bronn's Klassen u. Ordn. Thierreichs, Bd. VI, Abth. V, Mammalia, Bd. I., Leipzig, 1874-1900.

LYDEKKER, RICHARD.

1894. A Hand-Book to the Marsupialia and Monotremata. Allen's Nat. Lib., London, 1894 .

1899. The Dental Formula of the Marsupial and Placental Carnivora. Proc. Zool. Soc. Lond., pp. 922-928, p1. LXII, 1899.

Macalister, Alexander.

1870. On the Myology of the Wombat (Phascolomys wombata) and the Tasmanian Devil (Sarcophilus ursinus). Ann. \& Mag. Nat. Hist., (4), V, pp. 153173, March, 1870 .

1872. Further Observations on the Myology of Sarcophilus ursinus. Ann. \& Mag. Nat. Hist., (4), X, pp. I7-20, July, 1872.

1872. The Muscular Anatomy of the Koala (Phascolarctos cinereus). Ann. \& Mag. Nat. Hist., (4), X, pp. 127-134, Aug., 1872.

Matthew, W. D.

1915. Climate and Evolution. Ann. N. Y. Acad. Sci., XXIV, pp. I7I-3I8, Feb. 18,1915 .

Metcalf, M. M.

1920. Upon an Important Method of Studying Problems of Relationship and of Geographical Distribution. Proc. Nat. Acad. Sci., VI, pp. 432-433, 1920.

Mrtchell, P. Chalmers.

1905. On the Intestinal Tract of Mammals. Trans. Zool. Soc. Lond., XVII, Pt. V, pp. 437-535, 1905.

Ortmann, A. E.

1902. Tertiary Invertebrates. Repts. Princeton Univ. Exped. to Patagonia, IV, Paleon., pp. 45-332, pls. XI-XXXIV, April I9, 1902.

Osborn, Henry Fairfield.

1907. Evolution of Mammalian Molar Teeth. Pp. I-250. New York, 1907. 1910. The Age of Mammals in Europe, Asia and North America. Pp. XVIII635. New York, October, 1910.

OsGood, WiLfRed H.

1912. Mammals from Western Venezuela and Eastern Colombia. Field Mus. Nat. Hist., Zool., X, pp. 33-66, Jan. Io, 1912. 
PARsons, F. G.

1896. On the Anatomy of Petrogale xanthopus, Compared with that of Other Kangaroos. Proc. Zool. Soc. Lond., I896, pt. 3, pp. 683-714, Io figs., I 896.

I898. The Muscles of Mammals with Special Relation to Human Myology. Journ. Anat. \& Phys., XXXII, pp. 428-450, 72 I-752, I 898.

I 898. The Limb Myology of Gymnura rafflesii. Journ. Anat. \& Phys., XXXII, pp. 312-324, 1898 .

1903. On the Anatomy of the Pig-footed Bandicoot (Charopus castanotis). Journ. Linn. Soc. Lond., Zool., XXIX, pp. 64-8o, Io figs., I903.

Poulton, E. B.

1883. On the Tongues of the Marsupialia. Proc. Zool. Soc. Lond., pp. 599-628, pls. LIV-LV, I883.

RUGE, GEORG.

1878. Untersuchung über die Extensorengruppe am Unterschenkel und Füsse der Säugethiere. Morph. Jahrb., IV, pp. 592-643, pls. XXXII-XXXV, I878.

1878. Zur vergleichenden Anatomie der tiefen Muskeln in der Fusssohle. Morph. Jahrb., IV, pp. 644-659, pls. XXXIV-XXXV, I878.

Scotr, W. B.

1913. A History of Land Mammals in the Western Hemisphere. Pp. I-693. Sidebotham, E. J.

1885. On the Myology of the Water-Opossum. Proc. Zool. Soc. Lond., pp. $6-22,1885$.

Sinclair, W. J.

1905. The Marsupial Fauna of the Santa Cruz Beds. Proc. Amer. Philos. Soc., XLIV, pp. 73-81, 2 pls., I905.

1906. Mammalia of the Santa Cruz Beds. Marsupialia. Repts. Princeton Univ. Expeds. to Patagonia, IV, Paleon., I, pp. 333-46o, Sept. 14, 1906.

SPENCER, BALDWIN.

1900. A Description of Wynyardia bassiana, a Fossil Marsupial from the Tertiary Beds of Table Cape, Tasmania. Proc. Zool. Soc. Lond., pp. 776-794, pls. XLIX-L, 1900.

Stirling, E. C.

I891. Description of a New Genus and Species of Marsupialia, Notoryctes typhlops. Trans. Roy. Soc. South Aust., XIV, pp. I54-I87, pls. II-IX, I89I.

STONE, WiTMER.

1914. On a Collection of Mammals from Ecuador. Proc. Acad. Nat. Sci. Phila., pp. I7-I9, Mch. 31, I9I4.

Sweet, Georgiana.

1904. Contributions to our Knowledge of the Anatomy of Notoryctes typhlops Stirling. Parts I and II. Proc. Roy. Soc. Victoria, N. S., XVII, pp. 76-I I I, 4 pls., I904.

1907. The Skin, Hair, and Reproductive Organs of Notoryctes. Contributions to our Knowledge of the Anatomy of Notoryctes typhlops Stirling. Parts IV-V. Quart. Jour. Micr. Sc., LI, pp. 325-344, 2 pls. I fig., I907.

Symington, JoHnson.

1898. The Thymus Gland in the Marsupialia. Jour. Anat. \& Phys., XXXII, N. S. XII, pp. 278-29I, figs. I-4, 1898 .

Thomas, OldField.

1887. On the Homologies and Succession of the Teeth in the Dasyuridae. Philos. Trans. Roy. Soc. Lond., CLXXVIII, B, pp. 443-462, pls. 27-28, I887. 


\section{I56 Field Museum of Natural History - Zoölogy, Vol. XIV.}

1888. Catalogue of Marsupialia and Monotremata in the British Museum. Pp. I-40I, pls. I-XXVIII, 1888.

1895a. Descriptions of Four Small Mammals from South America, Including One Belonging to the Peculiar Marsupial Genus "Hyracodon" Tomes. Ann. \& Mag. Nat. Hist., (6), XVI, pp. 367-370, Nov., 1895.

1895b. On Canolestes, a Still Existing Survivor of the Epanorthidae of Ameghino. Proc. Zool. Soc. Lond., p. 87o, 1895.

1896. On Canolestes n. g. of Marsupials. (Abstr.) Zool. Anz., XIX, no. 493, p. $31,1896$.

1917. Preliminary Diagnoses of New Mammals Obtained by the Yale-National Geographic Society Peruvian Expedition. Smiths. Misc. Coll., LXVIII, p. 3, Apr. ro, r9i7.

1920. Report on the Mammalia Collected by Mr. Edmund Heller during the Peruvian Expedition of 1915 under the Auspices of Yale University and the National Geographic Society. Proc. U. S. Nat. Mus., LVIII, pp. 217249, pls. 14-I 5, I920.

Thompson, Peter, and Hillier, W. T.

1905. The Myology of the Hind Limb of the Marsupial Mole (Notoryctes typhlops). Jour. Anat. \& Phys., XXXIX, pp. 308-331, pls. XXXVIII-XXXIX. Tims, H. W. M.

r903. Evolution of the Teeth in the Mammalia. Jour. Anat. \& Phys., XXXVII, pp. 132-140, 1903 .

TOMES, R. F.

1860. Notes on a Second Collection of Mammalia Made by Mr. Fraser in the Republic of Ecuador. Proc. Zool. Soc. Lond., p. 213 , 1860.

1863. Notice of a New American Form of Marsupial. Proc. Zool. Soc. Lond., pp. 50-51, pl. VIII (col.), I863.

Trouessart, E. L.

r898. Catalogus Mammalium, V, p. 1205, r898.

WATERHOUSE, G. R.

1846. Natural History of the Mammalia, Vol. I., Marsupiata, 1846.

WEBER, MAX.

1904. Die Säugethiere. Pp. I-866. Jena, 1904.

WILsON, J. T.

1894. On the Myology of Notoryctes typhlops, with Comparative Notes. Trans.

Roy. Soc. South Aust., XVIII, pp. 3-74, pls. II-XV, I 894.

WILson, J. T., and Hil.L, J. P.

1897. Observations upon the Development and Succession of the Teeth in Perameles; Together with a Contribution to the Discussion of the Homologies of the Teeth in Marsupial Animals. Quart. Jour. Micr. Sci., XXXIX, N. S., pp. 427-588, pls. 25-32, 1897 .

Windle, Bertram C. A., and Parsons, F. G.

1898. On the Anatomy of Macropus rufus. Jour. Anat. \& Phys., XXXII, N. S., XII, pp. II9-134, 1898 .

Winge, Herluf.

I882. Om Pattedyrenes Tandskifte, isaer med Hensyn til Tændernes Former.

Vid. Medd. f. d. Naturh. Foren., Kjöbenhavn, pp. 15-67, 1882.

WOODWARD, M. F.

1893. On the Development of the Teeth in the Macropodidae. Proc. Zool.

Soc. Lond., pp. 450-473, 1893 .

1896. On the Teeth of Certain Insectivora. Proc. Zool. Soc. Lond., pp. 557-594. 


\section{THE BRAIN OF CAENOLESTES OBSCURUS.}

By C. Judson Herrick.

Plates XXI-XXII.

These notes are based on a single female specimen which had been preserved in formalin and later transferred to alcohol. Since the cranial cavity had not been opened before the specimen was put into the hardening fluid, the preservation of the brain is not as perfect as might be desired. In particular, the swelling of the brain tissue produced by the formalin has caused considerable compression of the brain within the endocranial cavity, thus possibly exaggerating somewhat the superficial relief, so far as this conforms to the sculpturing of the endocranial cavity, and obscuring some other features.

The brain was very skillfully removed from the skull of the alcoholic specimen in the Anatomical Laboratory of the University of Chicago by Dr. G. W. Bartlemez and drawn under the Zeiss stereo-binocular microscope by Mr. A. B. Streedain. Since it seemed desirable to preserve the brain intact in the hope of a later opportunity to prepare it for microscopic examination, this report must of necessity be limited to the superficial anatomy.

Measurements. - The dimensions as measured on the alcoholic specimen are as follows:-

Total length, tip of olfactory bulb to first spinal nerve.

Length, tip of olfactory bulb to rostral end of cerebral hemisphere

$14.1 \mathrm{~mm}$.

Length of cerebral hemisphere

$2.6 \mathrm{~mm}$.

Length of cerebellum on longitudinal axis of brain in median plane

$10.0 \mathrm{~mm}$.

Greatest width of both olfactory bulbs . . . . . $7.6 \mathrm{~mm}$.

Greatest width of both cerebral hemispheres . . . . II.8 mm.

Total width of cerebellum and flocculi . . . . . II.0 mm.

Width of cerebellum exclusive of flocculi . . . . $8.8 \mathrm{~mm}$.

For our most precise knowledge of the brains of lower mammals we are indebted to the researches of Elliot Smith. Throughout this account we shall make frequent references to his papers and base our interpretations to a large extent upon them. His papers cited in the appended bibliography give references to the other relevant literature.

The general form of the brain of this little marsupial is evident from the figures. It is apparent that we have here before us one of the simplest types of mammalian brain hitherto described. The brain is strongly macrosmatic, as shown by the enormous size of the olfactory bulbs and secondary olfactory area. 


\section{I58 Field Museum of Natural History - Zoölogy, Vol. XIV.}

The olfactory bulbs are closely appressed to each other in the median plane, convex above and concave below. They are very slightly overlapped dorsally by the cerebral hemispheres. From the widely flaring lateral borders of the bulb the lateral olfactory tract passes spinalward and ventralward along the lateral border of the very large tuberculum olfactorium.

The cerebral hemispheres extend backward quite to the cerebellum, these two structures being in intimate contact for the entire width of the body of the cerebellum. There is a very slight divergence of the posterior borders of the hemispheres from the median plane, which is somewhat exaggerated in Figure I (Pl. XXI), so that even if the meninges were entirely removed from the median longitudinal fissure (as has not been done), but little if any of the mesencephalon would be visible from the dorsal surface. This is in contrast to the usual marsupial arrangement, for the corpora quadrigemina are in most cases well exposed dorsally. (Petaurus is another exception; see Elliot Smith, '95, p. I68.)

Superficially the cerebral hemisphere, exclusive of the olfactory bulb, exhibits three chief regions:-(I) the dorsal convexity; (2) the lateral convexity, or pyriform lobe; (3) the ventral convexity, or tuberculum olfactorium.

The dorsal convexity of the hemisphere is purely neopallial; that is, it is non-olfactory cortex. About one-fifth of the distance backward from the frontal to the posterior pole of the hemisphere there is a distinct, though shallow, transverse sulcus which probably represents the sulcus orbitalis of Elliot Smith's descriptions. Otherwise the dorsal convexity is smooth.

The dorsal convexity is bounded laterally by an imperfectly developed fissura rhinalis. This begins anteriorly as a sharp sulcus in the transverse fissure between the olfactory bulb and the cerebral hemisphere at the dorso-lateral angle of the tuberculum olfactorium (P1. XXI, fig. 2) and extends backward. On the lateral aspect of the hemisphere it is obscurely confluent with the orbital sulcus, and behind this level it disappears in a depressed area on the lateral wall of the hemisphere. Two-thirds of the distance back from the anterior to the posterior pole of the hemisphere this depressed area is slightly deepened, thus marking more precisely the location of the fissura rhinalis in this region; and at the posterior end of the hemisphere there is a wide, shallow notch which marks the posterior end of this fissure (Pl. XXI, figs. I and 2).

The pyriform lobe (lobus piriformis) comprises the larger part of the lateral and ventral aspects of the hemisphere. As we have seen above, it is very imperfectly separated from the dorsal neopallial cortex, though the location of this boundary, the fissura rhinalis, is evident. 
Antero-ventrally it is separated from the tuberculum olfactorium by a very sharp fissura endorhinalis. The ventral surface of the pyriform lobe shows two shallow depressions separated by an elevated ridge running obliquely backward and lateralward from the posterior margin of the tuberculum olfactorium. Further information regarding the internal structure is desirable before the signification of this sculpturing is explained. It may be due merely to the conformation of the brain to the wall of the cranium.

The tuberculum olfactorium is very large and strongly convex ventrally. The medial borders of the two tubercula are divaricated posteriorly, exposing a portion of the anterior perforated space in front of the optic chiasma which probably includes the diagonal band of Broca (P1. XXII).

The lateral olfactory tract arises from the ventrolateral border of the olfactory bulb and can readily be seen as a clear white stripe accompanying the fissura endorhinalis. This band of fibers lies distinctly on the ventromedial side of the fissura, that is, within the tuberculum olfactorium, though we may infer by analogy with other mammals that many of the fibers are distributed within the pyriform lobe on the other side of the fissure. Microscopic examination will probably show that a portion of the tract lies in the floor and walls of the fissure.

The tuberculum olfactorium in mammals generally is a basal, that is, subcortical, reflex center, receiving olfactory fibers of the second order from the olfactory bulb. The pyriform lobe, on the other hand, is a structure of transitional type. So far as it and the underlying amygdala receive secondary olfactory fibers from the lateral olfactory tract it should be considered as a part of the basal secondary olfactory area (nucleus olfactorius lateralis). So far as its differentiated cortex is in physiological connection with this secondary olfactory area it should be regarded as archipallial in type, i. e., olfactory cortex of the same type as the hippocampal cortex. So far as its cortex is in physiological connection with the non-olfactory thalamic projection fibers it is neopallial, i. e., of the same type as the dorsal cortex. The surface characteristics suggest that in Canolestes these three components of the pyriform lobe are very incompletely differentiated, thus resembling the still more generalized reptilian condition (cf. Elliot Smith, 'ro, and Crosby, 'I7). In higher mammals, on the other hand, these components of the pyriform lobe attain much more distinct spatial localization in the gyrus hippocampi formation, though even in the human brain we find the same transitional type of structure in the uncus region.

The cerebellum.-The cerebellum is smaller and simpler than in any hitherto described mammals with the exception of Notoryctes and 
Perameles, though the elephant-shrew, Macroscelides, has a cerebellum but little more complex than that of Perameles (Elliot Smith, 'o2b).

The cerebellum is composed of a simply organized transverse body and the two lateral floccular lobes. (In the preparation of the brain the left flocculus was destroyed. In the figures it has been restored after the one on the opposite side.) Each flocculus is mushroom-shaped with a slender pedicle and a widely expanded cap or pileus, whose surface is somewhat lacerated but apparently was smooth or nearly so.

The body of the cerebellum, so far as it is visible from the surface, is a transverse bar with two shorter convolutions under its posterior border. The main bar consists of a plump median lobe and two lateral lobes, each of which is somewhat less than half the length in tr $\&$ transverse plane of the medial lobe. The median lobe and the two smaller posterior convolutions apparently correspond with the vermicular portion of higher cerebella and the lateral lobes with the hemispheres.

Since only a part of the cerebellum is visible in the undissected specimen, it is impossible to determine with certainty the homologies of the exposed structures. But comparison with the very similar cerebella of Notoryctes and Perameles as described and figured by Elliot Smith ('o3a and 'o3b) suggests that in Ccenolestes the lobus anterior and fissura prima are entirely concealed in the transverse fissure between the cerebellum and the cerebral hemispheres, the transverse bar is the lobus medius, the fissure limiting it posteriorly is the fissura secunda, the first of the two shorter convolutions is the uvula, the fissure behind the latter is the fissure postnodularis, and the posterior one of the shorter convolutions is the nodulus, these names being used as defined by Elliot Smith ('o3a).

The brain stem.-On the ventral surface (Pl. XXII) the optic nerves are seen to be very slender. Behind the optic chiasma is a rather wide tuber cinereum whose surface is somewhat obscured by meninges which in view of the poor state of preservation of the specimen it seemed inexpedient to attempt to remove. The pituitary body is mushroomshaped and elevated on a very short infundibular stalk. On account of the flexure of the brain in the isthmus region the cerebral peduncles are entirely concealed. Stumps of the third and fourth cranial nerves are seen in the usual relations.

The medulla oblongata under the cerebellum is very wide. The sculpturing of the ventral surface is obscured by pressure against the floor of the cranial cavity and posteriorly by a blood clot in the meninges. Nevertheless the roots of all of the cranial nerves were identified. The trigeminus is large, arising from the posterior border of the pons, which is very slender. The abducens is very minute and is recognized (with 
some uncertainty) at the posterior border of the pons. Immediately below the pons is a broad, flat, transverse band which is probably the trapezoid body and at whose lateral ends are the stumps of the VIII nerves. The facialis root arises from the infero-lateral surface of the trapezoid body; the IX, X and XI nerves arise from the lateral surface of the medulla oblongata; and medially of these are the XII roots. The pyramidal tracts are visible as light colored bands near the mid-iventral line extending downward from the posterior surface of the pons. At the level of the first spinal roots there is a strong cervical flexure.

General considerations. - Comparing the brain as a whole with those of other mammals, it is seen to resemble most closely those of Notoryctes and Perameles. In all three cases the rhinencephalon is enormously developed, the olfactory bulbs and tubercles being very large. The cerebral cortex is nearly smooth and apparently relative to the total size of the brain less extensive than in any other mammals hitherto described. Elliot Smith's figures of Notoryctes ('95) indicate that in this genus the cerebral hemispheres are relatively smaller than in Canolestes; his figure of the ventral surface of Perameles ('O2, p. I 7 I, fig. 52) suggests that here the hemisphere is relatively as large as in Canolestes or larger. In absolute dimensions the brain of Notoryctes is about the same size as that of Canolestes, while that of Perameles is more than three times as long. The simplicity of these brains cannot, therefore, be correlated directly with the size of the animals. In fact, our figure of the ventral view of the brain of Canolestes resembles more closely Elliot Smith's figure of the ventral surface of the larger Perameles than of the Notoryctes of equal size. Both Notoryctes and Perameles belong to the Polyprotodontia. The larger members of the Diprotodontia, such as the kangaroos, have larger and more highly convoluted brains than any of the Polyprotodontia. The brain of Canolestes is more simply organized than that of any Australian diprotodont.

\section{LITERATURE.}

Crosby, Elizabeth Caroline. 1917. The Forebrain of Alligator mississippiensis. Jour. Comp. Neur., Vol. 27, pp. 325-402.

Smith, G. Elliot. 1894. A Preliminary Communication upon the Cerebral Commissures of the Mammalia, with special Reference to the Monotremata and Marsupialia. Proc. Linnean Soc. New South Wales, Series 2, Vol. 9, pp. 635-657. 1895. The Comparative Anatomy of the Cerebrum of Notoryctes typhlops. Trans. Roy, Soc. South Australia, I895, pp. 167-193.

1899. Further Observations on the Anatomy of the Brain in the Monotremata. Jour. Anat. and Physiol., Vol. 33, pp. 309-342. 


\section{i62 Field Museum of Natural History - Zoölogy, Vol. XIV.}

1899a. The Brain in the Edentata. Trans. Linnean Soc. London, Series 2, Zoology, Vol. 7, Part 7, pp: 277-394.

1902. Descriptive and Illustrated Catalogue of the Physiological Series of Comparative Anatomy contained in the Museum of the Royal College of Surgeons of England, 2 Ed., Vol. 2.

1902a. On a Peculiarity of the Cerebral Commissures in Certain Marsupialia, not hitherto Recognized as a Distinctive Feature of the Diprotodontia. Proc. Roy. Soc. London, Vol. 7o, pp. 226-231.

I902b. Notes on the Brain of Macroscelides and other Insectivora. Jour. Linnean Soc. London, Zoology, Vol. 28, pp. 443-448.

1902c. The Primary Subdivision of the Mammalian Cerebellum. Jour. Anat. and Physiol., Vol. 36, pp. 38r-385.

r903. Notes on the Morphology of the Cerebellum. Jour. Anat. and Physiol., Vol. 37, pp. 329-332.

1903a. Further Observations on the Natural Mode of Subdivision of the Mammalian Cerebellum. Anat. Anzeiger, Bd. 23, pp. 368-384.

1903b. On the Morphology of the Brain in the Mammalia, with special Reference to that of the Lemurs, Recent and Extinct. Trans. Linnean Soc. London, Series 2, Zoology, Vol. 8, Part 1o, pp. 319-432.

1910. The Arris and Gale Lectures on Some Problems Relating to the Evolution of the Brain. The Lancet, Jan. I, I5, and 22, I9IO. 





\section{Plate II.}

\section{External Characters.}

Three times natural size.

Fig. I. Head.

Fig. 2. Dorsal aspect of rhinarium.

Fig. 3. Sole of hind foot.

Fig. 4. Sole of fore foot. 


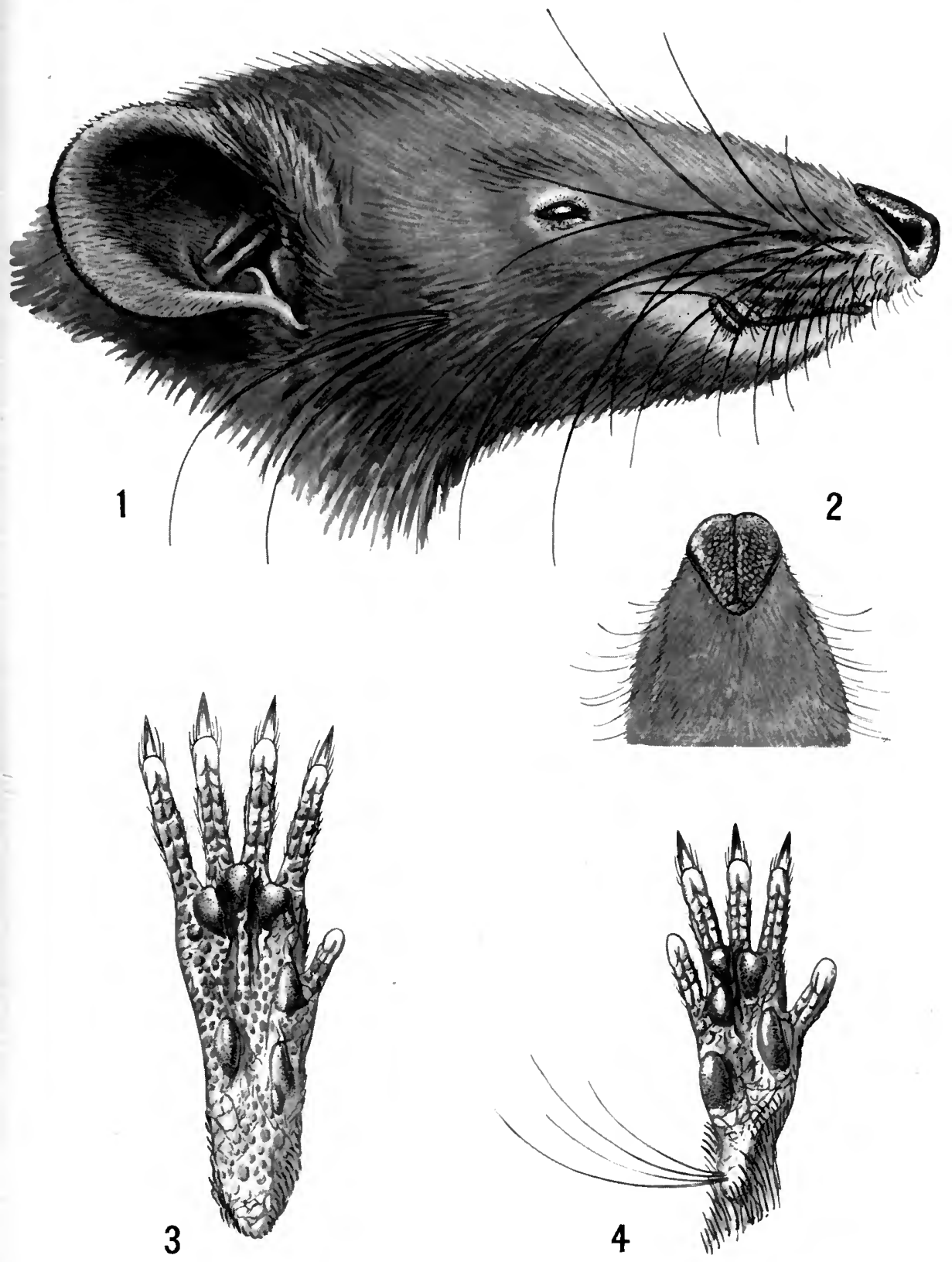

External Characters.

Three times natural size. 


\section{Tii-: 'RPARY \\ OF THE \\ HWIVERSITY OF ILLIMOIS}




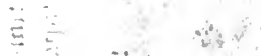

$n$
0

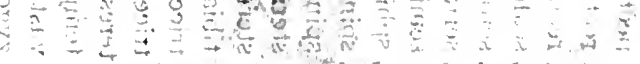

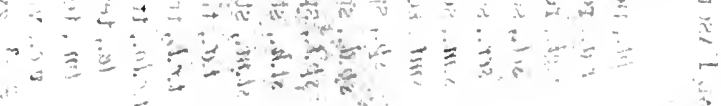

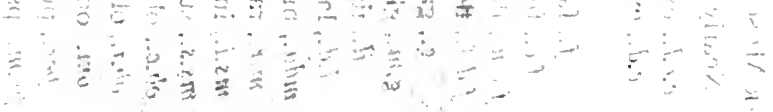

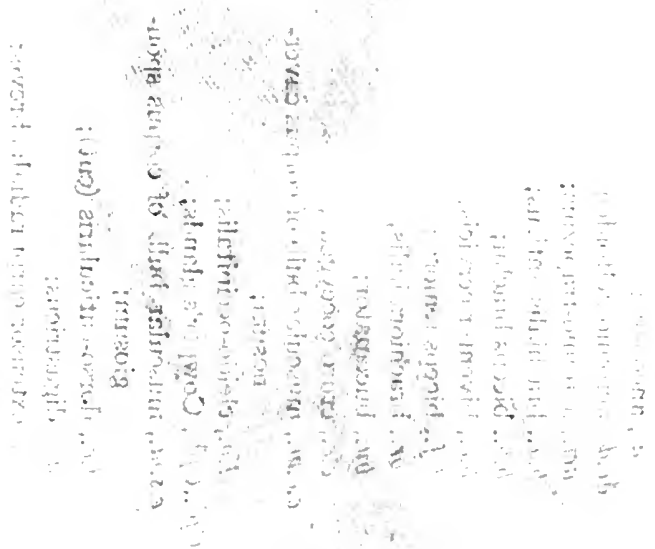

$\because 4$ 


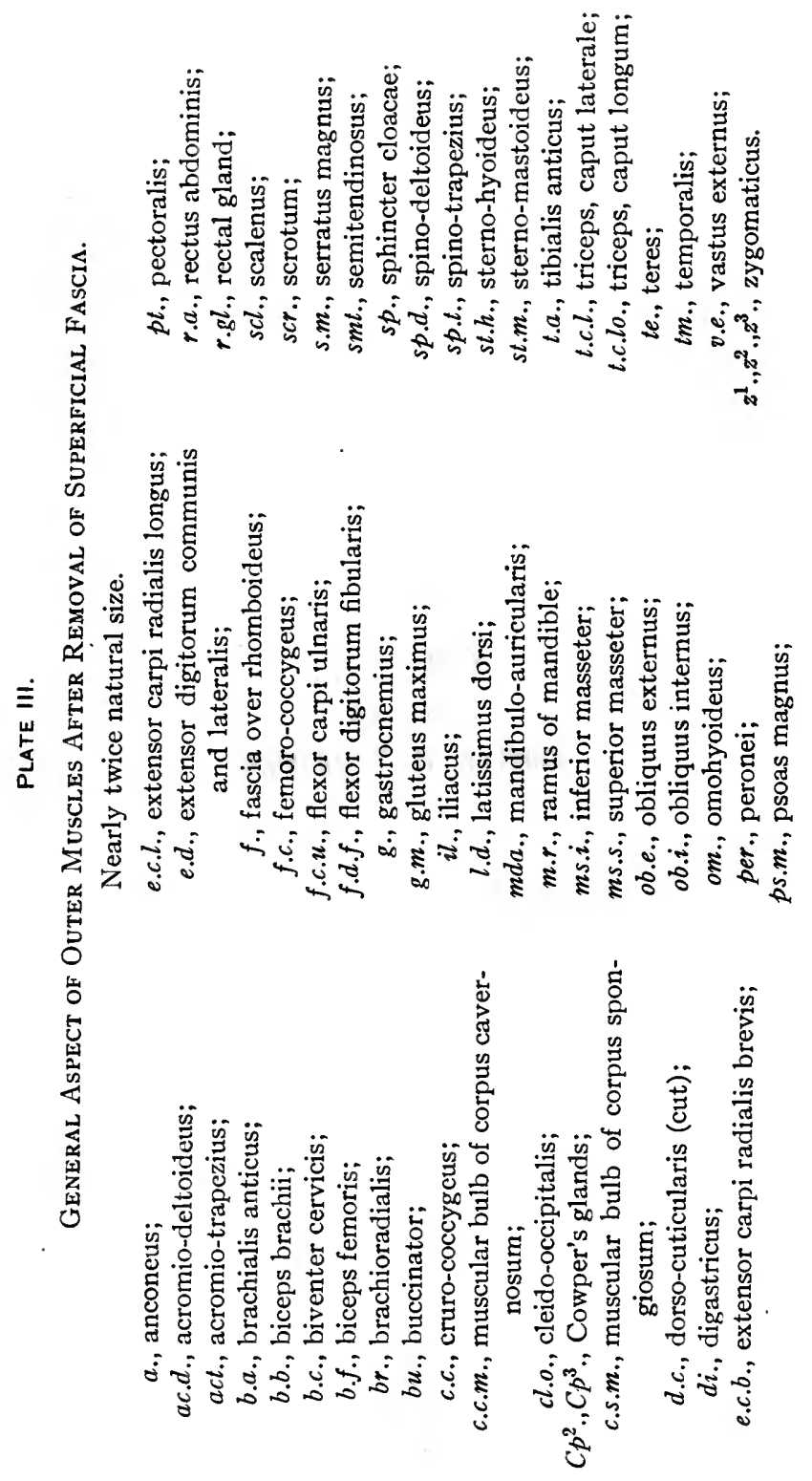


高

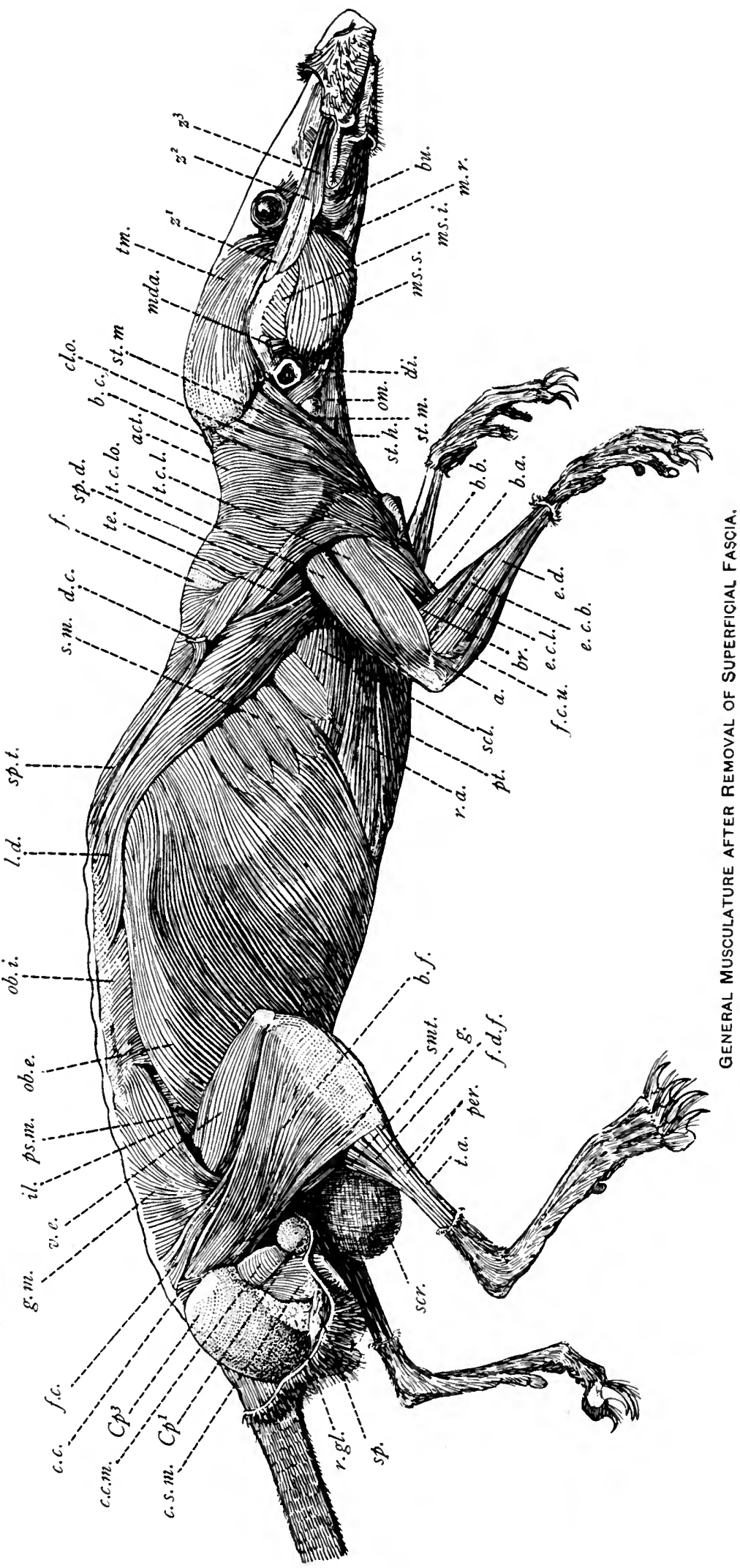


Tii.: 'DRARY

OF THE

HNIVERSITY OF ILLINOIS 


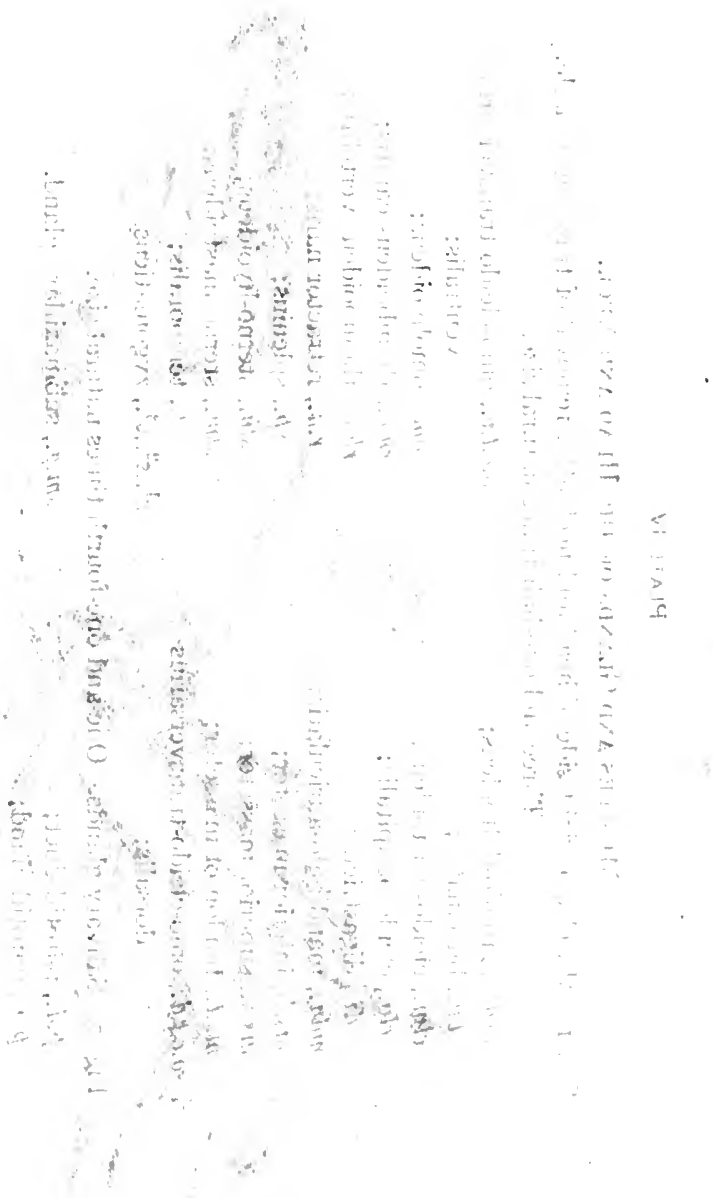




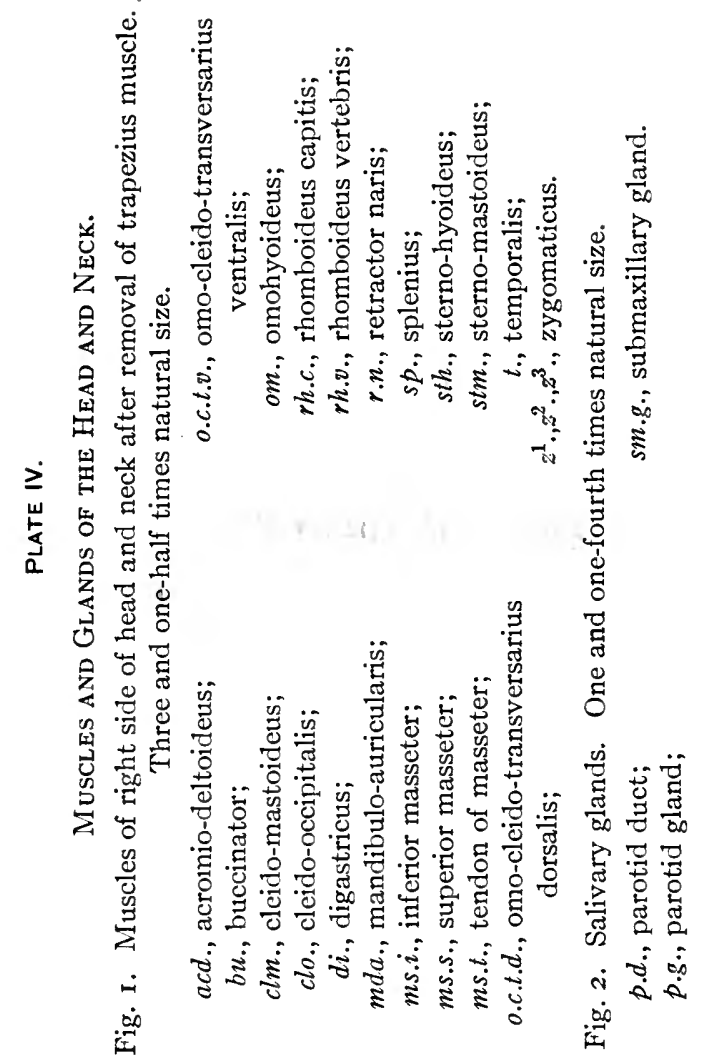




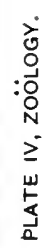

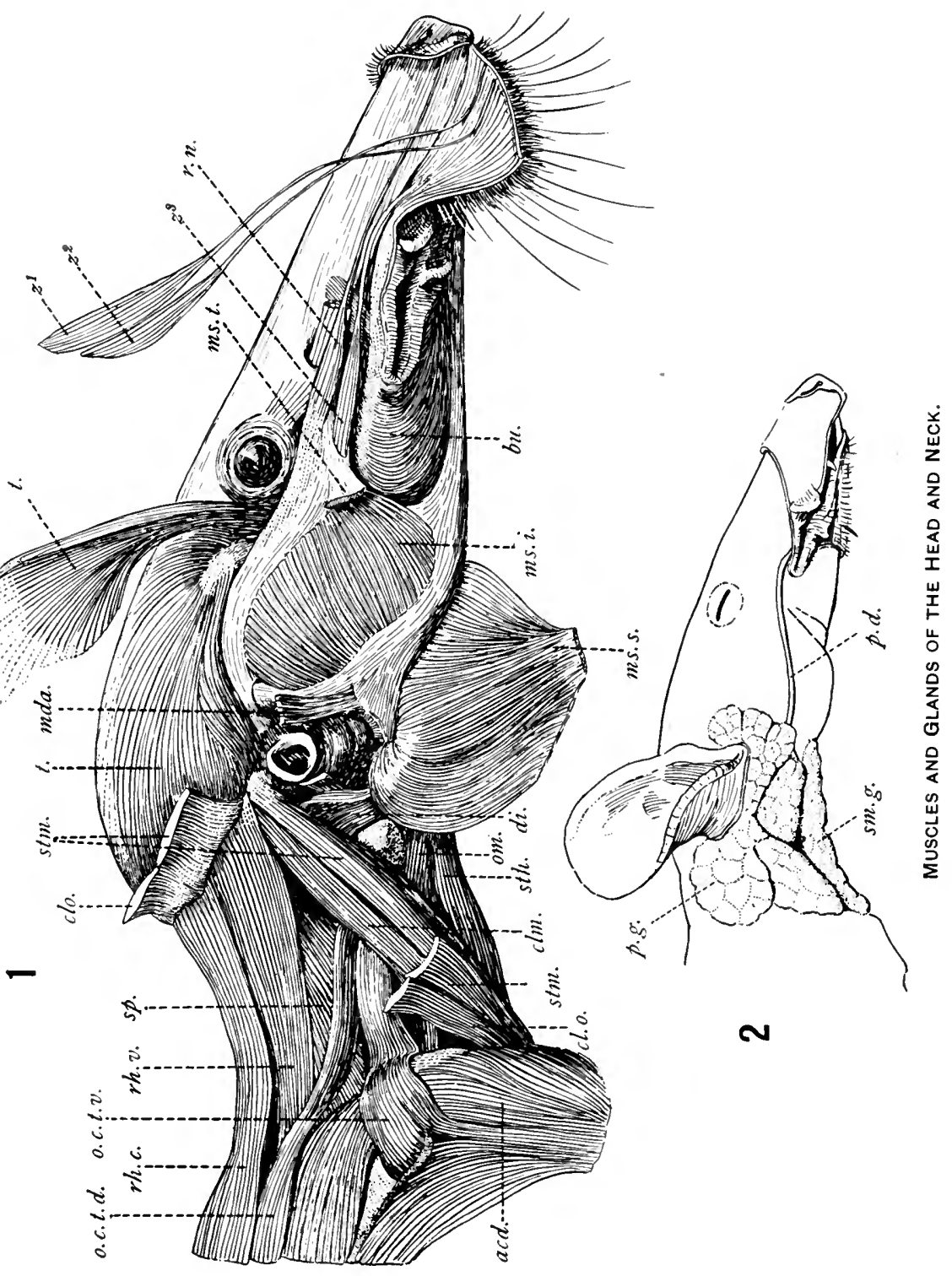




\section{TiI: : 'SRAPY \\ OF THE \\ HNIVERSITY AF IIIIIHOIS}



Plate V.

MUSClES OF THE LEGS.

Two and one-half times natural size.

Fig. I. Left hind leg from outside.

b.f., biceps femoris;

c.c., cruro-coccygeus;

$c f$., caudo-femoralis;

e.c., extensor-caudae;

f.c., femoro-coccygeus;

f.d.f., flexor digitorum fibularis;

g., gastrocnemius; g.m., gluteus maximus;

p., peronei;

r.f., rectus femoris;

$s m$., semimembranosus;

st., semitendinosus;

t.a., tibialis anticus;

v.e., vastus externus.

Fig. 2. Right foreleg from inside.

$a .$, anconeus;

b.a., brachialis anticus;

b.b., biceps brachii;

$b r$., brachioradialis;

cl., clavicle;

cl.m., cleido-mastoideus;

cl.o., cleido-occipitalis;

c.m., cutaneus maximus;

$d .$, deltoideus;

e.c.r., extensor carpi radialis brevis;

et., epitrochlearis;

f.c.r., flexor carpi radialis;

f.c.u., flexor carpi ulnaris;

f.d.p., flexor digitorum profundus;

l.d., latissimus dorsi;

l.s., levator scapulae;

o., omohyoideus; o.c.t.d., omo-cleido-transversarius dorsalis (atlanto-scapularis);

o.c.t.v., omo-cleido-transversarius ventralis (atlanto-acromialis);

p.l., palmaris longus;

p.mi., pectoralis minor;

p.mj., pectoralis major;

p.t., pronator teres;

$s c$., subclavius;

s.m., serratus magnus;

ss., subscapularis;

tr., trapezius;

t.c.l., triceps brachii, caput laterale;

t.c.lo., triceps, caput longum;

t.c.m., triceps, caput mediale;

t.m., teres major. 
FIELD MUSEUM OF NATURAL HISTORY.

PLATE V, ZOOLLOG.
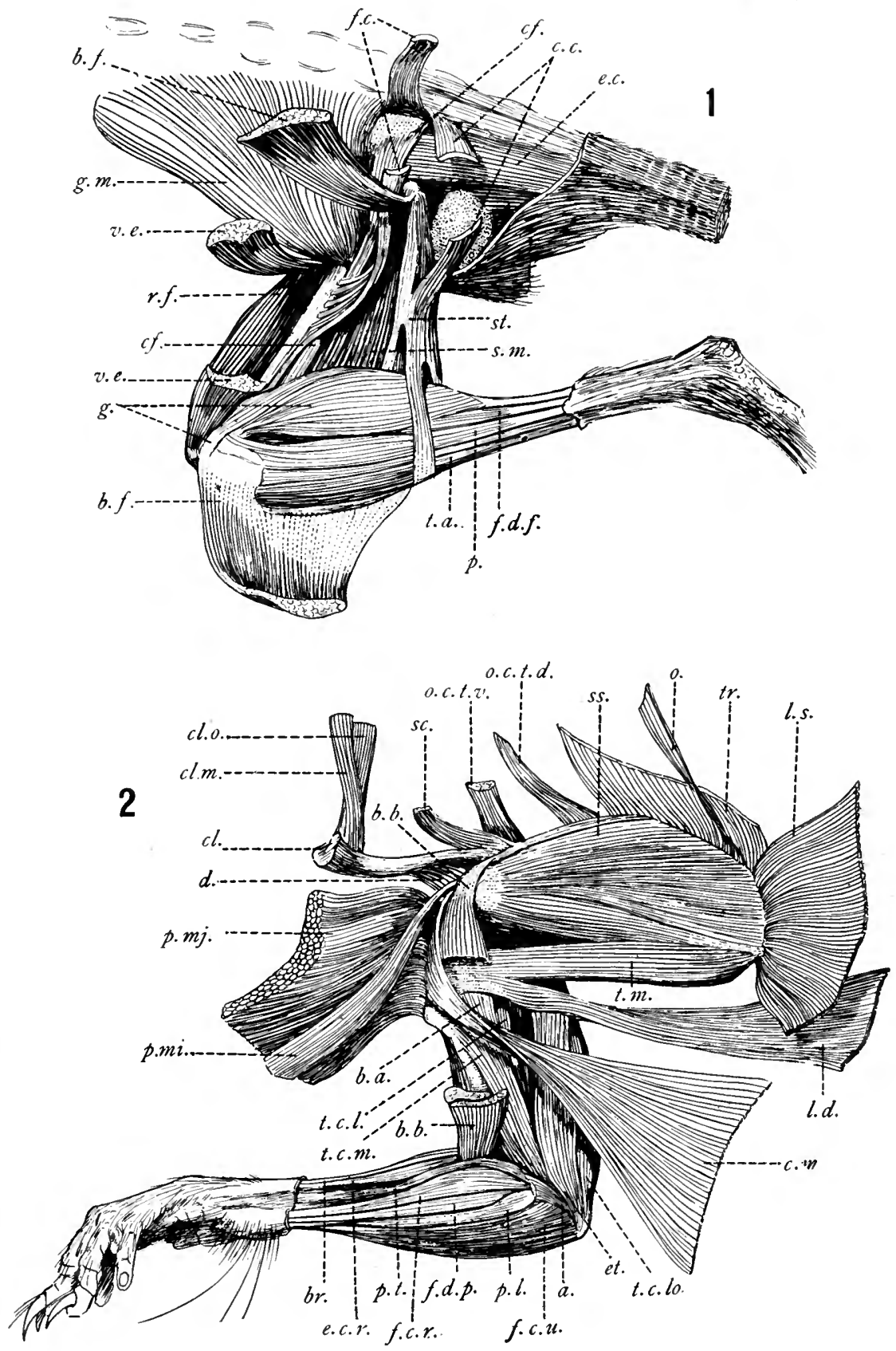

MUSCLES OF THE LEGS.

Two and one-half times natural size. 


\section{T... Brapy \\ OF THE \\ DNIVERSITY OF ILLIKOIS}




$$
\text { F. IV ITAJA }
$$

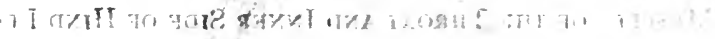

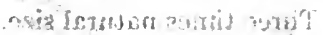

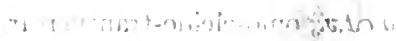

$$
\text { i. } 1, \ldots, \cdots
$$

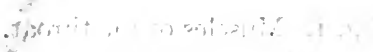

$$
\text { (1) }
$$

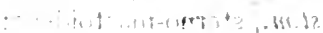

$$
\begin{aligned}
& \{i, i, i s, \ldots, j, \text { : }
\end{aligned}
$$

$i=1+1,1+\ldots$

$$
\therefore \quad i_{1}: i_{3}
$$

ic..., i i . . '

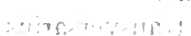

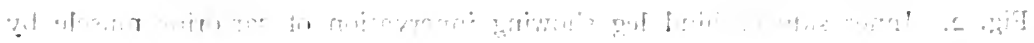

$$
\begin{aligned}
& \text { amsitomat a } \\
& \text { : } 7 \text { a }
\end{aligned}
$$

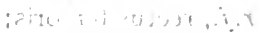

$$
\begin{aligned}
& \because \therefore \ldots 17: \%^{-},
\end{aligned}
$$

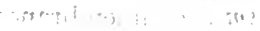

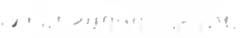

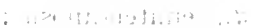

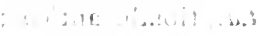

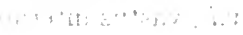

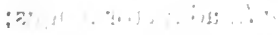

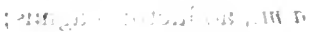

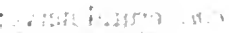

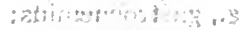

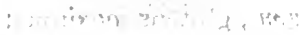

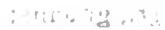

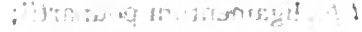

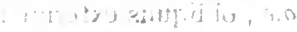

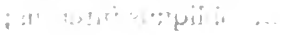

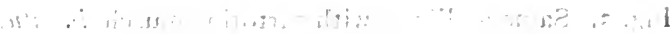


Plate VI.

Muscles of the Throat and Inner Side of Hind Leg.

Three times natural size.

Fig. I. Muscles of the throat.

cl.m., cleido-mastoideus;

cl.o., cleido-occipitalis;

o.c.t.v., omo-cleido-transversarius

$d$. digastricus;

gh., geniohyoideus;

hg., hyoglossus;

l.gl., lymphatic gland;

o., omohyoideus; ventralis;

$s c .$, scalenus;

st.h., sterno-hyoideus;

st.m., sterno-mastoideus;

st.t., sterno-thyroideus;

t.gl., thyroid glands;

o.c.t.d., omo-cleido-transversarius dorsalis;

$t . h$., thyro-hyoideus.

Fig. 2. Inner side of hind leg showing innervation of sartorius muscle by saphenus nerve.

a.l., adductor longus;

a.m., adductor magnus;

c.n., crural nerve;

g., gastrocnemius;

g.m., gluteus maximus;

gr., gracilis;

l.p., ligamentum poupartii;

o.e., obliquus externus;

$o . i$., obliquus internus;

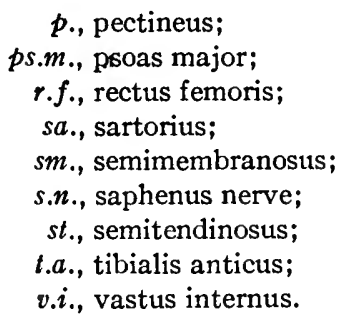

Fig. 3. Same as Fig. 2 with sartorius muscle in silu. 
FIELD MUSEUM OF NATURAL HISTORY.

PLATE VI, ZOÖLOGY.
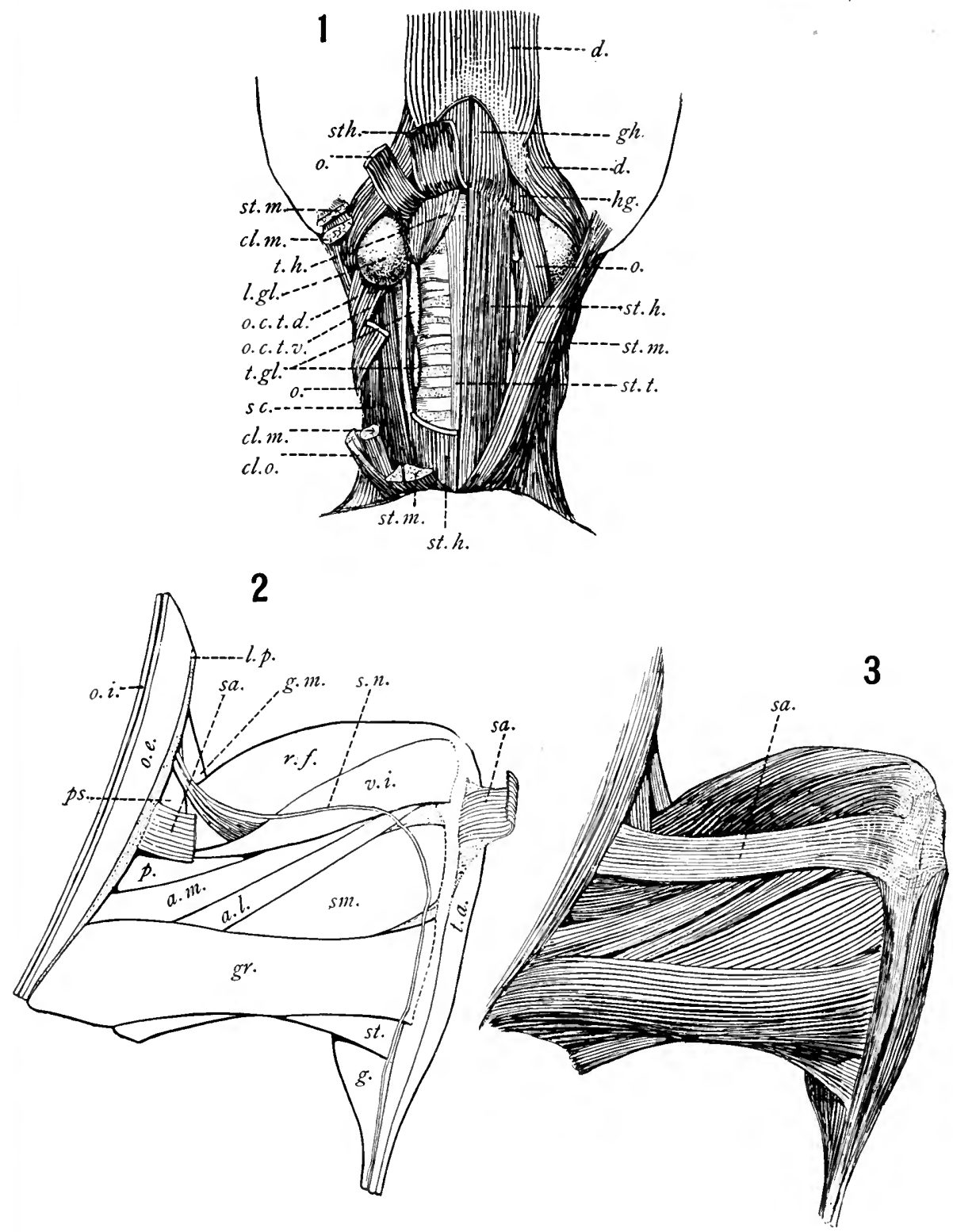

MUSCLES OF THROAT AND INNER SIDE OF THIGH.

Enlarged. 


$$
\begin{aligned}
& \text { in- : RARY } \\
& \text { OF THE } \\
& \text { ANIVERSITY OF ILIINOIS }
\end{aligned}
$$




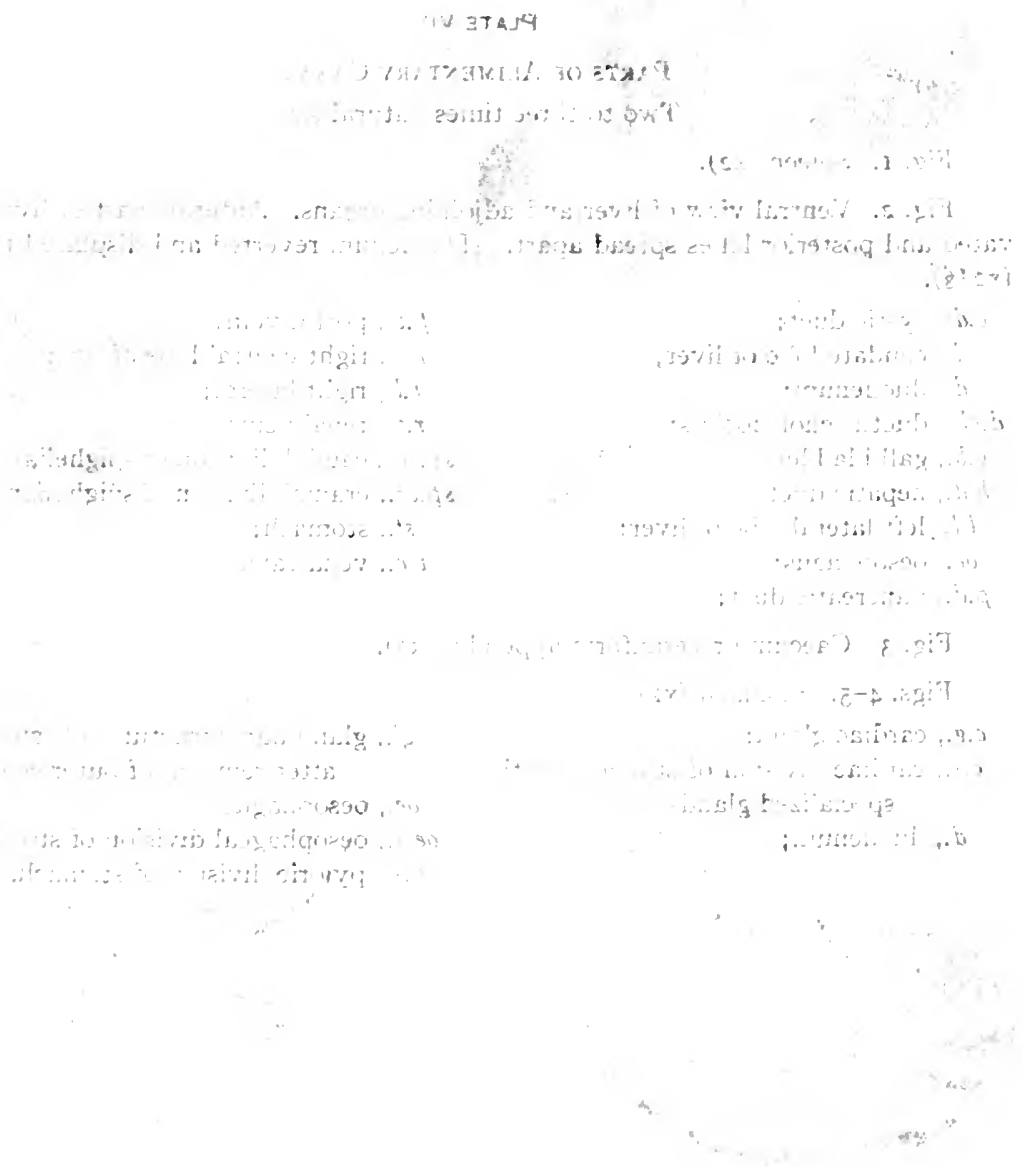


Plate VII.

\section{Parts of Alimentary Canal.}

Two to three times natural size.

Fig. I. Spleen (x2).

Fig. 2. Ventral view of liver and adjoining organs. Anterior part of liver elevated and posterior lobes spread apart. Duodenum reverted and displaced to left (x2 $1 / 8)$.

c.d., cystic duct;

c.l., caudate lobe of liver;

$d$., duodenum;

d.ch., ductus choledochus;

g.b., gall bladder;

h.d., hepatic duct;

l.l., left lateral lobe of liver;

oe., oesophagus;

p.d., pancreatic duct; p.v., portal vein;

r.c., right central lobe of liver;

r.l., right lateral;

r.v., renal veins;

sp.ca., caudal division of spighelian lobe; $s p . c r$., cranial division of spighelian lobe;

st., stomach;

\&.c., vena cava.

Fig. 3. Caecum or vermiform appendix ( $\left.x_{3}\right)$.

Figs. 4-5. Stomach (x2).

c.g., cardiac gland;

c.s., cardiac division of stomach, with specialized glands;

d., duodenum;

$$
\begin{aligned}
& g l ., \text { glandular structure of stomach } \\
& \text { after removal of outer coat; } \\
& \text { oe., oesophagus; } \\
& \text { oe.s., oesophageal division of stomach; } \\
& \text { p.s., pyloric division of stomach. }
\end{aligned}
$$


FIELD MUSEUM OF NATURAL HISTORY.

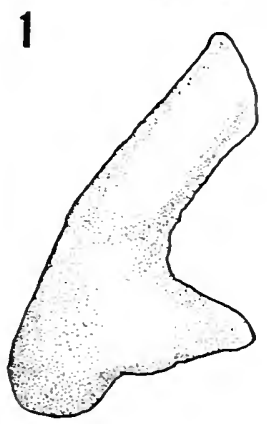

3

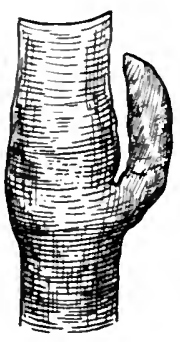

PLATE VII, ZOÖLOGY.

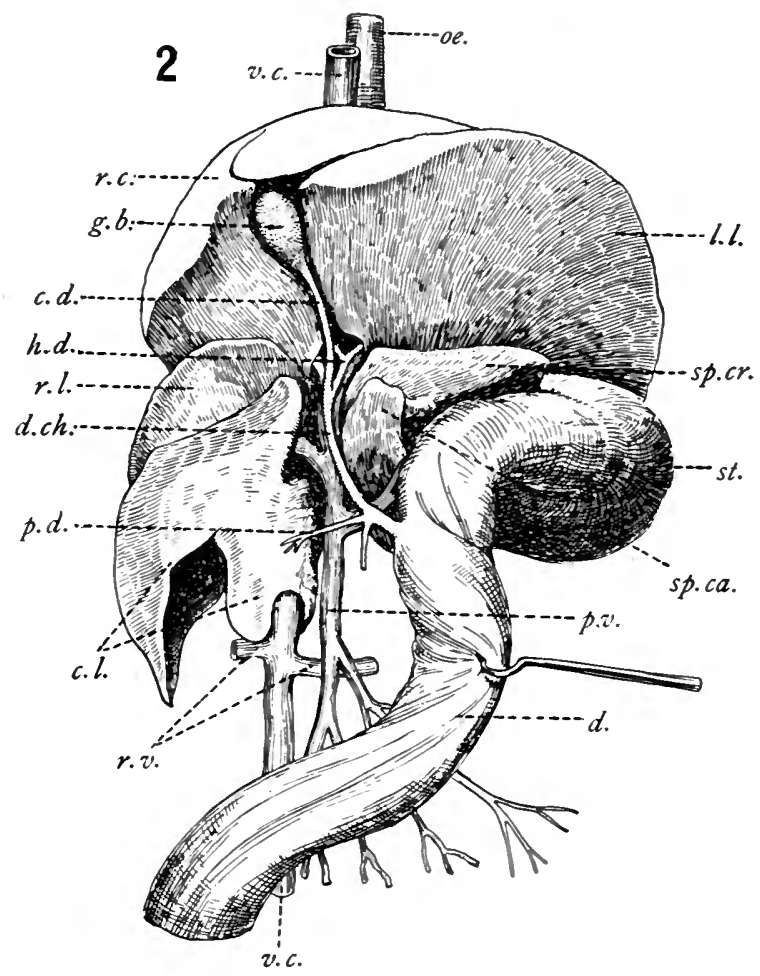

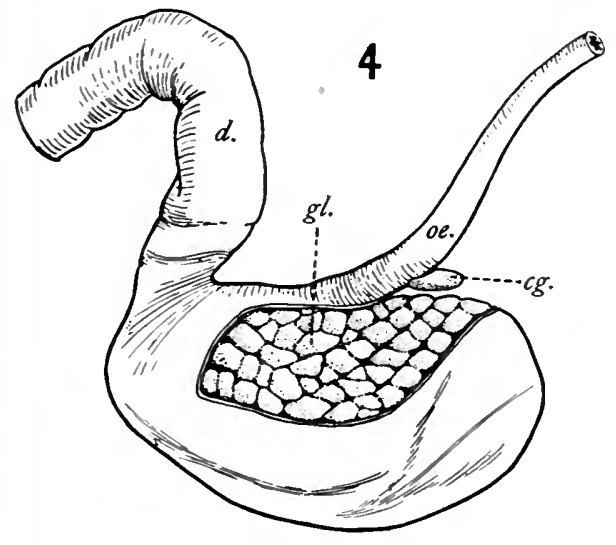

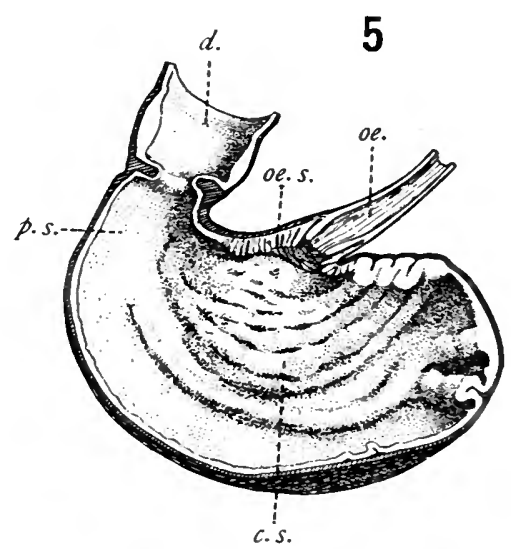

PARTS OF ALIMENTARY SYSTEM.

$$
\text { Enlarged. }
$$




$$
\begin{gathered}
\text { i.: } \\
\text { OF THE } \\
\text { SHIVERSITY MF IIIIMOIS }
\end{gathered}
$$





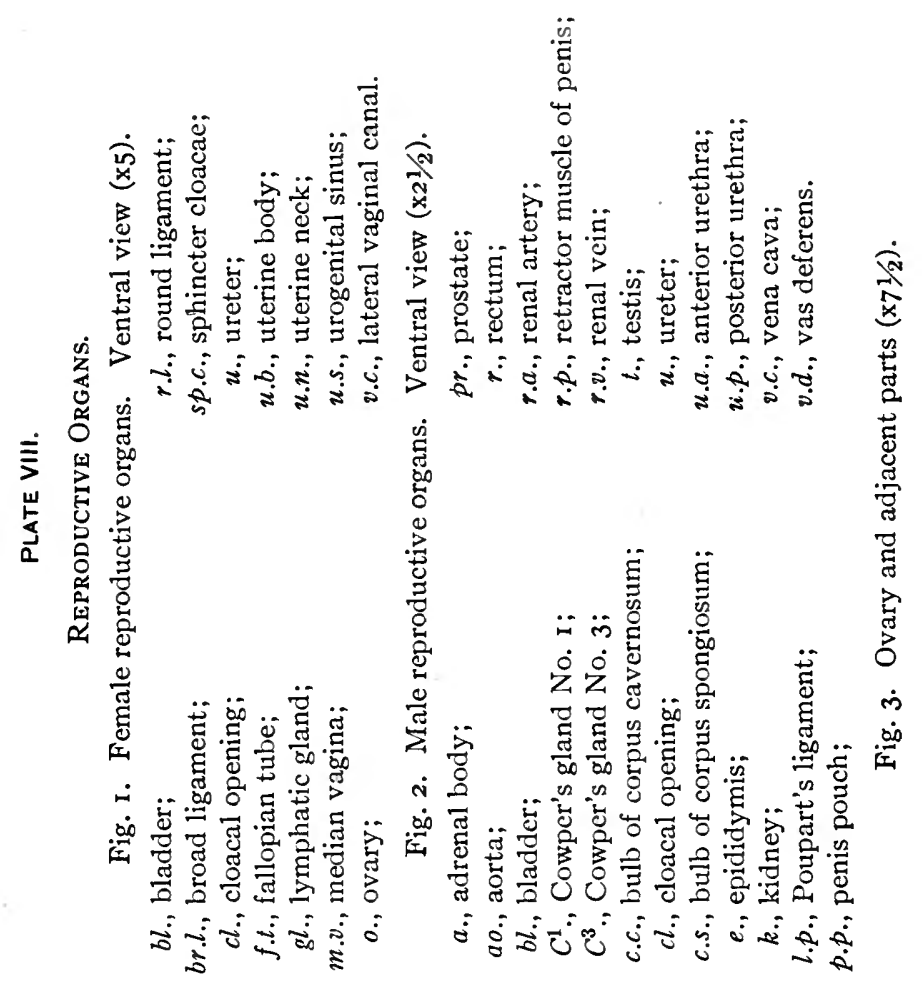




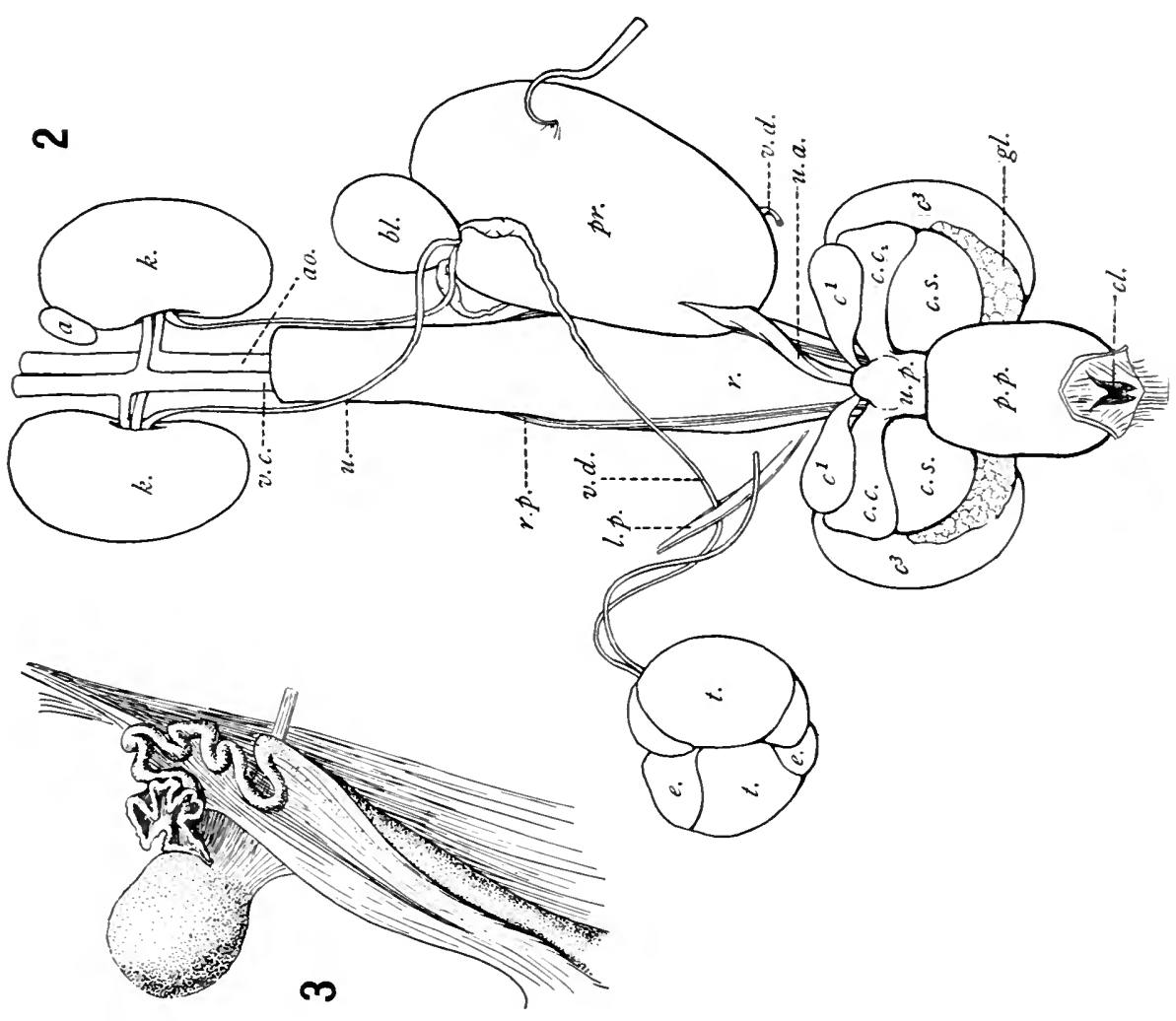

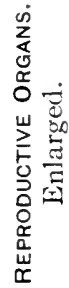

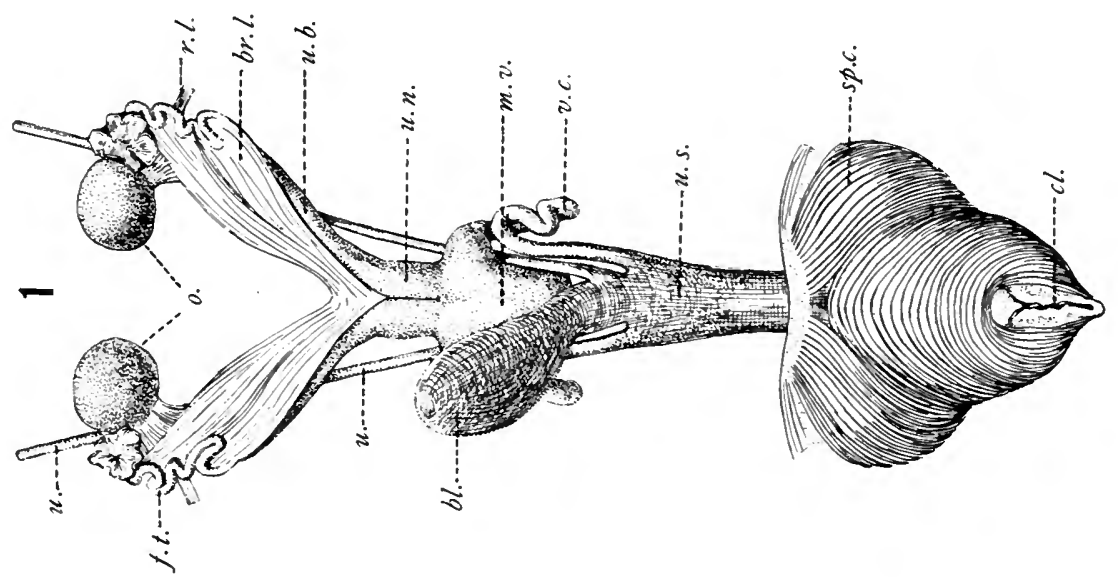




$$
\text { Tu: ' ' RAPYY }
$$

OF THE

HAIVERSITY MF IILIIHOIS 


$$
\begin{aligned}
& x i=4-9
\end{aligned}
$$

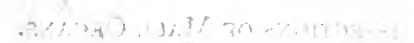

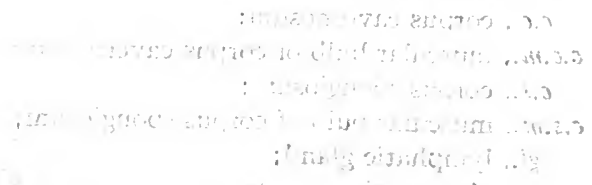

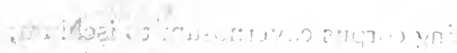

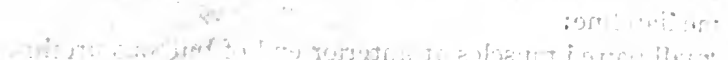

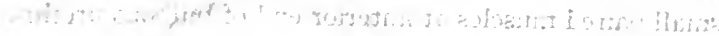

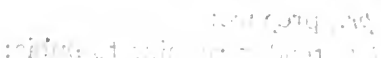

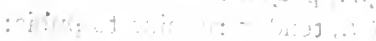

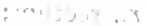

Stiptitis? a t

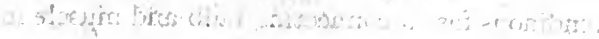

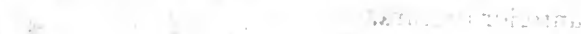


Plate iX.

Dissections of Male Organs.

Enlarged.

Fig. I. Dorsal view of parts surrounding bulbous urethra. Two Cowper's glands removed from left side $\left(\mathrm{x}_{3} \frac{1}{2}\right)$.

Fig. 2. Ventral view of bulb of corpus cavernosum and adjoining parts (x6).

Fig. 3. Longitudinal section of urethra with adjoining parts ( $\left.x_{5}\right)$.

b.u., bulbous urethra;

b.w., body wall;

c.c., corpus cavernosum;

c.c.m., muscular bulb of corpus cavernosum;

c.s., corpus spongiosum;

c.s.m., muscular bulb of corpus spongiosum;

gl., lymphatic gland;

g.p., glans penis;

i.t., tendon attaching corpus cavernosum to ischium;

$l$., median line;

$m^{1}, m^{2}, m^{3}$, small paired muscles at anterior end of bulbous urethra;

p.p., penis pouch;

pr., prepuce;

p.t., tendon running to pubis;

$r .$, rectum;

r.m., rectal muscle;

r.p., rectractor muscle of penis;

$s \dot{p} . f$., fascia to covering of bulb and to sphincter;

t.f., tendinous fascia connecting bulb and muscle in front of bulbous urethra;

u.a., anterior urethra. 
FIELD MUSEUM OF NATURAL HISTORY.

PLATE IX, ZÖOLOGY.
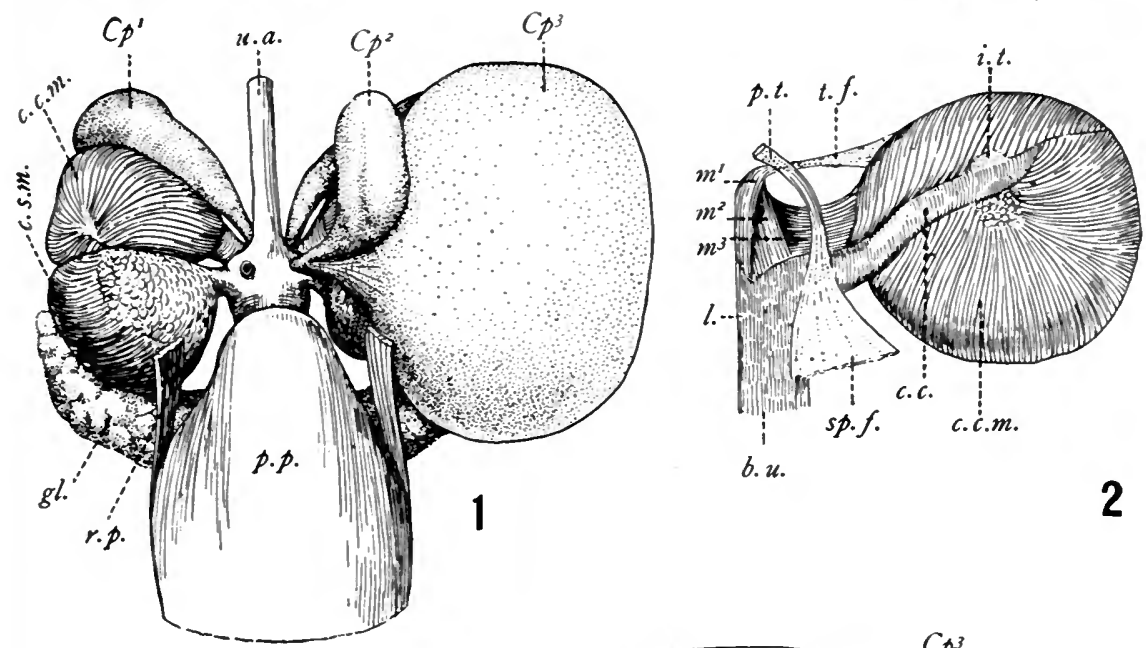

b.u.

2

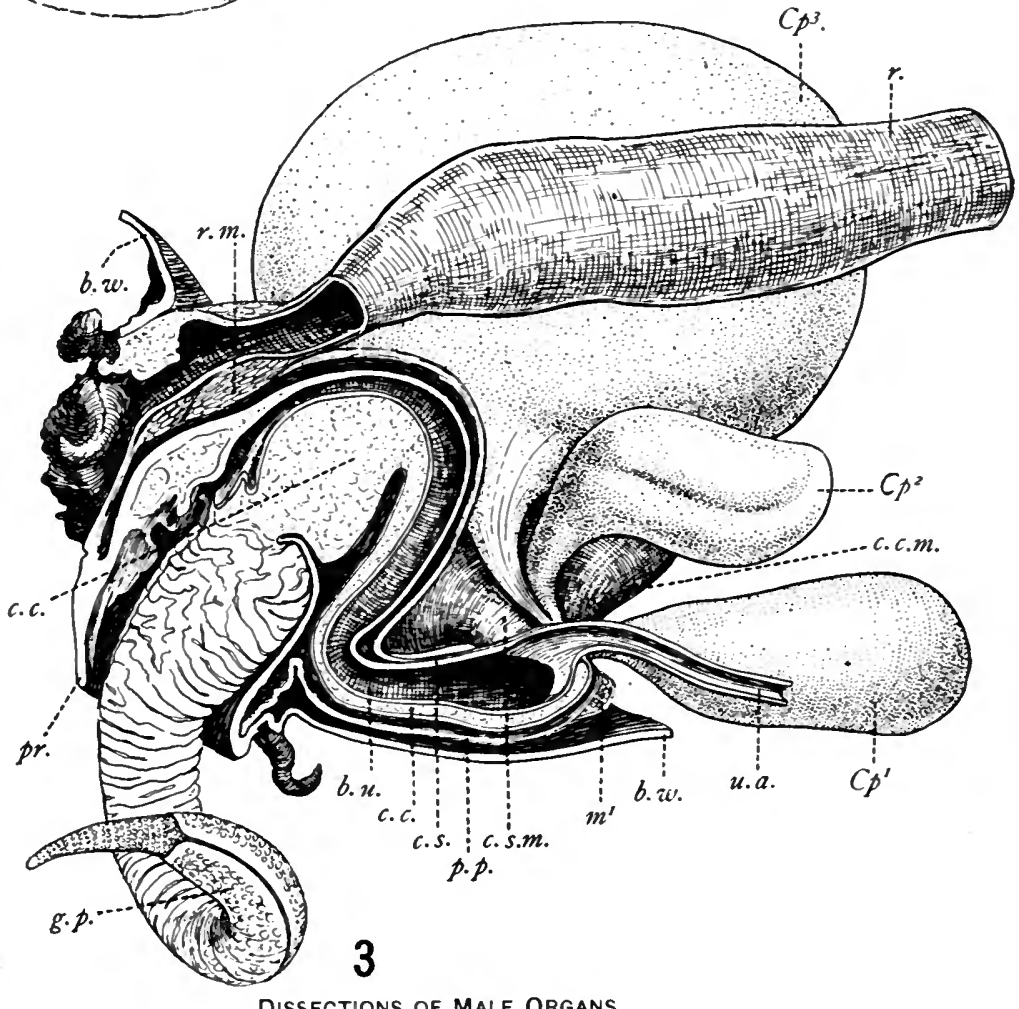

Dissections of MaLe ORgans.

Enlarged. 


$$
\begin{gathered}
\text { OF. 'DRARY } \\
\text { OF THE } \\
\text { AHIVERSITY OF ILLINOIS }
\end{gathered}
$$




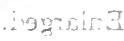




\section{Plate X.}

Parts of Reproductive, Alimentary, and Respiratory Systeys.

\section{Enlarged.}

Fig. I. Dissection of base of bladder showing endings of ureters and vasa deferentia (x5).

Fig. 2. Ventral aspect of lungs and trachea $\left(x_{2} \frac{1}{2}\right)$.

Fig. 3. Lateral view of tongue $\left(x_{3} \frac{1}{2}\right)$.

Fig. 4. Base of tongue from above (xio).

Fig. 5. Transverse section of prostate gland ( $\left.x_{5}\right)$.

$a z .$, azygos lobe of lung;

$b l .$, bladder;

c.p., coronate papillae;

c.v.p., circumvallate papillae;

ep., epiglottis;

fg.p., fungiform papillae;

l.l., left lobe of lung;

p.t., columnar tissue of prostate gland;

r.l.a.. anterior division of right lobe of lung;

r.l.p., posterior division of right lobe of lung;

u.a., anterior urethra;

v.d., vas deferens. 


$$
\begin{gathered}
\text { OF THL } \\
\text { HAIVFASITY OF ILLINOIS }
\end{gathered}
$$


ix 3 T4. 9

. Iค

cos:

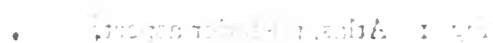

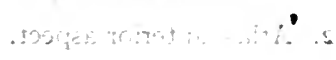

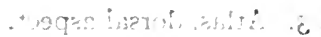

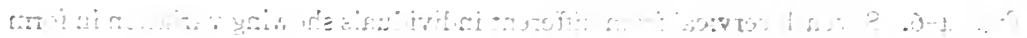

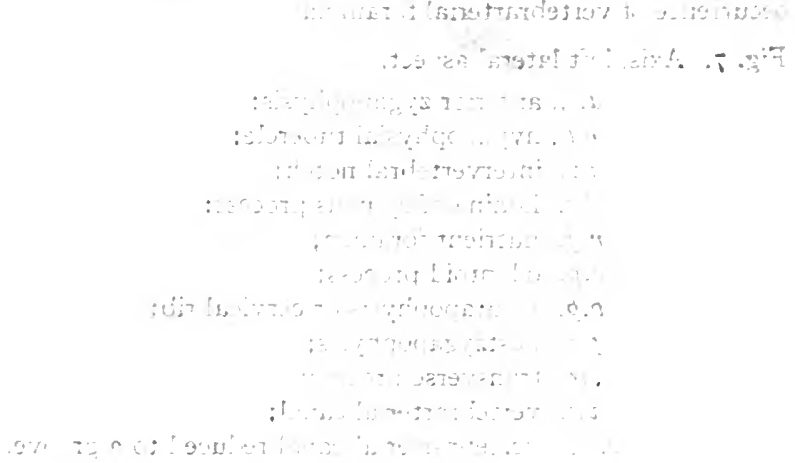




\section{PLATE XI.}

\section{Cervical Vertebrae.}

Five times natural size.

Fig. I. Atlas, posterior aspect.

Fig. 2. 'Atlas, anterior aspect.

Fig. 3. Atlas, dorsal aspect.

Figs. 4-6. Seventh cervical from different individuals showing variation in form and occurrence of vertebrarterial foramina.

Fig. 7. Axis, left lateral aspect.

a.z., anterior zygapophysis;

h.t., hypapophysial tubercle;

i.v., intervertebral notch;

l.s., lamina of spinous process;

$n . f .$, nutrient foramen;

$o . p$. , odontoid process;

p.p., pleurapophysis or cervical rib;

p.z., postzygapophysis;

tr., transverse process;

v.c., vertebrarterial canal;

v.c.g., vertebrarterial canal reduced to a groove. 
FIELD MUSEUM OF NATURAL HISTORY.

1

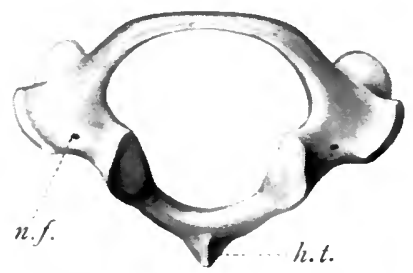

4

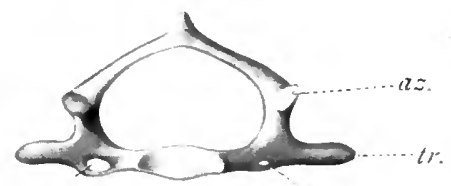

$\because . c$.

i.c.

5

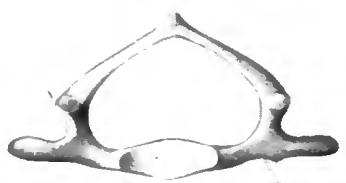

i.C.g.

6

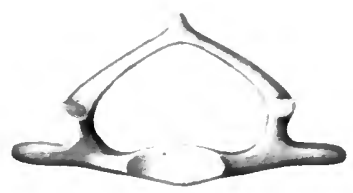

PLATE XI, ZOÖLOGY.

2

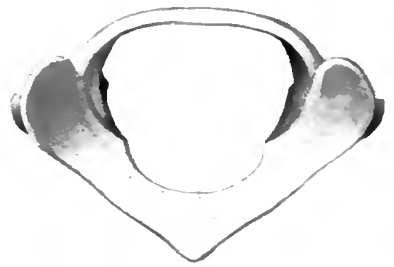

3

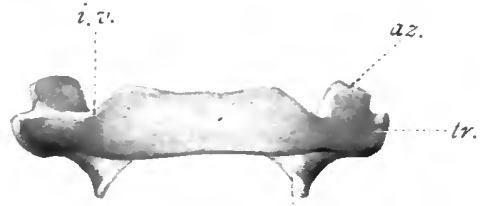

p. $\approx$.

\section{7}

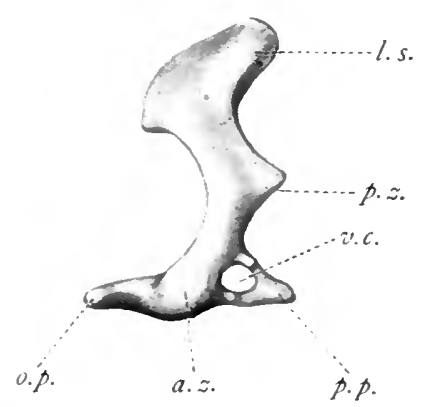

Cervical vertebrae.

Five times natural size. 


$$
\text { ‥ " } R A R Y
$$

OF THE

HAIVFRSITY OF ILIINOIS 

Plate XII.

Bones of Sternum, Hind Leg, and Thoracic Region.

Five times natural size.

Fig. I. Right femur, posterior aspect.

Fig. 2. Sternum and attachment of ribs.

Fig. 3. Right tibia and fibula with adjoining part of femur, outer aspect.

Fig. 4. First and second ribs and attachments, outer aspect.

Fig. 5. Clavicle.

$c^{7}$, seventh cervical vertebra;

$f$., fibula;

$f b$., fabella;

g.t., greater trochanter;

$h$., head of femur;

i.r., intertrochanteric ridge;

l.t., lesser trochanter;

$m .$, manubrium of sternum;

p., osseous patella;

$r^{1}$., first rib;

s., shaft of femur;

t., tibia;

t.t., rudimentary third trochanter of femur;

$t^{1}$., first thoracic vertebra;

$t^{2}$., second thoracic vertebra;

$x$., xiphisternum;

$x . c .$, xiphoid cartilage;

2-7., costal attachments of second to seventh ribs. 
FIELD MUSEUM OF NATURAL HISTORY.
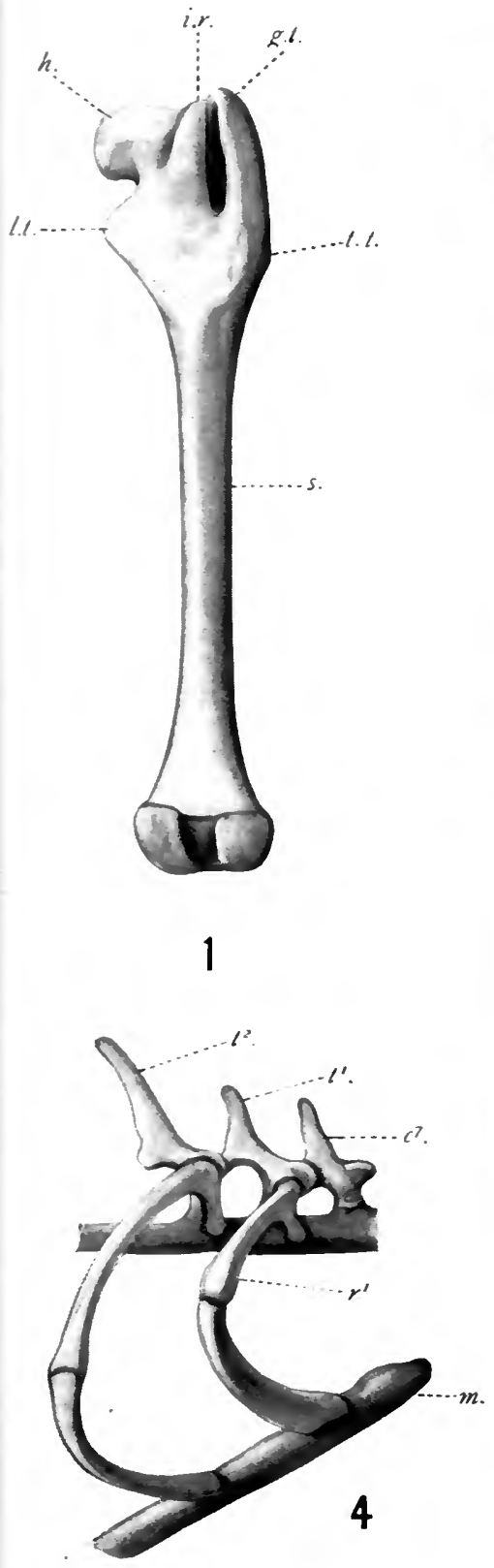

PLATE XII, ZOÖLOGY.
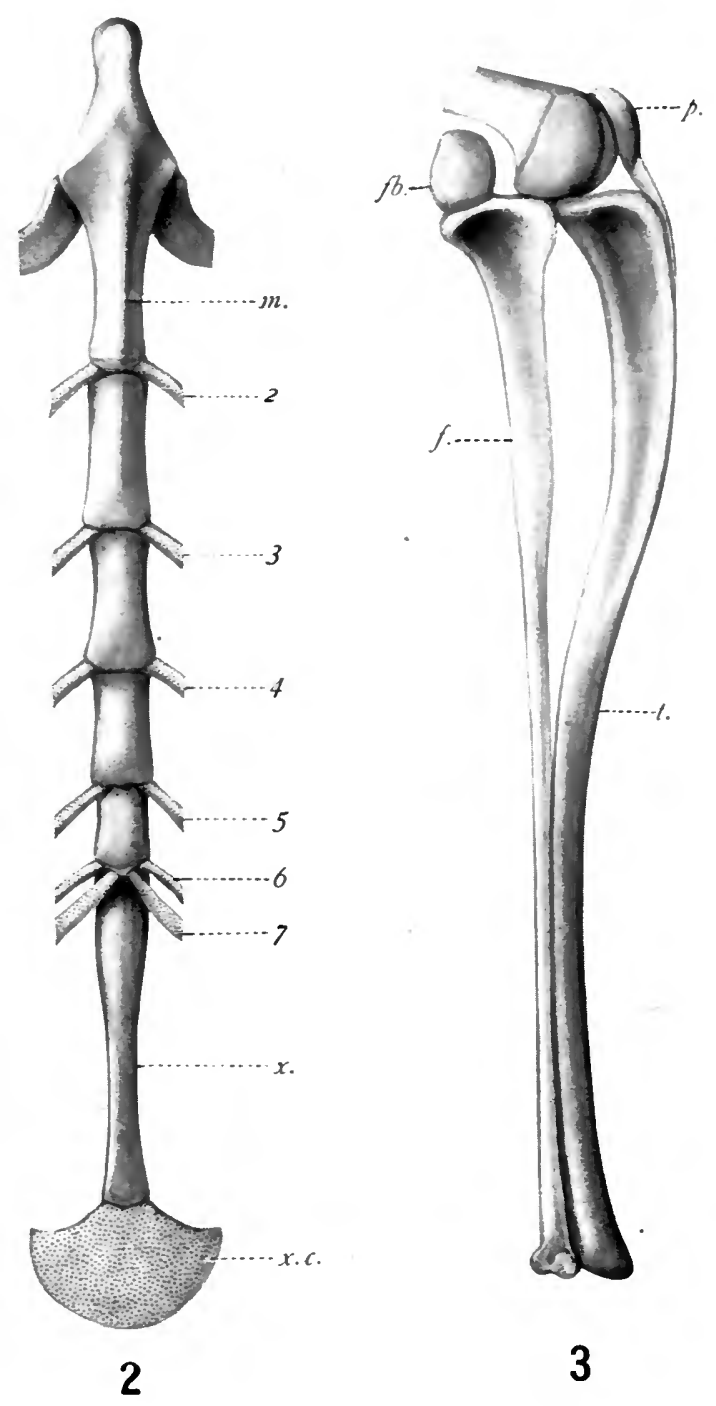

BONES OF STERNUM, HIND LEg, AND THORACIC REgION. Five times natural size. 


$$
\begin{gathered}
\text { OF. ORRRY } \\
\text { OF THE } \\
\text { HHIVERSITY OF ILLIKOIS }
\end{gathered}
$$




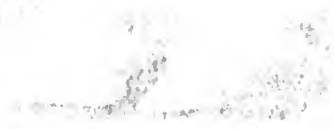

$.11 ! X \div-T A \perp 9$

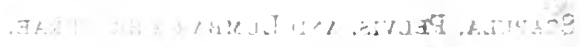

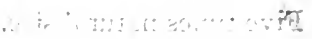

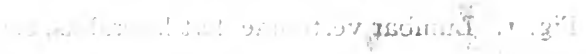

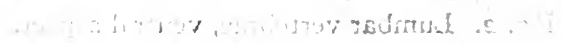

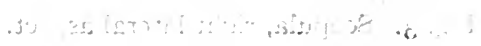

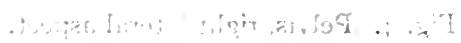

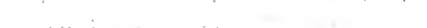


Plate Xili.

Scapula, Pelvis, and Lumbar Vertebrae.

Five times natural size.

Fig. I. Lumbar vertebrae, left lateral aspect.

Fig. 2. Lumbar vertebrae, ventral aspect.

Fig. 3. Scapula, right lateral aspect.

Fig. 4. Pelvis, right lateral aspect.

ac., acromion;

co., coracoid process;

$i$., ilium;

ip.t., iliopectineal tubercle;

i.t., ischial tuberosity. 

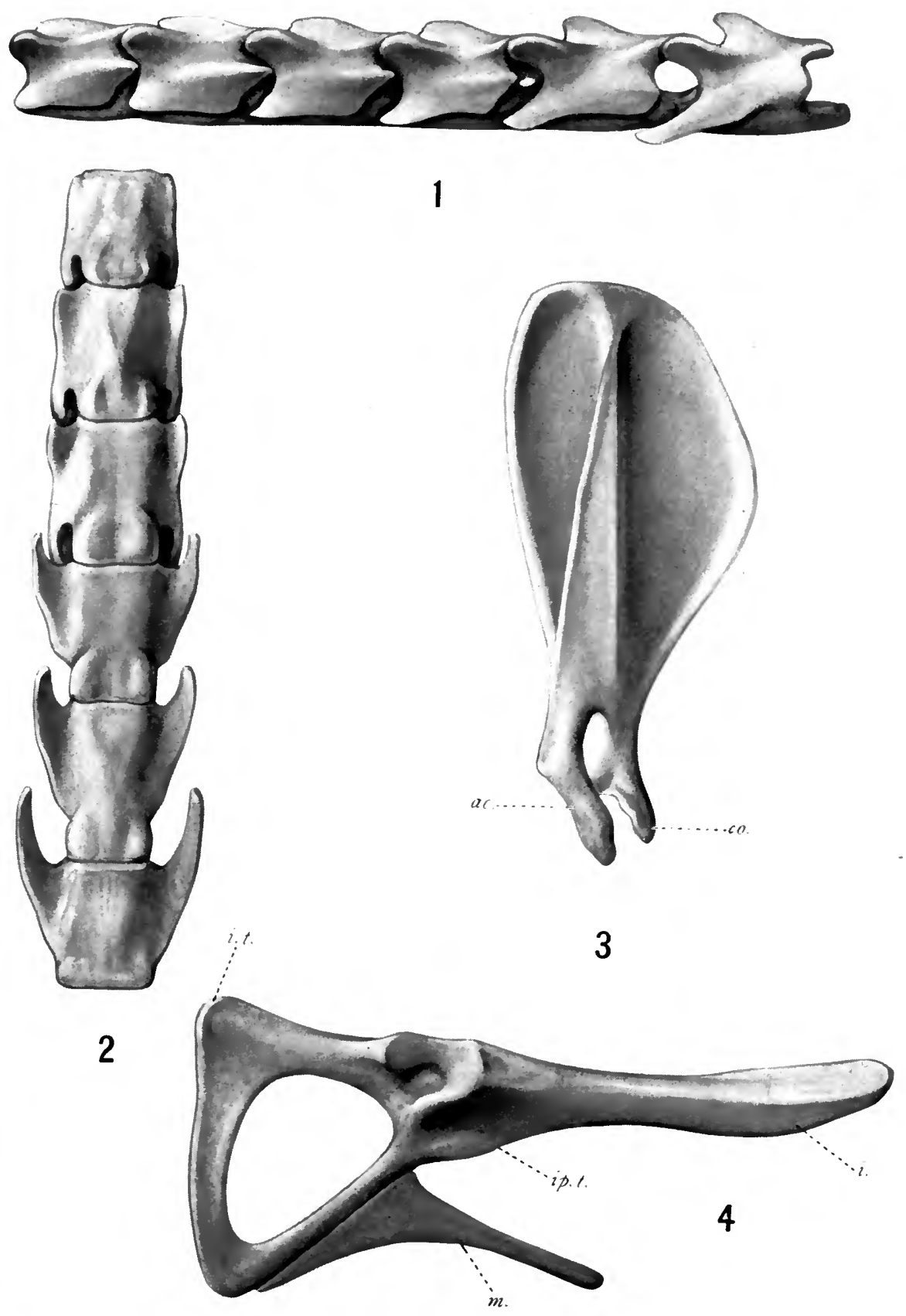

Scapula, Pelvis, and lumbar Vertebrae.

Five times natural size. 


$$
\begin{aligned}
& \text { OF THL } \\
& \text { GNIVERSITY OF IILIWGIS }
\end{aligned}
$$





\section{Plate Xiv.}

\section{Sacral and Caudal Vertebrae.}

Five times natural size.

Fig. I. Sacral and first six caudal vertebrae, dorsal aspect.

Fig. 2. Second to ninth caudal vertebrae, ventral aspect.

$$
\begin{gathered}
c^{2}, c^{3} ., c^{6} ., c^{8} ., \text { caudal vertebrae; } \\
\text { ch., chevron bone; } \\
s^{1} ., \text { first sacral vertebra. }
\end{gathered}
$$


FIELD MUSEUM OF NATURAL HISTORY.

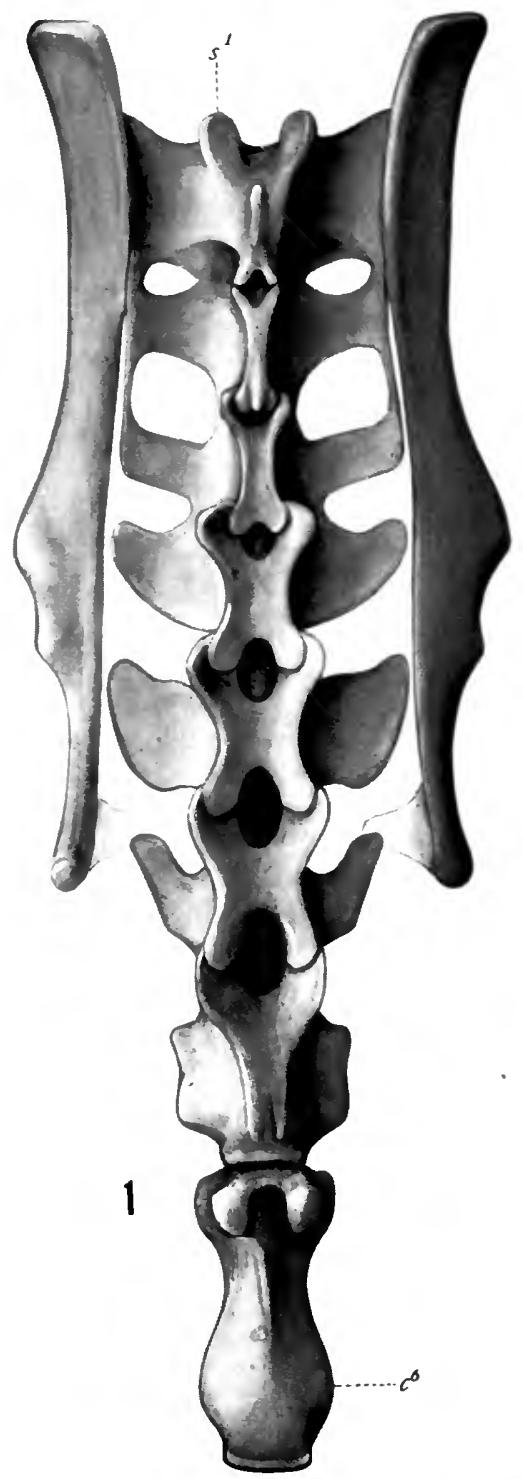

PLATE XIV, ZOÖLOGY,

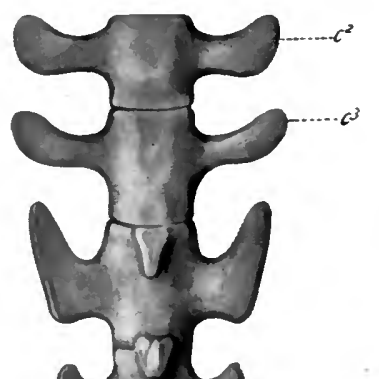

SaCral and CaUdal Vertebrae.

Five times natural size. 


$$
\begin{gathered}
\text { OF THL } \\
\text { OF THIVERSITY OF IILAOS }
\end{gathered}
$$



Plate XV.

Humerus, Ulna, and Radius.

Five times natural size.

Fig. I. Right humerus, posterior or caudal aspect.

Fig. 2. Right humerus, anterior or cranial aspect.

Fig. 3. Right radius and ulna, outer lateral aspect.

Fig. 4. Right ulna, anterior aspect.

ca., capitellum;

d.r., deltoid ridge;

e.f., epicondylar foramen;

g.s., greater sigmoid cavity;

g.t., greater tuberosity;

$h$., head of humerus;

i.a., inner articular surface of distal end of humerus;

i.c., inner condyle;

l.t., lesser tuberosity;

$o l$., olecranon and fossa;

$r .$, radius;

s.r., supinator ridge;

tr., trochlea;

$u$., ulna. 
FIELD MUSEUM OF NATURAL HISTORY.

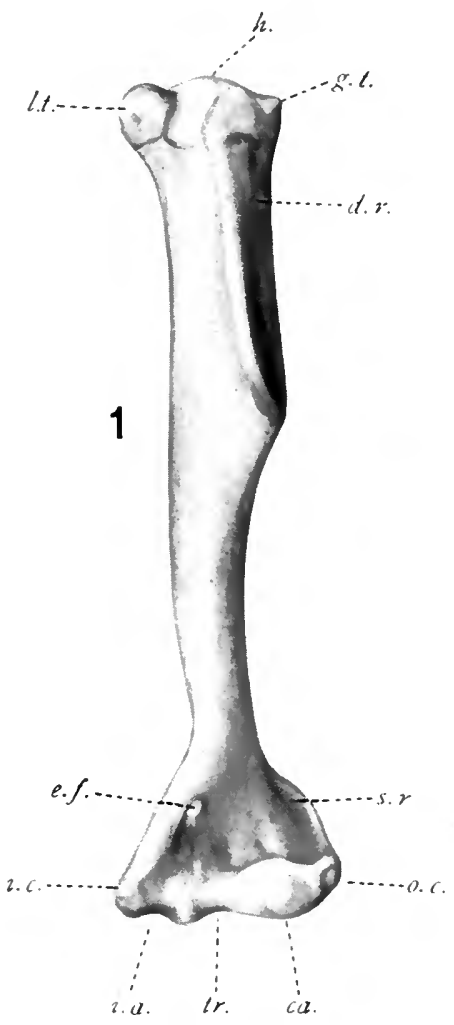

PLATE XV, ZOÖLOGY.

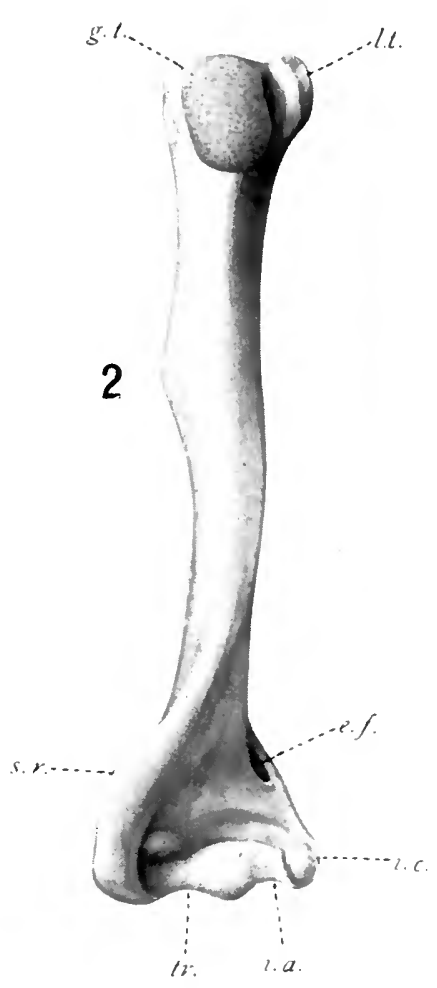

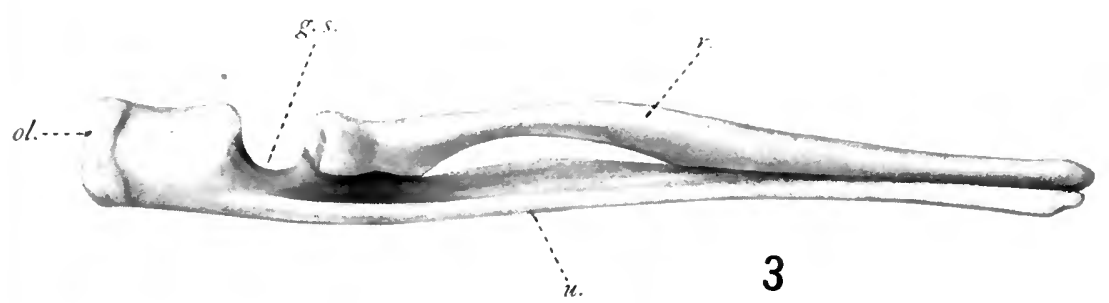

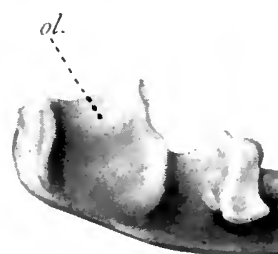

4

HUMERUS, ULNA, AND RADIUS.

Five times natural size. 


$$
\therefore \cdots \cap R P Q V
$$

OF THE

AMIVERSITY OF IIIIKOIS 

Plate XVI.

Manus And Pes.

Enlarged.

Fig. I. Right manus, anterior aspect $\left(x_{5}\right)$.

Fig. 2. Right pes, anterior aspect (x5).

Fig. 3. Left astragalus, posterior aspect (xIo).

Fig. 4. Left astragalus, anterior aspect (xIo).

Fig. 5. Right os calcis, anterior aspect (xio).

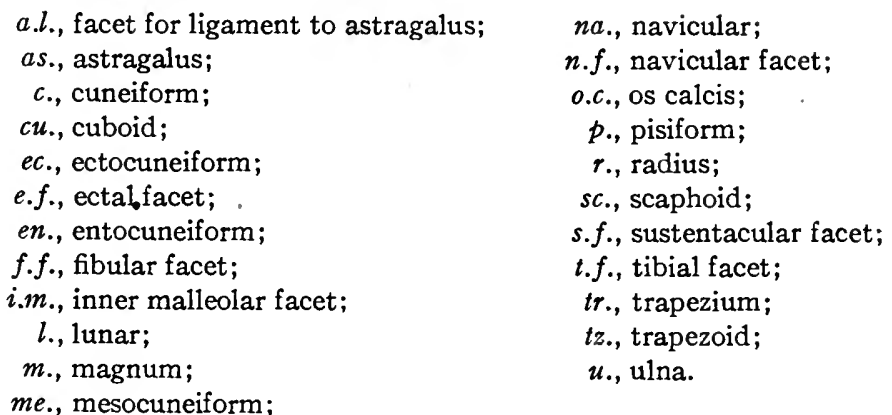




$$
\begin{gathered}
\text {... nRADY } \\
\text { OF THL } \\
\text { HAIVERSITY OF ILLINOIS }
\end{gathered}
$$




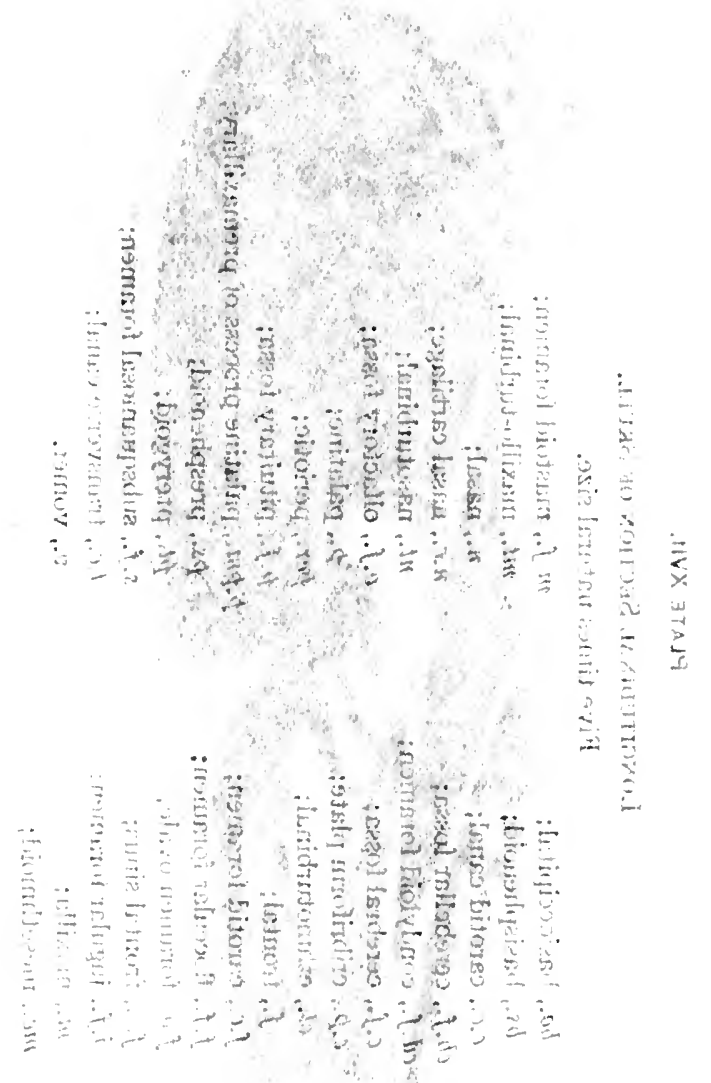




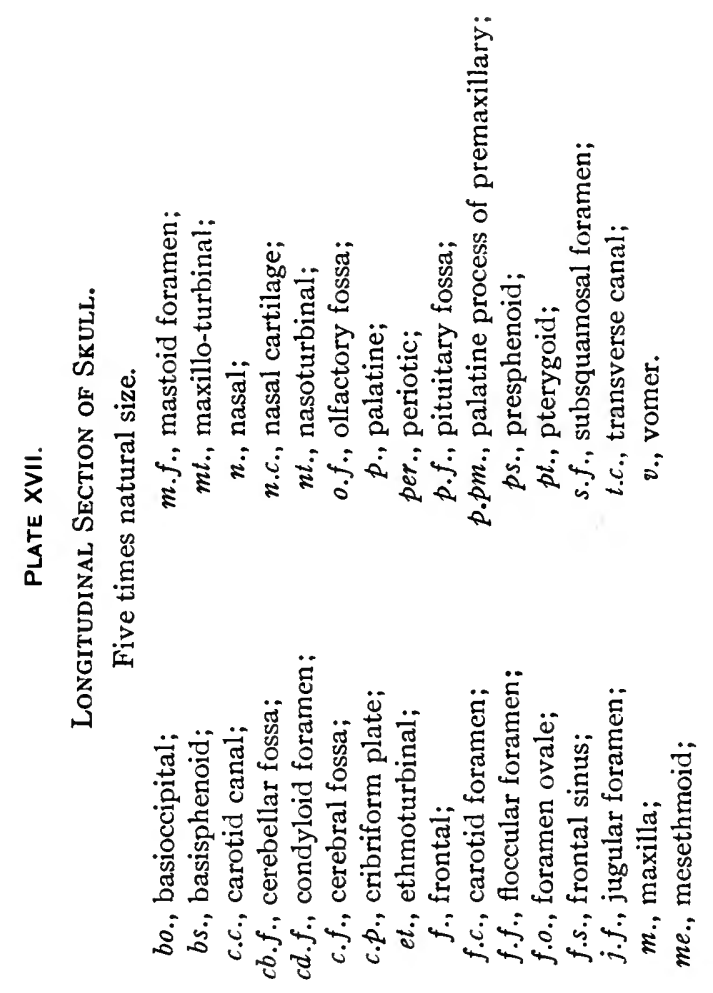




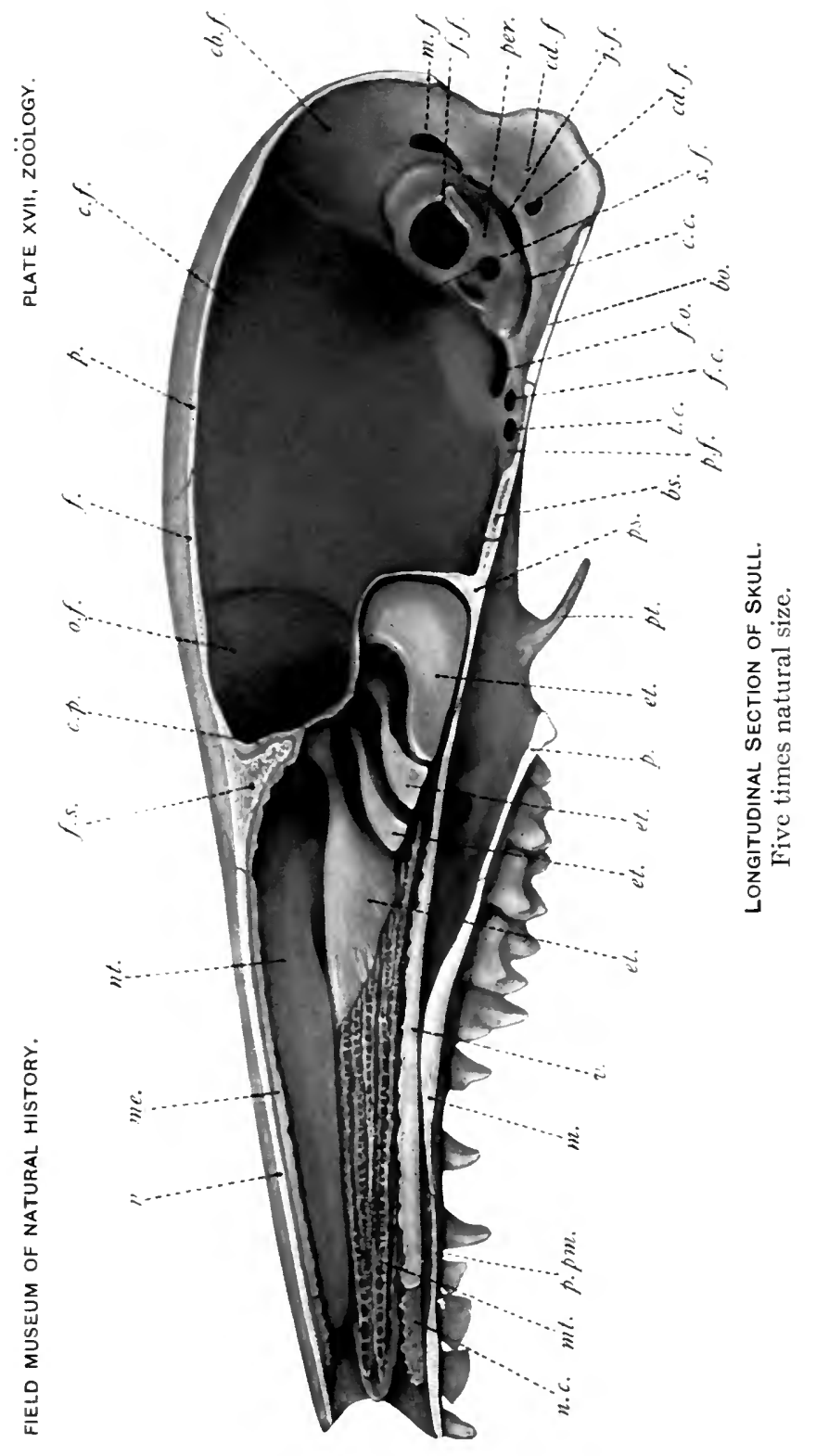




$$
\begin{gathered}
\text { OF TRAY } \\
\text { OF THE } \\
\text { SUIIVFRSITY OF IIIINAIS }
\end{gathered}
$$




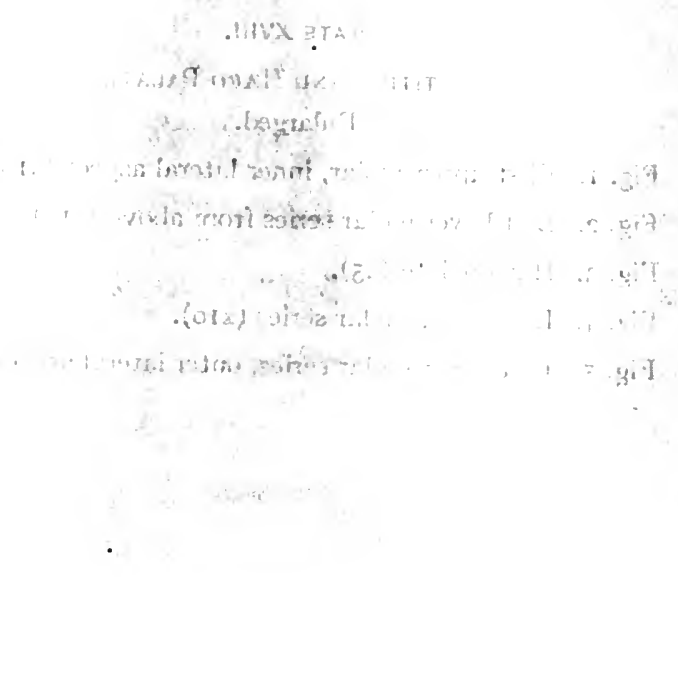


Plate XVIII.

Dentition and Hard Palate.

Enlarged.

Fig. I. First upper molar, inner lateral aspect (xIo).

Fig. 2. Left lower molar series from above (xIo).

Fig. 3. Hard palate (x5).

Fig. 4. Left upper molar series (xIo).

Fig. 5. Left lower molar series, outer lateral aspect (xIO). 
FIELD MUSEUM OF NATURAL HISTORY.

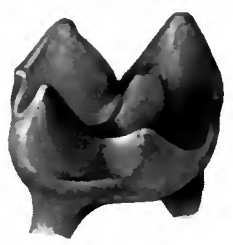

1

2
3
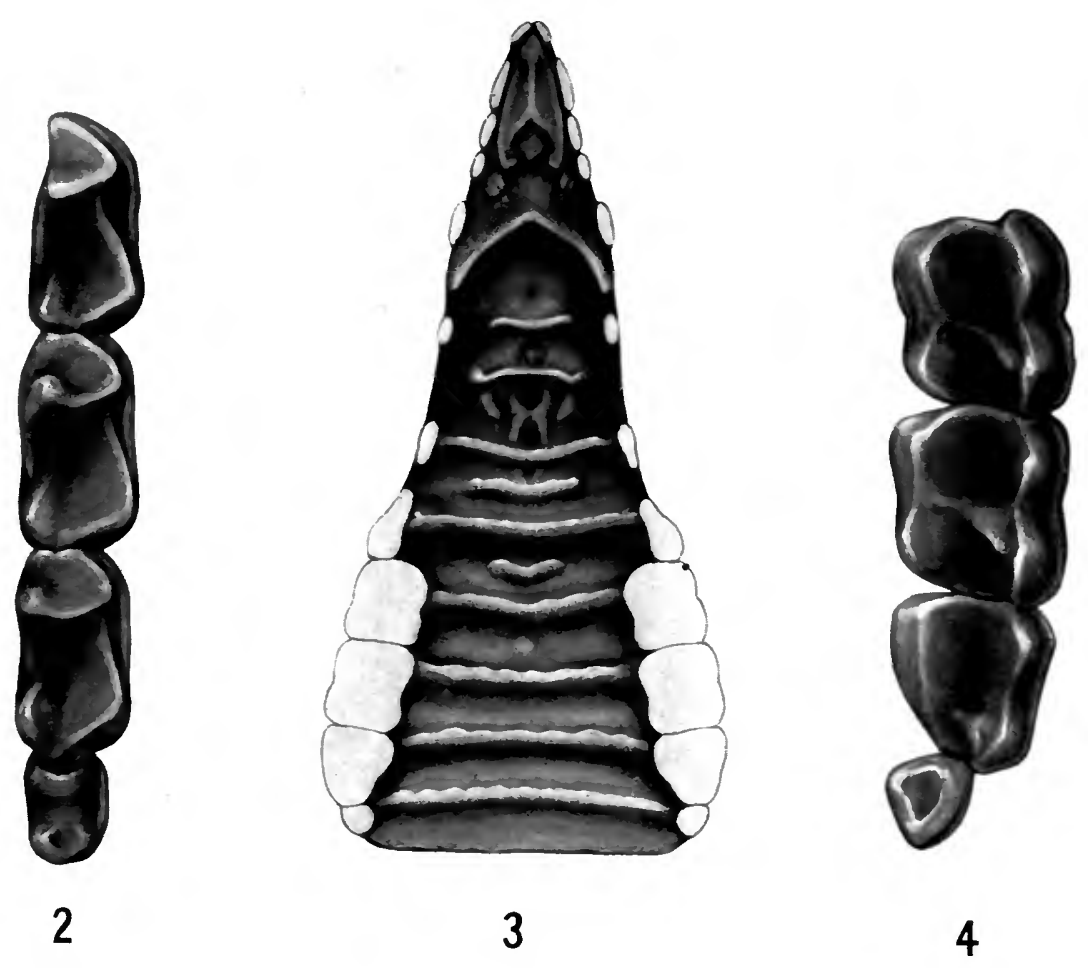

PLATE XVIII, ZOÖLOGY.

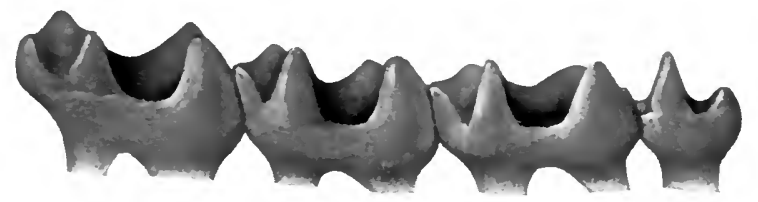

5

DENTITION AND HARD PALATE.

Enlarged. 


$$
\begin{gathered}
\text { "ORFPY } \\
\text { OF TILL } \\
\text { GMIVEBSITY OF IIIINOIS }
\end{gathered}
$$




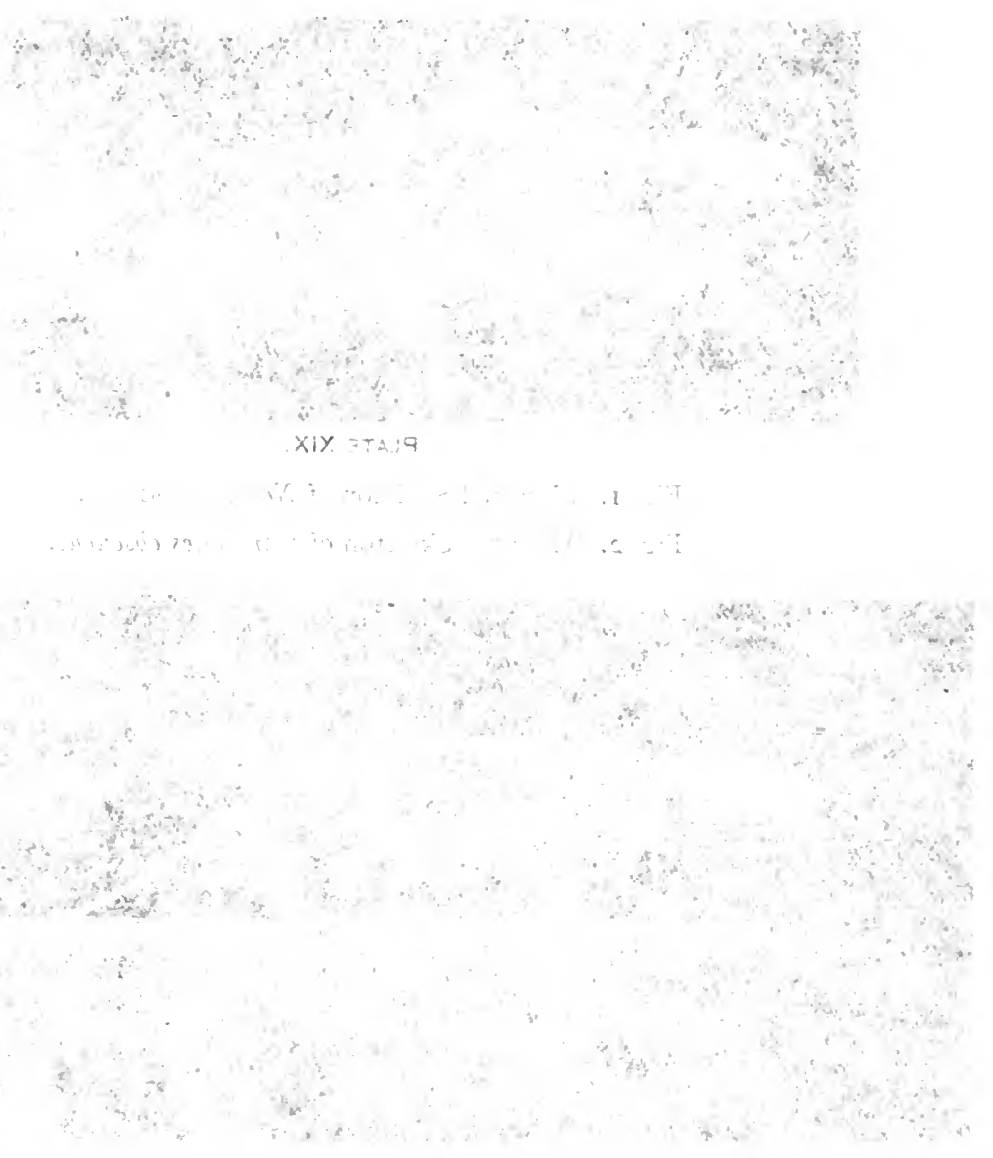


Plate xix.

Fig. I. Mounted Skeleton of Nesogale dobsoni.

Fig. 2. Mounted Skeleton of Canoles!es obscurus. 


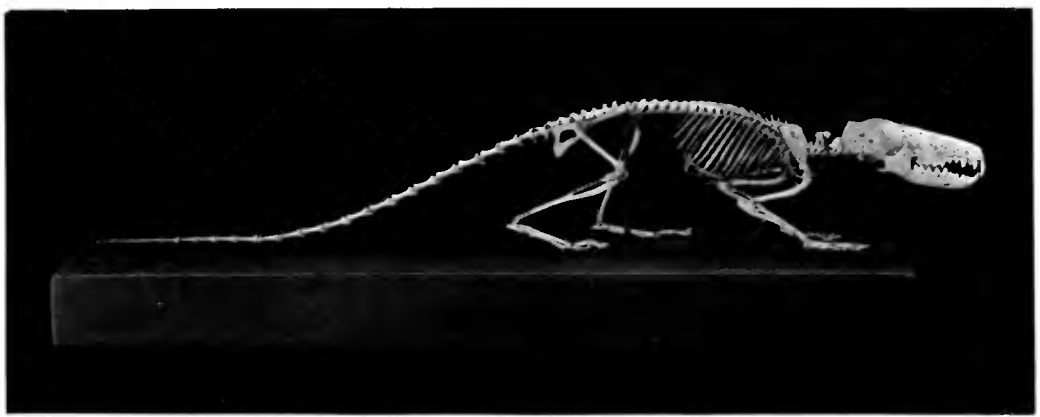

1. Mounted Skeleton of Nesogale dobsoni.

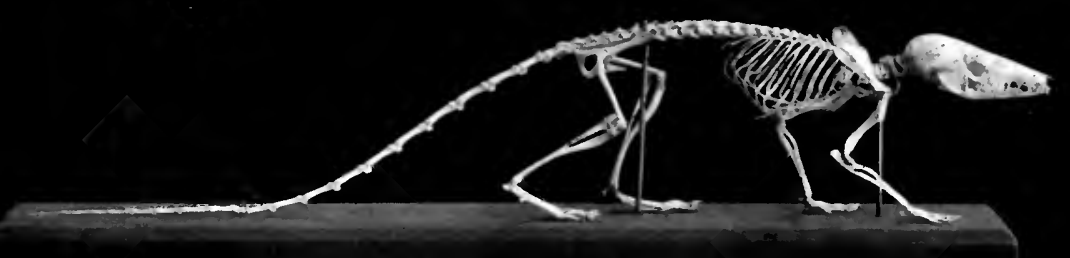

2. MOUNTED SKeleton of CaEnolestes ObSCuRus. 


$$
\begin{aligned}
& \text { ……ngay } \\
& \text { CF The } \\
& \text { ANIVFRSITY AF ILLIHOIS }
\end{aligned}
$$




$$
\begin{aligned}
& x \times \text { गुस } 19
\end{aligned}
$$

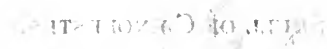

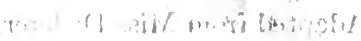

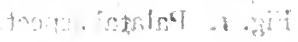

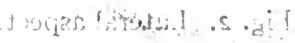

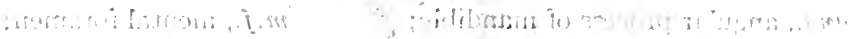

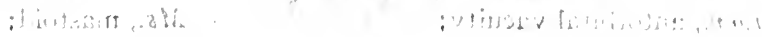

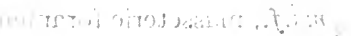

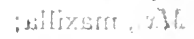

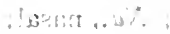

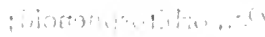

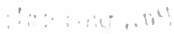

$$
\begin{aligned}
& \text {;it! inet , rat }
\end{aligned}
$$

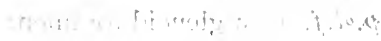

$$
\begin{aligned}
& \text {......, ju }
\end{aligned}
$$

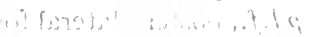

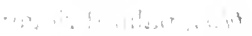

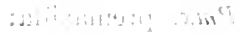

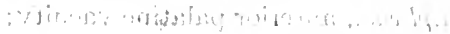

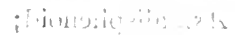

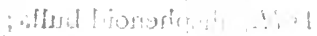

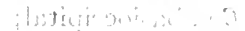

$$
\begin{aligned}
& \text { andination is }
\end{aligned}
$$

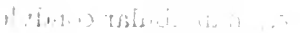

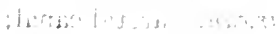

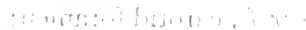

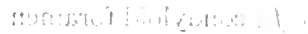

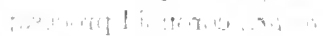

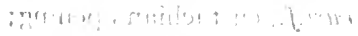

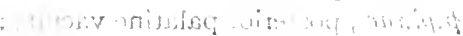

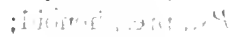

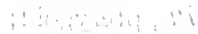

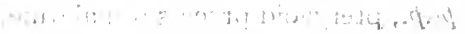

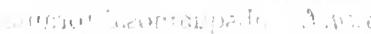

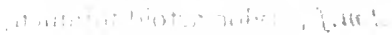

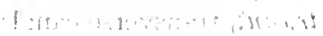

$$
\begin{aligned}
& \cdots+, 1,1+1
\end{aligned}
$$

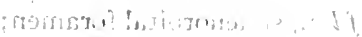

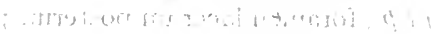

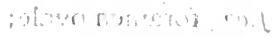

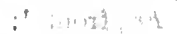

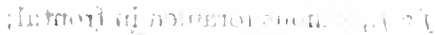

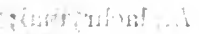

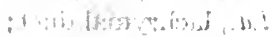

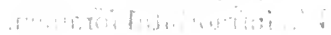

$$
\begin{aligned}
& \text { :H,ist... Wh! }
\end{aligned}
$$


Plate XX.

Skull of Canolestes. Adapted from Miss Dederer.

Fig. I. Palatal aspect.

Fig. 2. Latèral aspect.

ang., angular process of mandible;

a.o.v., antorbital vacuity;

a.pl.vac., anterior palatine vacuity;

As., alisphenoid;

As.bl., alisphenoid bulla;

Bo., basioccipital;

$B s .$, basisphenoid;

c., mandibular condyle;

car.can., carotid canal;

car.f., carotid foramen;

c.f., condyloid foramen;

cor.pr., coronoid process;

eust.f., eustachian opening;

Exo., exoccipital;

f.l.a., sphenorbital foramen;

f.l.p., foramen lacerum posterum;

f.ov., foramen ovale;

Fr., frontal;

f.v.f., venous foramen in frontal;

L., lachrymal;

l.d., lachrymal duct;

Ma., malar; m.f., mental foramen;

Ms., mastoid;

$m s . f .$, masseteric foramen;

$M x .$, maxilla;

Na., nasal;

Os., orbitosphenoid;

$P a$., parietal;

Per., periotic;

p.gl.f., post glenoid foramen;

Pl., palatine;

p.l.f., postero-lateral foramen;

pl.r., palatal ridge;

Pmx., premaxilla;

p.pl.vac., posterior palatine vacuity;

Ps., presphenoid;

Pt., pterygoid;

pt.p., pterygoid process of palatine;

s.sq.f., subsquamosal foramen;

st.m.f., stylomastoid foramen;

tr.can., transverse canal;

$T y$., tympanic;

$V^{2}$., infraorbital foramen. 
fielo museum of natural history. PLate XX, zö̈logy.
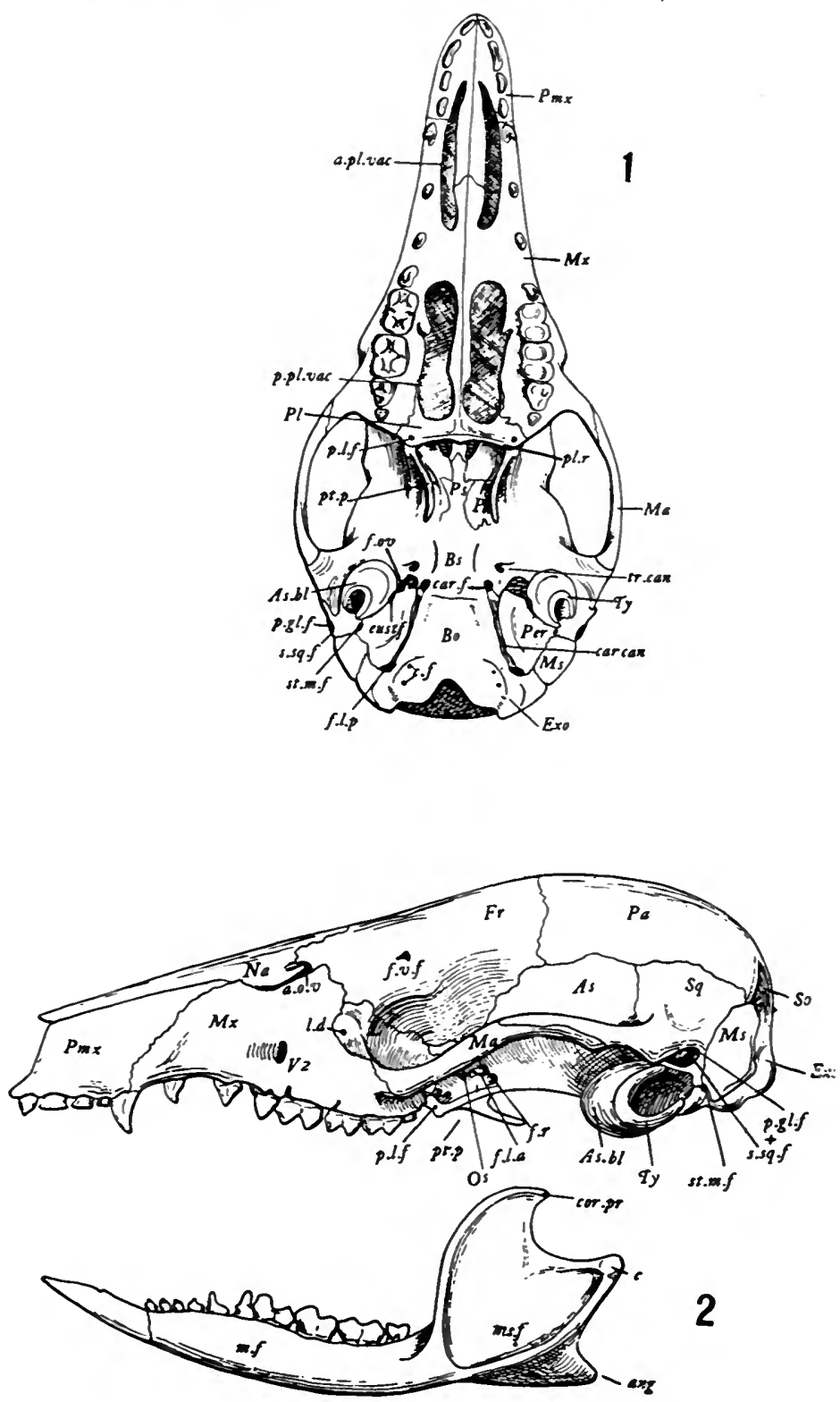

SKull of CAENOLESTES.

Adapted from Miss Dederer. 


$$
\begin{aligned}
& \text { Tw: : "RAPY } \\
& \text { OF THE } \\
& \text { MUIVFRAITX OF IILINOIS }
\end{aligned}
$$




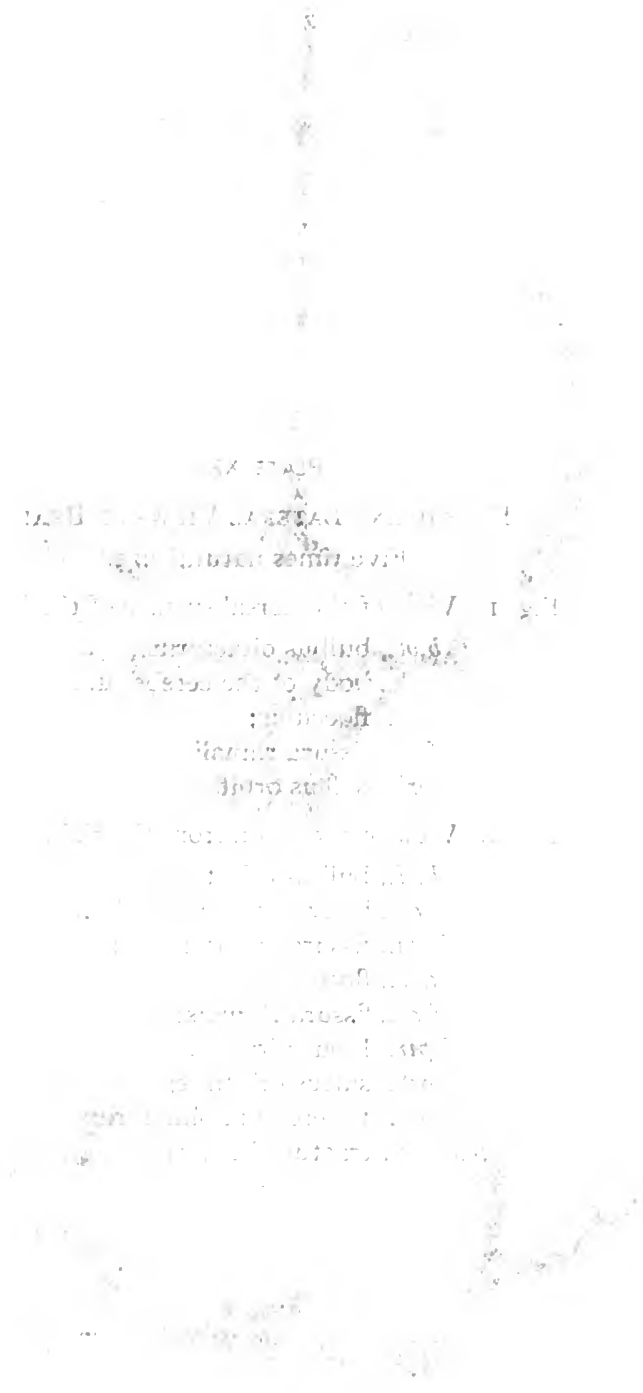


PLATE XXI.

Dorsal and Lateral Views of Brain.

Five times natural size.

Fig. I. View of the dorsal surface of the brain.

b.ol., bulbus olfactorius;

$c b$., body of the cerebellum;

floc., flocculus;

f.rh., fissura rhinalis;

s.orb., sulcus orbitalis.

Fig. 2. View of the brain from the right side.

b.ol., bulbus olfactorius;

$c b$. , body of the cerebellum;

f.erh., fissura endorhinalis;

floc., flocculus;

f.rh., fissura rhinalis;

l.pir., lobus piriformis;

s.orb., sulcus orbitalis;

t.o., tuberculum olfactorium;

tr.ol.lat., tractus olfactorius lateralis. 

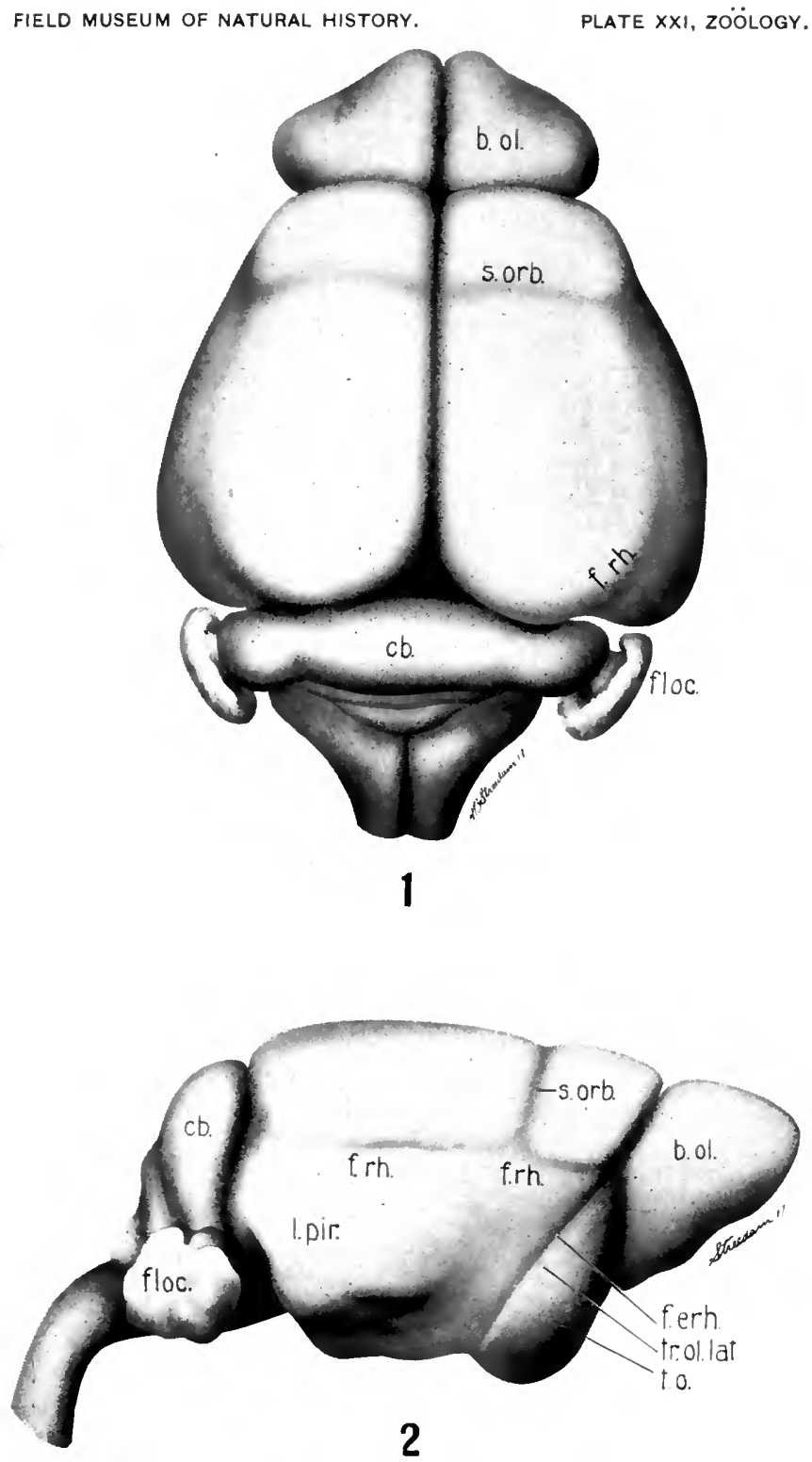

Dorsal and Lateral surfaces of brain.

Five times natural size. 


\section{… …" "RARY \\ OF Tit: \\ HAIVERSITY OF IILINOIS}




$$
.4 x \times \geqslant-1
$$

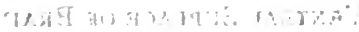

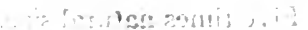

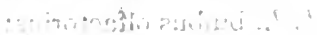

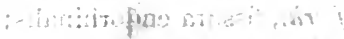

intis $+\cdots$

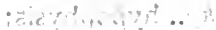

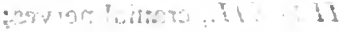

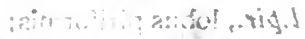

it istonus ..t?

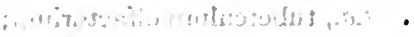

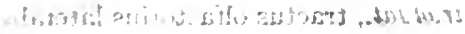

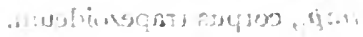


Plate XXII,

Ventral Surface of Brain.

Five times natural size.

b.ol., bulbus olfactorius;

f.erh., fissura endorhinalis;

floc., flocculus;

hy., hypophysis;

II to XII., cranial nerves;

l.pir., lobus piriformis;

pyr., pyramid;

t.o., tuberculum olfactorium;

tr.ol.lat., tractus olfactorius lateralis;

trap., corpus trapezoideum. 
FIELD MUSEUM OF NATURAL HISTORY. PLATE XXII, ZÖOLLGY.

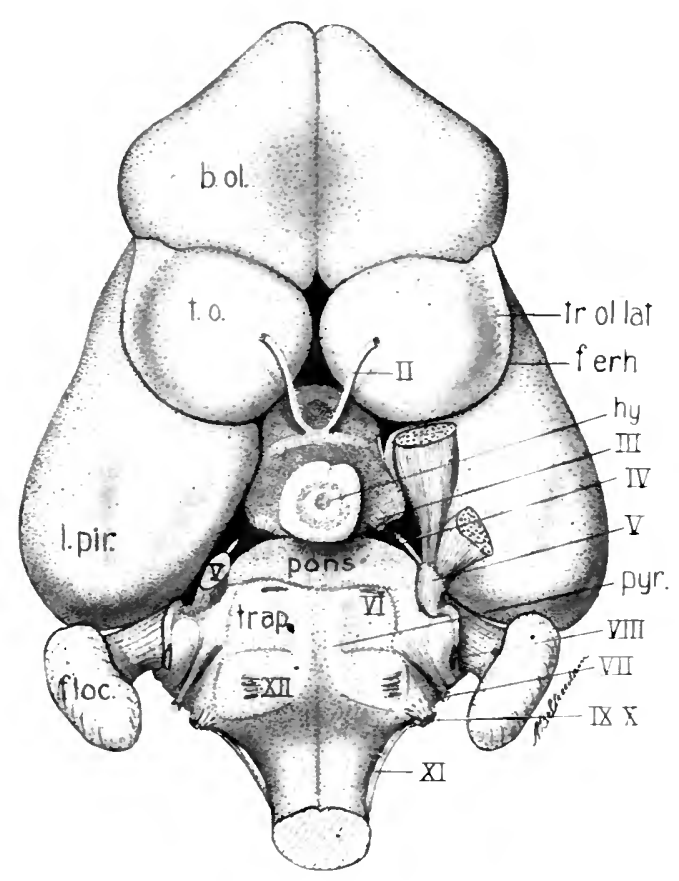

VENTRAL VIEW OF BRAIN.

Five times natural size. 


\section{Tw - " "RBPY \\ OF Titi \\ MUIVRSITY OF IILIHOIS}







